\title{
A Hermeneutical Study of Authorial Intent With Respect To Systems Analysis and Design Textbooks
}

\author{
By \\ Shawn Smith-Chao, B.Comm.
}

A thesis submitted to the Faculty of Graduate Studies and Research in partial fulfillment of the requirements for the degree of

Master of Business Administration

Sprott School of Business

Carleton University

Ottawa, Ontario

April 9, 2009

Copyright $@ 2009$ 
Library and

Archives Canada

Published Heritage

Branch

395 Wellington Street

Ottawa ON K1A 0N4

Canada
Bibliothèque et

Archives Canada

Direction du

Patrimoine de l'édition

395 , rue Wellington

Ottawa ON K1A 0N4

Canada

Your file Votre référence

ISBN: 978-0-494-52002-4

Our file Notre référence

ISBN: 978-0-494-52002-4

NOTICE:

The author has granted a nonexclusive license allowing Library and Archives Canada to reproduce, publish, archive, preserve, conserve, communicate to the public by telecommunication or on the Internet, loan, distribute and sell theses worldwide, for commercial or noncommercial purposes, in microform, paper, electronic and/or any other formats.

The author retains copyright ownership and moral rights in this thesis. Neither the thesis nor substantial extracts from it may be printed or otherwise reproduced without the author's permission.
AVIS:

L'auteur a accordé une licence non exclusive permettant à la Bibliothèque et Archives Canada de reproduire, publier, archiver, sauvegarder, conserver, transmettre au public par télécommunication ou par l'Internet, prêter, distribuer et vendre des thèses partout dans le monde, à des fins commerciales ou autres, sur support microforme, papier, électronique et/ou autres formats.

L'auteur conserve la propriété du droit d'auteur et des droits moraux qui protège cette thèse. $\mathrm{Ni}$ la thèse ni des extraits substantiels de celle-ci ne doivent être imprimés ou autrement reproduits sans son autorisation.
In compliance with the Canadian

Privacy A'ct some supporting forms may have been removed from this thesis.

While these forms may be included in the document page count, their removal does not represent any loss of content from the thesis.
Conformément à la loi canadienne sur la protection de la vie privée, quelques formulaires secondaires ont été enlevés de cette thèse.

Bien que ces formulaires aient inclus dans la pagination, il n'y aura aucun contenu manquant.

\section{Canadä}




\begin{abstract}
The core of the undergraduate Information Systems degree is systems analysis and design (SAD). Although the primary teaching device, the textbook, has a profound impact on what students learn of $S A D$, some academics and practitioners feel that SAD textbooks reflect neither their opinions about proper content, nor the IS Curriculum guidelines. This study extends another study, Misic and Russo (2000), which demonstrated this trend. This study used a hermeneutical method, however, and attempted to interpret the intent of textbook authors with regard to the content in their books. A preliminary study of three editions of the popular Whitten et al. textbook series showed that, in fact, the authors had worked very hard to mirror the opinions of academics, practitioners, and the IS curriculum guidelines at that time. Therefore it may be inappropriate to judge authors without properly considering the context of the time each book was written.
\end{abstract}




\section{Acknowledgements}

I would like to thank Professor Alex Ramirez, my thesis supervisor. He was very careful to give me just enough rope to explore my chosen topic, but not enough to hang myself. His guidance led to the most important determination of this thesis; that it is the journey and the knowledge that we gain about ourselves for which our success in any endeavour must be judged.

I would also like to thank the IS faculty at the Sprott School of Business. They have been my mentors, and most importantly, my friends. In particular, I would like to express my thanks to Professor Shaobo Ji, who guided me in my first steps on the Information Systems path.

Finally, I would like to express my love, adoration, and appreciation to my wife Chhor. Her love, support, and her occasional but very necessary prodding kept me focused and determined to complete this journey and the document before you. 


\section{Table of Contents}

Part 1: Introduction ............................................................................................. 1

Contradictions between Theory, Education, and Practice ............................. 1

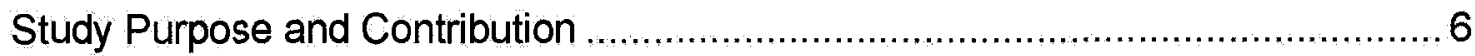

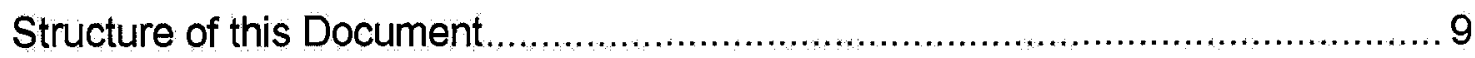

Part 2: Literature Review ............................................................................ 10

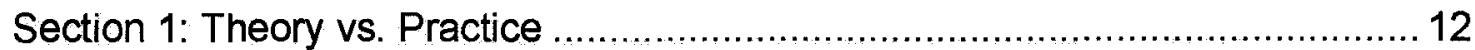

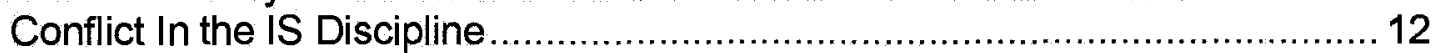

Conflict in IS Education .............................................................. 13

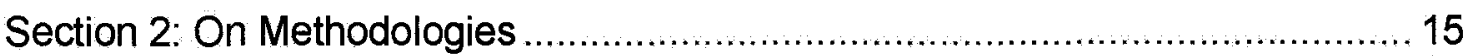

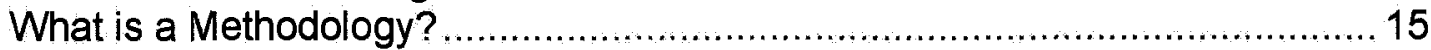

The Creation of System Methodologies ............................................... 16

Early Dissemination of Methodologies .................................................. 16

Introduction of the Systems Development Textbook .................................. 17

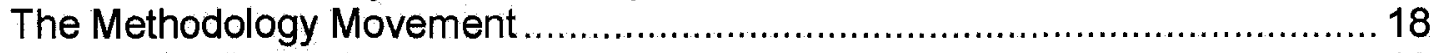

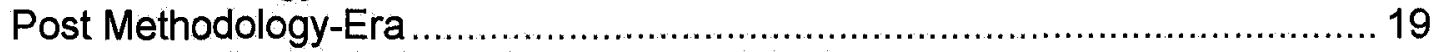

Evidence in Support of the Use of Methodologies ................................... 20

Methodologies and Project Failure ...................................................... 25

The Argument against Structured Methodologies.................................... 26

The Argument against Methodologies in General ....................................... 30

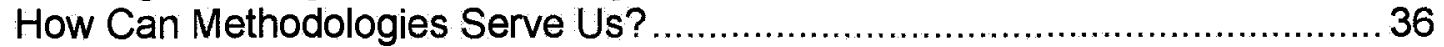

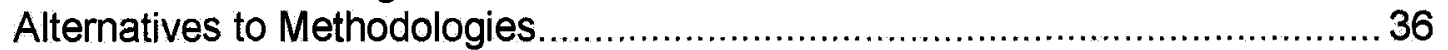

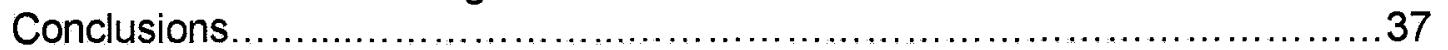

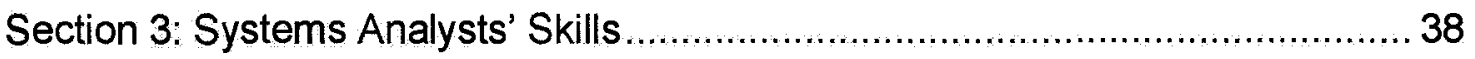

Practitioner and Educator Positions ................................................... 38

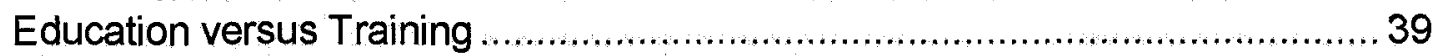

The Case against Teaching Methodological Knowledge ............................. 40

Career Skill Development .............................................................. 41

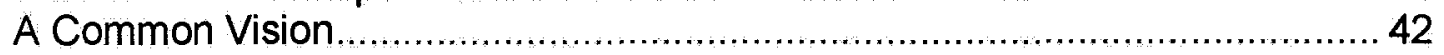

Section 4: Information Systems Education................................................ 43

Initial Development of Curriculum Guidelines ......................................... 43

Competing Curriculum Developments ............................................... 50

1981 ACM Curriculum Adoption Report and the 1982 ACM Curriculum.......... 50

1995 ACM Curriculum Guidelines ...................................................... 53

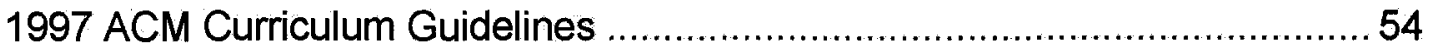

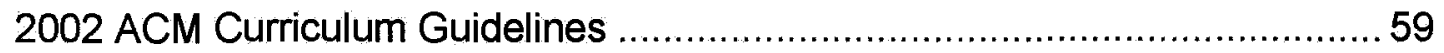

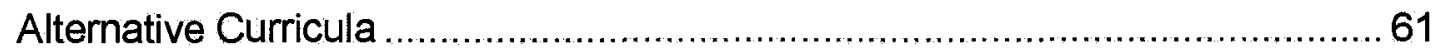

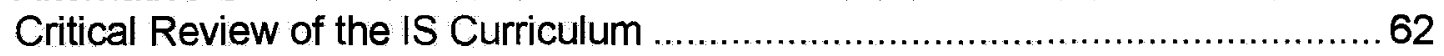

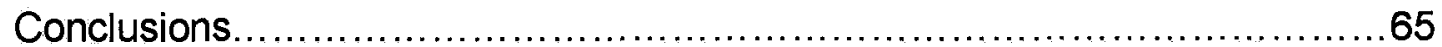

iv 


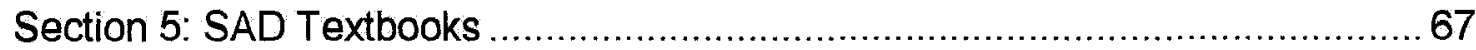

Applying the Relevance Question to IS Texts............................................67

A Lack of Cumulative Progress in IS Teaching ............................................67

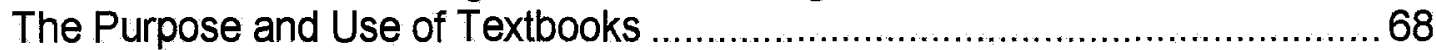

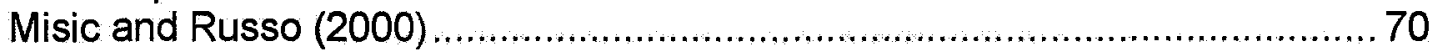

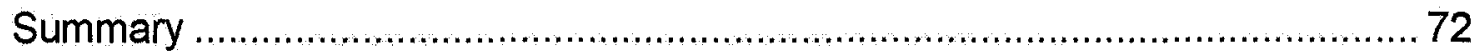

Part 3: Research Questions and Study Methodology ................................. 73

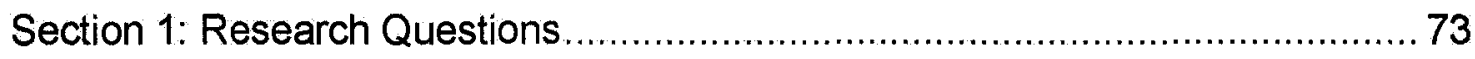

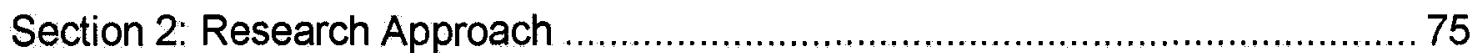

Introduction to Research Approach ........................................................ 75

Summary of Literature Review for Research Methodology .............................75

Issues Impacting the Study Methodology ....................................................90

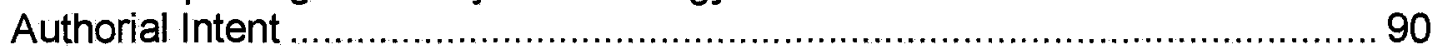

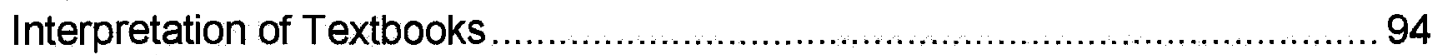

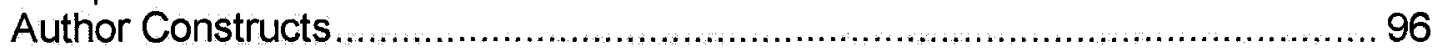

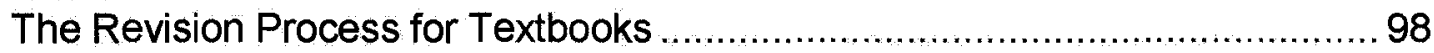

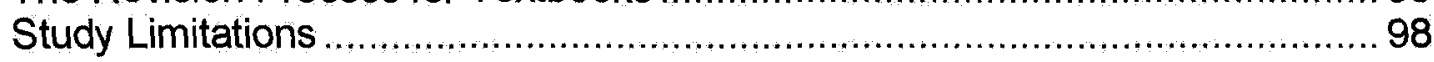

Section 3: Research Methodology ................................................................ 100

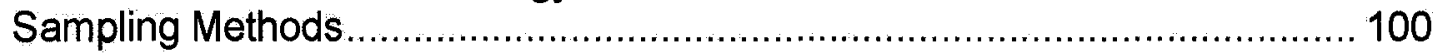

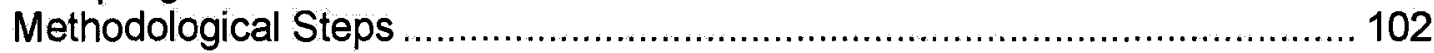

Presentation of Foreknowledge and Potential Bias .................................... 107

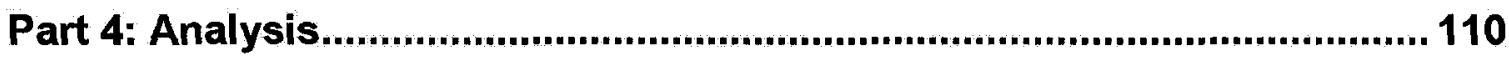

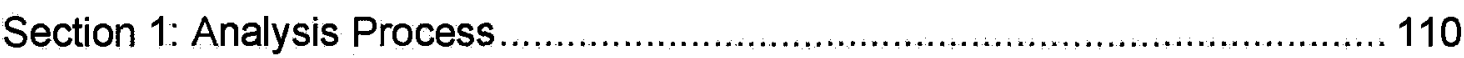

Section 2: Answering the Research Questions ........................................... 112

Question 1 - Changes between Editions................................................ 112

Question 2 - Update Process Alignment With the IS Curriculum Guidelines and

Opinions of Practitioners and Academics ............................................. 121

Question 3 - Justification and Presentation of Content Choices ................... 130

Question 4 - Methodological Justifications .............................................. 135

Question 5 - Content Justifications and Misic and Russo (2000) ................. 143

Question 6 - Importance of Textbooks to the Learning Process .................. 150

Question 7 - Alignment with Practitioners, Academics, and the IS Curriculum

Guidelines .................................................................................... 155

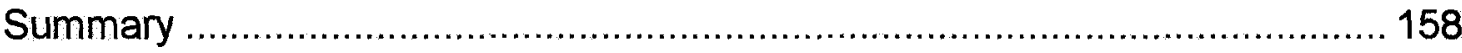

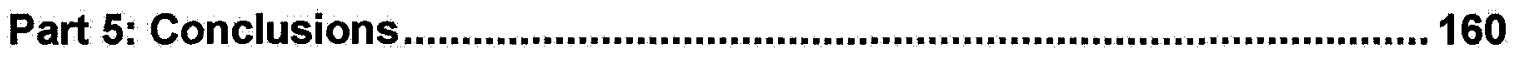

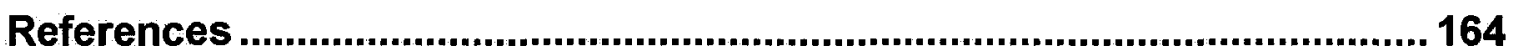

v 


\section{List of Figures}

Figure 1. Literature Review Structure and Topic Links............................ 11

Figure 2. Courses for Graduate Curriculum....................................... 46

Figure 3. Courses for Undergraduate Curriculum.............................. 49

Figure 4. Concept Database Structure................................... 105

\section{List of Tables}

Table 1. IS 2002.7 Analysis and Logical Design (Gorgone et al., 2003)............. 2

Table 2. IS 2002.7 Topics (Gorgone et al., 2003)................................ 3

Table 3. Chapter Summary for Satzinger et al. (2006) ............................ 5

Table 4. Attributes of Information Systems Program Graduates.....................54

Table 5. Pedagogical Tools for Various Knowledge Levels........................ 58

Table 6. Comparison of IS'97 and IS'2002 SAD Course Scopes.....................60

Table 7. Summary of Major Content Changes in Whitten et al. Series............... 114

Table 8: Alignment between ACM 1982 Guidelines and Whitten et al. ........... 124

Table 9. Content Percentages for Tools, Techniques, and Methodologies for

Whitten et al. (1994) in Misic and Russo (2000) ................................... 148

\section{List of Appendices}

Appendix 1 - Hermeneutics Literature Review .......................................... 181

Section 1: Hermeneutics as a Research Approach ................................. 181

Section 2: Principles of Interpretation .................................................. 183

Section 3: Hirsch and the Dialectic of Single or Infinite Interpretations ........... 191

Section 4: Betti and the Concept of Objective Interpretation........................ 194

Section 5: Validating an Interpretation .............................................. 196

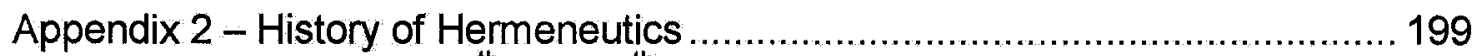

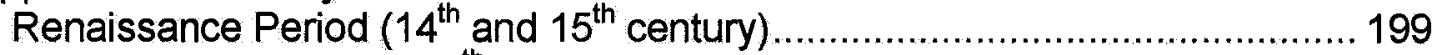

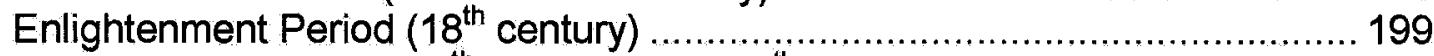

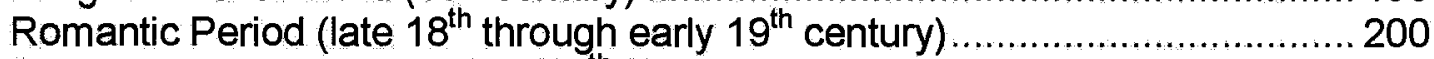

Contemporary Hermeneutics $\left(20^{\text {th }}\right.$ Century) ........................................... 202

Appendix 3 - Hermeneutical IS Studies .................................................. 206

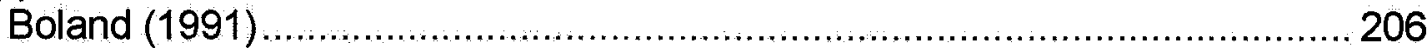

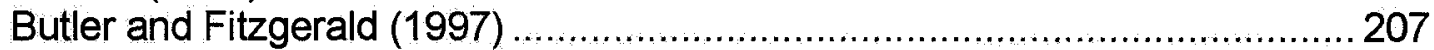

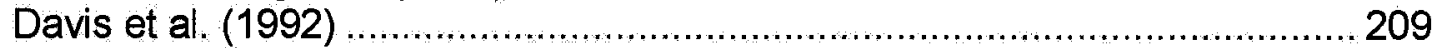

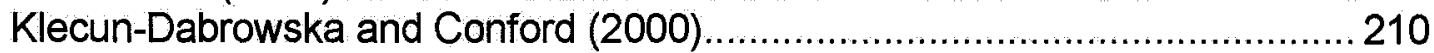

Klein and Myers (1999) ................................................................ 212

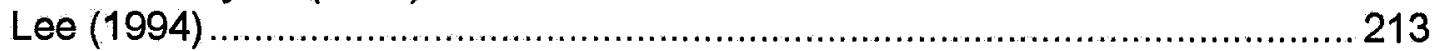

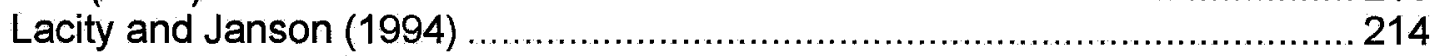

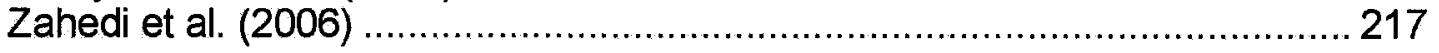

Appendix 4 - Citations for Sample Textbooks........................................ 219

Appendix 5 - Contextual Timeline for Subject Texts .............................. 220

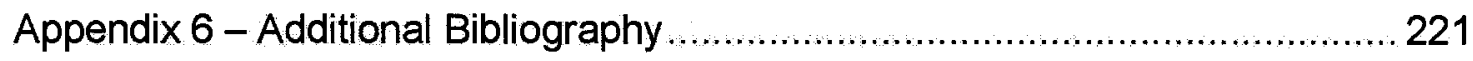




\section{Part 1: Introduction}

\section{Contradictions between Theory, Education, and Practice}

The conflict between theory and practice has been well established in the information systems (IS) discipline. There are numerous views, however, regarding where the problem lies. For some, academics spend too much time researching obscure theories, rather than business driven problems (Zmud, 1996). For others, the overly complex nature of academic writing is inaccessible to business managers (Byrne, 1990). A common theme in this critique is that academia has difficulty keeping up with practice, and that a great deal of research is irrelevant simply because it becomes available too long after interest in the research topic has passed (Benbasat and Zmud, 1999).

This gap in relevance has been extended to the realm of IS education. It has been argued that the IS curriculum guidelines are part of a vicious circle with education attempting to catch up with practice (Mandt, 1982). Academics and practitioners both stress the need for educating IS professionals by developing analytical and problem solving-skills within an organizational context (Nelson, 1991), rather than focusing on methodological knowledge that is increasingly being challenged on theoretical and practical grounds (Avgerou and Cornford, 1993).

The core of an IS education is systems analysis and design (SAD) (Misic and Russo, 2000). IS professionals have been traditionally known as analysts, a term whose usage has been associated with many functions and technologies, such as database analyst, network analyst, and the more general business analyst and systems analyst. Systems analysis and design courses have traditionally focused on methodological teaching, though contemporary IS guidelines have increasingly moved away from this position (Gorgone et al., 2003).

A study conducted by Misic and Russo (2000) notes that Systems Analysis and Design (SAD) textbooks are misaligned with not only the recommendations of academics and practitioners, but also the IS curriculum guidelines. SAD textbooks continue to focus nearly exclusively on methodological approaches as a means to teach systems analysis and design. In addition, structured and traditional approaches dominate methodological content, though both researchers and 
practitioners feel they are the least successful methodological approaches (Fitzgerald, 1996).

A demonstration of the misalignment perceived by Misic and Russo (2000) can be made by comparing the most current IS curriculum guidelines, IS2002 (Gorgone et al., 2003) to a contemporary SAD textbook, Satzinger et al.'s Systems Analysis and Design in a Changing World, $4^{\text {th }}$ edition (2006). Table 1 lists the learning goal requirements for the SAD course (IS2002.7) from the IS2002 guidelines. These are the abilities that a student who successfully completes the course should possess.

\begin{tabular}{|c|c|}
\hline $\begin{array}{l}\text { Learning } \\
\text { Unit } \\
\text { Number }\end{array}$ & Learning Unit Goal \\
\hline 72 & $\begin{array}{l}\text { To present necessary concepts to provide the skills necessary to do the } \\
\text { analysis, modeling, and definition of information systems problems }\end{array}$ \\
\hline 73 & $\begin{array}{l}\text { To give students exposure to using commercial program products to } \\
\text { implement information systems }\end{array}$ \\
\hline 74 & $\begin{array}{l}\text { To show how to collect and structure information in the development of } \\
\text { requirements and specifications }\end{array}$ \\
\hline 75 & $\begin{array}{l}\text { To show how to develop a logical design, and develop and analyze } \\
\text { alternatives involving implementation using packages, tailoring of packages, } \\
\text { constructing software, or CASE tools }\end{array}$ \\
\hline 76 & $\begin{array}{l}\text { To develop a functional understanding of rapid prototyping and other similar } \\
\text { alternative mechanisms for rapid development of information systems }\end{array}$ \\
\hline 77 & To show how to assess risks and feasibility \\
\hline 78 & $\begin{array}{l}\text { To show students how to analyze organizational systems to determine how } \\
\text { the systems might be improved }\end{array}$ \\
\hline 79 & $\begin{array}{l}\text { To develop skills for effective interpersonal communication to develop } \\
\text { consensus using classical techniques as well as computer facilitated } \\
\text { groupware }\end{array}$ \\
\hline 80 & $\begin{array}{l}\text { To demonstrate and analyze small group dynamics as related to working } \\
\text { with users }\end{array}$ \\
\hline 81 & $\begin{array}{l}\text { To develop application skills for implementing database and applications by } \\
\text { operating and testing these databases }\end{array}$ \\
\hline 82 & To present and use complexity metrics to assess developed solutions \\
\hline 83 & $\begin{array}{l}\text { To develop quality metrics for assessment of software development and } \\
\text { project control of software development }\end{array}$ \\
\hline 84 & $\begin{array}{l}\text { To develop quality metrics for assessment of customer satisfaction at all } \\
\text { phases of the life cycle }\end{array}$ \\
\hline 85 & $\begin{array}{l}\text { To explain the use of a professional code of ethics to evaluate specific IS } \\
\text { actions }\end{array}$ \\
\hline
\end{tabular}

Table 1. IS 2002.7 Analysis and Logical Design (Gorgone et al., 2003) 
Learning Unit Number 72 specifies that students have the skills necessary for analysis, modeling, and definition of information systems problems. Learning Unit Number 74 specifies knowledge of the collection and structuring of development requirements and specifications. Learning Unit 76 requires knowledge of rapid prototyping and other mechanisms for rapid development of information systems. In this list, we do not see a requirement for a specific methodology, other than possibly rapid application development methodologies, due to Learning Unit 76.

If we look at the course topics for IS 2002.7 we see a very broad list of topics (Table 2), that seems to specify a number of methodologies for teaching. Joint application development (JAD) methodologies, rapid application development (RAD) methodologies, structured methodologies and object-oriented methodologies all seem to have a place in the course. No mention is made with respect to the priority of a particular methodological stance.

Life cycle phases: requirements determination, logical design, physical design, and implementation planning;

Interpersonal skills, interviewing, presentation skills

Group dynamics

Risk and feasibility analysis

Group-based approaches: project management, joint application development (JAD), and structured walkthroughs

Structured versus object-oriented methodologies

RAD, prototyping

Database design

Software package evaluation, acquisition, and integration

Global and inter-organizational issues and system integration

Profession code of ethics

Table 2. IS 2002.7 Topics (Gorgone et al., 2003)

If we look at other courses in the curriculum, we find that IS 2002.8 Physical Design and Implementation with DBMS and IS 2002.9 Physical Design and Implementation in Emerging Environments do not specify methodological knowledge as a skill requirement. Both courses do list structured and object-oriented methodologies as course topics.

It would seem that a preference for a particular methodological approach is not given in the IS 2002 guidelines, and a variety of SAD approaches are listed. Interesting, if we look at the previous IS'97 guidelines (Davis et al., 1997), only 
object-oriented and JAD development methodologies are specified. There is no specific mention of structured methodologies for the course listing. Though included in the IS 2002 curriculum, structured methodologies are included as an alternative to object-oriented methodologies. As a group, structured and object-oriented methodologies hold a place seemingly equal to other methodological alternatives, such as JAD and RAD.

Gorgone et al. (2003) does not prioritize or provide course coverage percentages for the topics. Since no topics are given specific priority, we must therefore that all topics would receive roughly the same coverage in a general textbook for a course such as 2002.7 .

As a demonstration of the potential disconnect between the IS curriculum guidelines, and textbooks in the market, table 3 gives the chapters' content of the Satzinger et al. (2006) Systems Analysis and Design textbook. Most, but not all (for example, learning topic 80), of the learning units from the IS 2002 curriculum appear somewhere in the text, but we see that some learning points greater topic coverage with respect to numbers of pages. Some topics are given only a minimal treatment. The structured and object-oriented approaches represent a far larger portion of the book than other, more contemporary options, such as JAD or RAD. Case tools, groupware, system improvement, and software installations are small sections sprinkled throughout the text. The focus of the text is clearly the two approaches. 


\begin{tabular}{|l|l|l|}
\hline Chapter & Chapter Name & Learning Units Covered \\
\hline 1 & The World of the Information Systems Analyst & 85 (One paragraph) \\
\hline 2 & Approaches to System Development & $\begin{array}{l}\text { Summary of Chapter 3, 5, 6, } \\
7,16\end{array}$ \\
\hline 3 & The Analyst as a Project Manager & 77,83 \\
\hline 4 & $\begin{array}{l}\text { Beginning the Analysis: Investigating System } \\
\text { Requirements }\end{array}$ & $74,77,79$ (Partial) \\
\hline 5 & Modeling System Requirements & 72,74 \\
\hline 6 & The Traditional Approach to Requirements & 72,78 \\
\hline 7 & The Object-Oriented Approach to Requirements & 72,78 \\
\hline 8 & Evaluating Alternatives for Requirements, & 82 (Partial) \\
\hline 9 & Environment, and Implementation & 75 (Partial) \\
\hline 10 & Moving to Design & 72 \\
\hline 11 & The Traditional Approach to Design & 72 \\
\hline 12 & The Object-Oriented Approach to Design & 81 \\
\hline 13 & Designing Databases & 72 \\
\hline 14 & Designing the User Interface & 72 \\
\hline 15 & Designing System Interfaces, Controls, and Security & 73 (Partial), 78 (Minimal), 84 \\
\hline 16 & Making the System Operational & 76 \\
\hline
\end{tabular}

\section{Table 3. Chapter Summary for Satzinger et al. (2006)}

Misic and Russo (2000) indicate that it may require a disproportionate number of pages to express the content for some topics in the curriculum guidelines. Though this may be the case, we must assume that the intent of the IS 2002 Curriculum guidelines is that these topics would be covered in more depth than a few paragraphs.

Satzinger et al. (2006) was chosen as the textbook for this example because, unlike many other SAD textbooks available, it balances the content with respect to structured and object-oriented approaches. The most popular SAD textbook (as stated by Misic and Russo, 1996), Whitten and Bentley (2007), focuses on the structured approach and features the object-oriented approach as only a secondary element. Contemporary approaches do not appear at all, or are mentioned minimally, in most of the textbooks that Misic and Russo (2000) examined.

Textbooks are the primary and often only pedagogical tool used for most courses (Ornstein, 1989). The content in textbooks is critical, because of the manner in which this content is perceived by students. The content in textbooks is assumed to be the consensus view of the field (Bierman, 2006), and material that is minimally covered or is ignored by textbook is considered "false" or "irrelevant" 
(Raywid, 1980, p. 63). Since the IS curricula receive the support of the major IS societies (Gorgone et al., 2003, p. 6), and are the basis for university accreditation requirements for IS degrees, we should then expect textbooks used in SAD classes to reflect the content in the most recent curriculum guidelines. The authors of textbooks are also generally academics themselves, a major contributor to the content of the academic guidelines (Gorgone et al., 2003). Authors should be aware of the guidelines, and adjust their textbook content to match them based on the necessity to support course requirements and accreditation guidelines.

\section{Study Purpose and Contribution}

Since Misic and Russo (2000) established a misalignment between the content in SAD textbooks, and the views of academics and practitioners and the IS curriculum guidelines, it is logical then to ask why authors have allowed this to occur. Misic and Russo (2000) speculate that the reasons for the misalignment may be due to the "differing nature of activities required to learn a process versus activities required to do a process" ( $p$. 71, emphasis in original). Therefore, by Misic and Russo (2000), textbooks are meant to provide pre-knowledge for SAD activities rather than being a source for the actual activities themselves. Demonstration and practice of the SAD skills would be facilitated by other pedagogical tools, such as cases, projects, and presentations from IS professionals. Ornstein (1989) warns us, however, that textbooks are often the only source of material for a course. Even if projects and cases are standard parts of the SAD course material, the actual course content guiding students' decisions regarding these materials is drawn from the textbooks (Bailey, 1988). Additionally, both practitioners and academics have disputed the soundness for methodological approaches as a basis for systems analysis and design.

Although Misic and Russo (2000) develop a strong case to indicate that the content in SAD textbooks does not match the requirements of academics and practitioners, they do not explore the motivations of the authors of these textbooks as an explanation for this conclusion. Since authors are a primary determinant for the content in their textbooks and are therefore the objects under study within the domain of textbook content, it is a natural extension of Misic and Russo (2000) to examine the motivations of authors with respect to the content that they choose. 
Misic and Russo (2000) employed a content analysis methodology in their study. Misic and Russo (2000) quote Berelson (1952)'s description of content analysis as a "research technique for the objective, systematic, and quantitative description of the manifest content of communication" (p. 66). Lee (1994) describes such a study as positivistic and indicates that we can extend and improve a positivistic study by employing an interpretivist approach. An interpretivist approach can be used to understand how members of the group under study make sense of their own reality. By possessing a different understanding of the matter under study (in particular the view of the subjects themselves), improved positivistic explanations can be formed (Lee, 1991, p. 352). Lee (1991) cautions that a positivistic theory that is not formed on the basis of a proper interpretation of how the subjects perceive themselves may be subject to methodological error, based on the author ascribing their own viewpoint to the motivations of the subjects under study.

This study aims to extend the work of Misic and Russo (2000) by providing an interpretation of the motivations of authors of SAD textbooks. Since textbooks provide a key role in the education of systems analysts (Misic and Russo, 2000), it is critical that the views of authors, academics, and practitioners are aligned. Currently, the views of SAD textbook authors have not yet been explored. A study of the motivations of authors of SAD textbooks is therefore both useful and necessary.

The alignment of academics' and practitioners' views is not static however, and is subject to change over time, based on technological as well as business changes. Therefore, in order to properly evaluate whether authors have attempted to align their views with those of academics and practitioners, their views must be understood over time. As each edition of a particular author's textbook is released, the forces that influenced its creation are dynamic, and may have led to changes from the previous edition.

This creates a second dimension for this study. If authors do consider the dynamic opinions of academics and practitioners in the IS discipline and the updates to the IS curriculum guidelines, then we would be likely to see changes in their textbooks between editions. These changes might reflect not only content, but also the author's opinions with respect to that content. Therefore, in order to consider the dynamic nature of each author's intent and the context itself, we should study multiple editions for a particular author's textbook. This provides an historical 
perspective of the impact of the opinions of academics and practitioners and the IS curriculum guidelines on authorial intent with respect to $S A D$ textbooks.

This perspective also improves upon the methodology of Misic and Russo (2000), since the textbooks they selected in their study were published between 1988 and 1999, and thus potentially reflect a broad range of academic, practitioner, and author intentions. Their determinations, however, reflected the state of academic and practitioner views at the time of their study. Therefore, they may have misjudged the intentions of authors, since it is possible that academic and practitioner views changed during the eleven-year-period in which the textbooks selected were published. By considering a single textbook over multiple editions and matching each edition's content to the contextual changes in academic, practitioner, and IS curriculum guideline views at that particular time, it can be better assessed whether authors have attempted to align their content with these views. By doing this for all editions of a particular textbook, a broader sense of this alignment can be determined.

To summarize, the purpose of this study is to examine the intentions of authors with respect to their textbook content. This study will assess whether authors have attempted to align their views with academics, practitioners, and the IS curriculum guidelines in the process of creating and releasing multiple editions of their textbooks, and how they have evidenced their rationale for matching or diverging from academic and practitioner views and the IS curriculum guidelines in their textbooks.

The methodological approach to be used in this study is hermeneutics. The central purpose of hermeneutics is the interpretation of texts. Though the term "text" has expanded in definition to include conversation, art, and other forms of expression (Ricoeur, 1991), traditional hermeneutics focused on the interpretation of written words with the purpose of determining the intentions of the author. Though some philosophical hermeneutic scholars, such as Heidegger and Gadamer have moved away from this traditional purpose, others such as E.D. Hirsch Jr. and Emilio Betti have continued to focus on interpreting texts to decipher authorial intent. This study will follow the traditions described in Hirsch (1967) and Betti (1980). By employing a hermeneutical interpretation guided towards determining authorial intent, this study attempt to fathom the justifications of the authors by drawing them 
out of the text, and hopefully come to an understanding of why, as shown by Misic and Russo (2000), authors of SAD textbooks have not aligned their content with the views of academics and practitioners, and perhaps more importantly, the IS curriculum guidelines.

\section{Structure of this Document}

Although a literature review is a common element in any thesis, a hermeneutic study that follows the writings of Betti and Hirsch requires a solid foundation in the contextual information related to the topic at hand. To that end an extensive literature review of the topic matter has been prepared in Part 2 of the study. This study's research questions and methodology are presented in Part 3 of the study. The analysis of the data is presented in Part 4 of the study, and conclusions and recommendations are presented in Part 5. 


\section{Part 2: Literature Review}

The literature review has been organized specifically to bring the reader from a general understanding of a prominent conflict in the IS discipline to a particular understanding of how SAD textbooks play an important role in the overall conflict. Section 1 describes this conflict between academic theory and the actions of IS practitioners. Section 2 brings a tighter focus on a particular element in the theory vs. practice conflict, the dominance of SAD methodological approaches, particularly structured approaches, although both practitioners and academics question their usefulness. SAD approaches are taught by educators and are a focal skill in the IS professionals skill set. Section 3 therefore examines the opinions of academics and practitioners to determine what skills they believe are truly important for IS professionals. Section 4 begins to focus on the educator's position, by examining how the skills described in section 3 impact the IS curriculum guidelines. These guidelines determine what skills are actually taught to students, and, in theory, determine the content of SAD textbooks. In section 5, however, it can be seen that although the textbook is a critical pedagogical tool that may have a profound impact on the education process for IS professionals, they are not aligned with the views that have become clear in the previous sections.

Figure 1 provides a summary of the organizational structure for the literature review. 


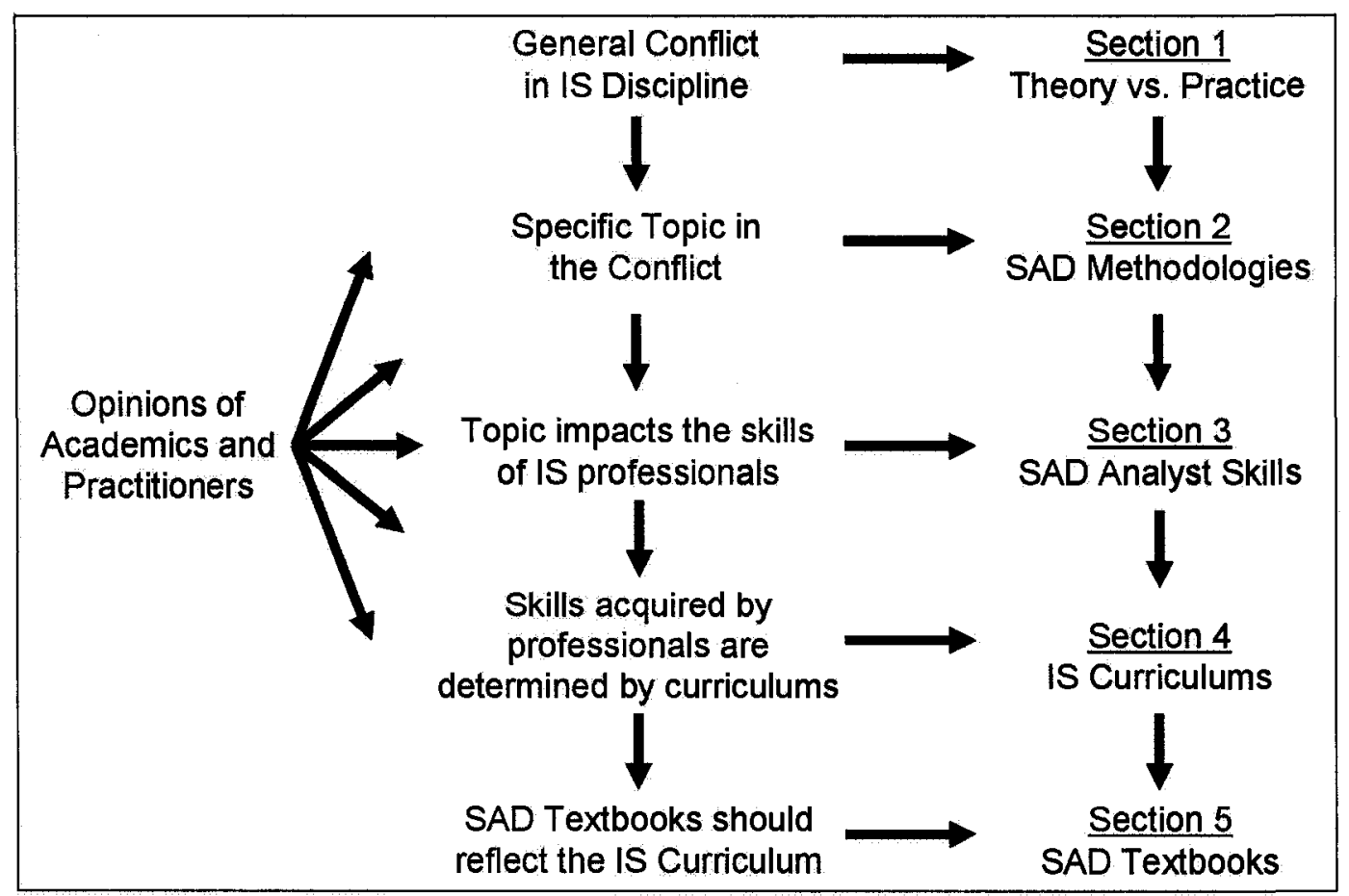

Figure 1. Literature Review Structure and Topic Links 


\section{Section 1: Theory vs. Practice}

\section{Conflict In the IS Discipline}

In perhaps one of the most influential articles on the state of IS research, Peter Keen (1980) shared his opinions with an audience at the first International Conference on Information Systems (ICIS). In his address, he criticized previous research efforts, indicating that without substantial change MIS was unlikely to establish itself as an actual field and would be subsumed by other fields. His argument promoted increased research rigor, though he was careful to stress the importance of maintaining links to practice. He also criticized a lack of cumulative tradition in IS research. The article spurned a generation of research papers with a strong focus on rigor.

Indicating that the response may have been too strong, (Byrne, 1990) called into question the quality of academic journal research. The article quotes college deans referring to it as: "It's often crap", " $80 \%$ of management research may be irrelevant", and "what passes for research has no value". Byrne's opinion was that research was inaccessible to business executives, and that professors were spending too much time focusing on obscure theories that had little likelihood of practical value. Rigor seemed indeed to have been increased at the cost of relevance.

Zmud (1996) made a call for further relevancy in IS research articles in editorial articles in MIS Quarterly. Though he did not wish to condemn the research in MIS Quarterly as irrelevant, he created two categories of relevance: "weak relevance" and "strong relevance". "Weak relevance" for an article implies that its topic matter is drawn from items of practitioner interest, and have clearly defined applications to practice expounded at the end of the article. "Strong relevance" articles can actually be implemented in practice and discuss the validity of applying the concepts of the article in practice. Though he defends previously published articles in MIS Quarterly as having "weak relevance", he admits that articles with "strong relevance" are rare, and makes a call for changes to the nature of submitted articles.

Avison et al. (2001) in a ten year summary of research in Information Systems Journal, make a similar assessment of the journal's research. They do 
offer some defence for researcher's behaviour, however. Researchers may focus on theoretical issues as a response to a perceived tendency for practitioners to adopt too many atheoretical "quick fixes" (Avison et al., 2001, p. 16). This may push researchers away from practice, rather than towards it.

Benbasat and Zmud (1999) made an important response to Byrne's article, and to other similar complaints from other is researchers. They agree with the thrust of Byrne's article, and conclude that unless researchers can provide implementable research (Benbasat and Zmud, 1999, p. 5), research that provides results that can find a practical method of utilization, IS research will continue to be perceived as irrelevant by practitioners. They cite a number of reasons for this perception of IS research, including a focus on academic rigor over relevance (Benbasat and Weber, 1996), delays in publication that lead to stale research, and a lack of a cumulative tradition in IS (Keen, 1980). Benbasat and Zmud (1999) note that it takes on average three or more years from the submission stage to the publication stage of an academic article. They make a number of recommendations in order to make research more relevant to practitioners.

Byrne (1990) points to a growing proportion of time that academics spend on their research endeavours instead of in the classroom. If students are not provided the guidance and direction they may need by academics in their role as educators, businesses may suffer due to poorly trained graduates. This moves the conflict from a general business vs. practice context to a conflict inside the classroom.

\section{Conflict in IS Education}

One manifestation of this conflict is an "expectation gap" (Trauth et al., 1993, p. 293) between the skills businesses expect graduates to emerge from university with and the skills required by IS curricula. Businesses feel IS curricula focus too much on traditional systems development, including the systems lifecycle, structured approaches, and model building (Avison and Fitzgerald, 1991). Increasingly, practice has moved away from these ideas, focusing on communication with users, prototyping, and solving business problems (Nelson, 1991). Universities feel, however, that businesses are not consistent in the messages that they send to universities (Trauth et al., 1993). Universities are meant to provide career education 
rather than job training, and therefore they feel responsible for instilling core skills in their students.

Historically, the IS discipline emerged from its roots in computer-science and engineering. Avison et al. (2001) state that in 1991 in the UK, IS academics were found primarily in computer systems departments, and that this reflected a "technology-driven view of the world" (p. 10). In 2001, they note that this has changed drastically, with many IS researchers now equally distributed in computer science and management departments. In the US, IS academics are predominantly in business departments. Lyytinen and Robey (1999) maintain however, that:

"Since the dawn of business computing, training in IS has meant 'computer training', and IS professionals remain technologists at heart...The profession's technical focus is manifest in the predominant root metaphor for IS professionals: engineering" (p. 94).

The dominance of the engineering metaphor for the IS field is quite extensive. Yourdon's (1979) book, a cornerstone textbook of the structured methodology movement, is titled "Classics in Software Engineering". In Keen's (1980) article, he promotes an "intellectual grounding in a coherent tradition in science" with production of methodologies that can be properly tested and applied. Gibbs (1994) berates the software industry for its inability to live up to the term "software engineering", and compares the current state of system design to a pre-industrial age; a craft composed of "artisans using techniques they neither measure nor are able to repeat consistently" (p. 87).

Lyytinen and Robey (1999) note that when IS professionals are integrated into the work force, they assume that their biggest challenge will be to acquire technical knowledge. Lyytinen and Robey (1999) insist, however, that IS professionals also need to learn how to exercise judgment when organizational issues cannot be separated from technical issues. Unfortunately, they are not properly prepared by our education system to value the importance of organizational problem solving.

If methodological approaches are an integral element of the education process, it would make sense that strong support for them exists in practice and academia. The authors presented in this literature review, however, challenge the use of methodologies. A number of arguments against traditional system 
development methodologies, and even methodologies in general exist, and have been vocalized for a number of years by these authors and others. By understanding the nature of the conflict with respect to methodologies, we can then step back and see whether the dominance of methodologies is justified for IS curricula.

\section{Section 2: On Methodologies}

\section{What is a Methodology?}

Although there is considerable debate about exactly what a system development methodology (SDM) is (Wynekoop and Russo, 1995; Fitzgerald, 1996; livari and Maansaari, 1998), a general definition is that an SDM is a collection of rules, procedures, steps, techniques, tools, documents, and training used to develop a system (Avison and Fitzgerald, 2003). Methodologies aim to regulate and systematize the process of development, and to provide controls and feedback during the development process. The use of SDMs is prevalent in systems analysis and design today, and has been since the 1960's (Avgerou and Cornford, 1993). Unfortunately, most research involving methodologies describes new or existing methodologies and what methodologies should contain, rather than evaluating them or determining the actual usage of particular methodologies in practice (Wynekoop and Russo, 1995; livari and Maansaari, 1998).

There is a distinction made in some of the literature between a system development methodology and an approach. Methodologies may belong to certain "families" which contain a common set of goals, guidelines, fundamental concepts, and principles (livari et al., 1998). This collection of system development methodologies is considered an approach. Commonly voiced approaches are the "structured approach", "object-oriented approaches", and "rapid development approaches" or "agile approaches".

Most of the literature, however, does not distinguish between approaches or methodologies explicitly, though the terms "methodologies based on the Systems Development Lifecycle (SDLC)", "lifecycle methodologies", and "structured methodologies" are quite commonly used to refer to all methodologies that fall under the structured "approach". In most cases, the terms are used interchangeably. 


\section{The Creation of System Methodologies}

The first system methodologies were developed in the early 1960's (Ward, 1991). They evolved as a response to the need to organize and systematically produce ever larger groupings of code. As small code blocks grew to become major systems, the need for a methodical means to build these systems became necessary. Two major methods of systems analysis evolved, one developed by Douglas Ross, and one developed by Larry Constantine and Ed Yourdon.

Ross developed the Structured Analysis and Design Technique (SADT) methodology, a theory-oriented methodology based on a priori considerations. It focused on process flows within the system, though a little-used data modeling process was also developed. Ross's initial conception involved boxes called plexes (Ross, 1961), which evolved into the SA activity boxes which formed the processbased model at the core of the SADT (Ross and Brackett, 1976). Initially, the entire SADT methodology was proprietarily owned by Ross's company, SofTech. The methodology did not become public domain until an extremely lucrative contract with the US Air Force led to the publishing of part of the SADT methodology as the IDEFO public domain methodology (much to Ross's consternation) (Ward, 1991).

Unlike Ross, Constantine desired for his work and the work of his colleagues to be freely distributed. It was Constantine who developed the structure chart (Barnett and Constantine, 1968; Stevens et al., 1974). He opened the Information and Systems Institute in 1966, designed with the purpose of creating a climate for systems research and publishing. The institute provided SAD training services. Ed Yourdon was the institute's lead trainer, and his work was incorporated with Constantine's to become the Yourdon SA.

\section{Early Dissemination of Methodologies}

The SADT methodology was owned by SofTech, and access to the methodology required the purchase of a $\$ 50,000$ license. A license purchase included extensive training for the software developers in the company, and subsequent inspection of analysis documentation by SofTech consultants. Therefore, during most of the 1970's a relatively small number of software developers were trained in the use of SADT, but they had a very strong 
understanding of the underlying methodology. There were no academic outlets for teaching of the methodology, until IDEFO entered the public domain.

In contrast, the Yourdon SA and later the Gane and Sarson SA techniques were available in academic papers, through training sessions from Constantine's Information and Systems Institute, or in the numerous textbooks that began to appear in the mid- to late-1970's. Yourdon's methodology was therefore much more widely used in the industry, but software developers often had only a very shallow understanding of the methodology. The ready availability of the Yourdon methodology, and the cursory understanding of its techniques, led to mass customization of the methodology.

\section{Introduction of the Systems Development Textbook}

One of the earliest actual SAD textbooks was Yourdon's Real-Time Systems Design, published in 1967 (Yourdon, 1967), and based on Yourdon's and Constantine's initial work. At the time, Yourdon was employed as a contracted trainer working out of Constantine's ISI. In 1974, Yourdon and his wife created a rival training company called Yourdon, Inc. His course material was based on the concepts that he and Constantine developed, and was not widely adopted, due to the lack of a data modeling technique. He asked two of his employees, Trish Sarson and her husband Chris Gane, to more fully develop the analysis aspects of his course. They believed that the missing component was a data analysis and modeling technique.

Gane, however, was dissatisfied with his compensation at Yourdon, Inc. and he and his wife left nd began writing a new boaok that included their work. Their Structured Systems Analysis: Tools and Techniques was released in July (Gane and Sarson, 1977). At the same time, Tom DeMarco, a trainer who remained at Yourdon, Inc. proposed that they release a competing SAD text. Yourdon's printing company, Yourdon Press had already committed to printing a systems analysis text by another author, so Yourdon Inc. printed DeMarco's text itself. This led to the concurrent release of two SAD texts in 1978, Weinburg's Structured Analysis (Weinburg, 1978) and DeMarco's Structured Analysis and System Specification (DeMarco and Plauger, 1978). The content of the texts was widely disseminated 
(Tesch et al., 1995), and the texts themselves found their way into the $1982 \mathrm{ACM}$ curriculum guidelines (Nunamaker et al., 1982).

\section{The Methodology Movement}

Constantine and Yourdon began to feel increasing financial pressure from competing training companies in the late 70's and early 80's since their methods were public domain. In addition, a number of the trainers that had been previously working for Constantine's and Yourdon's companies left to start their own practices. The proliferation of text books allowed virtually anyone to learn these methods, and adapt them to their own work environment. This led to a host of new and modified methodologies.

At the same time, the strong desire in research and practice to implement systematic methods of developing systems created the "methodologies movement" (Avgerou and Cornford, 1993). Research became consumed with finding and developing the 'holy paradigm' that could be considered the best way for developing all systems (Hackathorn and Karimi, 1988). Often, authors would develop 'unique' and 'superior' methodologies based on very minor differences from other existing methodologies (Fitzgerald, 1996). The methodologies were then packaged and marketed as products and services, complete with software tools and training. Therefore, there existed a financial motivation to stress how different a methodology was from its competition.

Literature can have an important impact on practice (Fitzgerald, 1996). But this is problematic in a situation where the academic literature does not actually reflect practice, yet nevertheless dictates how is should be managed. This was certainly the case during this period, where literature pushed for the adoption of 'best practice' methodologies, though evidence indicated a lack of agreement among which, if any, methodologies actually reflected best practices. This disagreement has not yet been resolved, and a lack of research regarding choice and evaluation of methodologies makes it unlikely that the methodology question will be resolved soon (Wynekoop and Russo, 1997). 


\section{Post Methodology-Era}

According to Avgerou and Cornford (1993), methodologies in the 1990's remained prescriptive in nature. They describe tasks to be performed in a particular order, explain who should be responsible for these tasks, and how they should be completed. The systems analyst is the central figure of these methodologies, although they do prescribe responsibilities for other members of the organization. These responsibilities, however, are generally subordinate to the analyst's with regard to the overall development process.

Methodologies based on the life cycle were the most widely cited as practiced by firms at that time (Wynekoop and Russo, 1995). They find origins in system specifications from the mid- and late-1970's though they are more contingent in nature, and allow tasks to be performed in parallel, rather than sequentially. It would seem however that firms actually adapted or ignored the methodologies they cited as used, as contingent factors exceeded the capacity of the methodology to stipulate action or provide guidance (Avgerou and Cornford, 1993). Additionally, Doherty and King (1998) indicate that organizations rarely improved the systems development processes they did employ, even when these methods produced failure.

IS Research in the late 1990's also focused on methodological development, primarily as a means of control (Avison et al., 2001). However, the techniques of object-oriented design gained a greater foothold in this era, and the concept of component and "off-the-shelf" software gained popularity (Welke, 1994). Because of this, Welke (1994) suggested that system methodologies would suffer a paradigm shift and would split into two streams. One stream would move away from traditional lifecycle methods towards the selection and configuration of pre-built component packages, in order to provide the desired functionality. The second stream would focus on the development of these components, employing more rapid cyclical object-based design methodologies. In either case, the move would be away from the traditional SDLC.

End-user development also took hold during this period, with the implication that users, rather than analysts and designers, would develop tools for solving their unique business problems (Taylor et al., 1998). The applications and tools used to develop these systems raised the user to the level of pseudo-system analyst. If 
used at all, the methodologies employed for these personal systems would be very different than traditional or object-oriented methodologies.

Overall, current trends have moved away from the use of traditional methodologies. Companies have abandoned the use of methodologies, due to their inability to live up to the promises that their use foretold (Avison and Fitzgerald, 2003). Many methodologies were also developed in an era without extensive use of packaged software, and web-based applications. These methodologies are not appropriate to development with these types of systems, which tend towards small groups of developers who typically work on projects with a three-month development time on average (Lang and Fitzgerald, 2006). The agility required to work in this environment has led developers to forgo formal methodologies, and to return to adhoc measures where they tinker with designs in a trial-and-error method (Eriksen, 2000).

The combination of many driving factors makes it unclear how methodologies will adapt to the future. Component-based development, web-based development, packaged software implementation, end-user development, and other trends demand new development methods to address the unique aspects of each type of development. Increased outsourcing of the IT development function promotes the use of "in-house" methodologies by consulting firms as they strive to secure contracts from clients through marketed differentiation. Small design teams require agile methods of development and find the formal methods present in traditional methodologies to be cumbersome and ineffective. Finally, dissatisfaction with traditional methodologies promotes the constant reconsideration of their use and the potential abandonment of methodologies entirely.

\section{Evidence in Support of the Use of Methodologies}

Though Avgerou and Cornford (1993) present substantial evidence of how the pursuit of methodological system development has impeded progress in academic, educational, and research endeavours, they do list some positive effects from this pursuit. By educating most students in the structured methodology, we have been given a common language of analysis and design which facilitates communication. In addition, the production of consistent analysis and design documents promotes the understanding of systems by individuals other than the 
creator. Finally, the use of common methodologies allows professionals to be graded and evaluated on the basis of their understanding of these common facets of design.

As a prelude to his argument against methodologies, Fitzgerald (1996) presents a number of classical arguments that support the use of methodologies. Methodologies were developed in response to a perceived crisis in the development of software projects (Gibbs, 1994). They provide a means to control and manage projects, by presenting an orderly sequence of steps that can be monitored and assessed (Ahituv et al., 1984). After each step, costs can be compared to estimates to demonstrate how project development is progressing.

The importance to management of being able to monitor and control costs cannot be understated, and led to the widespread adoption of the SDLC and other methodologies by organizations and even countries. Contracts with the UK government require use of the SSADM (Structured Systems Analysis and Design Method), while other countries such as France, Holland, and Italy have developed their own methodologies which are required for contracts with these governments (Fitzgerald, 1996). The American Department of Defense (DoD) has established guidelines for software development that require the use of the Software Engineering Institute's (SEI) Software Capability Evaluation (SCE). Meeting the requirements of the SCE and its predecessor, the Capability Maturity Model (CMM), requires the use of a formalized methodology. Similarly, the pursuit of an ISO-certification requires the adoption of a formalized methodology. This creates an industry-based pressure to adopt a methodology, as companies will want to secure certifications in order to attract clients and be eligible for government contracts.

What constitutes a methodology for the purposes of satisfying these certifications, however, may be somewhat unexpected. An important note about the CMMI (the current incarnation of the CMM) is that it does not specify a particular lifecycle methodology for development. In fact, the CMMI for Development, Ver 1.2 document states: 
"Lifecycle models may be developed for a variety of customers or in a variety of situations, since one lifecycle model may not be appropriate for all situations. Lifecycle models are often used to define the phases of the project. Also, the organization may define different lifecycle models for each type of product and service it delivers." (SEI, 2006a, p. 223)

From this passage, we might interpret "lifecycle model" to simply imply any planned manner of development, which is essentially what the CMMI model advocates.

The CMMI evaluation system categorizes software development groups into one of six categories. Level 0 groups are at a very early stage and do not have enough completed projects to complete the CMMI evaluation. Level 1 groups develop software in an "ad hoc" manner, without any form of planned management. Level 2 groups have planned development processes, but these plans may only be applied only to a single project, rather than to all projects the group develops. At Level 3 , the group has a development process that applies to all projects, though, as mentioned above, it may not be the same process for all projects. At Level 4 , in addition to widespread SDM use, the group uses quantitative measures to provide feedback on development progress, and at Level 5 , these quantitative measures are used to provide a means to upgrade the development process itself.

It must be noted that there are issues with the evaluation method for the $\mathrm{CMMI}$, however. Since the CMMI is a self-evaluation, companies may not be completely honest about their current CMMI standing. Additionally, Levels 2 and 3 simply require a "managed" process, and though there are some restrictions, there can be a tremendous amount of variation in the quality of the process that is put into place. Only at Levels 4 and 5 are quantifiable methods of evaluation required and only $22.9 \%$ of the firms that publish their evaluations are at Level 4 or Level 5 (SEI, 2006b, slide 5). Two-thirds of reporting firms are at Level 2 and Level 3. It must also be realized that when SEI touts $88 \%$ of firms at Level 2 and above, that firms that consider themselves to be very low on the CMMI scale may not have an incentive to report. In total, only 1264 appraisals were provided to SEI (SEI 2006b, slide 4) which would seem to be a relatively small number of total organizations.

Fitzgerald's (1996) note on the pursuit of methodologies to secure government contracts is supported by the CMM statistics. Looking at the countrybased demographics for CMMI reporting, $72 \%$ of firms in the United States were 
either government or military contractors, or were actual government or military agencies (SEI, 2006b, slide 13). This substantiates the belief that often the pursuit of methodologies may be due to external, rather than internal, pressures. Although, nearly $90 \%$ of non-USA firms that followed the CMMI guidelines were commercial (SEI, 2007), many of these firms are foreign subsidiaries of US companies, and may have also adopted CMMI due to pressures from the home office.

There are numerous studies and articles which indicate that pursuing CMMI levels leads to cost and time decreases for software development (see Lawlis et al., 1995; Isaac et al., 2003; Humphrey et al., 1991). Galin and Avrahami (2006) analyzed a number of previous studies on the impact of $\mathrm{CMMl}$ and determined that, for a range of criteria including density of errors, productivity, cycle time, and ROI, a higher CMMI level led to improvements for all of the criteria. This supports the contention that some form of managed process of software development, and therefore methodological adoption, promotes better software development.

Another rationale for methodological adoption presented by Fitzgerald (1996) is the division of labour. By segmenting the development process into parts, organizational members can focus on specific functions. This allows workers to specialize, and may also allow work to be done in parallel. Additionally, since different activities may require different pools of labour, it is not necessary for all individuals to be skilled in all aspects of development.

The ability for individuals to specialize in certain aspects of the development process also allows for standardization (Fitzgerald, 1996). Since the same individuals may be used in the same stage of all development projects for an organization, their work will be similar across all projects. Without this specialization, it is likely that individuals would concentrate on particular projects, and the work would be less homogenous across the organization. Taken to a greater level, this applies to industries as well. Based on specialization, firms emerge that specialize in certain aspects of the development process, providing a consistent service quality for all of their customers. This leads to "best practices" in the industry, which can be adopted by all development firms of that type.

Another important side-effect of standardization of development phases in an organization is that personnel develop consistent channels of communication with the other development groups. Each group understands what is expected of it, and 
what other groups it needs to communicate with. This can lead to higher productivity and decreased maintenance time (Avison and Fitzgerald, 2006, pp. 571-572)

Fitzgerald (1997) indicates that a prevalent, but perhaps less justifiable reason for adoption of methodologies is a strong apparent bias towards them in the literature. Many authors are very critical of developers in the industry and call for more formalized development that adheres to accepted SDMs. Boehm (1979) indicates that "the average coder ... (is)... sloppy, inflexible, in over his head, and undermanaged" (p. 67). Fitzgerald (1997) offers compelling evidence, however, that non-adoption of methodologies is not ignorance based.

Many methodologies are marketed products, and an important thrust that has provided incentives to adopt methodologies are the existence of tools which automate the IS development process (Avison and Fitzgerald, 1988). Computeraided software engineering (CASE) tools have become a staple of many of the marketed methodologies and are attractive to IT professionals and managers because they can lessen the burden for analysts who employ that methodology. Potentially, these tools have become major factors in the purchase of particular methodologies.

In some cases, the use of CASE tools has even changed the nature of the methodology itself. CASE tools can minimize the time required to carry out specific steps in the methodology, or even possibly remove the need for the step entirely (MacDonald, 1988). This can make a CASE-supplemented methodology very attractive as it lessens the burden of documenting and implementing development.

A methodology may also be employed to provide "legitimacy" for the actions of a particular development group (Nandhakumar and Avison, 1999). By indicating to management that they intend to employ a particular methodology, developers may feel they are providing reassurance to management that development will precede in an ordered manner. It is important to note, however, that in many cases the methodology may simply be a front, and actual development may progress very differently than what is expected.

Methodology use is also potentially linked to developer experience. Fitzgerald (1997) provides some evidence supporting the idea that inexperienced and very experienced developers are attracted to methodologies, though for very different reasons. Inexperienced developers require the stability and structure of 
methodologies since they do not have sufficient experience to make their own development judgments. An examination of the process of learning methodologies by Wastell (1996) reveals that novice developers find comfort in the structured nature of methodologies, relying on them until their personal confidence with development allows the developer to exercise discretion when employing the methodology. Once experienced in development, developers are not reliant on methodologies, but may employ them to support their development tasks. Experienced developers are aware of the pitfalls of disorganized development, and adopt methodologies to provide guidelines to organize development (Fitzgerald, 1997). In this case, however, experienced developers are very likely to have modified the methodology to their own circumstances, and are likely to reject strict methodological rules, instead favoring experience and common sense solutions.

\section{Methodologies and Project Failure}

Lyytinen and Hirschheim (1987) suggest that over half of all systems developments end in failure. Deficiencies in methodologies are a primary cause for this failure (Lyytinen, 1987). Although many researchers have promoted the use of methodologies (usually their own), a systematic survey of methodologies to demonstrate their benefits has not been completed (Wynekoop and Russo, 1995). Although there are "success stories" taken from numerous case studies, many of these studies provide anecdotal, rather than convincing proof of methodology success.

Methodologies seem to be unable to prevent the primary causes of project failure. Projects may excessively exceed budgetary expectations; there may be excessive project delays of perhaps even months or years; the system may be of poor quality; or it may not meet the requirements of the users. Poor business requirement determination is cited as the primary cause of IS project failure (EwusiMensah, 1997; Lindquist, 2005; Standish Group, 2001; Vessey and Conger, 1994; Wand and Weber, 2002). Jenkins et al. (1984) reported that for two thirds of the projects they surveyed, the business requirement step had to be repeated. For these repeated analyses, the primary cause was faulty or incomplete analysis.

It is ironic that methodologies, which are designed to ensure successful consideration of the necessary factors to ensure proper analysis and therefore 
project success, would, in fact, be tied to the failure of many projects. One of the principle reasons for the failure of methodologies to properly capture business requirements is that business requirements are usually linked to organizational issues (Doherty and King, 1998). Organizational issues can include power imbalances that lead to only some requirements being deemed necessary, lack of buy-in from important stakeholders, and resistance to change. Unfortunately, most methodologies do not consider organizational factors sufficiently, even though these factors are generally the most difficult to resolve (Clegg et al., 1997).

Hornby et al. (1992) reported that many systems analysts consider involving end-users to be sufficient to address any relevant organizational and human issues, even though having a system the user wants does not guarantee that it will provide an overall positive impact for the organization. In most cases, analysts and organizations focus on the technical elements of development first, and attempt to cope with organizational and human factors as they arise (Doherty and King, 1998). Although IT managers are beginning to address organizational issues, they are usually expected to be handled by user management representatives.

\section{The Argument against Structured Methodologies}

Structured methods are still very much a part of the current learning cycle for information systems students. The top selling SAD textbook, Systems Analysis \& Design Methods, $7^{\text {th }}$ Edition (Whitten and Bentley, 2007) focuses on the structured methodology. Misic and Russo (2000) determined that structured methodologies were by far the most common methodology taught in SAD textbooks, and that structured methodologies or diagrams related to the structured approach dominated textbook content.

There is considerable evidence, however, that structured methodologies do not actually improve the software development process (Lyytinen, 1989; Baskerville et al., 1992), and somewhat surprisingly, may even slow the pace of development (Wynekoop and Russo, 1995; Ciborra and Lanzara, 1994)

Structured analysis attempts to reduce work situations into logical models that treat humans and machines as equivalent entities that process information (DeMarco, 1978, p.27-28). Bansler and Bødker (1993) present several reasons, however, why conflicts arise when this form of analysis is employed. Structured 
analysis undervalues the skills and problem solving ability of employees, which extends beyond the tools they have at their command (Sachs, 1995). It also underestimates the amount of information that is passed through informal channels. Structured analysis ignores the importance of errors and exception cases, though this may be a driving force in the actual use of the system (Suchman, 1983; Winograd and Flores, 1986). Most importantly, structured analysis ignores the impact of power and influence on the outcomes of work, and ignores the organization context that may determine how systems are integrated with jobs (Eason, 1988; Hornby et al., 1992).

The SDLC lifecycle is supported by a number of key assumptions in order for it to work optimally (Bansler and Bødker, 1993). We assume that each problem that underlies the systems analysis can and has been clearly defined as a business requirement. We also assume that the designer is rational, and has a perfect understanding of the system context. Finally, we assume that the design can be separated from the actual implementation and that we focus on the "logical" aspects of design while ignoring the "physical" aspects of design.

In reality these assumptions rarely hold. Frequently, design is begun with an incomplete set of requirements, since the actual design process itself often exposes further requirements (Malhotra et al., 1980). Requirements may also need clarification or negotiation, and it is unlikely that the designer has a perfect knowledge of all forces in play (Hirschheim and Klein, 1989). As was stated above, structured methodologies tend to ignore organizational factors which can have a profound affect on the system context. Finally, systems usually have prescribed implementation elements, such as a specific platform, at the outset. Structured methodologies were created in an age where it was reasonable to assume that a completely new system was being designed, rather than upgrading or altering an existing system (Fitzgerald, 1996). This is rarely the case in the current business environment.

The SDLC also considers development as a discrete event that is segmented into phases. There is evidence however, that it is unrealistic to consider a system as ever being a finished product (McCracken and Jackson, 1982; Alter, 2002). When we consider a system as "complete", it builds the mistaken belief that system development does not continue long after the system in implemented. A number of 
researchers have put forward the idea that systems must be evolutionary, constantly reviewed and modified, in order to deal with the dynamic context in which they are surrounded.

Ahituv et al. (1984) indicate that the SDLC is too rigid to be used in practice, and must be adapted to be used effectively. They suggest that the SLDC only be used as a general framework, and that projects vary so much in the nature of their development that there cannot be a "universally correct way to run all projects" ( $p$. 70). In some extreme cases, the structured methodology may be used "in name" only, as simply a template for organizing work (Lang and Fitzgerald, 2006). In these cases, the methodology is only loosely followed, and consists of a general plan for work, and a number of techniques for analysis and design. The more rigid control elements of the methodology are abandoned. Increasingly, it is seen that project development must be flexible and adaptable, and cannot be deterministic (Ciborra, 1999).

The structured methodology tends to be more popular with managers than with developers, and its widespread adoption is likely to be based on external management pressure on developers (Fitzgerald, 1996). Structured, prescriptive methodologies provide a rigid order and structure for the project management aspects of development (Avgerou and Cornford, 1993). Bansler and Bødker (1993) indicate that project management and cost control were the primary reasons why the Danish firm they interviewed in their study adopted the structured method. The methodical nature of the structured methodology appeals to those who promote control and measurement in development, and while livari and Huisman (2007) present some evidence that hierarchical organizations are likely to adopt structured methodologies, organizations that prefer more flexible or flatter management styles are not drawn to them, and may even reject them.

Often the decision to adopt a structured methodology is made by management, and this decision is often made with little knowledge of alternative system methodologies. Huisman and livara (2006) support this notion as management tends to have a more favorable view of SDM than developers themselves. Developers may chafe under the restrictions that are imposed by this rigid structure. In many cases, management may say that structured methodologies are being used in the organization, while developers may actually be using different 
methodologies, or may be working in a completely ad-hoc environment (Lyytinen and Robey, 1999).

Clegg et al. (1997) interviewed a number of IS academics and business professionals whose reactions to the structured method were even stronger, "...some reported that these methods simply do not work, that they omit too much, and that they are too technically oriented" (p. 858). The interviewees also felt that structured methods limited the roles of the user, and prevented a sufficient level of user involvement in system development. Low user involvement, according to the interviewees, leads to decreased system viability, decreased likelihood of system adoption, and increased likelihood of system failure.

Avison and Fitzgerald (1988) note that traditional methodologies, though they may voice an interest in user needs, tend to place the analyst in the position of power with regard to system design. An inability to get user buy-in, however, is a frequently cited reason for system failure (Lyytinen and Hirschheim, 1987). Participative methodologies, such as Mumford's ETHICS method (Mumford, 1986) treat the role of the analyst as a facilitator, who presents the user with different options from which they can chose. The importance of participative methods is growing for IS development groups, who are dedicating an increasing amount of their developer time towards facilitating user needs (Grindley, 1987).

In Keyes (1992), Ed Yourdon is quoted as saying that the traditional methodologies are outdated, and that a new generation of methodologies needs to be considered to deal with new software development concerns. Hevner and Park (2004) state that, "design-science research is perishable" (p. 9), and that rapid advances in technology can invalidate not only previously designed artifacts, but also the process of SAD itself. Misic and Graf (2004) note that while the use of structured approaches, tools, and methodologies declined slightly from 1994 to 2001 , the use of object-oriented and rapid development approaches climbed considerably.

Even as the structured methodology was being introduced in organizations, Colter (1984) warned against the single-minded domination of any methodology. He noted that the structured methodology did not address issues that even "premethodology" development techniques considered important, and that newly trained analysts did not have a proper perspective of the traditional techniques, due to an 
overwhelming dominance of structured textbooks in universities. He supported the use of a broad range of methodologies and techniques, and maintained that this balanced view should be brought to the classroom, so that analysts understood that they must adapt their methods to particular organizational situations.

\section{The Argument against Methodologies in General}

In addition to arguments against structured methodologies, a number of researchers have expressed doubt about the success of employing methodologies at all. Methodologies were considered a necessity in the 1960's and 1970's, in order to organize the large software projects of that time, but they are increasingly being viewed as an hindrance in the more dynamic development environments of today. Overall, it may be that our quest for methodologies as a solution to SAD failure may have done more harm than good.

Avgerou and Cornford (1993) present substantial evidence that the pursuit of methodologies has impeded growth of the academic discipline, development of successful systems, and progress for the IS profession. The pursuit of methodologies had promoted a distinctly normative tone for research in the IS field. There is a feeling that research must prescribe action, rather than simply explore and analyze. This is an engineering model, and prevents IS research from being recognized as its own field (Mumford et al., 1985). In fact, evidence suggests that methodologies are employed in only a fragmented form in practice (Bansler and Bødker, 1993; Fitzgerald 1997). Rarely are they strictly adhered too. DeMarco and Lister (1987) present evidence that even in organizations where methodologies are rigidly enforced the actual design styles of developers vary considerably. Fitzgerald (1997) indicates that this divergence from the methodology as specified is a conscious decision, rather than the result of sloppiness or inattention. The methodologies simply were not able to meet the contingencies of the development environments. An interesting comment on the inability for methodologies to prescribe designs is made, rather ironically, by DeMarco and Yourdon themselves. Yourdon states that design generation is "an act of creativity for which there are no mechanical rules" (Yourdon, 1982, p. 84). 
Sachs (1995) uses an organizational example to demonstrate how actual work rarely follows the structured patterns in which it is molded, and requires a broad range of problem solving and negotiation skills in order to complete. Workarounds are a necessary element of work, in order to surpass limitations in the system. It then follows that strict adherence to methodological structures limits the ability of the designer to solve work problems at hand. Smith refers to this dilemma as 'confusing the menu with the meal' (quoted in Naur et al., 1976, p. 88).

Bansler and Bødker (1993), after interviewing several Danish software development groups, find that although the tools of methodologies, such as diagrams and tables, may be used in practice, the actual methodological process is largely ignored. Designers find that the rigid structure of the SDLC requires too many activities which do not generate visible results, and therefore are not productive. Time pressures and demands from users to see working prototypes necessitates the abbreviation or abandonment of most formal SDLC activities, especially systems design. Usually, system analysis will proceed directly to implementation. Data flow diagrams (DFDs) and other systems analysis documents include both physical and logical elements. Modeling of the current system is very rarely done as designers will rely on their intuitive knowledge of the current system to guide the description of the new system. Documentation of the current system is only done when the designer is unfamiliar with the existing system and must rely on the documents to bridge understanding with the users.

Lyytinen and Robey (1999) note that companies employ "theories in use" when developing systems. Theories in use include methodologies, since they prescribe actions to be taken in the development of systems with expected results, but can also include assumptions about the roles of in-house developers, consultants, users, and management. Theories in use are important for companies, since they often determine what constitutes fact in systems development (Hedberg \& Jönsson, 1978), and because the practices and methodologies employed by theories in use may differ quite markedly from what the company may say they are employing (Lyytinen and Robey, 1999). Additionally, theories in use are constantly subject to modification, and are rarely subject to any form of scientific substantiation. They contain the internal wisdom of the company, with respect to what actually 
works, or at least what is expected to work. This can vary from project to project, depending on how the organizational members interpret the current theories in use.

Middleton (1994) finds that employees often have no idea why they are following a particular methodology, but follow it blindly, often as an excuse not to think. Methodologies can often be a crutch for developers, giving them an object on which they can transfer their responsibility for project success (Wastell, 1996). Rather than internalizing project failures and blaming themselves, blame can be transferred to the methodology, on the basis that it is the methodology, not the developer, that failed. This idea is enforced by many of the highly structured methodologies, which demote the importance of the designer in the process of development. Some methodologies even view this domination of the methodology over the developer as a strength of the methodology (Fitzgerald, 1996), though this is often insulting to the designers (Stolterman, 1992).

Fitzgerald (1996) noticed that a consuming focus on meeting the strict demands of the methodology detracted from the actual production of work. DeGrace \& Stahl (1990) found that $90 \%$ of the documentation from several projects simply indicated the progress of the project, and did not contain content that actually promoted the progress of the project. DeMarco and Lister (1987) find that detailed methodologies prevent developers from being creative, and lead to decreased, rather than increased, productivity. Developers can also be trapped by a methodology, particularly if the adoption of a methodology requires the use of specific development tools (Nandhakumar and Avison, 1999). They can find themselves in a situation where even though they are aware that they must make modifications to development in order for the project to succeed, they are forced to consider rejecting the methodology in total in order to make these changes.

Surprisingly, when methodologies fail to produce the results we expect, IT professionals are often the first to push for even more structure, and more methodological plans (Ciborra and Lanzara, 1994). IS professionals will superstitiously believe that established methodologies and technologies are correct, even when faced with evidence that this is not the case. We lay blame on improper use of techniques, insufficiently rigorous methods, or circumstances beyond our control. Lyytinen and Robey (1999) call this unwavering belief in the efficacy of our technologies and our methodologies the "myth of the technological fix" (p. 95). This 
myth can be very dangerous because it prevents us from considering other potential solutions to our problems, and from learning from our mistakes. Rather than accepting the possibility that our methodologies may be insufficient to develop systems within an organizational context and that the design skill of the developers is the central element to design, we perpetuate a cycle of denial by simply admonishing ourselves for our inability to properly execute the routines within these flawed methodologies.

The trend of denying the potential flaws in methodologies seems to be changing over time however. Jenkins et al. (1984) reported that most organizations were satisfied with the methodologies, even though their study showed consistent cost and time overruns for projects. This would seem to imply a faith in the efficacy of methodologies at the time, despite evidence to the contrary. Russo and Klomparens (1993, cited in Wynekoop and Russo, 1995) paints a very different picture, showing that at that time IS managers were generally dissatisfied with their methodologies. Possibly, IS developers have lost faith in the potency of SDM's and have decided to lay blame on the methodologies rather than their inability to follow them. That said, it may still be the case that although developers recognize that methodologies cannot lead them to successful design, developers still wish to emulate the engineering principles that promote the use of methodologies (Stolterman, 1992).

The scientific legitimacy of methodologies stems from this strong tie to software engineering (Avison and Fitzgerald, 1988). Methodologies and software engineering have been deliberately linked since the inception of the concept of methodologies. Yourdon's (1979) cornerstone textbook, titled "Classics in Software Engineering", links methodologies to a scientific and rational conceptual base. Since then, researchers have often attempted to provide theoretical justifications for their variant methodologies. Fitzgerald (1996) however, argues that methodologies rarely have an a priori theoretical base, and are usually the collection of techniques and tools that were used by a particular researcher for their latest research study (Maddison et al., 1984). The conceptual underpinnings of the 'new' methodology are argued based on the success of some of the techniques, which are then leveraged to provide differentiation from existing methodologies. 
In the pursuit of academic noteworthiness and differentiation, it is possible that the authors of these methodologies have actually hampered the actual applicability of their ideas. Without a true conceptual and empirically founded basis for developing new methodologies, the generalizability of the methodology is suspect (Lyytinen, 1987). In fact, the actual existence of so many alternative methodological conceptualizations undermines the concept of a methodology itself, given that the differences are grounded in contextual and situational factors. Moving beyond the claims of specific methodologies, it is questionable whether any process, including SAD methodologies, can be universally applicable, giving the contingent factors of any situational context (Chikofsky, 1989; Wastell and Newman, 1993).

Even in situations where authors demonstrate a conceptual basis for their methodology, they rarely demonstrate empirically that their methodology is superior to existing methodologies (Wynekoop and Russo, 1995). In many cases the new methodologies are designed based on methodologies that have not themselves been empirically tested (Lyytinen, 1987). Even if the methodology can be shown empirically to be superior to other methodologies, we cannot assume that this is not due to the skills and talents of the methodology's designer, or the other developers. Wynekoop and Russo (1997) further note that most of the studies which supported the use of particular methodologies looked at only certain phases or techniques of the methodology, which may not be representative of the entire experience.

Introna and Whitley (1997) suggest that even if the author of the technique or methodology is able to produce promising results using that methodology, it does not necessarily mean that others will. The methodology's author possesses intrinsic knowledge about the nature of the methodology that cannot be easily transferred, even when the methodology is explained in detail. Based on the hermeneutic idea of distanciation, the methodology takes on a life of its own. It is unlikely that a developer who employs the methodology at a later time will be able to exactly match the author's mode of use, which could result in a loss of the methodology's efficacy.

The issue of organizational size is also important to the success of a methodology. Methodologies generally assume that the organization is large. Most methodologies therefore are ill-suited to small enterprises, which require simpler and more flexible development plans (Avison and Fitzgerald, 1988). Today, the industry seems to be moving towards very small groups of developers (Lang and Fitzgerald, 
2006). Cumbersome methodologies are not appropriate to this development environment.

Though not necessarily unsuited for the development of packaged software, most methodologies do not specifically address concerns related to the configuration and integration of these types of software (Avison and Fitzgerald, 1988). The traditional SDMs had their origins in the 1960's and 1970's, and most current methodologies are simply modifications of these original versions. Changes in the nature of business, such as the prevalence of microcomputers, end-user computing, and widespread use of prepackaged software necessitate methodologies which are better adapted to today's business model (Fitzgerald, 2000). Development times are shrinking with small groups of developers working six months on average per project (Fitzgerald, 2000). This contrasts the methodological environment of the traditional methodologies where large groups of developers might have worked for many years on one project.

It may even be the case that the current SDM offerings are actually hampering the ability for companies to respond to changes in their business environments (Baskerville et al., 1992). IT is having a dramatic impact on the actual structure and form of organizations, and therefore it is imperative that methodologies evolve to provide agility to organizations.

Wastell (1996) suggests that systems development may have reached the point where methodologies are no longer useful. Fitzgerald (1998) found that $60 \%$ of the companies in Ireland he surveyed were not using formalized SDM's, and that there was a definite need for methodologies that could adapt to rapid delivery cycles, rather than the cumbersome methodologies of the past. His follow up study in the UK (Fitzgerald et al., 1999) found that a larger number of businesses used some form of methodology (57\%); however flexibility in analysis and design was still a central concern. Perhaps the most telling complaint about the pursuit of methodologies is that it has not been conclusively demonstrated that employing a methodology produces better or more maintainable systems over an ad hoc method (Cerveny and Joseph, 1988; Ciborra and Lanzara, 1994). 


\section{How Can Methodologies Serve Us?}

It is becoming clear that methodologies must be adapted to be successful. Jenkins et al. (1984) reported that project leaders modified the SDM for $81 \%$ of their projects. In Fitzgerald's (1996) large study of IS developers, he found that all of the organizations he surveyed modified their formal system development methodologies. Lang and Fitzgerald (2006) found that developers were moving towards "in-house" methodologies, which are developed from bits-and-pieces of other methodologies that made sense to the developers. Lyytinen and Robey (1999) insist that designers must adapt their development methodologies based on their own experiences and the experiences of others.

Ciborra et al. (1980) supports the "contingent" use of methodologies. Each design situation requires a different methodological approach, based on different organizational contexts, different technologies, and different designer preferences. It might even be the case that system analysts will need to treat each particular design situation as unique, in order to leverage their understanding of the techniques applicable to that situation. In this case, then analysts will need to have access to a wide variety of methodological tools and skills, to allow them to find the best match for their situation (Hidding, 1997).

Overall, methodologies serve us best when they are transparent, and they are used simply as tools that extend our own skills (Introna and Whitley, 1997), or as checklists that organize work in a team (Stolterman, 1992). For experienced designers, methodologies fade into their background skills, and the designer may not even be aware that they are employing a particular element of an SDM (Fitzgerald, 1997). Vitalari (1985) found that experienced designers do not consider development techniques during the cognitive processes during systems analysis. Designers simply act based on the belief that this is what their experience guides them to do.

\section{Alternatives to Methodologies}

Vitalari and Dickson (1983), after studying the problem-solving processes of system analysts, found that analysts required a variety of problem-solving strategies to be successful in systems analysis problems. Methodologies limit this process, by 
enforcing rules and structures that stunt the creativity of designers (Fitzgerald, 1996). Vitalari (1985) finds that systems analysis skills are highly dependent on the type of system being built, which would preclude the use of a single method of developing systems. Floyd (1987) calls for the use of methodologies simply as guidelines, and that systems development be embodied in the continuous learning and growth of designers based on their previous experiences.

If we need to move beyond an age of methodologies, Introna and Whitley (1997) suggest we rely instead on traditions. Traditions embody techniques and ideas that are passed from generation to generation. The flexibility of traditions to minor variation actually guards the tradition against obsolescence, unlike methodologies, which become supplanted quickly when they are unable to deal with specific contexts.

Cross (2001) speaks of an underlying body of knowledge that is inherent to design itself, which can be employed in any design situation. It is suggested that rather than attempting to codify the design process, an effort should instead be made to ensure that designers are well trained, and to allow them the flexibility to deal with the contingencies of each unique design situation (Schön, 1983). Designers must possess a core of analytical skills that they can leverage when needed.

\section{Conclusions}

Though Fitzgerald (1996) notes support for ordered processes which can be monitored and verified, such as the Capability Maturity Model, overall, he and other academics challenge the efficacy of methodologies. Methodologies are simply too rigid to be used in practice (Ahituv et al., 1984), and the use of methodologies may be a strong contributing factor in project failure (Lyytinen, 1987), since most methodologies do not properly the organizational factors that drive business requirement analysis (Clegg et al., 1997). Methodologies often decrease, rather than improve, productivity (Fitzgerald, 1996), and employees often follow a methodology blindly, without understanding what value, if any, using the methodology provides (Middleton, 1994). Little proof has been given that the use of a methodology produces better systems than an ad hoc method (Cerveny and Joseph, 1988; Ciborra and Lanzara, 1994). 


\section{Section 3: Systems Analysts' Skills}

\section{Practitioner and Educator Positions}

Trauth et al. (1993) identified a distinct difference in the perceptions of practitioners and educators with respect to what skills were important for system designers and IS professionals to possess and for emerging IS graduates to have studied in university. Closing this gap is difficult. Not only do practitioners and educators have a different vision of what skills IS professionals need to employ in their everyday work environments, they differ in opinion with respect to how and where these skills should be acquired.

In the early 80 's, the focus for graduate skills was systems analysis and programming (Archer, 1983). Practitioners looked primarily for specialists (Mandt, 1982), who possessed tremendous experience with general systems design. Over time, this view changed, and organizational and communication skills were regarded as critically underdeveloped in university graduates. In 1977, more than half of employed graduates said they would change the content of their degrees to include more courses that aided communication, human relations, and business administration (Mandt, 1982). Cheney (1988) notes an improvement in the ranking of the importance of organization skills for systems analysts from a previous 1980 study.

With the passage of more time, even that focus has changed. During the late 80 's and early 90's, businesses wanted IS professionals with stronger business skills and specific technical skills (Sullivan-Trainor, 1988; Cheney, 1988). In particular, positions became dependent on the knowledge of specific technologies and applications. The development and proliferation of new technologies led to rapid change for the skill sets desired for new graduates.

The most consistent statement about what practitioners have desired from graduates is that it is a "balance of technical and organizational skills" (Nelson, 1991, p. 506; McCubbrey and Scudder, 1988), and that it changes over time (Misic and Graf, 2004; Nord et al., 1998). In a study of IS professional and end-user skill requirements and deficiencies, Nelson (1991) found that, in general, organizational skills ranked higher in usefulness than IS skills, particularly IS technical skills. 
Interestingly, the two "least" useful skills were model building and model application. IS practitioners and end-users felt that their greatest skill deficiencies were general IS knowledge skills, including IS governance, and IS/IT potential. Nelson (1991) recommends that more time is spent in university focusing on general IS topics as this appears to be a common deficiency for both IS professional and for other users. Williams and Pomykalski (2006) cites a lack of general IS skills in university teaching despite the requirements of the IS curriculum standards.

IS professionals also require more organizational knowledge. Nelson (1991) mentions that the development of organizational skills takes more time than technical skills, and should be integrated with the learning of technical skills to promote the ability for IS professionals to apply these skills in context. Many IS professionals in the field face retraining, in order to develop the business and organizational skills that were lacking in their initial degrees (Crane, 1990). Another critical issue with existing IS professionals is the degradation of their technical skills and knowledge (Radding and Magitta, 1993).

\section{Education versus Training}

Unlike practitioners who would prefer graduates to have skills that are directly relevant to their job positions, educators feel that their duty is to provide students with career education rather than job training (Trauth et al., 1993). If this is the case, the educator's focus should be to provide basic analytical skills and to move away from more volatile skills that are best delivered in an on-the-job training environment. This creates an "education" versus "training" element to IS skill development. According to Nelson (1991):

"In general, education teaches problem-solving approaches while focusing on the ability to reason abstractly. Training, on the other hand, provides the tools (i.e., skills) for implementing problem-solving approaches while focusing on the ability to work concretely." (p. 505)

Nelson's (1991) suggestions are not unchallenged. Many current employers look for applicants with experience in particular technologies (Callahan and Pedigo, 2002), even for entry-level positions (Seymour et al., 2006), which places emerging graduates who have not developed particular technical skills at a disadvantage. This is ironic, since a key requirement of the IS curricula is preparing students for entrylevel positions (Couger et al. 1995; Lee et al., 1995). 


\section{The Case against Teaching Methodological Knowledge}

Increasingly, the demand for IS analysts and developers is being driven by their knowledge of technologies rather than their knowledge of methodologies (Davis et al., 1997). Technology management skills are more important than particular hardware or software skills (Callahan and Pedigo, 2002). Boehm (1981) and DeMarco and Lister (1987) point out that methodologies are less important than the skills and ingenuity of developers. Preliminary results from Mawhinney et al. (1999) show that problem solving and communication skills ranked high in their survey, while methodological knowledge rated at only a "concept" level. No particular methodology was specified as significant by their respondents. Caputo et al. (2006) surveyed a variety of IT professionals and found that system development tools and technology skills consistently rated in the bottom half of the professional's common skill set.

With regard to learning system development skills, Stolterman (1992) interviewed a number of experienced designers who nearly unanimously believe that these skills are developed through experience, and cannot be transferred or taught to less experienced designers. Therefore, teaching these skills in universities may be unrealistic. Unfortunately, few employers are willing to pay for technical training for new employees, expecting graduates to already be experienced in some technologies and techniques (Callahan and Pedigo, 2002).

Stolterman (1992) and Fitzgerald (1996) both believe that it is important, however, for analysts to be able to speak a common 'language'. This language is developed through a shared understanding of design techniques and tools, which allow information to be passed from one analyst to another. This material is valuable to be taught to students; however, it is difficult for students to understand how to apply this knowledge in an academic setting. It is only when they are actually faced with actual real-world design problems that they begin to learn how to apply the concepts they have been taught. 


\section{Career Skill Development}

Many IS professionals also seem to plateau with respect to skills in the middle of their careers, though this should be a prime period of productivity for them (Hunter, 1998; Radding and Magitta, 1993). The problem comes from an inability to remain current with technology and from apathy toward training on the part of both employer and employee. Schambach and Blanton (2002) claim that IS professionals are not given incentives to remain current with their skills. Jiang et al. (1999) concede that there may need to be different specializations of systems analysts with either a technical or organizational/business bias.

The interviewees that Clegg et al. (1997) spoke to mentioned that although project managers do not properly manage the organizational and human aspects of system development, this is caused in part due to a lack of training and education regarding their importance. What seemed particularly frustrating for interviewees is that the importance of human and organizational factors in system development seemed to be well known in practice, however academics and consultants seem to keep 'endlessly re-inventing the wheel' (p. 864), instead of focusing on disseminating the existing knowledge and expertise. Doherty and King (1998) also add that when some researchers do address human and organizational factors in development, the factors are not differentiated and are simply labeled as 'non-technical' factors.

In addition to a lack of training in educational and research settings, once analysts are in the workforce, they may still not pressed to address organizational and human factors. Hornby et al. (1992) explain the issue as:

"Systems analysts do not claim to have knowledge of organizational issues in IT systems, and there is no evidence that they are encouraged or rewarded for considering such issues. In fact it could be said that the reward and control systems within which analysts work actively encourage them not to consider them. They are rewarded in the main, for delivering technically sound systems on time and to budget" (p. 165).

Therefore, although organizational and human factors are cited as a primary cause of project failure, analysts are not trained in either academic or work situations in how to address these factors. 


\section{A Common Vision}

Although Trauth et al. (1993) discovered a substantial gap between the expectations of practitioners and educators with respect to IS professionals, this gap does not result from a lack of a common vision. Practitioners and educators agree substantially with regard to the importance of many elements of an IS education. A mix of human, technical, and business skills is critical for IS professionals, and there is a reasonable amount of agreement with respect to the priority of specific skills in these skill categories. In particular, practitioners and educators agree on a need for strong analytical and problem solving skills (Misic and Graf, 2004). A key difference between experienced and inexperienced analysts is the possession of these skills (Frampton et al., 2006). Where practitioners and educators disagree is how to implement this shared vision into a university curriculum. 


\section{Section 4: Information Systems Education}

\section{Initial Development of Curriculum Guidelines}

In the late 1960's, the need for business-based information degrees emerged. Reports such as IBM Corporate Staff for Manpower Planning and Personnel (Hunter, 1969) identified a need for education for systems analyst positions. Concurrently, reports such as Elliot (1968) claimed that the newly developing computer science degree curricula generally ignored systems analysis and design topics and businessrelated aspects of computer and information use topics, and focused primarily on programming and computer operation topics. Although some training programs in systems analysis and design were offered by independent organizations and businesses, such as IBM and the International Federation for Information Processing (IFIP), educational institutions had just begun to make these offerings (McKenney and Tonge, 1971).

Responding to this need for business-related curricula in the information and computer domains, the Association for Computing Machinery (ACM) began producing curriculum suggestions and recommendations in the early 1970's. Based on a study funded by the National Science Foundation (Teichroew, 1971), two curriculum reports were developed. The first was a graduate study program curriculum (Ashenhurst, 1972), followed by an undergraduate program curriculum (Couger, 1973).

Teichroew (1971) was a sweeping study that examined the role of information systems in organizations, and determined how educational institutions could play a role in the training and development of IS skills. It also considered the role of professional organizations and other computer organizations. The curricula that were spawned from this report treat the role of information systems as specialized, and they focus on systems analysis and design. Although the more general use of computers is identified in the report, the primary skills to be developed for information systems specialists were systems analysis and design related.

Teichroew (1971) identified three categories of positions related to information systems in organizations, which correspond to the steps in the system development life cycle (SDLC): 
- Information analyst positions which correspond to systems analysis and requirements determination

- System designer positions which correspond to system design

- Programming positions which correspond to system implementation and maintenance

Therefore each position supports the actions of the other positions. Interestingly, Teichroew (1971)'s conception of the analyst position was specified as an "information analyst" rather than "systems analyst". This distinction, according to Teichroew, was made to emphasize the importance of requirements gathering, rather than design of systems ( $p$. 576). Other related positions, such as data administrator and information security officer were theorized, but relegated to later discussion.

The education required for both the information analyst and the system designer positions was believed to be at a graduate level at that time. This perception began in Teichroew (1971) and was sustained by the graduate study curriculum requirements study (Ashenhurst, 1972). IS as an undergraduate degree was proposed in the later undergraduate curriculum requirement study (Couger, 1973), but the ability for a student completing the undergraduate degree to reach an analyst or design position would require "experience and [further] advanced education" (Couger, 1973, p. 730). This implied that analyst and design positions would require additional graduate study.

The initial description of a graduate IS degree in Teichroew (1971) focused on five primary areas of education:

- Computer Science - Hardware and software systems

- Information Systems - General systems theory and the management and socio-technical aspects of systems

- Management - Introduction to management principles and functional areas

- Operations Research - Techniques for model building and quantitative and probabilistic model design

- System Design Techniques - The SDLC, and techniques for specifying systems

This initial template was based on a balance of organizational and technological skills that were manipulated within a systems development framework. This initial 
template was pre-methodological, since methodologies were only being introduced at the time, and did not have widespread adoption.

The graduate curriculum recommendations (Ashenhurst, 1972), which formalized the determinations of Teichroew (1971), maintained the idea of an organizational / technological balance for the IS development curriculum. Students learn basic system concepts, the roles and importance of organizational functions, and the nature of human behaviour in order to build a foundation for analyzing the needs of organizations. Students also learn about computer software, hardware, and programming in order to understand how computers can be leveraged to solve business problems. Students learn about operational models and quantitative analysis techniques to provide additional ways to solve business issues and to provide a basis for evaluating systems. These three areas form the foundation for the information analysis and system design courses which teach the fundamentals of the systems development process. This process remains largely in place in the current IS curricula, and the layout of the progression through the courses is given as Figure 2. 


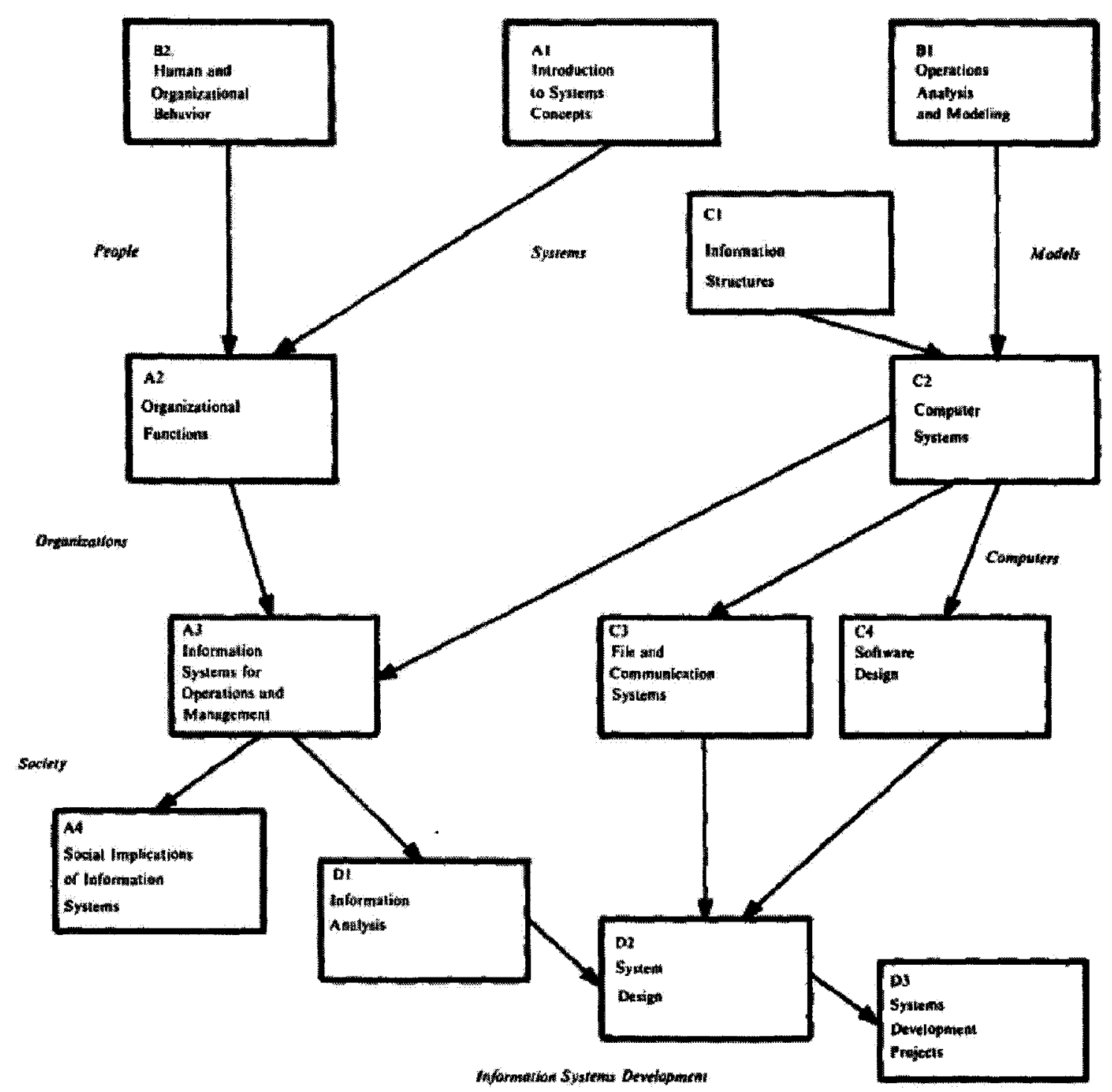

Figure 2. Courses for Graduate Curriculum (Ashenhurst, 1972, p. 373)

One of the interesting elements of this early curriculum is the recognition that "hard' technological material tends to get attention at the expense of the 'soft' organizational material" (Ashenhurst, 1972, p. 374). Therefore it was important, even at this early stage, that the curriculum addressed and attempted to prevent too narrow a view of system development as a methodological process, or a technologically-focused exercise. Ashenhurst (1972) stresses the need for providing a context for the learning of the system development skills that brings the organizational and human elements into focus. The curriculum should not produce "practitioners who ignore or only pay lip service to the "people problems"' (p. 381). 
Ashenhurst (1972) also comments that a systems focus rather than a technology focus is important, due to the rapid rate of technological change.

The pedagogical materials for the graduate program at this time were all nontextbook formats, and relied on readings, case studies, projects, and business games. Ashenhurst (1972) comments that textbooks did not exist at that time for most of the courses.

Couger (1973) follows Ashenhurst (1972) to provide undergraduate curriculum recommendations. The report demonstrates some subtle changes in ideology from the two reports that support it. First, although Ashenhurst (1972) discusses the positions of Information Analyst and System Designer, only one course curriculum is presented. Couger (1973) outlines two different concentrations for an information systems degree. The first was an organizational concentration, which paired a series of information systems and computer use courses with another business concentration, such as accounting or marketing. The purpose of this concentration was to prepare a student who will be working in a particular functional area to analyze their business function and prepare requirements documents while interacting with other system developers and programmers. The second concentration was a technological concentration. This concentration prepared a student to become a programmer in an organization involved with the implementation of systems. Eventually the technological concentration graduate would move to a system design position. Therefore Couger (1973) begins to separate the functions of Analyst and Designer with slightly different curricula for each position.

Couger (1973) also begins to adopt much of the emerging information systems ideology. Though Ashenhurst (1972) deals very broadly with system development as an organizational function, the course concentrations in Couger (1973) focus very specifically on the system life development cycle (SDLC). Additionally, the concentrations encompass only three stages of system development: analysis, design, and implementation. Specifically, the organization concentration focuses on systems analysis, while the technological concentration begins with implementation and migrates to system design. In the curriculum recommendations, the general use, maintenance, and support of systems is termed the operations stage, and is outside the scope of the degree. This reflects an 
emerging belief that systems analysis and design is extremely specialized, requiring focused training in certain techniques. Couger (1973) supports this claim by stating that "the education for the [IS] professional depends on the position" (p. 729). Couger (1973) also suggests that the organizational concentration should be delivered in a business school, while the technological concentration would be delivered in an engineering school, indicating another separation in the perception of the SAD function. Couger (1973) builds a foundation of skills with the understanding that experienced graduates will later return for a graduate degree that would reintegrate the organizational and technical based roles in the undergraduate curriculum.

With regard to output expectations, the undergraduate curriculum focuses less on organizational functions and the ability to understand human behaviour, based on a belief that the context for this understanding must be found from actual business experience, and therefore is not appropriate for an undergraduate environment. This reflects Couger's (1973) claim that the undergraduate program is still meant to be a stepping stone to an information analyst or system designer position rather than being a direct entry path to these positions. The undergraduate curriculum does, however, have an increased computer focus, with additional programming courses a part of the technological concentration. Overall, however, course content for the undergraduate curriculum is similar to the graduate program, although the content is partially divided between two concentrations (Figure 3). 


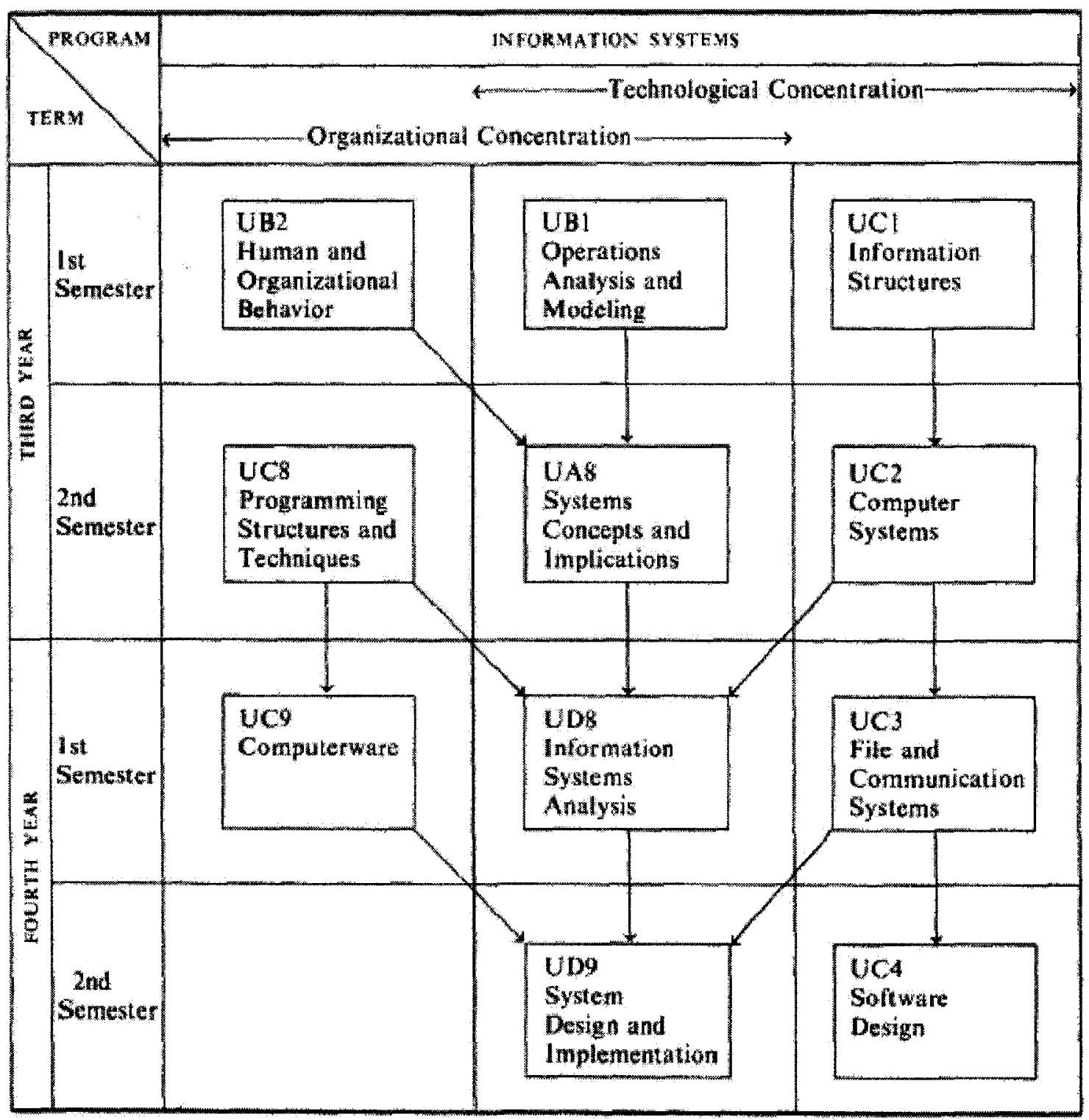

Figure 3. Courses for Undergraduate Curriculum (Couger, 1973, p. 732)

Here we begin to see the separation of the organizational aspects of SAD from the technological aspects. The Technological concentration is no longer responsible for Human and Organizational Behaviour content, while the Organizational focuses on software rather than hardware aspects of system development. 


\section{Competing Curriculum Developments}

The ACM guidelines were not the sole guidelines available. The Data Processing Management Association (DPMA), now called the Association of Information Technology Professionals (AITP), produced a competing set of guidelines. Additionally, the Association for Information Systems (AIS) also produced undergraduate guidelines. For the purposes of this study however, the early DMPA and AIS curriculum guidelines were not included, not due to their unimportance, but rather due to a lack of their availability. Most of these guidelines were not produced as academic articles (unlike the ACM guidelines) and therefore the guidelines became unavailable when they were discontinued. An exhaustive search through printed and online sources failed to turn up these early reports. In any event, these guidelines were merged with the ACM guidelines during the 1990's.

Fowler and Discenza (1986) and Unger et al. (1987) indicate that the DPMA guidelines were the dominant guidelines for business schools during the 1980's, and that the ACM guidelines were used primarily in computer systems departments. It is important to remember however, that most IS academics at the time were found primarily in computer systems departments (Avison et al., 2001). It was not until later that the systems analysis and design degrees migrated to business departments. By this time, the ACM, DPMA, and AIS curricula had merged.

\section{ACM Curriculum Adoption Report and the 1982 ACM Curriculum}

In 1981, the ACM released an assessment of educational programs in information systems (Nunamaker, 1981). The purpose of the report was to survey university IS programs at the B.A., M.S., and Ph.D. levels and to assess how well the previous curriculum recommendations had been adopted. The report also examined the current state of the industry with respect to information systems positions.

The number of types of IS positions expanded after the release of the undergraduate report (Couger, 1973) which reported only two primary IS positions. The range of positions considered to be IS positions grew to include database administrators, programmers, communication analysts, system librarians, and IS managers. Nunamaker (1981) places the positions on a spectrum from organizational focus to technical focus and claims that the shortage in IS graduates 
with organizational skills led to a job mismatch in the industry. Too many technicallyoriented employees were being placed in these organizational skill-focused positions, where they were unprepared for systems analysis and design tasks. This led to poor systems development in the industry. Universities were partially blamed for this trend, as the ratio of computer science degree programs to information systems degree programs was five-to-one at the time.

In the survey portion of the report, over five hundred business, computer, and engineering schools were polled. 91 reported that they offered some form of IS course program. 70 offered undergraduate programs, while 54 offered master's level programs.

Serious deficiencies were found between the criteria of the ACM undergraduate curriculum and the offerings of the universities. Most of the universities were not able to meet the course content requirements of the curriculum. This was attributed to an inability by universities to leverage existing educators to teach the new course content. Additionally, the SAD course content was deemed particularly poor. Very little standardization could be found across universities, with most content being ad hoc or a general overview with a focus on programming rather than actual analysis and design.

It is in this report that we began to hear the chime of the methodological bell. Nunamaker (1981) states that at the time, structured design and top-down approaches had become available, but had not been integrated into the course content yet. Methodologies move from limited practical use to educational inclusion beginning with the 1982 ACM Curriculum recommendations (Nunamaker et al., 1982).

The curriculum change comes from four developments in the business landscape:

- Increased importance of information systems

- Advances in technology

- Improvement in systems analysis and design processes

- Increased need for information systems management skills.

These changes expanded the spread of topics for the IS degree in the 1980 IS Curriculum. Data management and communication courses were added to the curriculum. Information management courses were also introduced. An important 
overall change to the perception of the IS degree is that the undergraduate IS degree is now seen as a direct entry path to the systems analyst and designer positions, instead of as a stepping stone to such. The graduate and undergraduate programs are now essentially mirrors of each other, with differences primarily related to the amount of time spent on each particular topic within a specific course. The graduate degree program has a more managerial focus, while the undergraduate program focuses on teaching core analysis and design skills. This was based on market pressures to fill entry-level positions quickly with undergraduates from IS degree programs, rather than other technical degrees (Nunamaker, 1981). The graduate degree program students were positioned to move into the managerial positions that were beginning to emerge as IS groups acquired some autonomy.

Perhaps the largest structural change to this round of curriculum requirements is the specification of the percentage of time that each topic should encompass within each course. This begins an important shift in the nature of the curriculum, as standardization of the actual topics now becomes a focus. Previous to this, course structure was largely the whim of the educator, but now, based on the issues cited in Nunamaker (1981), we see the formal determination of content for the curriculum. We also begin to see the importance of methodological content establish itself in the IS curriculum.

In the authors' words:

"In assigning weights to undergraduate curriculum topics there is an emphasis on tools of programming, systems analysis, and systems design. The supervisory/managerial tools, such as project management, and the advanced techniques, such as network design and computer-aided system design are deemphasized. Only a general understanding of these topics is provided; they are not covered in depth as they are in the graduate level program. For example, in IS5, the information analysis course, weighting of the life cycle management topics is reduced from 25 to 15 percent while the topic on requirement analysis and logical design is increased from 20 to 30 percent." (p. 788)

We also begin to see the emerging SAD textbooks become staples of the course pedagogical materials. DeMarco, Gane and Sarson, Yourdon, and other methodological textbooks are listed as source texts for the introductory systems course and for the systems analysis and design courses. With the increasing 
percentage of course time directed towards these courses and course topics, the stage is set for these books to become major influences on the overall IS curriculum.

\section{ACM Curriculum Guidelines}

The next major curriculum update from the ACM does not appear until 1995 (Couger et al., 1995). At this time, however, all of the undergraduate curriculum offerings, including those of other groups such as the DPMA (Data Processing Management Association), ICIS (International Conference on Information Systems), and the AIS (Association of Information Systems), are merged. From this point forward, the ACM curriculum becomes the sole IS degree curriculum standard.

One of the important changes to the IS'95 curriculum is that the several options are now available for study at the undergraduate level. Due to the increasing pervasiveness of technology, all undergraduate university student needs are now addressed under the IS'95 curriculum. General students are taught basic computer skills and the use of database and end-user applications. Students who intend to interact with systems more extensively, but do not wish to pursue a career in IS, can consider a minor in IS. Students who focus on IS are now considered to be majoring in IS. One topic requirement list is used for all students, but the competency level of each group varies. Course topics are now spread out more evenly among the introductory courses, with later courses building on previously learned skills. This differs substantially from the previous curricula, where courses were more topic-specific.

The IS'95 undergraduate curriculum requirements represent a culmination of the methodologies movement in the educational curriculum. At this point, "systems analysis and design" becomes "knowledge of system development methodologies", as shown by Table 4 . Students are expected to be able to "select and utilize appropriate methodologies" (p. 346) as a requisite skill for graduation. The purpose of the SAD course in the curriculum (now called "Analysis and Logical Design") is to "enable students to evaluate and choose a systems development methodology" ( $p$. 350). A specific methodological approach is not stated for the course, although the curriculum content refers to the SDLC, therefore the structured methodology may be assumed. Adaptive and object-oriented methodologies are not mentioned and were still considered "new" to the market in the mid 1990's (Misic and Russo, 2000), 
although object-oriented programming design is a part of the physical design course content.

A number of new concepts also enter into the curriculum. CASE tools are mentioned as an essential development tool. Telecommunications has also been added as a new course in the curriculum, and we see the curriculum continue to change and respond to new developments in practice and in academia.

\begin{tabular}{|l|l|}
\hline \multicolumn{1}{|c|}{ Characteristic } & \multicolumn{1}{|c|}{ Competence to ... } \\
\hline Communication & $\begin{array}{l}\text { exchange information in a professional manner using a variety of } \\
\text { tools and techniques }\end{array}$ \\
\hline Computer Applications Systems & $\begin{array}{l}\text { understand how and where to apply application systems to } \\
\text { organizational functions }\end{array}$ \\
\hline Information Technology and Tools & understand computer and intormation technology and its function \\
\hline Interpersonal Relationships & successfully interact with a diverse population \\
\hline Management & plan and direct people and projects \\
\hline Problem Solving & $\begin{array}{l}\text { define and interpret complex problems using qualitative and } \\
\text { quantitative methods }\end{array}$ \\
\hline Systems Development Methodologies & develop or acquire sofware \\
\hline Systems Theory and Concepts & view, describe, and define any situation as a system \\
\hline Professionalism & engage in appropriate behavior consistent with professional standards \\
\hline
\end{tabular}

Table 4. Attributes of Information Systems Program Graduates

(Couger et al. 1995, p. 345)

\section{ACM Curriculum Guidelines}

The next curriculum update follows quickly in 1997. This format of this document (Davis et al., 1997) is much larger than previous updates, and it contains considerably more detail. A chronology of the curriculum development is included, as well as very detailed course outlines, which now include precise specifications for the units of knowledge that are expected to be taught. Davis et al. (1997), the IS'97 curriculum, is a revision of IS'95, rather than an update. IS'95 was reviewed extensively after its release, and amended considerably based on the review. Although the reviewers are predominantly from US universities and colleges, Canadian universities, and even a Japanese University were also listed. Practitioners from several influential IS firms, including IBM, were also reviewers. This makes a sound case for the argument that the IS curriculum guidelines are 
better representative of the desires of both practitioners and academics for new IS graduates.

According to the IS'97 guidelines, practitioners are now expected to be contributing members in the IS education process. They should be familiar with the competencies that are expected of emerging IS graduates, so that they can compare these to their own needs, and so that they can suggest changes to keep curricula current. IS practitioners should also take a direct role in curriculum changes by serving on advisory boards for universities and colleges, and by offering their time to interact with students. Businesses should also provide work experience opportunities for students.

IS educators are also expected to keep close to practice. Davis et al. (1997) state that IS faculty must consider continuous skills training as one of their general workload tasks. The rapid changes in technology place a heavy burden on IS staff to be knowledgeable with respect to changes in the field. This training is also necessary in order to tailor the curriculum to the local environment.

This call for curriculum customization is somewhat ironic given that the curriculum document is meant to serve as a template for all IS curricula. The opinion of Davis et al. (1997) is that educators should have flexibility to ensure that their graduates have skills relevant to their local area, while still possessing a core of knowledge. That said, the individual course outlines are very detailed, and it might be difficult to customize extensively while still covering all of the specified material.

Each course in the curriculum is broken down into learning units, which are major subjects of the course. Each learning unit is then further subdivided and specified in detail as knowledge elements, which are topics within the subject. The Programming, Data, and Object Structures course (IS'97.5) has twenty different learning units, with each unit having between two and twenty knowledge elements. In many cases, the knowledge elements themselves are quite complex. The programming course, IS'97.5, includes structured and object-oriented design languages topics, basic system diagramming skills, and even data definition languages as knowledge elements.

It is likely that educators are expected to customize the courses with respect to technology platforms, rather than to vary considerably from the specified topics. Although structured and object-oriented languages are specified as necessary, the 
actual language choices and technology platforms are not. Therefore, it seems to be expected that educators would tailor the curriculum to match the programming languages, platforms, and perhaps development methodologies that dominate that business area, but to remain true to the fundamental skills of the curriculum.

The IS'97 curriculum extends the world of the IS educator and their responsibilities. Many of the technical functions with respect to maintaining computer labs, acting as a technical liaison, and being an ambassador to practice are now considered under the IS educator's purview. This demonstrates the perception of Davis et al. (1997) that IS and IT practitioners are subsuming many of the responsibilities previously held by computer science and engineering practitioners. The IS educator is also now expected to be an active member in both academic and professional IS societies, a reflection of the drive to build the community's numbers, given its small size at the time. This push for a common IS community and for increased linkage to practice comes at the same time that Benbasat and Weber (1996) and Zmud (1996) released papers beginning to criticize the poor relevance of IS research.

IS'97 is certainly reflective of many of the industry changes of the time. In the document, Davis et al. (1997) state that:

Industry has expressed a need for both increased emphasis in technical orientation and improved skill in individual and group interactions. Graduates need to be able to interact more effectively with clients and to work effectively in teams. Students must have good written and oral communication skills. This report gives the specific recommendations necessary to successfully implement and maintain a program in Information Systems meeting both technical and behavioral emphases" (p. 4).

With respect to courses, new sociotechnical concepts such as business process reengineering (BPR) and total quality management (TQM) are now part of the curriculum. Networks are added to the IS'95 Telecommunications course.

Methodologies are still a strong element of the curriculum, with much the same emphasis that was present in the IS'95 curriculum. CASE tools, however, now play a central role in SAD, and for the first time, rapid application design (RAD) methods enter into the SAD topic list, though only as an element of the prototyping learning unit, rather than as a full learning unit. 
Pedagogical methods are mentioned briefly in the IS'97 curriculum (Table 5). Though textbooks are not espoused or condemned, a number of other pedagogical tools, such as labs (supervised and unsupervised), projects, presentations, and cases are suggested for the learning requirements for IS majors (level 3 and higher). Textbooks seem relegated to the knowledge levels for IS minors (level 2) and for general student knowledge (level 1).

A potentially problematic element of the pedagogical suggestions, and the new course design based on gradually developing knowledge levels, is that textbooks to match these new designs would have to be designed in progressive levels rather than by topic. This is not the way most textbooks other than introductory IS course textbooks are designed. Additionally, some courses have such large learning unit sets that it would be difficult to conceive of a textbook with less than 1000 pages covering the topics in sufficient depth to meet the course requirement levels. It is not explained in the curriculum how either issue would be handled, though perhaps by relegating textbooks to the lower knowledge development levels, Davis et al. (1997) feel that only introductory or superficial topic coverage is appropriate for textbooks. If this is the case, then we would expect that textbook design should follow horizontal development schemes, where large numbers of topics are covered with minimal depth, rather than a concentrated focus on a few topics. Since methodological content is only one of many learning topics in the SAD course, it would then be only a small part of what we would expect in SAD textbooks that follow the design of the IS'97 curriculum. 


\begin{tabular}{|c|c|c|c|}
\hline $\begin{array}{l}\text { IS'90,'94,'95 } \\
\text { Depth of } \\
\text { Knowledge }\end{array}$ & $\begin{array}{l}\text { Bloom Levels of } \\
\text { Knowledge }\end{array}$ & $\begin{array}{l}\text { Template for Writing Behavioral } \\
\text { Objectives } \\
\text { Students completing ... will be able to }\end{array}$ & $\begin{array}{l}\text { Meaning of Depth of Knowledge Level } \\
\text { and Activities Associated with Attaining } \\
\text { that Level }\end{array}$ \\
\hline 1 Awareness & $\begin{array}{l}1 \text { Knowledge } \\
\text { Recognition }\end{array}$ & $\begin{array}{l}\text { Define ... } \\
\text { List characteristics of .... } \\
\text { Name components of .... } \\
\text { Diagram ... } \\
\text { List advantages/disadvantages of ... }\end{array}$ & $\begin{array}{l}\text { Introductory Recall and Recognition } \\
\text { Class presentations, discussion groups, } \\
\text { reading, watching videos, structured } \\
\text { laboratories. Involves only recognition, but } \\
\text { with little ability to differentiate. Does not } \\
\text { involve use. }\end{array}$ \\
\hline 2 Literacy & 1 Differentiation & $\begin{array}{l}\text { Compare and contrast ... } \\
\text { Explain ... } \\
\text { Write/execute simple .... } \\
\text { Define functional capabilities that are .... } \\
\text { Describe interrelations of ... to related } \\
\text { objects }\end{array}$ & $\begin{array}{l}\text { Knowledge of Framework and } \\
\text { Contents, Differential Knowledge } \\
\text { Continued lecture and participative } \\
\text { discussion, reading, team work and } \\
\text { projects, structured labs. Requires } \\
\text { recognition knowledge as a prerequisite. } \\
\text { Requires practice. Does not involve use. }\end{array}$ \\
\hline 3 Concept/Use & $\begin{array}{l}3 \text { Comprehension } \\
\text { Translation / } \\
\text { Extrapolation } \\
\text { Use of } \\
\text { Knowledge }\end{array}$ & $\begin{array}{l}\text { Use ... } \\
\text { Communicate the idea of ... } \\
\text { Form and relate the abstraction of ... as .... } \\
\text { Given a set of .... interpolate/extrapolate to } \\
\ldots \text { List concepts/major steps in ... }\end{array}$ & $\begin{array}{l}\text { Comprehension and Ability to Use } \\
\text { Knowledge when Asked } \\
\text { Requires continued lab and project } \\
\text { participation, presentation involving giving } \\
\text { explanations and demonstrations, } \\
\text { accepting criticism; may require } \\
\text { developing skills in directed labs. }\end{array}$ \\
\hline $\begin{array}{l}4 \text { Detailed } \\
\text { Understanding } \\
\text { Application }\end{array}$ & $\begin{array}{l}3 \text { Application } \\
\text { Knowledge }\end{array}$ & $\begin{array}{l}\text { Search for correct solution to ... and apply it } \\
\text { to .... } \\
\text { Design and implement a ... for .... } \\
\text { Write syntactically correct ... and/or debug } \\
\text {... } \\
\text { Apply the principles of ... to ... } \\
\text { Implement a .... and maintain it }\end{array}$ & $\begin{array}{l}\text { Select of the Right Thing and Using It } \\
\text { without Hints: } \\
\text { Semi-structured team-oriented labs where } \\
\text { students generate their own solutions, } \\
\text { make their own decisions, commit to and } \\
\text { complete assignments, and present and } \\
\text { explain solutions. }\end{array}$ \\
\hline 5 Skilled Use & $\begin{array}{l}4 \text { Analysis } \\
5 \text { Synthesis } \\
6 \text { Evaluation }\end{array}$ & $\begin{array}{l}\text { Develop/originate/institute ... } \\
\text { Construct/adapt ... } \\
\text { Generate novel solutions to .... } \\
\text { Come up with new knowledge regarding .... } \\
\text { Evaluate/ judge the relative value of .... with } \\
\text { respect to ... }\end{array}$ & $\begin{array}{l}\text { Identiflcation, Use and Evaluation of } \\
\text { New Knowledge } \\
\text { An advanced level of knowledge for those } \\
\text { very capable of applying existing } \\
\text { knowledge in which denovo solutions are } \\
\text { found and utilized in solving and } \\
\text { evaluating the proposed new knowledge. }\end{array}$ \\
\hline
\end{tabular}

Table 5. Pedagogical Tools for Various Knowledge Levels (Davis et al. 1997)

Davis et al. (1997) also include a table that compares the academic, practitioner, and IS curriculum importance ratings for various elements in the IS body of knowledge. Methodologies rate reasonably highly for all categories, though analysis skills rank slightly (possibly not statistically) higher. Notable disagreements occur between practitioners and the IS curriculum with regard to the importance of system implementation (practitioners rate it higher), and system development tools and techniques (practitioners rate it lower). This is in line with practitioner opinions of the importance of developing systems over designing them (Fitzgerald, 1996) and the general apathy towards CASE tools in practice (Alavi, 1993). 


\section{ACM Curriculum Guidelines}

The current IS curriculum, IS'2002 (Gorgone et al., 2003) is very similar in format to IS'97, though it is a briefer document. The structure and rhetoric of IS'97 has been carried over, though much of it has been abbreviated. Some rhetoric changes were made, such as the removal of the training requirement for educators, possibly due to backlash from educators who felt they were being overburdened. The principal factors for change between the IS'97 and IS'2002 curricula as stated by Gorgone et al. (2003) are the growing importance of the Internet, increasing functional knowledge of computers by students before entering the IS program, and a continuing drive for IS accreditation in universities and colleges.

With respect to courses, the IS'2002 underwent two major changes from IS'97. First, two of the introductory courses whose purpose was to develop basic computers skills and applications knowledge were merged. This reflects the increasing rate of computer literacy of students before they enter university, and the pervasive nature of computer use in all university courses, which aids general skillbuilding with applications. The second major change was the addition of an electronic business course, to build familiarity and skills with Internet-based companies and architectures.

Within the SAD courses, we now see the fading of the role of traditional methodologies. The physical design course has been renamed to Physical Design and Implementation in Emerging Environments to reflect the importance of agile development methods. The importance of analytical and critical thinking skills has also become the central exit characteristic for graduates, reflecting the academic and practitioner calls for focus on this characteristic (Trauth et al., 1993). References to "methodology" or "approach" have been removed from most areas of the document other than the specific SAD course. In the IS'97 curriculum (Davis et al., 1997), "System Development Methodologies" is listed as a major representative capability of emerging IS graduates, however that reference has been removed from the IS'2002 curriculum (Gorgone et al., 2003). Methodologies are no longer even mentioned directly as a graduate requirement, replaced with references to "systems analysis", "logical and physical design", and "application development". Similarly, the focus in the SAD course has moved away from methodologies. Note the changes in the course scope between IS'97 and IS'2002 (Table 6). 


\begin{tabular}{|l|l|}
\hline \multicolumn{1}{|c|}{ Curriculum } & \multicolumn{1}{|c|}{ Course Scope } \\
\hline $\begin{array}{l}\text { IS'97 (Davis et } \\
\text { al., 1997) }\end{array}$ & $\begin{array}{l}\text { This course provides an understanding of the system } \\
\text { development and modification process. It enables students to } \\
\text { evaluate and choose a system development methodology. It } \\
\text { emphasizes the factors for effective communication and } \\
\text { integration with users and user systems. It encourages } \\
\text { interpersonal skill development with clients, users, team } \\
\text { members, and others associated with development, operation and } \\
\text { maintenance of the system. Object oriented analysis and design. } \\
\text { Use of data modeling tools. Development and adherence to life } \\
\text { cycle standards. }\end{array}$ \\
\hline $\begin{array}{l}\text { IS' 2002 } \\
\text { (Gorgone et al., } \\
2003\end{array}$ & $\begin{array}{l}\text { This course examines the system development and modification } \\
\text { process. It emphasizes the factors for effective communication } \\
\text { and integration with users and user systems. It encourages } \\
\text { interpersonal skill development with clients, users, team } \\
\text { members, and others associated with development, operation, } \\
\text { and maintenance of the system. Structured and object oriented } \\
\text { analysis and design, use of modeling tools, adherence to } \\
\text { methodological life cycle and project management standards. }\end{array}$ \\
\hline
\end{tabular}

Table 6. Comparison of IS'97 and IS'2002 SAD Course Scopes

The removal of the second sentence from IS'97 that states that the course purpose was to "evaluate and choose a system development methodology" (Davis et al., 1997, p. 20), confirms a move away from a methodological dominance in the SAD course. Though structured and object-oriented approaches are listed as course learning units, the approaches seem to now have balanced importance, and other approaches such as rapid application development (RAD) have become equally important learning units. Overall the importance of methodologies to the IS curriculum has been distinctly muted.

Although the next curriculum update has not yet been published, a Wiki was established to promote discussion and provide draft versions of the curriculum changes (Joint ACM/AIS Undergraduate Curriculum Revision Task Force, 2009). Organizational issues, and "agile methods" factor prominently in the new curriculum, but references to the traditional life cycle and the structured methodologies still remain. In the discussion portion of the Wiki entry for the SAD course, it states that: 


\begin{abstract}
"The course specification intentionally leaves discussion regarding specific methods and approaches unanswered. Institutions have to make these decisions regarding the capabilities of their faculty and the needs of the companies hiring the students. It is, however, important that the course will provide some exposure to the structured SDLC, object-oriented analysis and design (some Unified Process variant using UML as a grammar) and agile methods" (IS Curriculum Wiki, http://cis.bentley.edu/htopi/SystemsAnalysisandDesign_IS2008_Core. pdf).
\end{abstract}

Though there now appears to be a balance in the importance of structured, object-oriented, and agile methodologies, the continued appearance of the structured analysis and design approaches may signal a belief that the structured approach holds techniques which are still believed to be building blocks to develop skills. It would also appear that methodologies in general are still perceived to have a place in the IS Curriculum, though many other topics, such as user acceptance, security, and organizational factors receive equal or greater attention.

\title{
Alternative Curricula
}

The ACM IS Curriculum recommendations have been the principal, and essentially sole major curriculum guide used in the United States and Canada since 1995, when the competing AIS, and DPMA (now the Association for Information Technology Professionals, AITP) curricula were merged into the ACM curriculum. Since then, the major IS organizations have all promoted the ACM curriculum as the standard.

The IEEE did submit a competing curriculum in 1999, however, called the Information Systems-Centric Curriculum (Lidtke and Stokes, 1999). The ISCC 99 curriculum was a combined systems engineering / information systems curriculum advanced by the IEEE. It was designed to be used as a replacement to existing IS degrees, or as a possible track for IS programs. The focus of the curriculum was on developing analytical skills, communications skills, and technical skills through hands-on study of systems, particularly enterprise resource-planning systems (ERPs). The courses demonstrated a distinct engineering focus, with most courses involving building or studying systems of a specific type. Methodological content is minimal though some specific modeling techniques are mentioned. 
References to ISCC 99, including the main source document in a detailed format, and the actual home website, are no longer available. This makes it likely that the curriculum has been abandoned, as no further updates are mentioned and references to the curriculum end with the 1999 version. The engineering-focused nature of the curriculum may have made it unattractive to business schools, as would the price of implementing and sustaining the ERP program requirements. IS educators may also have felt uncomfortable with the extensive technical skills that would have been required to maintain and teach the curriculum.

The increased role of IS Professionals as primarily business analysts has led to the development of IT degree curricula (Lawson et al., 2006). IT degree programs, like the ISCC 99 curriculum, focus on support and installation of various types of systems but the degree is more of a hybrid of information systems and computer science degrees than a new engineering-type degree (Chu et al., 2001). Strong business, communication, and project management skills are still essential.

\section{Critical Review of the IS Curriculum}

Fowler and Discenza (1986) note that adoption of the various IS curricula during the 1980's was very high. University reviews of the DPMA and ACM curricula were generally very favourable, and it was felt that the curriculum objectives and course structure fit well with the university objectives. That said, Fowler and Discenza (1986), after doing a very small-sized survey of practitioners, determined that few practitioners were aware of the curricula at the time, and concluded that the curricula were not being properly marketed to elicit practitioner interest. Landry et al. (2001) note that at an instructor level, although awareness of the IS'97 ACM curriculum was high $(85 \%)$, adoption was low $(12 \%)$. This was primarily due to a lack of perceived benefit from the curriculum. It was felt, however, that the increasing pressure for AASCB accreditation would increase adoption and use of the IS curricula. Interestingly, Gorgone (2001) notes that awareness and use of the IS'97 guidelines expanded beyond the US and Canada, and that the document was used as a planning document in many nations' universities.

Since the release of the initial IS curricula, numerous papers have been released that have commented on or guided its development. Cheney (1988) found that throughout the 80 's technical skills were very important for system analysts. 
Though he felt that, in general, the curriculum functioned well, it was lacking with respect to technical knowledge. Conversely, O'Toole and Mitroff (1989) believed that universities were moving in the wrong direction with respect to training and education. The attempt to provide specific technological or methodological skills was misguided due to the volatility of these skills. Universities could not be held entirely to blame for this direction, as practitioners pushed for universities to create specialists during the early 1980's (Mandt, 1982). In order to be effective, however, the curricula must be consistently and regularly updated (Nord et al., 1998). Universities should focus instead on providing a foundation in basic analytical and problem-solving skills upon which specific training skills are added in a business training setting (Nelson, 1991). Curriculum designers therefore face the challenge of balancing technical and business skills knowledge in the IS curriculum (Trauth et al., 1993).

Mawhinney et al. (1999) noted that the IS'97 curriculum included ten required courses, plus electives; something that cannot be normally accomplished by an AASCB accredited school without substantial outsourcing of courses to a Computer Science (CS) department. Similarly, Williams and Pomykalski (2006) surveyed universities to determine how well they implemented the IS'2002 curricula and found that no university completely matched the IS'2002 curriculum requirements. The primarily reason cited for this is that the 33 hours of course work required for the curriculum could not be sustained while including other university and business school requirements. A secondary reason cited was a lack of faculty knowledge to teach everything in the curriculum. Unger et al. (1987) attempted to create an alternate curriculum which melded requirements of an IS and CS degree in order to appease the demands of practitioners, and produced curriculum programs that either required five years to complete, or did not meet the AASCB requirements.

McKenzie (2006) adds that professional certifications are increasingly important for employers. IS and CS certifications rarely require a bachelor's degree, and therefore students may perceive these types of degrees as unnecessary. Therefore IS curricula should be designed with an eye towards professional certification, as accounting and other business degrees are.

Sweeney (2003) demonstrates that creative problem-solving skills are essential to the development of IS professionals, and although the IS curricula 
espouse the development of the skill, the actual course topics and pedagogical materials do not develop these skills. Walz and Wynekoop (1994) similarly determined that IS curricula neither degrade, nor enhance, the creativity of graduates, although IS graduates tend to be naturally more creative than other business majors.

In general however, educators seem to support the curriculum as is. Landry et al. (2003) surveyed deans from computer engineering, computer science, information systems, and information science departments about the IS'2002 curriculum guidelines, and found that they were largely in agreement over the importance of system development topics to the curriculum, including methodologies. Students exhibited a satisfactory level of knowledge on an is exit exam in institutions where the IS'2002 curriculum guidelines where in place (Reynolds et al., 2004). Seymour et al. (2006) surveyed the employers of IS graduates and the graduates themselves and found high overall levels of satisfaction with the courses taught to students under the IS'2002 curriculum. Saulnier (2003) argues that curricula may describe "what" should be taught, but a more pressing issue is "how" the material should be taught to ensure that it is absorbed by students.

Mandt (1982) believes that the most pressing issue is the perception that universities are participating in a vicious cycle of attempting to catch up to practice. Academics bring back lessons from practice, which are then considered for upcoming curriculum changes. By the time these changes are actually implemented in a university setting, they are already obsolete in practice. The rate of change of technology prevents universities from ever having current technical curriculum requirements (Mandt, 1982, p. 49). Additionally, universities seem to focus on teaching what their educators are most comfortable with or have existing resources to support, rather than striving to provide students with a complete experience (Williams and Pomykalski, 2006). Williams and Pomykalski (2006) state that this leads to critical gaps in student knowledge, even when the area is addressed by the IS curriculum. They do believe however that the pressures for accreditation will promote university adoption of the curriculum guidelines.

Jackson and Satzinger (2003) note that insufficient focus is made in the IS'2002 curriculum on object-oriented (OO) analysis and design, although it is the 
dominant programming paradigm. Without a stronger background in $\mathrm{OO}$ principles students may be unable to apply the skills that they do acquire. Moreover, attempting to teach both structured and object-oriented paradigms in the same curriculum (and in only two or three courses, based on the IS'2002 curriculum) will result in students who are not competent in either approach. Jackson and Satzinger (2003) present a completely object-oriented curriculum to prepare students for the growing importance of $\mathrm{OO}$ programs and software development tools (McCarthy et al. 2005), and to ensure they have a strong foundation in UML as a tool for solving problems.

Kautz and Pries-Heje (1999) determined that even when students are taught only a single methodology, and this methodology was the focus of the course content, most students considered themselves only to have an introductory level of skill using it. With regard to most skills related to system development, students considered themselves only to be novices with respect to the skill's use. Very few actually used the methodology (in this case Multiview) after graduation. Students themselves, however, perceived the teaching of methodological content as useful (Kohli and Gupta, 2003).

Introna and Whitley (1997) suggest that rather than providing short courses on different methodological viewpoints, future systems analysts should instead be apprenticed in actual SAD firms. This will provide for them the necessary contextual understanding of systems development so that students can become familiar with how methodologies are applied in real practice, and how they must develop skills and understanding of organizational factors that extend beyond where the methodology can take them.

\section{Conclusions}

The ACM IS Curriculum guidelines are generally accepted by academics and practitioners as representative of the skills and topics that IS graduates should possess (Landry et al., 2003; Seymour et al., 2006). Unfortunately, actual adoption of the curriculum is hampered by an inability to squeeze all of the courses into a four year academic program, and a lack of faculty knowledge to teach everything in the curriculum (Williams and Pomykalski, 2006). Over time, the IS Curricula have moved away from a dominance of methodological content, but methodologies are 
still a part of the curriculum. Based on the content in the IS Development Wiki, it seems unlikely that methodological content will be removed from the curriculum in the near future. 


\section{Section 5: SAD Textbooks}

\section{Applying the Relevance Question to IS Texts}

Lyytinen et al. (1999) state that the theory vs. practice question is important because "relevant research complements the teaching mission of the university" ( $p$. 574). Research that is not relevant to organizational concerns may not be of interest to students, and may not prepare them for careers after their graduation. According to Stolterman (1992), if we want to effect radical change in the way that systems are designed, this can only be done by designers themselves. This implies that our methods must mirror and be developed from the best designers, rather than attempting to enforce ideas on them that have no basis in practice.

The message of the theoretical vs. practical relevance argument is mirrored in the development of IS textbooks. If we consider IS texts as another vehicle for growth and information transfer for the academic community, then we might expect that the criteria for relevance could also be practically applied to IS textbooks. It is likely that relevance to practice is of even greater importance for IS textbooks, as most students will enter the workforce directly after graduation, rather than choosing further academic pursuits. Therefore practical relevance is essential to provide skills which can be leveraged in work duties.

Saulnier (2003) finds that most SAD courses rely on the textbook and the associated materials as the primary pedagogical tools. These tools are insufficient to provide students with a "hands-on" feel for SAD, and limit the student's ability to develop the key analytical and problem-solving skills. Saulnier (2003) promotes "service learning" oriented classes which include work in the community as a central component of the course curriculum. Chen (2006) found that the introduction of realworld projects in SAD courses helped students develop an awareness of the skills necessary for the work environment.

\section{A Lack of Cumulative Progress in IS Teaching}

The lack of a cumulative tradition in IS, as evidenced by Keen (1980) and linked to a lack of relevance of IS research by Benbasat and Zmud (1999), may be directly applicable to IS textbooks. Is it the case that IS texts have ignored the 
progress which has been made in industry or by researchers, in favour of reiterating the original theories with small and deliberate changes that bring the appearance of originality? With academic articles, competition arises from a finite number of vehicles of publication, with varying levels of prestige attached to each, and a much larger supply of potential articles. For textbooks, competition is for the attention of professors and the dollars associated with adoption of a text for a particular course offering. The appearance of originality may serve to improve the likelihood that a particular textbook may be perceived as a "fresh take" on the core material.

This particular mode of book construction may also aid in the adoption of the book (Bierman, 2006). If the text book authors were to present material that is unfamiliar to the professor, then the learning load for the professor will be greater. By repackaging the original IS development methodologies, this could create an immediate rapport with the professor. Then, by emphasizing the "new" aspects of the text's treatment of the original material, the professor can quickly assimilate the new text, and use it for their lectures.

Unfortunately, this leads to a lack of progress in actual subject development. For example, Wang and Wang (2005) note that although SAD functions have primarily moved from the traditional role of system construction to one of system acquisition, the major SAD textbooks cover the system acquisition role only superficially. Misic and Russo (1999) find that undue influence from SAD textbooks, particularly the dominance of traditional methodologies, is preventing SAD courses from leading or influencing future practice.

\section{The Purpose and Use of Textbooks}

Textbooks are an important pedagogical tool. They often provide the basis for content that is taught in courses, and therefore course material is often determined by what is available in the market (Bailey, 1988). In many cases, the textbook is the only source of material for a particular course (Ornstein, 1989). Therefore, textbooks can be dangerous because they can become the only viewpoint offered in the course. The opinions of the authors may be a singular influence on many generations of students (Ornstein, 1989). Generally, textbooks are perceived to present the consensus view of the field (Bierman, 2006), though 
this may not actually be the case. Often, the material drawn from "content experts" may be based solely on their own experiences (Saroyan and Geis, 1988), rather than best practice or industry consensus. Material that is not included in a textbook is often perceived as "false" or "irrelevant" (Raywid, 1980). In extreme cases (such as history texts), textbooks can be used to promote a particular outlook with respect to the content, and to suppress any form of dissent.

Many textbooks today are designed as a team effort combining authors, editors, content scholars, textbook researchers, designers, and other interested government and educational parties (Saroyan and Geis, 1988). In these instances, the publisher is often the final decision maker, and revisions may be screened by them. Since the underlying interest for many publishers is sales volume, not all revision advice is accepted.

In most cases, textbooks are generated for a national audience, in which case local practices and the distinct needs of a particular student are not considered. Curriculum guidelines are considered when developing material (Saroyan and Geis, 1988), but authors and publishers may have their own views of what constitutes proper curriculum knowledge (Crawford, 2003). To garner the greatest number of sales, ideas that are controversial or topics that have many divergent opinions may be avoided. Most textbooks tend to be homogenous in content, with variety typically relegated to presentation aspects (Raywid, 1980). Finally, textbooks will generally need to summarize a great deal of information, in which case they deal with topics superficially, and avoid discussions which would move beyond the scope of the book.

Bailey (1988) suggests that course material must be determined before a textbook selection is made, and it should consider the impact of current practices. A checklist of curriculum items should be devised, and textbooks should only be chosen if they can meet these criteria. Teachers must also avoid pressure from publisher sales representatives to adopt particular books. Publishers will often pay teachers to "review" books as a ploy to promote adoption (Bartlett, 2003). Good textbooks should be scrutinized by scholars, educators, and minority groups (Ornstein, 1989) before adoption.

Bierman (2006) suggests textbooks that are modular. This will allow more rapid inclusion of new material, as well as the ability to specialize textbooks to local 
needs. Textbooks should also have resources which allow students to increase their depth of knowledge in a particular topic.

\section{Misic and Russo (2000)}

My proposed study is, in many ways, a continuation of the work of Misic and Russo (2000). Misic and Russo (2000) is the only study to have directly addressed the question of SAD textbook content, and is one of the few studies to have addressed the issue of textbook use in the IS discipline itself. The study is important, perhaps more than it would seem, due to the interlocking blocks in the educational chain that Misic and Russo (2000) sets before us.

Systems Analysis and Design is the central course in the IS degree. The skills which are taught in the course are directly linked to a greater percentage of the exit characteristics of graduates than any other courses, and they are consistently listed in the skill requirements by practitioners. As such, it is essential that the material that is in the course reflects what academics and practitioners require. Since the IS curriculum guidelines seem to reasonably reflect these requirements (Seymour et al., 2006), the onus is on educators to deliver the material in the curriculum guidelines.

Ornstein (1989) shows and Misic and Russo (2000) emphasize that the SAD textbook is the primary and often sole pedagogical tools used in the SAD course. As such, the textbook must reflect the curriculum requirements, or at least attempt to match the requirements cited by academics and practitioners. Misic and Russo (2000) demonstrate, however, that SAD textbooks do not reflect the curriculum requirements, or the recommendations of academics and practitioners.

Misic and Russo (2000) survey 29 systems analysis and design textbooks, with release dates from 1988 to 1999 . They include all of the prominently-used textbooks including the dominant textbook, Whitten et al.'s Systems Analysis \& Design Methods. They find that SAD textbooks are dominated by model building activities, though this is cited as an infrequent activity of the SAD process. Additionally, despite the consistent criticism of practitioners and academics, the books focus primarily on structured approaches and techniques. In most books, object-oriented or rapid development approaches receive secondary treatment or 
are ignored. On average, topics that are not based on the structured approach or its techniques and tools each receive less than $5 \%$ coverage in any textbook, while structured SAD techniques and tools often receive greater than $10 \%$ coverage each.

Misic and Russo (2000) speculate that the rationale for the dominance of the structured approach and model building in textbooks is that textbook authors focus on the core skills necessary to learn how to develop systems, rather than attempting to teach the actual system building activities themselves. Misic and Russo (2000) stress that these activities may require "learning by doing", and that textbook authors intend for educators to supplement textbook content with group exercises and activities not drawn from textbook material that develop the ability for students to use what the textbook attempts to teach. There are, however, several flaws with this logic.

If authors are attempting to teach core skills that will be developed in the workplace, why focus on model building to the exclusion of many of the activities that IS professional must perform in their daily activities? Would it not make more sense to provide a balanced introduction to all SAD development activities and not just one? Misic and Russo (2000) believe that model building is one of the most difficult skills to learn in practice and therefore more time must be spent developing its foundation.

Academics and practitioners have stressed a need for developing analytical and problem-solving skills, however Misic and Russo (2000) show that topics that would develop these skills, such as analyzing system requirements or evaluating systems versus these requirements, do not rank in the top ten topics with respect to textbook importance. Communication-based topics such as preparing reports and interviewing users, which are also cited as important by practitioners and academics, are ranked very low with respect to textbook coverage. It is difficult to understand how authors feel they are providing core SAD skills, given these trends.

Finally, the dominance of the structured approach simply is not supported by the literature, which promotes either newer methodological approaches, or no methodological approach. In this respect, however, an important limitation of Misic and Russo must be considered.

Since there is such a large date range in the release dates of the textbooks surveyed, the generalizations with regard to methodological content need to be 
reconsidered. Textbooks from the late 1980's and early 1990's would be expected to be dominated by structured approaches, since it was only during the mid- to late1990's that object-oriented approaches gained a foothold in the market. Misic and Russo (2000) break down the content in each textbook, and they demonstrate however that structured approaches dominate object-oriented approaches with respect to coverage even in the newer texts.

It is reasonable, given the outstanding questions with regard to author motivations and the historical matching of textbook content to academic and practitioner recommendations, to consider either an update or an extension of Misic and Russo (2000). Misic and Russo (2000) employ a content analysis approach, which is effective at categorizing content. Qualitative research, however, is effective at examining the underlying rationale for actions, particularly if we hope to understand how the subjects under study view themselves (Lee, 1991, p. 352).

\section{Summary}

The purpose of this literature review has been to present the factors that have impacted the content chosen for SAD textbooks. Section 1 introduces the conflict that practitioners and academics have with respect to the purpose and content of IS literature in general. Section 2 discusses the contentious issue of the use and adoption of SAD methodologies. Practitioners and academics did not agree with each other, or even among themselves, as to the efficacy and appropriateness of SAD methodologies, despite their long history of development. However, if methodologies were accepted during some period, they are decreasingly so. The requirements of rapid development and the increasing focus on the organizational factors that have historically led to system failure have demanded a new way of approaching SAD. Section 3 presents a new approach focused on developing the analytical and organizational skills of IS professionals, rather than instilling methodological knowledge. In section 4, we traced the development of the curricula that were a response to the demands of academics and practitioners and noted that despite delays which seem to place curricula permanently in a state of catching up to practice, a concerted effort has been made to align practitioner, academic, and educator views. Section 5 , however, shows that the primary pedagogical tool, the $S A D$ textbook, does not seem to be following this same trend. 


\section{Part 3: Research Questions and Study Methodology}

This section begins with a description of the research questions posed in the study. This is followed by a description of the research approach and a review of the literature relevant to the methodology. Next, a description is given of the issues which have impacted the choice of methodology. Finally, the research methodology is described in detail, including the sampling methods, and the methodological steps and techniques.

\section{Section 1: Research Questions}

The initial research questions to be asked in the study focus on its base purpose of determining how textbook content as chosen by authors does or does not reflect the opinions of academics and practitioners and the IS curriculum guidelines:

1. How does IS textbook content change over editions? Are changes gradual and progressive, or sudden and extensive?

2. How well does the update process of textbooks through editions reflect the updates to IS curriculum guidelines, and the opinions of practitioners and academics?

3. What justifications do authors provide for their content choices? How do they present these choices to readers, and what support exists within the text to support these choices?

Since Misic and Russo (2000), Introna and Whitley (1997), Kautz and Pries-Heje (1999), and O'Toole and Mitroff (1989) indicate that methodological content receives too much focus in IS curricula, and within SAD textbooks, further questions are asked to specifically address the presence of methodological content:

4. Do authors provide justifications for including large sections for methodological content, particularly the structured approach, in their textbooks despite changes in the IS curriculum requirements and the opinions of practitioners and academics? 
5. If authors have sound justifications for their content choices, how do they demonstrate these choices in their texts? Do authors present justifications that match the determinations of Misic and Russo (2000), that is, these topics are provided to be foundations for later skill development and growth?

Finally, it is useful to assess the general perception of authors with respect to their textbooks. As we have seen, textbooks seem to be the dominant pedagogical tool for teaching material to students. What are authors' views in this matter:

6. How do authors perceive the importance of their textbooks to the process of educating systems analysts, as evidenced in their textbooks?

Misic and Russo (2000) indicate that many elements of SAD must be learned through practical exercise, rather than through textbook learning. If authors believe this is the case, then textbooks may be designed intentionally to ignore the aspects that must be taught using other pedagogical tools. Alternatively, if authors agree that the textbook is the central pedagogical, what are the justifications for ignoring important material that students must understand in order to put what they have learned into practice.

These questions are intended to capture a spectrum of author views with respect to the content within their textbooks. By answering these questions within a historical context, we can then answer the overall question with regard to authorial and textbook content:

7. Do authors follow or ignore the views of academics, practitioners, and the IS curriculum guidelines, and are there reasons that explain the apparent lack of content alignment as evidenced in Misic and Russo (2000)? 


\section{Section 2: Research Approach}

\section{Introduction to Research Approach}

This study is a hermeneutic study following the traditions of Emilio Betti and E.D. Hirsch, Jr. It employs the hermeneutic canons as laid out by Betti (1980), and the interpretive processes found in Hirsch (1967). The specific methodological techniques are drawn from Lincoln and Guba (1985), though many of the common hermeneutic principles, such as the hermeneutic circle, and the resolution of apparent conflicts in the text, will also be employed.

\section{Summary of Literature Review for Research Methodology}

Before considering the specific steps to be followed in this study's methodology, it is important to review the relevant hermeneutic literature. This section provides a summary of this literature as it applies directly to the study. More extensive descriptions of the hermeneutics tradition, its history, and its relation to information systems can be found in the appendices. Appendix 1 provides a comprehensive description of the hermeneutic principles. Appendix 2 is a historical timeline of the hermeneutic tradition. Appendix 3 describes of a number of information systems studies which leverage hermeneutics as a research methodology.

\section{Hermeneutics as a Research Approach}

Boland (1991) defines hermeneutics as "the study of interpretation, especially the process of coming to understand a text" (p. 439). This presents hermeneutics as a general process of interpretation, though not all hermeneutic scholars have felt that hermeneutics should be expanded beyond the written form and some, such as Ricoeur (1991), feel the written word holds more value for interpretation than other forms. Heidegger and Gadamer expanded the purpose of hermeneutics to make it an ontological position for understanding existence itself.

Hermeneutics is an obvious choice for the interpretation of texts (Lee, 1994). Though the term "text" has been expanded considerably to cover a host of communicative forums including conversation and most other expressive acts 
(Ricoeur, 1991; Myers, 2004), the original purpose of hermeneutics was the study of written texts, particularly the Bible (Boland, 1991). As this study will involve the interpretation of textbooks, hermeneutics is immediately appropriate.

\section{Principles of Interpretation}

Hermeneutics is, in many ways, an art of interpretation. The term "art" is used in this context to imply the personal, fluid, and often imprecise nature of interpretation rather than the clear, concise, global, and static nature of a science. Interpretation can be shared, and can form a dialogue, however it is ultimately something that we each possess, and which we are intrinsically bound to. Our interpretations reflect not only our understanding of the phenomenon in question, but also ourselves. Our interpretations are subject to change, based on our increased exposure to the phenomenon at hand, and to others' interpretations of the same phenomenon. This implies that the interpretations of two individuals can be compared, or that we can evaluate a single individual's interpretations at multiple points in time (Ricoeur, 1991).

\section{The Fluidity of Interpretive Research}

Interpretive research can be both celebrated and criticized for this fluid nature. Interpretive research is forgiving by nature. Since our interpretations are molded constantly by what we encounter, it is generally felt that there is no "perfect interpretation". That said, there are guidelines which can be set to determine how valid a particular interpretation is, based on a greater understanding of the subject matter and the intent of the author (Hirsch, 1967). This does not, however, invalidate one's view if they lack a complete understanding, since interpretation is largely a personal exercise.

This belief, however, can be abused. Statements like "I understand the author better than themselves" or "the author's intent can never be understood and is therefore irrelevant" betray the spirit of hermeneutics as a tool for understanding. It may certainly be possible to understand the subject matter of an author's text better than they, or to realize meaning that the author may have unconsciously inserted into the text, but the wholesale dismissal of the author and their intended message is not generally valid (Hirsch, 1967). 
Hermeneutics therefore lacks a definitive methodological process which can guide interpretation. Though there are certainly guides for determining validity of interpretation, such as Lincoln and Guba (1985) and Hirsch (1967), many flavors of hermeneutics discount these on philosophical grounds. Unfortunately, without rules to govern interpretation, and a united belief in the validity of individual interpretation, less circumspect researchers can essentially justify predetermined and highly personally biased interpretations (Hirsch, 1967).

\section{Stages of Interpretation}

Interpretation is a three-part process (Hirsch, 1967). First, before we can make a valid interpretation of a particular text, we must first understand it. Understanding can be difficult to evaluate, but exists at numerous levels, including:

- An understanding of the physical symbols and signs used in the language in which the text is written

- An understanding of the use of these symbols in linguistic and grammatical structures

- An understanding of the contextual factors which give to these linguistic structures one of a number of potential meanings

- Knowledge of the author's intent which formulates a particular meaning for the contents of the text and a perspective for why it was written and what the author meant to convey.

Once we have an understanding of the text, we move to the second interpretive stage, where we can then make an interpretation of the text that includes our perception of the nature of the way in which the text was written, its stylistic elements, and how well the author managed to make their point. Our interpretation precedes the formulation of our response, since it occurs during and in tandem with the understanding process. Our interpretation is also subject to change, as our understanding of the text and its contents grows.

When we have completed our interpretation we then write our own text, so that we may convey that interpretation to others. This forms the final part of an interpretation, the "commentary" on the text (Hirsch, 1967, p. 143) which may be critical or praiseworthy in nature, but relies on the reasonableness of our interpretation, and our skill in communicating that interpretation to others. 


\section{The Hermeneutic Circle}

Perhaps the most enduring concept within hermeneutics is the hermeneutic circle. It is the perception of the interpretive process as a continual shifting between looking at the text as a whole, and looking at it based on its component parts. As we read each part of the text, a picture of the entire text as a whole forms. This understanding of the whole text, however, influences how we continue to evaluate the other parts of the text. We therefore alternate back and forth from whole to parts until we come to an overall understanding of the text and its contents.

We can also extend the analogy of the hermeneutic circle beyond the actual text itself. If we consider the author's life, other writings produced at the same time, and other contextual factors as additional "parts" of the interpretation, we see that they also contribute to the "whole" (Hirsch, 1967; Klecun-Dabrowska and Conford, 2000). Therefore, our hermeneutic circle extends to become a much larger cyclic journey as we increase our knowledge of the subject matter of the text and the context surrounding the text (Betti, 1980).

The cyclic nature of the hermeneutic circle also includes repeated readings of the text (Lacity and Johnson, 1994). Our understanding of the text improves not just with the better development of background knowledge of the subject matter of the text, but as we re-read the text we uncover nuances of the meaning of the text we may have missed before, and which build from what we have previously learned. With regard to editions of books, not only are the ideas of the authors reinforced through repeated readings of successive editions, but the reader can also begin to notice changes in the intentions of the authors as they make changes between editions.

Since, in principal, the hermeneutic circle could follow infinite cycles, there must be some reasonable determination of when to halt the interpretation. According to Hirsch (1967), when developing an interpretation the interpreter will develop many alternative hypotheses for the author's intended message. When the number of plausible alternative hypotheses has been reduced to one, and the evidence supporting the chosen alternative outweighs all alternative hypotheses, the interpreter can consider the interpretation to be complete. When using this method of ending the circle, the researcher follows a pattern of gestating new hypotheses, 
and then either building support for them, or dismissing them based on the evidence that can be procured from the interpretive process.

Myers (2004) presents an alternative method of determining when to complete a hermeneutic cycle. If we perceive apparent absurdities or internal conflicts in the text, then the goal of each successive pass with the hermeneutic circle will be to resolve these conflicts by improving our understanding the true meaning of the actors' motivations in the text. When we have reached the point where all internal conflicts and absurdities have been explained using rational theories of action, we can consider our hermeneutic process to be complete. Care must be exercised when using this method of evaluating an interpretation, however. If the goal of finding a plausible theory to explain the conflicts found within the text becomes more important than the interpretation itself, the researcher can lose the intent of the hermeneutic process and stretch the bounds of plausibility.

\section{The Importance of Narrative}

A hermeneutic study is a chronicle. It explains a series of events that are tied together and bring us from an initial realization of an underlying conflict in the text through the factors which unearth the nature of the conflict to a final understanding of the true nature of the elements of the text (Ricouer, 1991, pp.1-7). The task of hermeneutics according to Ricouer (1991) therefore is to find the:

"internal dynamic that governs the structuring of the work and, on the other hand, the power that the work possesses to project itself outside itself and give birth to a world that would truly be the 'thing' referred to by the text" (p. 17).

In any text, be it novel or conversation, fictional or historical account, we attempt to decipher the plot of the text. The plot is important, not only as an account of the message of the text, but because it aids us in coalescing our interpretation. We conceive of stories as a journey from a beginning to an end, and therefore the use of this device enables us to build our interpretations as a journey from idea to realization.

With respect to textbooks, the purpose of a textbook is to transfer knowledge to the reader. Therefore the plot of a textbook drives this learning process. A wellformed plot within a textbook will relate the concepts within the content of the text and aid in the learning process. It will reinforce and build a greater understanding 
from component parts. A poorly-formed plot makes it more difficult for the student to understand the concepts within the text, since the student will not understand how to relate the contents together.

Beyond the textbook itself, the context within which the book is created is also a plot. Academics, practitioners, and authors are players in the story that leads to the creation of a particular text. By examining the context of the situations within which the textbooks evolve over time, we can then build a story that explains why textbooks are now in the form they appear.

\section{Distanciation and Autonomization}

Hermeneutics is often employed when historical chronicles are created. Since we cannot be present at events of the past, we must attempt to decipher the meaning of the historical artifacts we uncover. As we move farther from the initial event, our interpretations become prejudiced by the events of our own time, and our interpretations begin to reflect not only the events of the past, but the events of the present (Wachterhauser, 1986).

This occurs due to two hermeneutic concepts called distanciation and autonomization. Distanciation occurs because the text itself cannot completely reimmerse the reader in the original context of the writing, nor completely express the author's intended message. Even if the author exhaustively described the contextual factors that impacted their work, the author cannot prevent the person reading the text from bringing their own preconceptions to the reading, and therefore interpreting the text differently from what the author might expect. Autonomization occurs as our understanding of the text then becomes separated from the original intent of the author, and takes on a life of its own. Through this separation of meaning from text, many generations of readers may form their own interpretations of a particular text, each one a unique blend of what the text can recreate of the original context and intent of the author, and the context brought by the reader. 


\section{Hirsch and the Validity of a Single Interpretation}

A dialectic with regard to the existence of a single or infinite number of valid interpretations divides the world of classical hermeneutics and the world of metaphysical hermeneutics. Classical hermeneutics tasks itself with finding the true message within a text, and attempts to unearth it with a detailed study of the text that is being studied, the author who wrote it, the subject matter of the text, other texts written at the same time, and the general history of that time period (Bleicher, 1980). Dilthey, Heidegger, and Gadamer, however, saw hermeneutics as an ontological means of understanding existence itself through the messages that evolve not just from the language of the text, but from our own existence. Since we are all individuals, this foretells an infinite number of potential valid interpretations, based on our own experiences, and our preconceptions of the meaning of the text. By communicating our unique interpretations to others, we share meaning with them and build a collective understanding.

E.D. Hirsch Jr., in his seminal literary criticism work - Validity in Interpretation (Hirsch, 1967), counters this idea of infinite interpretations based on practical, rather than philosophical, grounds. Although each of our interpretations of a text may be unique, that does not necessarily imply that our interpretations are sound, or follow the intent of the author when the author created the text. There are interpretations which are obviously superior to others, and which capture more of the original intent of the author.

Authorial intent is very important to Hirsch, since the creation of a work of literature, art, or even conversation has a purpose, and that purpose is meant to be communicated through the work. As readers, we attempt to learn that purpose in our reading of the text and therefore attempt to capture that author's intent. If distanciation creates a gulf between our world and the author's world, then our task is to recreate that world by immersing ourselves in the author's world, as they describe it in the text. Unlike classical hermeneutic scholars, however, Hirsch maintains that the text itself can contain enough of the context to properly convey the message. If it cannot, then we can then say that the author is not effective in communicating their message. We cannot say however that this is due to an impassable gulf caused by a separation of our relative contexts. 
Hirsch (1967) defends his ideas by noting the difference in interpretation between meaning and significance. Meaning is the linguistic determination of the words that the author organized, and how they interact to present a cohesive message. Meaning is therefore limited with respect to interpretation, since the lexical symbols employed by the author can only be deciphered in specific patterns and with particular results. Significance, however, is the importance of the author's work to the interpreter and the larger literary and historical world. Significance indicates how effective the author's message is, and is highly dependent on the contextual factors of both the author's and the interpreter's world. Hirsch (1967) holds that debates about the significance of a work are important, and may resurface in many ages with different determinations, but that debates about meaning can lead only to the singular determination of the author's intent. Debates about authorial intent can only focus on the usage of the language within the author's original context, and are inflexible with regard to distanciation.

Hirsch's claim is that as we become familiar with the text and with the subject matter of the text, we can recreate the context of the text. This is not to say that our own prejudices and perceptions do not impact our imaging of the context of the text, but the belief that we cannot somehow reach out and know the world of the author is extreme. Were I an expert with regards to a particular author, their writings, their culture and history, the works of other authors at the time, and the language in which the author wrote, it seems unreasonable that I could not proximate an understanding of the world in which the author wrote a particular text. If this were not the case, all writing would seem alien to us.

\section{Betti and the Concept of Objective Interpretation}

Emilio Betti, a hermeneutic scholar and theologian, believed in an 'objective form of interpretation'. Though Betti supported the idea of the impact of context on interpretation, he held that the objects of interpretation were autonomous with respect to their self-meaning. These "meaning-full forms" as he called the objects are artifacts created by authors with the purpose of carrying the author's message (Betti, 1980, p. 58). Therefore, the purpose of interpretation is not to "create" meaning in the Germanic tradition, but rather to expose the meaning within the meaning-full form. In this way, interpretation can be objective, since what is 
uncovered during an interpretation can be measured against the author's intention. Skill in interpretation is based on the interpreter's inner affinity for the object's purpose, and the interpreter's ability to accept the author's impregnated meaning.

Betti recognizes the possibility of misinterpretation due to the time and space between author and reader, but in his mind, the interpretive purpose is to bridge that gulf. Distanciation is therefore not an insurmountable impediment to recapturing the author's meaning. The author and reader are part of a triadic relationship where the object to be interpreted is the bridge between author and reader. It is the reader's duty to prepare themselves for a faithful interpretation by recognizing and setting aside bias, in particular (Bleicher, 1980, p. 34):

- The conscious or unconscious resentment of positions that differ from the generally accepted ones, or the reader's

- Self-righteousness or close-mindedness which sees issues only in black or white

- Conformist views which tend towards dominant positions

- Intellectual or moral laziness

Though the text of the object is subject to semantic intersubjectivity, this does not impinge on the autonomy of the text as embedded authorial meaning (Bleicher, 1980, p. 38). This creates the possibility for an objective, albeit possibly imperfect, interpretation.

The argument that objective interpretation is not possible because the author may be unaware of the meanings embedded in the text does not hold water. Hirsch (1967) explains that although the author may not be consciously aware of the meanings they have embedded in their texts, this does not imply unawareness ( $p$. 22). Even if the author has unconsciously embedded meaning into a text, that meaning is still the author's. It is simply impossible to create meaning without intent.

Betti, like Hirsch (1967), recognizes the difference between meaning and significance. He attributes the confusion between significance and meaning as a major stumbling block in objective interpretation. Though each age that encounters a historical artifact may interpret the importance of that artifact differently, the author's intended meaning for that artifact does not change. Therefore, the significance of a meaning-full form is dependent on the interpreter and the context of 
the interpretation, however, the actual meaning of the object should not be infringed by this context.

\section{Validating an Interpretation}

With respect to the criticism and interpretation of literature, an important gauge of the validity of a critical interpretation is the fidelity of that interpreter's determinations with respect to the subject manner (Hirsch, 1967, p. 8-10). We must question whether or not our critical interpretation reasonably considers both the verbal meaning of the text (what the author says by virtue of the use of language and linguistic symbols) and the intentions and aims of the author (what the author meant to convey as a message through their use of language). If we manage to convey to others that our understanding of a text follows the intentions of the author and we are able to speak meaningfully with respect to those intentions, then our critical interpretation may be valid (Hirsch, 1967, p. 161).

Since the evaluation of a critical interpretation of a text is based on the ability to understand the aims of the author with respect to the text, this is a focal element of the interpretation. Without a proper understanding of what message the author intended to convey with their text, it is impossible to later develop a meaningful and useful interpretation of the text, and finally to create a useful criticism of that text. It must be realized, however, that any divinations are in fact guesses. One cannot read the author's mind directly. Even if we could confront the author, it is unlikely they could reproduce their exact state of mind at the time the original text was written. Therefore, an interpretation is an approximation of the author's intention, though it is obviously our hope that the interpretation is a good approximation.

All interpretations must be guesses since they rely on the intrinsic characteristics of the interpreter (Hirsch, 1967, p. 166). Since there is no conclusive methodology that can promote the accuracy of guessing, there is no a priori method to ensure a correct interpretation. We can take several steps, however, to promote the likelihood of making good guesses.

First, a sound understanding of the subject matter improves the likelihood that the linguistic elements of the text are interpreted correctly. That is to say, before attempting to understand the motivations or the intended message of the author, we 
must first understand what the author is talking about. This follows both Hirsch (1967)'s and Betti (1980)'s requirements for proper preparation for interpretation.

Next, we can formulate a number of potential hypotheses for what the author's aim and message are (Hirsch, 1967, p. 171-2). During the interpretation, we divine and build evidence for each hypothesis, until it is clear which hypothesis is most likely. It is very possible that multiple hypotheses may have validity, which makes our task one of weighing the relative value of each hypothesis, or combining them to provide a single reasonable response.

Since it is likely that the interpreter has preconceived hypotheses even before the interpretation has begun, it is important that they divulge these hypotheses so that the interpreter is aware of the preconceptions, and the audience is not made to believe that the hypotheses evolved from the text. A preconceived hypothesis is not necessarily invalid, and may be a very accurate assessment of the author's intent. It may be based on previous knowledge of the author and their work, or through reference to the text from other sources. It is important to note, however, that a predetermined hypothesis is contextually different from an emergent hypothesis. A predetermined hypothesis is more likely to be shaped by the interpreter's contextual background, and their intended purpose for the interpretation (Hirsch, 1967, p. 166). The interpreter is likely to be hunting for proof within the text for a predetermined hypothesis, rather than allowing the hypothesis to evolve through an accumulation of evidence that becomes apparent from the contents of the text. By stating the nature of the origin of the hypothesis the audience can then judge if author has been circumspect or self-serving in their evidence gathering.

Evidence used to support a hypothesis can come from within or without the text (Hirsch, 1967, p. 185-8,197). Each hypothesis is defined by a set of traits that make it unique within the hypothesis set. The presence of these traits can be supported or refuted by the evidence we discover, and therefore we can dismiss disparate hypotheses.

Ultimately, the purpose of any critical review of a text is to convince the reader that the interpreter has made a convincing interpretation of the text. Therefore, the validity of an interpretation can be measured, in one sense, by the ability of the interpreter to convince the community of scholars knowledgeable in the subject matter of the text. In this case my purpose in this study is twofold: 
1. To demonstrate that I have, with careful planning and forthright execution, conducted a thorough and sound interpretation of the texts at hand.

2. Through convincing presentation and strong evidence from the text, demonstrate the above actions for your satisfaction and approval.

\section{Information Systems Studies Employing Hermeneutical Techniques}

A number of studies in the information systems discipline have employed hermeneutical techniques. What follows is a summary of the importance of some of these articles, the authors, and their main points. A more detailed synopsis of these articles is presented in Appendix 2.

My choice of articles for my literature review was based on a number of internal desires. First, I wanted to collect a series of exemplar articles. The list of these articles was provided by Myers (2007). My previous research with regard to hermeneutics revealed Myers to be an excellent source for general hermeneutical knowledge, and therefore I relied on his determinations as an initial source for strong hermeneutics articles.

My second desire was to capture articles authored by all of the core hermeneutical researchers in the IS discipline. This list included Allen Lee, Michael Myers, Richard Boland Jr., and Brian Fitzgerald. These authors feature prominently in most hermeneutics literature, and their studies are commonly referenced by other authors. Additionally, some of these authors, such as Lee and Boland, have developed their own contributions to the field of hermeneutics and are referenced as hermeneutics scholars, rather than simply researchers.

My third desire was to find studies that specifically addressed the interpretation of traditional written texts, as opposed to texts generated from interviews, and studies that included analysis methods for this type of text. The techniques and hermeneutical positions for interviews and case studies seem to differ from those employed to interpret traditional written texts. Therefore, I hoped to find articles which could provide directly applicable methodological processes and techniques.

Finally, to provide myself a glimpse of the "current" opinions of the IS discipline with regard to hermeneutics, I wanted to get at least one recent hermeneutic IS study. In this case the study I found was Zahedi et al. (2006). There 
were other articles that were more recent; however, these articles tended towards general interpretive discussions, rather than actual hermeneutic studies.

\section{Issues With IS Hermeneutical Studies}

A common feature of most of the IS hermeneutical studies is a wholesale referencing of many hermeneutical techniques (whether leveraged in the study or not), and the frequent naming of prominent hermeneutical researchers in studies, even though the hermeneutic styles of the researchers may not be compatible. For example, Lacity and Janson (1994) indicate that hermeneutics "typically deals with ancient manuscripts" (p. 152) and that "[hermeneutics] procedures may be unnecessary for analysis of contemporary texts and texts where participants share similar cultures" (p. 149). Later, however, they make reference to Winograd and Flores's Understanding Computers and Cognition (1986), which involves the contemporary interpretation of information systems in organizations, a sharp contrast to their previous statements. Similarly, Davis et al. (1992) state that "when we read a text, we interpret the meanings intended and expressed by the author" (p. 302). Immediately afterward they discuss Gadamer's contribution to hermeneutics, neglecting to mention that Gadamer refuted the purpose of hermeneutics with regard to determining authorial intent.

My intended original purpose in studying IS hermeneutical studies was to understand the methodological processes involved. Unfortunately, I was not able to complete this goal using the first group of studies that I examined, and I eventually decided to forgo reading other studies. With the exception of Davis et al. (1992), none of the studies I examined explicitly describes the methodological process they employed in their study. These articles tend to simply provide a great deal of background knowledge with respect to the hermeneutic principles they adhere to. Some, such as Lee (1994), may explicitly demonstrate the use of these principles with respect to the data they collected. Only Davis et al. (1992), however, actually described the complete process by which each of the hermeneutic principles was leveraged to produce the interpretation.

In general, the studies simply indicate that they are following a particular hermeneutic researcher's tradition, such as Klecun-Dabrowska and Conford (2000)'s Gadamerian approach, and then they proceed with the interpretation. As a reader, 
we are assumed to already understand what that particular hermeneutic scholar's position represents. This is problematic, since a terse description of a particular scholar's world may not sufficiently produce an understanding of the scholar's ideological standpoints. As a process of interpretation, the lack of sufficient background information provided by the study's author makes it difficult to reconstruct the context of the study.

Hermeneutic traditions are also mixed and matched as if they contained interchangeable parts. For example, Zahedi et al. (2006) claim to employ Gadamer's philosophical hermeneutics for the analysis of their data, while using Habermas' critical hermeneutics approach for the discussion of their results. This is problematic when a particular scholar's hermeneutic position requires an adoption of multiple techniques or principles, or when scholars who have incompatible views are leveraged in the same study.

\section{Value Drawn from the IS Hermeneutic Study Review}

Unfortunately, none of the studies I examined, with the exception of KlecunDabrowska and Conford (2000), involved the interpretation of a traditional written text. Most current hermeneutical studies employ the contemporary definition of "texts" to include all methods of human discourse. These studies typically examine texts based on interviews or from other communications directly with study subjects. The methodological steps for interpreting interview scripts and other direct statements from subjects are likely to be different from those used to interpret written texts. Additionally, overcoming the impact of distanciation is considerably easier when the subject can be questioned directly.

It cannot be said, however, that my time was wasted on these texts. Individually, each of these case studies provided important background information that aided in my understanding of the hermeneutic traditions. Additionally, they contributed important references to the source documents where the hermeneutic traditions could be found. Unfortunately, this shifted my burden of reading away from the IS studies and towards numerous books on hermeneutic theory. Though these books (particularly Lincoln and Guba, 1985; Hirsch, 1967; and Ricoeur, 1991) would prove invaluable in plotting the course of my own methodology, the transition 
from reading journal articles to books curtailed my investigation of other is hermeneutic studies.

The studies that I read provided individual contributions towards my research. Boland (1991) demonstrated that even the terms associated with hermeneutical studies are often subject to interpretation (in this case phenomenology and hermeneutics), which taught me to carefully consult multiple sources before I began employing these terms in my own study. Butler and Fitzgerald (1997) demonstrated the importance of carefully documenting the sources that are woven together to produce your text, particularly those that are considered part of your foreknowledge rather than being the primary source text.

Davis et al. (1992) is what I consider to be the exemplar for hermeneutical IS studies. The study's interpretive methodologies were developed by Lee and are the only exhaustively described methodology I encountered in my readings. The structure of the study is unconventional, but it excellently chronicles the entire hermeneutic process. We see multiple iterations of a hermeneutic circle, and how the authors were forced to deal with conflicts emerging through the interpretation. The study also provides substantial entertainment value as the determination of the study after careful construction and exhaustive interpretation is that systems fail primarily because employees are lazy.

Klecun-Dabrowska and Conford (2000) was the only study I could find that actually involved the hermeneutic interpretation of a traditionally written text, rather than a text based on transcribed interviews. The study also demonstrates the concept of multiple cycles of the hermeneutic circle.

Lee (1994) is perhaps one of the most important hermeneutic studies, due not to its content, but where it was published. As the first qualitative study to be published in MIS Quarterly, it legitimized the pursuit of qualitative research, and opened the door for other qualitative work to be published in prestigious research journals. Lee (1994) is also an excellent study that demonstrates how the hermeneutic principles and techniques are leveraged to interpret the data at hand, though some of Lee's definitions are confusing due to his use of traditional and contemporary hermeneutic sources.

Lacity and Janson (1994) is not a study per se, but is a treatise on textanalysis methods. It demonstrates positivist, interpretivist, and critical techniques 
and provides a number of excellent methodological considerations for hermeneutical studies. In particular, the study's reference to immersion in a text, based on the accumulation of a great deal of background knowledge of the text and multiple readings, seems well placed in my study.

Zahedi et al. (2006) displayed how hermeneutics can be incorporated with other research methods. Their study claimed the use of elements of Gadamerian and Habermasian hermeneutics, while employing semiotic data analysis, and a grounded theory methodology. Klein and Myers (1999) is an excellent study on the validation of hermeneutical field studies.

\section{Issues Impacting the Study Methodology}

The subject matter and nature of this study are difficult to categorize within a common research approach. Though it is qualitative and interpretive in nature, numerous factors impact the choice of the particular methodology to be used in this study. Some of these factors require the adherence to specific methodological choices, and therefore a proper exposition of these factors is necessary, before addressing in detail the actual methodology to be used in this study. These factors are:
1. Authorial Intent
2. Interpretation of Textbooks
3. Author Constructs
4. The Revision Process for Textbooks

\section{Authorial Intent}

The first and most influential factor affecting this study is the nature of authorial intent. Authorial intent is a vigorously debated topic within interpretive research circles and particularly among historians, hermeneutics scholars, and literary critics. (Wimsatt and Beardsley, 1954a).

Traditionalist hermeneutic scholars, historians, and literary critic schools believed firmly in the importance of authorial intent and the history of the author. These traditional schools were later influenced, however, by German philosophers 
and metaphysical hermeneutic scholars such as Heidegger and Gadamer. This led many scholars to shift emphasis to the contextual factors present during the reading and away from the author's intent. Not all hermeneutics scholars abandoned the belief in authorial intent, however, and scholars such as Emilio Betti questioned the German tradition (Bleicher, 1980).

Author intention in literary criticism was directly attacked by papers such as the "Intentional Fallacy" (Wimsatt and Beardsley, 1954a), which gave rise to the New Critic school which obviates the importance of the author in works. Readerresponse theory also developed which focuses on the importance of the reader as the creator of authorial intention during a particular reading (Keitel, 1997). Readerresponse theory, however, was similarly attacked in an essay entitled the "Affective Fallacy", also by Wimsatt and Beardsley (1954b). The resurgence of the authorial intent argument began with Hirsch's Validity in Interpretation (1967). From this work evolved the Intentionalist school, which makes the forceful argument that there is one and only one valid interpretation (Newton, 1989).

The authorial intent argument is not a straight-forward acceptance or denial of authorial supremacy of meaning, however and the opposing sides present reasonable cases. New Critics attack authorial intent on two grounds (Wimsatt and Beardsley, 1954a).

First, regardless of the intent of the author, the text is a work that can be appreciated based simply on the language within the text. The artistry of a poem is dependent on the ability to use language, not on what the intention for that language was. Therefore what separates the skill of a poet is not their intent, but the result of their execution.

Second, a poem can be validated based on internal or external evidence. Internal evidence is taken from the poem itself, and this is literary criticism. External evidence includes the intentions of the author and their history, and this is literary biography. Though New Critics express an appreciation and respect for literary biography, and they acknowledge that external evidence may be useful in understanding a poem, the act of criticizing a poem should be based solely on the internal evidence apparent within the poem itself.

The central element to the New Critic argument is not that authorial intent does not exist, but rather that it is unimportant for the purpose of criticizing the works 
of the author. The contemporary hermeneutical argument against authorial intent, however, refutes the ability for authorial intent to be reconstructed at all. Once a work has been completed it exists as a thing unto itself and becomes distanced from the original author in space and time (Ricoeur, 1991). It can be reinterpreted without any knowledge of the author. When a reader interprets a work, they create their own vision of who the author was, and what the intent of the work was. This vision is bounded by the reader's own context and history, and therefore any interpretation is uniquely guided by the work and by the reader, rather than by the author.

Hirsch recognizes the existence of many possible interpretations, but it is his feeling that the value of an interpretation is dependent on its proximity to the author's original intent. Hirsch (1967) argues that since there are so many possible interpretations, and some of these interpretations could unduly reflect the prejudices of the interpreter, the only yardstick to measure an interpretation against is the author's intent. Hirsch does allow for a co-existence of the contemporary and the traditional views by noting that the significance of a work to a person is abstract, unique, and wholly individual, while the meaning of a text is factual, definite, and is grounded in what the author intended for the work.

Betti (1980) also recognizes multiple possible interpretations, but believes that a work has an embedded meaning based on the author's intent. The purpose of interpretation is to (as faithfully as possible) reconstruct the author's message. Variance in interpretation is reflective of an inability to correctly open oneself to what the author is saying.

Intentionalists take a more extreme view. Without an author, they claim, the work cannot even stand as text. Without the intent of an actual author, symbols, whether intelligible or not, are simply random and without true meaning (Newton, 1989). Intentionalists accept only one meaning, the meaning intended by the author, since any other meaning denies that any act of speech, written or spoken, holds intent. Meaning and intent are synonymous in this respect.

Unfortunately, the IS tradition is not helpful in resolving the authorial intent argument. One of the foremost interpretivist IS authors, Allan Lee, appears to have conflicted opinions with regards to authorial intent as he provides arguments both supporting and refuting the importance of authorial intent: 
The motivating question in hermeneutics is: after a writer has implanted certain meanings in a text, how might readers of the text, especially those who belong to a different time and culture from the writer of the text, proceed to interpret the text for the meanings originally implanted in it, where other portions of the text itself are the primary, or sometimes the only, cross-referencing tools available? (Lee, 1991, p. 348)

In explaining how the interpretation of text occurs, Ricoeur (1981) argues that it is unnecessary to refer to the author's intentions, the text's originally intended audience, or the text's originating culture. A document typically becomes separated from its author, its originally intended audience, and its originating culture, whereupon we can say that the text takes on a life of its own. (Lee, 1994, p. 148)

Since Lee actually uses Lee (1991) to support his theories in Lee (1994), it is not clear whether his views evolved in the time between the two papers, or whether he was simply unaware of this contradiction.

The theoretical basis for an interpretive study and the research methods that follow from this position make the issue of authorial intent particularly poignant. It has been suggested that a study which pursues authorial intent can no longer be considered a hermeneutic study since it lies in opposition to much of the contemporary hermeneutic thought. Studies which pursue the more classical elements of hermeneutic study may be better situated as simply "interpretive studies". Thompson (1981) states however, that "There does not exist a general hermeneutics, that is, a general theory of interpretation, $[\ldots]$ there are only various separate and contrasting hermeneutic theories" (p. 46). Two contemporary hermeneutics scholars, Betti (1980) and Bleicher (1980) both recognize authorial intent. Betti's view is particularly important, because it views the duty of interpretation as understanding the messages left by authors.

Within the domain of textbook evaluation, authorial intent is not only recognized, but is a primary criterion for the determination of content quality. A review of an early textbook guide by Henry (1922) reveals that not only the author's ideas, but the reputation and history of the author are of considerable importance in choosing textbooks. Kearsey and Turner (1999) claim that the relationship between author and reader is a critical determinant of the success of the textbook as a teaching device. Thompson and Hunter (2000) note the importance of the writer's 
opinions in the evaluation of texts. Ironically, although Wimsatt and Beardsley (1954a) roundly denounce the importance of authorial intention in works of poetry and literature, it emphasizes that "In this respect poetry differs from practical messages, which are successful if and only if we correctly infer the intention" (p. 5).

For the purposes of this study, since authorial intent is a central element to the study's purpose, the theoretical positions of Betti (1980), Bleicher (1980), and Hirsch (1967) will be followed. Sufficient evidence exists to suggest that a hermeneutical interpretation that focuses on authorial intent can be conceived and executed. Moreover, the evidence disputing this possibility of conducting such a study is either simply a difference in theoretical positioning, or can be considered as inapplicable to the interpretation of textbooks.

\section{Interpretation of Textbooks}

IS researchers, when conducting hermeneutic interpretations, have primarily used interview data as the objects of their interpretation. Studies of actual book-like structures seem to be very rare. Klecun-Dabrowska and Conford (2000) is a notable exception that employed a hermeneutic process for the study of written texts, particularly because of the strength of its focus on the hermeneutic circle. It is likely, however, that an interpretive study in the IS domain for textbooks is unique. An interpretive study of textbooks with a purpose other than evaluation of the text for use in curricula is also likely to be unique, since such a study could not be found after extensive search in many scientific and literary domains.

This is not to say, however, that the studies which evaluate textbooks are rare. Thousands of governmental, educational, and humanitarian organizations conduct studies of textbooks each year, or publish guidelines for their evaluation. The purpose and method of these evaluations, however, is distinctly different from this study.

School boards and education establishments generally produce checklists to evaluate textbooks (Ornstein, 1989; AAAS, 2007). More involved processes may include scales which rate textbooks on the basis of the checklist criteria (Bailey, 1988). These methods facilitate expedient and objective processes for selection. In many cases, however, the checklists used are biased towards the experiences of a particular group rather than being based on empirical research (Saroyan and Geis, 
1988). The comparison of checklists often reveals misaligned or even conflicting requirements. Checklists are also very open to subjective interpretation by the persons employing them.

The classic literature in textbook and curriculum evaluation is founded on Cronbach (1963) and Scriven (1967). Cronbach (1963) claims that course evaluation and the evaluation of pedagogical materials must be based on the ability for the course to meet its outcomes, and that courses and course materials should be evaluated during the actual course execution, not after. Scriven (1967) reformulates this argument, stating that courses and course materials must be measured against an objective standard. A course which fulfills its own objective set well, but does not fulfill greater educational purposes, may be a flawed or valueless course. In this case, the ability for a course to meet standardized curriculum guidelines is a means of objective measure. Course materials, such as textbooks, should assist in meeting curriculum guidelines.

Academic studies of textbook evaluation vary quite substantially in method and technique. Misic and Russo (2000) is a content analysis study. Kearsey and Turner (1989) employ genre analysis, an interpretive technique framed in a metadata structure.

Shriver (1989) lists a host of different text evaluation techniques. These techniques fall into three categories:

- Text-Focused methods which are generally used to assess the presence or lack of particular content

- Expert-Judgment-Focused methods which are primarily interpretive reviews of the content based on expert, editor, or external opinions

- Reader-Focused methods which attempt to evaluate the success of the text in delivering material to the reader.

For this study, a text-focused method, such as Misic and Russo (2000), was not appropriate, since the goal of the study was to determine why content was chosen, not necessarily what content was chosen. Similarly, a reader-focused method was not appropriate since the purpose of the study was not to evaluate how well the authors deliver the material in the textbook to a reader. Expert-judgmentfocused methods can be used to determine why authors choose particular content for their textbooks, since these methods are more flexible and are generally 
interpretive in nature. Fulfilling the "expert-judgment" requirements, however, requires a strong understanding of the topic matter and relevant contextual issues. This is also a requirement of Betti (1980)'s method of hermeneutic interpretation.

This study followed an "expert-judgment-focused" method which was interpretive in nature and assessed the intent of the authors with respect to the content they have chosen for their textbooks. Shriver (1989) does not specify a particular methodological technique for an expert-judgment-focused method, therefore sound interpretive techniques, such as those found in Lincoln and Guba (1985), were appropriate.

\section{Author Constructs}

It must be noted that when a textbook has a collection of authors, it is usually not possible to isolate the ideas of each particular author. Unless a statement is attributed to a single author, the text would be considered to have an aggregate author, who holds the melded opinions of the individual authors. It is often required by book publishers that the authors adopt a common style of writing, or the authors may even be forced to adopt a "house style" which the publisher uses for all textbooks of a particular genre (Kearsey and Turner, 1999).

Therefore any determinations for a particular textbook edition will be considered the opinions of a collective "author construct" which will be named using the common APA inline reference style. For example, a reference to Whitten's, Bentley's, and Dittman's Systems Analysis and Design Methods, Sixth Edition would be made as Whitten et al. (2004). Note that this reference is not simply a referential construct, but an interpretive construct that associates the views found within that particular book with the collective author construct that will be employed in the study. This is not an atypical function of the APA inline reference, as statements like "Whitten et al. (2004) claim" or "Whitten et al. (2004) believe" are commonly used in academic papers.

These authorial constructs may change between textbook editions however, which raises the possibility that a particular authorial construct will not exist for the duration of the entire edition set. For example, the seventh edition of Whitten et al. (2004) was authored only by Whitten and Bentley, while the third edition was 
authored by Whitten, Bentley, and Barlow. It may be tempting to assign "primary author" status to some authors and "secondary author" status to others, but in some cases one of the primary authors leaves the authorial group and therefore this identification is not valid. Additionally, it may not be easy to attribute content to a particular author group, unless it is specifically denoted as such in the text. Even if author groups change between editions, the link between revised text and a particular author group usually cannot be made (Saroyan and Geis, 1988).

Some authors also have multiple textbooks in the market. It cannot be assumed that the intentions of the author span all textbooks, particularly in light of the possibility that author intent can change between editions of a single textbook. Therefore, it is not realistic to individually separate authors and to make claims as to their individual intentions.

Therefore, for the purposes of this study, the author construct is assumed to be a valid reflection of all authors associated with the text. It may be revealed in the course of the study that the addition or loss of a particular author has an impact on the nature of the textbook (which would be an interesting and important revelation), but this determination would be reflected as a change in authorial intent for the entire author group.

For example, if authorial intentions are determined to change between the sixth and seventh editions of the Whitten and Bentley textbook series, then it would be stated that the views of Whitten et al. (2004) changed when Whitten and Bentley (2007) was released. Even if it can be determined that the loss of Dittman as an author directly impacted the views expressed in the seventh edition, Whitten and Bentley must have been willing to adopt Dittman's views in the sixth edition. Therefore the changes in authorial intent from the sixth to seventh edition reflect changes in Whitten's and Bentley's views, not simply an additive element from Dittman present in the sixth, but missing in the seventh.

This preserves the intent of the study, which is to study the possible changes in authorial intent over time, but is a possible limitation of the study, since one author's views may have dominated the choices for content and the expressed views within the text. Determinations and conclusions for textbook edition chains list each different author set for each edition of the textbook, but the textbook chain will be treated as a contiguous evolving entity. This is necessary in order to demonstrate 
changes in authorial intent between editions, and is reasonable given that each edition is considered by publishers and consumers to be a member of the same set. If this were not so, the books would not be editions, but rather different textbooks entirely, with different titles.

\section{The Revision Process for Textbooks}

Textbooks will generally follow a revision process between editions. Saroyan and Geis (1988) and Shriver (1989) list a large number of potential sources for revised material which includes teachers, readers, experts, and editors. Saroyan and Geis (1988) note that it is generally impossible to identify the source of a particular revision as these are rarely attributed. This means that although changes can be identified between editions, the source and therefore the possible reason for the change is unlikely to be identifiable. In many cases, the publisher acts as a gateway for revisions, and may ignore review suggestions.

It is assumed in this study, however, that the final edition of any textbook must have been acceptable to the authors of the text. It seems unreasonable to believe that authors would associate their names with text material opposed to their own views, or that publishers would "sneak" material into a text without the authors' awareness. Therefore, again it is assumed for the purposes of this study that all revisions to a text reflect the authors' views, although it may be the case that the source of the revision is not the authors themselves. I believe this to be a realistic assumption for this study, since the research questions hinge on the possibility that external sources impact the content that authors place in their textbooks. Practitioners, academics, and the IS curriculum guidelines are primary and valid sources for these revisions (Shriver, 1989; Saroyan and Geis, 1988), and therefore the research questions are supported by the nature of the editing process.

\section{Study Limitations}

To summarize the above, it is difficult to map possible changes in the authorship of a particular textbook edition to changes in the authorial intent expressed in that edition. Therefore expressions of authorial intent are limited to discussions of intent as linked to the textbook, as opposed to discussion of intent as linked to the physical authors themselves. Expressed another way, this study can 
specify that Whitten et al. (2004) [an authorial construct] claims or believes something, but it cannot say that Jeffrey $L$. Whitten [the person] claims or believes anything, since he cannot be separated from the construct. This is a minor limitation however, since the purpose of the study is to explore authorial intent in general, rather than the specific authorial intent of a particular author.

A second limitation of this study deals with the nature of the review process that creates new editions. A study by Saroyan and Geis (1988) indicates that it is generally very difficult to identify the source for revised text between editions. The extensive set of possible review sources listed in both Saroyan and Geis (1988) and Shriver (1989) offer many possible alternatives for input into the review process. Therefore, though it will be possible to determine when a revision between editions occurs, it is probably not possible to identify what led to this change. It has been shown, however, that academics, practitioners, and curriculum guidelines are the most likely and reasonable sources for revisions.

Finally, although this study can make assessments with regard to the degree of alignment between academics, practitioners, and author between editions, it is unlikely that the rationale for this alignment can be directly inferred from the presence of change between editions. This does not exclude the possibility, however, that the content of the revision may explain the reason for change, or that it can be inferred by examining the text around it. This limitation directly impacts the ability to answer research question 2, but the more general questions regarding authorial intent are not impacted by this limitation. 


\section{Section 3: Research Methodology}

This study will be a hermeneutic interpretation that follows the tradition of Betti (1980), Bleicher (1980), and Hirsch (1967) for the purposes of assessing authorial intent in textbooks. The actual methodological techniques follow Lincoln and Guba (1985), a standard source for interpretive techniques. These techniques are guided by the hermeneutic principles of the hermeneutic circle and the resolution of apparent contradictions in the text (Myers, 2004). This study will extend the work of Misic and Russo (2000) by providing important answers to the question of why textbooks may not be aligned with academic and practitioner views, and the IS curriculum guidelines, by examining authorial intent with respect to textbook content.

\section{Sampling Methods}

Interpretive research justifies the selection of research subjects based on non-random sampling procedures (Glaser and Strauss, 1967; Mason, 1991). Termed "theoretical sampling", the purpose of sampling for interpretive research is to choose subjects which best represent the phenomenon at hand (Eisenhardt, 1989). There are a number of different methods of choosing samples non-probabilistically, including choosing extreme cases, choosing best representatives of a phenomenon, and choosing most accessible members of the extrapolated population.

For this study, three textbook series were chosen ${ }^{1}$. Each textbook series presents a different viewpoint with respect to the authorial intent question. Combined they should provide a good cross-section of different formats for textbooks, and different authorial intentions. A complete listing of the textbooks is given in Appendix 3.

The first textbook series is Whitten and Bentley's Systems Analysis \& Design Methods. This book has seven editions and is the most popular SAD textbook used (Misic and Russo, 2000). Whitten and Bentley can be considered a "classic" SAD textbook, and is categorized in Misic and Russo (2000) as being a strong example of a structured-methodology-focused textbook that demonstrates a high degree of

\footnotetext{
${ }^{1}$ Authors Note: During the thesis proposal defence, it was decided by my thesis committee that the requirements and scope of an MBA thesis would be better satisfied through the review of only one series of books (Whitten et al.). This section has been maintained, however, as it reflects the original intent of the thesis, and provides a background for later development of this thesis for other research purposes.
} 
misalignment with academic and practitioner views. As such it could be chosen as a "best representative" sample based on Eisenhardt (1989). Additionally, since the book has been printed in seven editions, it is an excellent choice to monitor for changes in authorial intent over many editions.

The second textbook series is Dennis and Wixom's Systems Analysis \& Design: An Applied Approach. In the introduction of the first edition of the text Dennis and Wixom (2000) state:

"Systems Analysis and Design (SAD) is an exciting, active field in which analysts continually learn new techniques and approaches to develop systems more effective and efficiently. However, there is a core set of skills that all analysts need to know - no matter what approach or methodology is used... This book captures the dynamic aspects of the field by keeping students focused on doing SAD while presenting the core sets of skills that we feel every systems analyst needs to know today and in the future." (Preface v)

This statement mirrors the conclusions of Misic and Russo (2000) and therefore this textbook is a strong selection to verify the conclusions of that study. Since this study attempts to provide an alternative view that expands upon Misic and Russo's (2000), choosing a textbook that can be studied to verify their conclusions is aligned with the purpose of this study. Dennis and Wixom (2000) has been released in three editions and falls within both the IS'97 and IS'2002 curriculum guidelines, and therefore is also a reasonable choice to ascertain whether the authors attempted to follow the IS guidelines.

The final textbook series chosen is Satzinger et al.'s Systems Analysis \& Design in a Changing World. Satzinger et al., when released in 2000, was one of the few textbooks that combined both structured and object-oriented methodological approaches. It is also the book that I was trained with, and is one of the primary reasons why this study was undertaken. I used the book when I taught systems analysis and system design courses, and I noticed that Satzinger et al. seemed to indicate that newer development methods, such as agile methods, had begun to supplant the other design methodologies. Yet, only one chapter of their book (chapter 17) is dedicated to these developments. In their words: 
"Rapid change in both business practices and information technology has created a significant management problem: how to quickly develop and deploy information systems that implement the latest business practices and employ cutting-edge technologies...The tools and techniques described in earlier chapters provide a foundation for rapid system development, but additional tools and techniques can be applied to speed up the process. This chapter presents a small but important subset of these tools and techniques." (Satzinger et al., 2004, p. 671)

The authors, following Misic and Russo (2000)'s determinations seem to indicate that the content previous to this chapter is meant to be a foundation for chapter 17. As they also state, however, they take only a cursory look at the rapid deployment techniques, though it would seem that these techniques are critical for current systems analysts. This rather ironic statement and the fact that 670 pages of text are used apparently to "prepare" the student for this brief introduction to the necessary information they will need in their work endeavours struck me, and prompted me to reexamine the motivations that authors gave for their textbook content choices.

Therefore this book set has been chosen for two primary reasons. First, the book poignantly presents the misalignment between textbook authors and those who would seek to guide SAD course content. Second, the book essentially sparked the motivation for this study, and therefore is included for personal reasons. As a theoretical choice, however, the book is also valid as it spans two IS curriculum guidelines making it a reasonable choice for the research questions based on edition revision, and fits within Misic and Russo (2000)'s conclusions for authorial intent based on core skill development. Finally, the book is also one of the few hybrid structured / object-oriented textbooks, and therefore provides a different perspective to the methodological research questions posed in the study.

\section{Methodological Steps}

In the first stage I will develop the background knowledge necessary to complete the study. This information is more than simply a literature review of the study's methodological and topical material. It will also develop my foreknowledge for the interpretation of the source texts, as is required based on Betti (1980). The 
completion of this stage is evidenced in the extensive literature present in the study. When this stage is completed, I will be prepared for my hermeneutic interpretation.

In brief, I will begin the hermeneutic interpretation for each textbook set with the first edition of each text. Once the interpretation for that textbook has been completed, I will proceed to the next edition, focusing on changes between the editions. When a particular textbook set has been completely interpreted through all editions, I will proceed to the next textbook set. The interpretive stage is complete once all editions of all textbooks have been interpreted.

Since Whitten et al. is the largest set, and covers the largest time span, I will begin with that set. Then, in order to present the maximum possible difference between textbook sets, and therefore to build a large set of potential answers to the research questions, I will move to Dennis and Wixom. Finally, to provide a possible balance between the two other textbook sets, and to move towards finalizing the potential answers to the research questions, I will finish with Satzinger et al.

The hermeneutical interpretation will be guided by the hermeneutical circle and the hermeneutic principle of resolving apparent contradictions within the text (Myers, 2004). For the purposes of this study, the contradiction is the misalignment between the content chosen by authors for their textbooks and the guidance provided by academics and practitioners and the IS curriculum guidelines, as evidenced by Misic and Russo (2000). The interpretation will be complete when the apparent contradictions can be resolved, that is, when the intent of authors with respect to their content choices can be presented as a rational decision. This is in line with both Hirsch (1967) and Betti (1980) since to resolve this apparent contradiction I will have to decipher the authors' intent.

A hermeneutic interpretation involves looking at the text at many levels. This process is the hermeneutic circle, and requires the following workings through the text (Ricoeur, 1991, p. 158):

1. The text must be understood as a totality. It exists as a complete work and must be understood as an individual object rather than a collection of sentences. This is done by looking at the purpose of the text, its genre, and its audience. Much of this has been done in the literature review by looking at the purpose of SAD methodologies, at IS education, and at the textbook itself. More can be understood however by identifying the purpose of the text as 
expressed in the textbook itself, through passages that discuss its purpose, or how it can be used.

2. The text must be understood as a hierarchy of topics and subtopics, particularly on the basis of methodological content. The choice of topics that are discussed and which are not discussed, and the relative weight and importance of topics provide evidence of the intent of the text. The organizational choices for topics and when they are introduced is also important.

3. The text must be understood based on the authors' style of writing, and their tone with respect to the material. Do their words reveal their intentions?

4. The statements of the authors directly provide obvious clues to their intent. Do they disparage or dismiss particular methodologies or content? Do they indicate that certain methodologies are becoming more prominent? Do they stress skill building over methodological knowledge?

5. If the comments of the authors indicate a shift in current practice or education, in which edition do they make the comment? How does the text change in subsequent editions?

By employing the technique of the hermeneutic circle I will transition through the text's various organizational groupings (sentence, paragraph, passage, and chapter). For the purpose of documenting my analysis, I will code and sequence the text at these various levels. In this way, I can ensure that I perceive the text using different perspectives.

The coding process is done to ensure that information can be crossreferenced and that the text can be envisioned in multiple ways. This follows the guidance of Lincoln and Guba (1985, pp. 346-351). My coding procedure will be based on their technique.

Each concept that is uncovered in the interpretation will be inserted as a record in a database table. The fields of the table will include the source text, as well as the edition, chapter and page, so that it can be traced back to the original text location for verification. Important points and keywords and any additional notes will also be included as fields. A sample of the database structure is presented as Figure 4. 
The rationale for using a database record for each concept card is two-fold. First, my handwriting speed and legibility are very poor, but I am a reasonably skilled typist. Therefore my progress through the interpretation will not be impeded by my own handwriting impairments if the records are typed rather than written. Second, the use of an electronic database record rather than a hand-written card will ensure better durability, transferability, and longevity for the data.

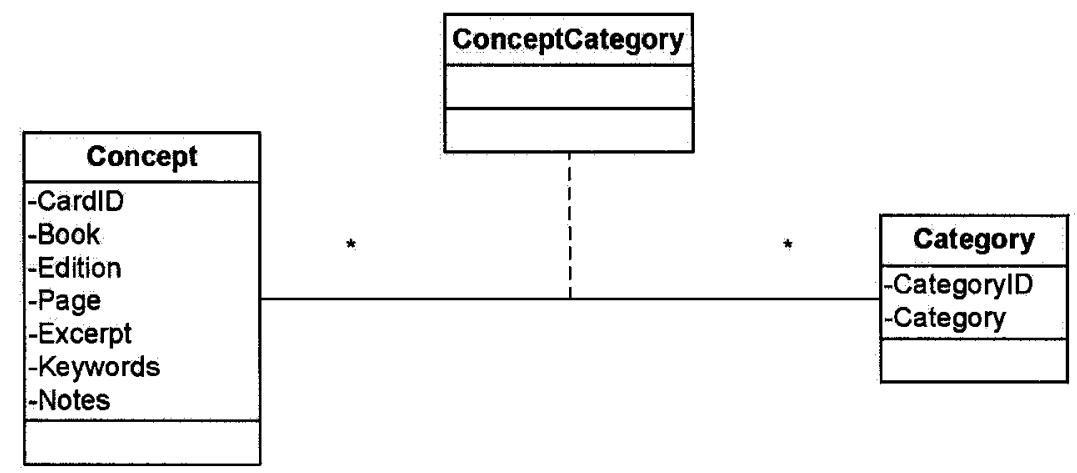

Figure 4. Concept Database Structure

Once the concept card records are complete for a particular interpretation cycle, they will be organized into categories which collect similar ideas. Concept records that follow a common idea will be linked together under a particular category record. The categories will identify the main attitudes, issues, hypotheses, and other content within the text that point towards a particular determination. Concept records that do not seem to fit into a particular concept category will create new category records. It is possible for concept records to span multiple categories; however, an attempt will be made to reduce the concepts to atomic elements which can better fit under a single category. When all the records have been categorized, categories that contain few concept records will be examined to see if the underlying concepts can fit within one of the other categories. Records that do not seem to fit in any category may signify conflicts that remain within the text. After the entire sorting procedure is complete, all concept and category records will be re-examined to confirm their placement. If, at that time, the authorial intent seems clear, and the conflicts within the text can be resolved, then the interpretation for that particular text is complete. 
If conflicts remain, then the concepts that bring the conflict to light will be examined. They will be traced back to their source content, and an attempt will be made to resolve the conflict based on pre-knowledge about the context, and hints from within the text itself. If this still does not resolve the issue, the records will be temporarily set aside. In a hermeneutical interpretation, sometimes these conflicts can be resolved by incorporating new information into the interpretation. This new information, which may arise from examining other texts, or other editions of the same text, may provide a new perspective to view the original conflict.

With subsequent hermeneutic cycles, new concept records will be created based on additional insights made through the interpretation of other editions of the textbooks, or by examining a different textbook set. These additional records may fit within existing concept piles, they may require piles of their own, or they may represent further signs of conflict within the interpretation. These additional concept records provide further evidence for particular determinations, may provide new insights, or may require the previous determinations to be reevaluated.

Differences between the content of subsequent editions of the same textbook set will be a focus for each hermeneutical cycle. The changes are important not simply based on the content within, but their presence indicates a transformation in the beliefs of the authors which is a central element of the study. Side-by-side comparisons will be made of each textbook edition to its predecessor, to ensure that any changes between the editions are uncovered. These changes will be included as content records, and reasons for the changes will be determined. Alterations to textbook content will be examined from two perspectives:

- As an individual content element which presents authorial opinions based on its content without regard to the nature of the change from a previous edition's content.

- As a modification of author opinions from the previous edition which will be compared to changes in the opinions of academics, practitioners, and the IS curriculum guidelines during the same period.

At the point where all editions of all textbooks sets have been examined, a final attempt will be made to resolve any remaining conflicts within the interpretation, if they persist, by reexamining the source texts. If these conflicts can be resolved, then the hermeneutic cycle will be considered complete. If the conflicts cannot be 
resolved, then they will be considered as separate categories in the final commentary, and will be judged based on their relative weight of importance to other categories and hypotheses as per Hirsch (1967, pp. 164-198).

\section{Presentation of Foreknowledge and Potential Blas}

Betti (1980) requires an open and honest attempt to allow the words contained with a meaning-full form that is being interpreted to reach the interpreter. This requires setting aside prejudice and being open-minded, as well as being knowledgeable about the material to be examined.

Hirsch (1967) presents a useful method of uncovering any potential bias on the part of the interpreter by setting them as possible hypotheses for the messages within the text. That way they can be identified and validated or refuted during the interpretation of the base objects of interpretation, or through external investigation of the context around the text. Hypotheses are also generated during the interpretation itself, through the hermeneutic process.

If we look at the reasons for authors to choose a particular content configuration for their textbooks, the following are my preconceived hypotheses:

- The choice of content is guided by what the author has a strong familiarity with. Therefore, authors that have been in the industry for an extended time are likely to choose traditional methods for their books. Younger authors are more likely to choose newer SAD methods for their books, and are more likely to change content between editions as they are less likely to have strongly established beliefs or traditions.

- Authors perceive that it is necessary to teach base skills to students and feel that these skills are best communicated through older methodologies. This is consistent with the determinations of Misic and Russo (2000).

- Authors are out of touch with current SAD development thought. Therefore they do not perceive a need to change from the traditional methodologies. This could be evidenced by few or inaccurate references to what is currently used in practice, or what other IS academics feel is necessary for teaching. Few revisions between editions may also be a sign that authors are out of touch with external views. 
With respect to a lack of change of content between editions, the following are my preconceived hypotheses:

- Authors become committed to a text once the initial edition has been created, possibly due to the tremendous work required to produce this first edition. Therefore they are reticent to alter the textbook in any major fashion once the first edition is complete, and therefore there is little change through many editions.

- The publishing process prevents the wholesale change of a text book after the first edition is created. This may be due to pressure by the publishing companies to maintain a consistent message in the text. It may also or alternatively be due to strict schedules which limit the time available to change editions. If the amount of content change within editions is minimal, but the authors' intent seems to stress the importance of current techniques, this might indicate that the publishing process itself is a barrier to the updating of content. If all three textbook sets show a similar trend toward minimal change between editions, this may evidence an industry-wide trend.

The previous hypotheses are important to evidence so that I am aware of these potentially biasing views, and so that I can be sensitive to cues within the text which may support, refute, or ignore these hypotheses. It is critical, however, to be sensitive to situations in which I believe that I am unduly forcing the ideas within the text to conform to these hypotheses. This can be accomplished in the following ways:

1. When concepts records are associated with a particular concept category, the category should be determined not by one of the above hypotheses, but by how homogeneous the concepts are as a group and how heterogeneous they are with respect to other piles. This is the method espoused in Lincoln and Guba (1985, pp. 348-349).

2. Once the concept groups have been established, piles which seem to follow a particular hypothesis should be validated as being congruent with that hypothesis, and incongruent with other reasonable hypotheses. In particular, concepts which seem to "fit perfectly" within a particular hypothesis should be challenged to determine if any other rational hypothesis can support the 
concepts. Until the alternate hypothesis can be dispelled by evidence found within the interpretation, the initial hypothesis will not be considered as the dominant hypothesis. This follows Hirsch (1967)'s guidance on survival of the fittest hypotheses (pp. 169-173).

3. When most of the concept records seem to have fit within plausible hypotheses, a review will be made to see what percentage of concept categories seem to fall within the preconceived hypotheses. Dominance of the preconceived hypotheses may be a sign of undue prejudice, and should trigger a re-examination of the existing concept piles to see if other plausible hypotheses could support the concepts. 


\section{Part 4: Analysis}

\section{Section 1: Analysis Process}

The study reviewed the first three editions of the Whitten et al. series (1986, 1989 , and 1994). It was determined by the thesis proposal committee that a review of the first three editions of Whitten et al. would be appropriate for this study. The first edition (Whitten et al., 1986) acts as a base to provide the initial determinations of authorial intent. The second edition (Whitten et al., 1989) demonstrates how this intent changes between editions. Reviewing the third edition (Whitten et al., 1994) validates the methodological process by demonstrating either consistency or change in the development of the series. Changes between Whitten et al. (1986) and Whitten et al. (1989) may be different than the changes between Whitten et al. (1989) and Whitten et al. (1994). Since the research questions explore the nature of these changes, it is essential to review the three editions.

The first book of the Whitten et al. series (Whitten et al., 1986) generated over 1300 analysis entries, and required more than three months to completely review. Whitten et al. (1989) generated an additional 700 cards and required six weeks to analyze. A smaller number of cards were required for the second edition as text that was not changed between editions was not recorded on a new card, unless the lack of change was notable. Whitten et al. (1994) required an additional eight weeks to review and added 800 new concept cards; bringing the total number of analysis cards to over 2800 . As expected, the amount of change between editions was the primary factor in determining how long the book took to analyze.

With respect to card density, the opening portions of the book generated the largest number of cards in all three editions. It was in sections like the preface and the opening chapters that the authors expressed their opinions most directly about the content contained in the book. The first part of all three books also focused on the concepts and concerns related to systems analysis and design, and therefore this section contained a substantial amount of the recorded notations. Part Two of each edition was the analysis section. Although ideas related to the research questions were discussed in this part, many of the statements were reiterations of concepts discussed in Part One, or the statements were simply the steps followed to execute a particular technique. These steps were not generally noteworthy, 
although discussions that linked to particular technologies, practices, or ideologies that were supported or condemned by either practitioners, academics, or the IS curriculum guidelines were noted. Part Three of each edition was the design section. In all three editions this section was predominantly a discussion of how to perform particular techniques, and therefore was less noteworthy. Part Four of Whitten et al. (1994) was the Implementation chapter. Since this chapter was new to the series, it contained a number of previously non-reviewed concepts. Part Four in Whitten et al. (1986) and Whitten et al. (1989) and Part Five of Whitten et al. (1994) was the Cross-Life Cycle Modules section. This section generated a number of concept cards due to the presence of concepts that spanned the entire system lifecycle. The modules were not changed substantially through the three editions, however, and therefore fewer concept cards were recorded in the editions after the first. Whitten et al. (1994) did add new content to the Modules section, and therefore a larger number of cards were recorded for this edition than Whitten et al. (1989).

Looking at the book from a chapter level, for all technique-based chapters, the bulk of the notes taken were from the beginning of the chapter, where the purpose, history, and importance of the technique were discussed. The actual mechanics of performing the technique were generally less important for the analysis, though comments by the authors that linked the technique to practice or academia, or otherwise discussed the technique beyond its actual steps were noteworthy. Chapters that were conceptual in nature or discussed the principles behind methodologies, practices, tools, or techniques used tended to be very dense with respect to concept cards. 


\section{Section 2: Answering the Research Questions}

\section{Question 1 - Changes between Editions}

Before discussing the changes tracked over the three editions of Whitten et al., it is important to address the core elements around which the authors assembled the book. From this core, one can better understand the nature and purpose of the changes in the series of books over time.

In the authors' words, Whitten et al. "is a practical book about information systems development methods" (Whitten et al. 1986, Preface xix, 1989 - p.2, 1994 p.2). The practical nature of the book is a central element to the books' delivery and organization. In all three editions, the book is divided into parts which move the reader from a general understanding of the nature of systems analysis and design (Part 1), to the specifics of analysis (Part 2), to the specifics of design (Part 3). In each part, the reader is introduced to the concepts, which are then followed with examples to provide a context to the concept. The authors criticize other books as being "too conceptual" (Whitten et al., 1989, Preface xxiii) or as being "practical, but too mechanical" (Whitten et al., 1989, Preface xxiii). To differentiate their books, the authors illustrate how their concepts and examples link to current practices, rather than simply expecting the reader to make these linkages. One of the prevailing themes of the series is this very close tie to practice. It is due to this linkage that we see most of the changes between editions of the series.

Although the core ideas of the book remain consistent throughout the three editions, the nature of the delivery of this content changes quite dramatically between editions. The changes between editions can be grouped into four main categories: Changes in Content, Changes in Attitudes toward Content, Changes in Content Organization, and Changes in Content Presentation.

\section{Changes in Content}

Content changes in the Whitten et al. series are both extensive and gradual. When viewed with respect to its most central elements, the SDLC and the phases of systems analysis and design, the changes in the book are fairly gradual.

Updates to the SDLC are made between editions, but overall it is consistent across all three editions. The tools and techniques that support this SDLC change 
considerably over the three editions, however. Technological developments and changes in practice play the largest role in these developments.

For example, in Whitten et al. (1986), databases are mentioned in a small module at the end of the book. At the time, database technologies were still emerging, and the authors felt that although databases were too advanced a topic to be covered in an introductory textbook, it was still important to present some information about them to the user (p. 806). At the time that Whitten et al. (1989) was released, database technology was more familiar to readers, and the database module was moved into the text as Chapter 14, complete with a new technique for developing databases, the Entity Relationship Diagram (ERD) (p. 223). This technique largely replaced the data definition technique in Whitten et al. (1986), the data dictionary. The dictionary is still a part of Whitten et al. (1989) but it is shown as a supplemental technique to the ERD (p. 493). By the time Whitten et al. (1994) was released, databases had become the dominant storage technology. Whitten et al. (1994) reflects this by combining the database and file design chapters into one. File design is a small part of this chapter, which focuses now on database design.

Similarly, prototyping was an emerging design paradigm when Whitten et al. (1986) was released. It is featured in the text as a Next Generation item (pp. 384-5); a feature which discusses emerging practices and technologies. In Whitten et al. (1989), prototyping is discussed as an emerging paradigm that has found great popularity in practice and academia (p. 124-5). Though it is not part of the SDLC itself, it is presented as a useful analysis and design technique (p. 522-3). In Whitten et al. (1994), prototyping is presented as an established and mature design strategy which is integrated directly into the SDLC (p. 284). 


\begin{tabular}{|c|c|c|c|c|}
\hline \multirow[b]{2}{*}{ Topic } & \multirow[b]{2}{*}{ Content } & \multicolumn{3}{|c|}{ Edition Representation } \\
\hline & & $\begin{array}{c}\text { Whitten et al. } \\
\text { (1986) }\end{array}$ & $\begin{array}{c}\text { Whitten et al. } \\
\text { (1989) }\end{array}$ & $\begin{array}{c}\text { Whitten et al. } \\
\text { (1994) }\end{array}$ \\
\hline \multirow{2}{*}{ SDLC Phases } & $\begin{array}{l}\text { System } \\
\text { Maintenance } \\
\text { Phase }\end{array}$ & Not included & Part of SDLC & $\begin{array}{l}\text { Full part of book } \\
\text { dedicated to it. }\end{array}$ \\
\hline & $\begin{array}{l}\text { System } \\
\text { Planning }\end{array}$ & Not included & Not included & $\begin{array}{l}\text { Chapter } \\
\text { dedicated to it }\end{array}$ \\
\hline \multirow{5}{*}{ Analysis } & $\begin{array}{l}\text { Modeling of } \\
\text { existing system }\end{array}$ & Part of chapter & Full chapter & Removed \\
\hline & Data modeling & Data Dictionary & $\begin{array}{l}\text { ERD (not } \\
\text { named) }\end{array}$ & Chen's ERD \\
\hline & $\begin{array}{l}\text { Process } \\
\text { Modeling }\end{array}$ & $\begin{array}{l}\text { DFDs (Chapter } \\
7 \text { ) }\end{array}$ & $\begin{array}{l}\text { DFDs } \\
\text { (Chapters } 7 \\
\text { and 9) }\end{array}$ & $\begin{array}{l}\text { DFDs (Chapter } \\
\text { 9) }\end{array}$ \\
\hline & $\begin{array}{l}\text { Network } \\
\text { Modeling }\end{array}$ & Not included & $\begin{array}{l}\text { Mentioned but } \\
\text { not explored }\end{array}$ & Chapter 10 \\
\hline & Prototyping & $\begin{array}{l}\text { Discussed as a } \\
\text { Next Generation } \\
\text { item }\end{array}$ & $\begin{array}{l}\text { Interwoven in } \\
\text { most analysis } \\
\text { and design } \\
\text { chapters }\end{array}$ & $\begin{array}{l}\text { Essential part of } \\
\text { SDLC } \\
\text { methodology. }\end{array}$ \\
\hline \multirow[t]{2}{*}{ Methodologies } & $\begin{array}{l}\text { Methodologies } \\
\text { used in the } \\
\text { book }\end{array}$ & $\begin{array}{l}\text { None, though } \\
\text { structured } \\
\text { techniques are } \\
\text { prevalent. }\end{array}$ & $\begin{array}{l}\text { Structured } \\
\text { Analysis and } \\
\text { Prototyping }\end{array}$ & $\begin{array}{l}\text { Own } \\
\text { methodology } \\
\text { based on } \\
\text { Information } \\
\text { Engineering, } \\
\text { Zachman } \\
\text { (1987), and } \\
\text { STRADIS. }\end{array}$ \\
\hline & $\begin{array}{l}\text { Methodology } \\
\text { Discussion }\end{array}$ & $\begin{array}{l}\text { Some } \\
\text { discussion in } \\
\text { specific } \\
\text { chapters }\end{array}$ & $\begin{array}{l}\text { One chapter } \\
\text { and discussion } \\
\text { in specific } \\
\text { chapters. }\end{array}$ & $\begin{array}{l}\text { Discussed in } \\
\text { some chapters, } \\
\text { but the book is } \\
\text { now essentially } \\
\text { a guide to the } \\
\text { authors' } \\
\text { methodology }\end{array}$ \\
\hline \multirow{2}{*}{ Design } & $\begin{array}{l}\text { Output / Input } \\
\text { and Interface } \\
\text { Design }\end{array}$ & Four chapters & $\begin{array}{l}\text { Three } \\
\text { chapters }\end{array}$ & Two chapters \\
\hline & Databases & $\begin{array}{l}\text { Discussion in } \\
\text { module }\end{array}$ & $\begin{array}{l}\text { One chapter, } \\
\text { separate from } \\
\text { file design }\end{array}$ & $\begin{array}{l}\text { One chapter for } \\
\text { database and } \\
\text { file design }\end{array}$ \\
\hline $\begin{array}{l}\text { Tools and } \\
\text { Techniques }\end{array}$ & C.A.S.E. & $\begin{array}{l}\text { Mentioned as a } \\
\text { Next Generation } \\
\text { item }\end{array}$ & $\begin{array}{l}\text { Section in } \\
\text { nearly every } \\
\text { chapter. }\end{array}$ & $\begin{array}{l}\text { One chapter, } \\
\text { plus sections in } \\
\text { most chapters. }\end{array}$ \\
\hline
\end{tabular}

Table 7. Summary of Major Content Changes in Whitten et al. Series

Table 7 provides a good summary of the major changes in content. To summarize, Whitten et al. (1986) collects a number of techniques (principally structured) used in practice and molds them around an SDLC. Whitten et al. (1989) 
adopts the structured methodology and prototyping as a foundation for their SDLC, and embraces technological developments in CASE and databases. Whitten et al. (1994) continues this trend by introducing networks, system planning, and systems support, but modifies their methodology to reflect criticisms of the structured methodology, essentially by using its successors (Information Engineering and STRADIS).

A consistent theme throughout the textbook series is that the authors alter and update content in each book to match what is used in practice (the dominant driver for change) and to reflect changes in academic views (a subordinate, but still important driver for change). As technology is introduced, it is similarly introduced to the series. As it becomes dominant, it occupies more space in the respective edition and is a focus of author comments. As it fades, so does its place in the Whitten et al. series, and in the opinions of the authors.

\section{Changes in Attitudes toward Content}

It is possible that, since the content in the textbook changes considerably between editions, the opinions of the authors would similarly change. It can be shown, however, that the attitudes of the authors are actually very consistent through editions. The authors demonstrate this opinion through consistent attitudes and consistent inclusion of some topics throughout the series. User-centric development is a pervasive theme of the series. Statements such as "Information systems are for knowledge workers!" (Whitten et al., 1986, pg. 84), "The analyst must recognize that the end-user is an integral part of the system." (Whitten et al., 1989, pg. 62), and "More emphasis is placed on client, end-user, and business perspectives" (Whitten et al., 1994, Preface viii) demonstrate this attitude. Similarly, the authors hold a consistent belief that discipline in the use of tools and techniques will lead to system success (Whitten et al. 1986, p. 712; Whitten et al., 1994, p. 23).

A struggle can be seen, however, when we juxtapose the attitudes of the authors with respect to concepts to their attitudes with respect to the implementation of these concepts. For example, the systems development life cycle (SDLC) is a central concept of the series. The authors are consistently its champion. 
"We organized the chapters around the proven roadpath [sic] to successful systems, the systems development life cycle." (Whitten et al., 1986, Preface xxiv)

"In any case, until a methodology comes along that supports the entire life cycle, the life cycle will remain a viable and essential foundation for the systems analyst and software engineer. Furthermore, if a methodology ever achieves this rather lofty goal, it seems to us that it will have to 'reinvent the wheel', that wheel being the life cycle." (Whitten et al., 1994, p. 113)

"Thus, the life cycle isn't dead -- it is merely disguised in the form of popular commercial methodologies, and those methodologies incorporate popular techniques." (Whitten et al., 1989, p. 143)

"Some analysts and systems development managers might argue:

The classic life cycle is the problem! It is an excessively long, drawn out process that leads to schedule and cost overruns. We could not disagree more!" (Whitten et al., 1994, p. 769)

The authors' opinions about the SDLC are quite strong, and demonstrate a firm belief in its efficacy. In contrast, however, the techniques that describe the SDLC, its phases and steps, and the tools used to manage and perform the tasks in their SDLC are quite fluid over the three books. In Whitten et al. (1986), the authors present their SDLC as an eight-stage process (pp. 140-1). A stage ("Maintenance and Enhancement") is added to their SDLC in Whitten (1989). Then, in Whitten et al. (1994), their SDLC is re-envisioned to be linked to a different concept in the book.

The emphasis on "their" SDLC is important, because the authors do not perceive the SDLC in a single format (Whitten et al., 1986, p. 120, 139). This interpretation of "an SDLC" rather than "the SDLC" allows them to make small modifications to their SDLC in Whitten et al. (1989), and then to substantially modify it in Whitten et al. (1994).

The authors justify these changes based on maturation or change of the SDLC as it is used in practice. In Whitten et al. (1989), the authors note that at the time, many business now had established information systems and needed to maintain these systems, rather than design new ones (p. 92). This leads to the addition of a maintenance and improvement stage to their SDLC (p. 89). In Whitten et al. (1994), the popularity of the Information Engineering methodology and the "Framework for Information System Architecture," a paper by John A. Zachman 
(Zachman, 1987), drive the changes to their SDLC. We can see from this that the authors demonstrate a consistent belief in the foundations of systems analysis and design, but, like many practitioners and academics of the time, are in conflict about how these principles should be practiced and executed.

Some of the most personal opinions expressed by the authors with respect to content reflect their realization that techniques fade in popularity over time.

"But it saddens us to realize that systems flowcharts are finding their way into fewer and fewer books and methodologies. Some of us who have used them successfully will resist. But we may be fighting a losing battle." (Whitten et al., 1986, p. 598).

We can see through this that the authors make their content choices through a combination of personal preference, and recognition of the trends in practice. As the editions progress, we can see this development in their attitudes.

"The DFD is the new kid on the block. And with the current emphasis on structured tools and techniques, the trend is toward using new tools like DFDs and placing less emphasis on systems flowcharts" (Whitten et al., 1986, p. 598)

"Systems flowcharts are a graphic tool used to show the sequence of processing and activities in a computer-based information system. Why not use data flow diagrams for this purpose? Many analysts are making this switch" (Whitten et al., 1989, p. 613)

"Before we teach you how to draw implementation (and design unit) DFDs, we should introduce an alternative. Before the popularity of DFDs, systems flowcharts were the popular tool for modeling design decisions. ... While the popularity of systems flowcharts is clearly on the decline, you may encounter them ..." (Whitten et al., 1994, p. 573)

The authors demonstrate a reluctance to remove the technique, providing justifications for maintaining the content after the technique is declined in use. The authors even go so far in Whitten et al. (1994) to recommend that readers refer to Whitten et al. (1989) if they want to learn more about systems flowcharts. 


\section{Changes in Content Organization}

Changes in content organization can be viewed differently depending on the structural levels of each textbook that you examine. At a very high level, the book changes very little between editions. At the chapter level, there are more substantial modifications to the text. At the section level, the book undergoes tremendous change over three editions. Ironically, at the paragraph level, the changes are more gradual than at higher levels.

Whitten et al. name the divisions of the major elements in their book as "Parts". These parts are the most consistent elements of the series. Part 1 of each book describes concepts and philosophies associated with systems analysis and design (Whitten et al., 1986, p. 2). Part 2 of each book describes the tools and techniques used for system analysis (Whitten et al., 1986, p. 134). Part 3 of each book describes the tools and techniques of systems design (Whitten et al., 1986, p. 356). Whitten et al. (1994) adds a fourth part, which describes systems implementation and support (p. 724). Portions of Part 4 can be found in the final chapters of Whitten et al. (1986) and Whitten et al. (1989). Finally, all books have a final part called the "Modules" (Whitten et al., p. 704) which contains content that spans all phases of systems analysis and design.

If we move beyond this largest organizational grouping, a distinct evolution in the organization of the content emerges. In Whitten et al. (1986), content in the second and three parts is organized entirely by technique. Chapter titles such as "Modeling an Existing or New Information System with Data Flow Diagrams" (p. 218) and "Designing On-line Terminal Dialogues" (p. 526) speak directly of the tool or technique used to perform that step of the development process. In Whitten et al. (1989), the titles of these chapters are somewhat transformed to "Process Modeling with Physical Data Flow Diagrams" (p. 178) and "Designing and Prototyping the User-Interface and On-Line Terminal Dialogues" (p. 574). Here we see a slight change in emphasis from the technique to the actual stage of analysis or design, though Whitten et al. (1989) still maintains very detailed titles. In Whitten et al. (1994), the system development stage becomes the focus, and the titles are simplified to "Process Modeling" (p. 346) and "User Interface Design" (p. 670). This change in focus from technique to development stage is consistent across the three editions, even though much of the content in each edition is the same. With regard 
to the chapters mentioned above, the Data Flow Diagram is the principal modeling tool used in all three editions with reasonably consistent text in all three editions. Similarly, the same guidelines for on-line dialogue development can be found in all three editions of the user interface design chapter with nearly the exact same wording.

The changes made to content organization mirror the changes in content itself and the authors' attitudes toward that content. As databases increase in popularity they transition from being a brief module in Whitten et al. (1986), to being a full chapter in Whitten et al. (1989) and Whitten et al. (1994). Conversely, file design topics shrink in size in the text over editions. Computer file design is a fifty page chapter in Whitten et al. (1986). It is a twenty-seven page chapter in Whitten et al. (1989). In Whitten et al. (1994), file design is no longer a chapter on its own, and fills only ten pages of the shared File and Database Design chapter.

Overall, content is merged, split, and reorganized based on how the authors perceive its importance. As can be expected, topics which are considered dated or which have been superseded by newer ideas receive progressively less coverage in later texts. Topics which grow in importance grow in size with respect to pages and references. Prototyping and CASE start as Next Generation articles in Whitten et al. (1986) but are full sections and chapters by the third edition.

Perhaps the most interesting aspect of the organization of content in the Whitten et al. series is that although the positioning of content may differ substantially between editions, much of the content at the paragraph level does not change. The transition from Whitten et al. (1989) to Whitten et al. (1994) sees a transformation of the book from technique-driven to SDLC-stage driven. All of the chapter titles in Whitten et al. (1994) are abbreviated to focus on SDLC stages or steps. Chapters 7 and 9 of Whitten et al. (1989), which deal with analysis modeling using DFDs, are merged into Chapter 9 of Whitten et al. (1994). Despite these substantial changes in the organization and focus of the content of the book, the actual sections and paragraphs of the Whitten et al. (1989) are mostly maintained in Whitten et al. (1994).

Overall, changes in content organization seem to be driven primarily by changes in the conceptual aspects of the series. Descriptions of tools and techniques follow their placement in the SDLC. In Whitten et al. (1986) content is 
grouped by SDLC stage primarily, and then by the granularity of the technique. DFDs and more general techniques are followed by data dictionary descriptions. This pattern is maintained in Whitten et al. (1989) but content is adjusted slightly to match the steps completed when following a structured methodology. Whitten et al. (1994) organizes all of its topics specifically by its stage in the book's SDLC.

\section{Changes in Content Presentation}

Changes in the visual nature of the books are the most pronounced between editions. Side-by-side, the books are barely recognizable as a series. Whitten et al. (1896) seems almost primitive when compared to Whitten et al. (1994). It is evident that the popularity of the series allowed the authors to substantially upgrade the graphical elements of the book over time, although this may be alternatively attributed to advances in printing methods.

Whitten et al. (1986) is marketed as an introductory text book (Preface xix), and uses figures and graphs to provide visual effect to the concepts. It was released by a small publishing group, Times Mirror/Mosby College Publishing. The graphic palette of the book is very small; diagrams are shaded using a red-brown hue. Whitten et al. (1989) was released by the much larger Irwin Publishing, and although it has a similar graphic layout, the diagrams are more polished. Whitten et al. (1994), released five years later and likely the dominant SAD book at the time, had a complete graphics overhaul. The book is in full-colour, contains photographs, and has significantly improved production values. Most importantly, the authors use colour as a pedagogical device in the book. They link each colour to an aspect of their SDLC building blocks, and link examples and diagrams to each aspect by using that colour for the figure. This not only enhances the look of the book, but aids in teaching as students can recognize what aspect of system development is impacted by the technique or concept being discussed.

The second major change to content presentation happens because of a repositioning of the book between editions. Whitten et al. (1989) is positioned as a reference book as well as a teaching book (Preface xxvi). To fit in all of the new content, the authors shrink the size of many of the diagrams, as well as the size of the font used for text in the book. The result is a book that has fewer pages than its predecessor, but actually includes more content. The verbiage in Whitten et al. 
(1989) is also considerably condensed, in order to save space. Longer anecdotes and examples are abbreviated. Whitten et al. (1994) is perhaps a maturation of the series however, and it returns to the original purpose of the first book. Many of the anecdotes that were pruned from the $2^{\text {nd }}$ edition return in the third edition, increasing its size to more than Whitten et al. (1986).

A good example of this transition is the Tower of Babel story in the Communication Skills module. In Whitten et al. (1986), the story is used as a preface to the module's discussion of communications problems (p. 757). The story is purged from Whitten et al. (1989) even though the reference to it in the content of the module is maintained (p. 745). Perhaps sensing that this possibly confused the reader, the story returns in Whitten et al. (1994). In this case, however, its inclusion is formalized as the chapter-opening minicase, rather than simply being included anecdotally.

\section{Summary of Content Changes}

Viewed over three editions we see instances of sudden and extensive changes, as well as gradual and progressive changes. Content is included as it becomes important to the IS discipline, and it is gradually removed as its importance wanes. Organizationally the book undergoes both subtle and dramatic changes as the authors modify their book to match the prevailing attitudes with respect to the SDLC and methodologies. The changes over editions reflect changes in the authors' attitudes towards that content, and its importance as a central element of $S A D$, or as a technique or tool used to express these concepts. Finally, the authors make considerable changes to the structure and presentation of the text over time, based on changes in the text purpose, and as either their book development budgets or printing technologies improved.

\section{Question 2 - Update Process Alignment With the IS Curriculum Guidelines and Opinions of Practitioners and Academics}

After looking at how much the content changes in the book over three editions, the next question we asked was: how well do these changes reflect updates in the is Curriculum guidelines, and the views of practitioners and academics? Although there may be considerable change between editions, these 
changes may be due to factors such as technology or simply the authors' preferences. To demonstrate alignment with the IS Curriculum guidelines or with the views or practitioners and academics, these changes should reflect statements of the authors that indicate alignment with the above groups, or the changes should coincide with changes in the opinions of these groups.

\section{IS Curriculum Guidelines}

All three books fall within the governance of only one IS Curriculum guideline document, the 1982 ACM Curriculum guidelines (Nunamaker et al., 1982). The next guideline document, the 1995 ACM Curriculum guidelines (Couger et al., 1995), would have applied to the fourth edition of Whitten et al. (1998). Therefore the analysis is guided generally by how closely each edition matches the 1982 ACM Guidelines, and whether the Whitten et al. diverges or becomes closer to the guidelines after each edition. As an exploration, since the 1995 ACM Guidelines follow shortly after the release of Whitten et al. (1994), a comparison will also be made between this edition, and the 1995 ACM Guidelines.

Whitten et al. (1986) seems to couple very nicely with the ACM 1982 Guidelines despite what may be perceived as a snubbing of the ACM itself. The book only mentions the ACM guidelines once, in the preface:

"This book can be used for any introductory systems course in either the DPMA, ACM, or independent computer information systems curriculum" (Preface xix).

The $A C M$ and the ACM guidelines are not mentioned again in the text, and the authors seem to drive readers to other organizations in place of the ACM:

"Students and professionals alike are encouraged to join organizations such as the Data Processing Management Association (DPMA) and the Society for Information Management (SIM)." (Whitten et al., 1986, p. 17)

The ACM is not mentioned in this list, though the authors have demonstrated awareness of its existence. This may not be coincidental, as Jeffrey Whitten was the President of the Sagamore Chapter of the DPMA in 1984 (Irwin McGraw-Hill, 2008). Subsequent editions of Whitten et al. maintain the above statement of adherence to the ACM and DPMA guidelines. 
Despite what may be an active attempt to minimize the influence of the ACM itself, the content of Whitten et al. (1986) seems to be well representative of the ACM 1982 IS Curriculum Guidelines. The ACM guidelines use the lifecycle concept as the basic framework for development, as does Whitten et al. (1986). The guidelines, however, require that management, organizational, technology, and economic perspectives of SAD are also presented. Whitten et al. (1986) has a very strong business and management focus, which consistently links to practice throughout the book, and a number of modules at the end of the book detailing business and management issues such as project management, feasibility, and communication. The book also explores the impact of databases, a burgeoning technology that had only recently entered the mainstream markets. In Whitten et al. (1989) and Whitten et al. (1994), databases play an even more important role in the book, drawing the series even closer to the ACM Guidelines.

The ACM 1982 Guidelines specify seven major topics for the System Analysis course. Whitten et al. (1986) closely follows three of these topics in the main text: Application System Development Life Cycle (Chapter 5), Information Requirements Determination (Chapter 6), and Requirements Analysis and Logical Specification (Chapters 7-11). With regards to the Application Development Strategies topic, Whitten et al. (1986) does not spend a great deal of time discussing software packages, but Whitten et al. (1989) and Whitten et al. (1994) have sections in Chapter 12 that follow the process of acquiring software. Whitten et al. (1994) also has a section in Chapter 19 - Systems Implementation that discusses integration and customization of software packages. Prototyping as a systems development method is discussed in Whitten et al. (1986) (pp. 166-8, 384-5), but is an integral part of both Whitten et al. (1989) and Whitten et al. (1994). This is summarized in Table 8. 


\begin{tabular}{|c|c|c|c|}
\hline ACM 1982 Topic & $\begin{array}{l}\text { Whitten et al., } \\
1986 \text { Coverage }\end{array}$ & $\begin{array}{l}\text { Whitten et al., } \\
\text { 1989 Coverage }\end{array}$ & $\begin{array}{l}\text { Whitten et al., } \\
\text { 1994 Coverage }\end{array}$ \\
\hline $\begin{array}{l}\text { Application } \\
\text { Development } \\
\text { Strategies }\end{array}$ & $\begin{array}{l}\text { Minimal coverage. } \\
\text { Some coverage of } \\
\text { prototyping. }\end{array}$ & $\begin{array}{l}\text { Sections in Chapter } \\
\text { 12. Pervasive } \\
\text { prototyping } \\
\text { coverage }\end{array}$ & $\begin{array}{l}\text { Sections in Chapter } \\
4,12 \text {, and Chapter } \\
\text { 19. Pervasive } \\
\text { prototyping } \\
\text { coverage }\end{array}$ \\
\hline $\begin{array}{l}\text { Application } \\
\text { Systems } \\
\text { Development Life } \\
\text { Cycle }\end{array}$ & $\begin{array}{l}\text { Chapter } 5 \text {, other } \\
\text { references in the } \\
\text { book. }\end{array}$ & $\begin{array}{l}\text { Chapter 4, other } \\
\text { references in the } \\
\text { book. }\end{array}$ & $\begin{array}{l}\text { Chapter } 3 \text {, other } \\
\text { references in the } \\
\text { book. }\end{array}$ \\
\hline $\begin{array}{l}\text { Application System } \\
\text { Development } \\
\text { Management }\end{array}$ & Module A & Module A & $\begin{array}{l}\text { Chapter 6, Module } \\
\text { A }\end{array}$ \\
\hline $\begin{array}{l}\text { Individual } \\
\text { Behaviour and } \\
\text { Group Dynamics in } \\
\text { the Development } \\
\text { Process }\end{array}$ & Module C & Module C & Module D \\
\hline $\begin{array}{l}\text { Problem Need } \\
\text { Identification and } \\
\text { Feasibility } \\
\text { Assessment }\end{array}$ & Module D & Module D & \begin{tabular}{|l|} 
Chapter 6, Module \\
C
\end{tabular} \\
\hline $\begin{array}{l}\text { Information } \\
\text { Requirements } \\
\text { Determination } \\
\end{array}$ & $\begin{array}{l}\text { Chapter 6, Module } \\
\text { B }\end{array}$ & $\begin{array}{l}\text { Chapter 6, Module } \\
\text { B }\end{array}$ & $\begin{array}{l}\text { Chapter 6, Module } \\
\text { B }\end{array}$ \\
\hline $\begin{array}{l}\text { Requirements } \\
\text { Analysis and } \\
\text { Logical } \\
\text { Specification }\end{array}$ & Chapters 7-11 & Chapters 6-11 & Chapters 7-11 \\
\hline
\end{tabular}

Table 8: Alignment between ACM 1982 Guidelines and Whitten et al.

The three remaining ACM 1982 Guideline System Analysis course topics are Application System Development Management, Individual Behaviour and Group Dynamics in the Development Process, and Problem Need Identification and Feasibility Analysis. The three editions address all three topics primarily in the Modules section of the book. The authors cover nearly all of the actual subtopics in each course topic in the modules, or somewhere in the main text. Many of the references used as source texts for the ACM 1982 Guideline topics can be found in 
Whitten et al. (1986). The authors often refer to academic references and other SAD textbooks.

An potential concem of Whitten et al. (1986) and to an even greater extent Whitten et al. (1989) was that the content in the modules was somewhat diminished in value as compared to the rest of the text, and therefore its value as meeting the requirements of the $1982 \mathrm{ACM}$ guidelines was similarly diminished. Content that is not part of the main text may be ignored by instructors or students. A confession by the authors in Whitten et al. (1989) that instructors, including themselves, were not able to cover the book in a single course (Preface xxviii) made this a particular concern. Though the authors have references to the modules in the main texts of Whitten et al. (1986) and Whitten et al. (1989), it is quite possible that these calls will be ignored. Whitten et al. (1994), however, is much more proactive with regard to the module content. In Whitten et al. (1994) the text often indicates that the actual techniques necessary to complete a particular activity can only be found within the modules (for example, p. 246). Rather than linking to the modules in a general manner, Whitten et al. (1994) links specific topics in the modules to system development actions within the main text. This is particularly important because the delivery of content in Whitten et al. (1994) is very methodical (Preface viii), and therefore there is an expectation that to complete a particular chapter or section of the text, the reader would have to consult the module that corresponds to that particular task

Overall, it can be observed that over three editions, the book moves closer to perfectly representing the 1982 ACM Guidelines. Each Whitten et al. edition after Whitten et al. (1986) increases the amount of content directed to fulfilling each of the seven major topics in the 1982 ACM Guidelines. The changes in Whitten et al. (1989) and particularly Whitten et al. (1994) address the deficiencies of the Whitten et al. (1986).

Interestingly but not surprisingly, Whitten et al. (1994) also nicely pairs with the 1995 ACM Undergraduate Curriculum Guidelines (Couger et al., 1995). It is not surprising, since the 1995 ACM Guidelines represented changes in practice and academia, and Whitten et al. (1994) could represent these same changes. In fact, Whitten et al. (1994) is actually closer to the state of practice at that time than the guidelines themselves. 
The ACM 1995 Guidelines could be considered the culmination of the methodologies movement, due to consistent language in the guidelines referring to the importance of methodologies (as shown in Table 4). System development methodologies are the focus of systems analysis and design (p. 346, 350). Whitten et al. (1994) is essentially the blending of three methodologies, Information Engineering (p. 2, 249), STRADIS (pp. 572-3) and Zachman (1987)'s Framework for Information Systems Architecture (Preface viii), into one. The content of Whitten et al. (1994) is laid out as a methodology in Part 2 and 3 , including very detailed steps for how to complete various steps and actions for each phase of system development. Object-oriented methods are mentioned only briefly in the IS'95 guidelines, but are given some treatment in Whitten et al. (1994) with a note that the authors expect them to become part of the next edition (p. 162). Finally, CASE is considered an essential tool for systems development in the IS'95 Guidelines, and it is a critical element of both Whitten et al. (1989) and Whitten et al. (1994). References to CASE pervade both books. Whitten et al. (1989) is actually paired with a CASE textbook using a CASE tool called Excelerator, written by Whitten et al. (Preface xxx). Whitten et al. (1994) includes an entire chapter on CASE (Chapter 5).

In summary, despite what could be perceived as a conscious decision to ignore the $\mathrm{ACM}$ organization, changes in the Whitten et al. series draw it very close to the ACM guidelines after three editions. Whitten et al. (1986) could be considered a good representative text book of the 1982 ACM Guidelines, and the two subsequent textbook editions seem to correct for differences between the textbook series and the guidelines. Whitten et al. (1994) not only forecasts the changes that come in the 1995 ACM Undergraduate Curriculum guidelines, it mirrors them perfectly.

\section{Practitioner Opinions}

Changes in the book can most easily and directly be linked to the views of practitioners. The book is written to reflect practical rather than academic concerns (Whitten et al., 1986, Preface xix; Whitten et al., 1989, Preface xxv) and the authors make numerous and consistent references to how things are done in the industry. Statements are often preceded by phrases such as "most analysts", "most businesses", "experienced analysts", or similar phrases. Discussions of 
technologies and techniques are linked to specific products or tools in the industry. When technologies are supplanted in practice, the authors use the latest products. Good examples of this can be found in the Analysts in Action cases which are found in all three editions.

"You're looking at our IBM 3033 mainframe computer." (Whitten et al., 1986, p. 28)

"You're looking at our IBM 3081 mainframe computer." (Whitten et al., 1989, p. 26)

"You are looking at our IBM AS/400 computer" (Whitten et al., 1994, p. 32)

In the statements above we see a progression of technology mirrored by the authors. The IBM 3033 mainframe was released in 1981, the IBM 3081 mainframe was released in 1983, and the AS/400 minicomputer was released in 1988 (IBM, 2009). This matching to the progression of technology is pervasive throughout the editions of the textbook. As each edition is released, the authors consistently update the references to reflect the newest technology.

Similarly, the authors follow and represent the tools and techniques used in practice. Whitten et al. (1986) focuses on the techniques that were used in practice during the early 1980's, when methodologies were still emerging. Although methodologies are mentioned in the text, the authors treat them as tools for advanced analysts, and dangerous in the hands of those who are not already grounded in the classical techniques (p. 2, 20, 139). By the late 1980's, the "methodology movement" was in full swing (Avgerou and Cornford, 1993), and Whitten et al. (1989) essentially is a textbook in Structured Methods and Techniques. The authors maintain the warnings about blindly following methodologies, but Whitten et al. (1989) includes a chapter on the Structured Methodology (Chapter 5), and the book draws nearly all of its tools and techniques from this methodology. Finally, as we move into the post-methodology era of the 1990's (see literature review p. 20), Whitten et al. (1994) begins to purge its direct references to methodologies, although the book is essentially a methodology, and is developed from three methodologies that were popular at the time. This is consistent with the observations of Avgerou and Cornford (1993) who found that 
methodologies at the time were prescriptive in nature, and described tasks to be performed in a particular order. Wynekoop and Russo (1995) state that most firms practiced methodologies based on the SDLC at that time. The Whitten et al. series consistently uses the SDLC as the foundation of its methodology.

\section{Academic Opinions}

The Whitten et al. textbook series seems to consider the opinions of academics during the period in which each textbook was written, although these opinions may seem to be subordinate to the opinions of practitioners. Certain groups of academics are given very important status within the book, however.

An important trend in the Whitten et al. series is that the authors very closely monitor the development of other SAD textbooks and methodological references. In many cases, the authors will actually drive the reader to examine other SAD textbooks if they have a particularly strong element. For example, in Whitten et al. (1989), Kendall and Kendall (1988), a competing textbook, is referred to as providing an alternative look to interface design.

In particular, methodological authors such as Gane and Sarson, and Yourdon factor prominently in the development of the Whitten et al. series. The most dramatic example of this is that Yourdon (1989) is actually a referenced source in Whitten et al. (1989) (p. 131-2). One might imagine that, anticipating its release, the Whitten et al. either held off the release of their own book, or rushed to incorporate the new content into their text. The influence of Yourdon's update is mentioned in Whitten et al. (1989) (p. 201), and Whitten et al. like many other SAD authors are likely to have followed his work.

In addition to SAD authors, authors whose work was considered influential to business or technological development are also mentioned. Barry Boehm's classic "Software Engineering" (Boehm, 1979) article is mentioned in Whitten et al. (1986) (p. 690). Papers by Mike Hammer (1990), the academic who introduced Business Process Reengineering, are references in Whitten et al. (1994) (p. 138), as are Kenneth Blanchard's popular One Minute Manager (Blanchard and Johnson, 1982), and its sequel (p. 789).

The most notable absence in Whitten et al. with respect to academic opinions is the opinions of the many researchers who had begun to question methodological 
use. Lyytinen (1989), Bansler and Bødker (1993), Malhotra et al. (1980) and Winograd and Flores (1986) would have been available to the authors for at least one edition. The work of Ciborra, Edith Mumford, and Avison and Fitzgerald (1988) were also available though Fitzgerald's stronger arguments would not come until Fitzgerald (1996) and Fitzgerald (1997). Perhaps the only concession that Whitten et al. makes is to state that methodologies are only effective when analysts have an independent and solid foundation in the techniques and tools that are the basis of these methodologies (Whitten et al, 1986, p. 2; Whitten et al., 1989, p. 2, 17; Whitten et al., 1994, 23).

A very important comment that may align with academic views is made in Whitten et al. (1994):

"Admittedly, many surveys show that the vast majority of IS shops have not yet invested in a standard commercial methodology. That doesn't mean that the programmers and analysts do not use the popular techniques such as structured analysis or information engineering (and some of them mistakenly call those techniques their 'methodology')." (Whitten et al., 1994, pp. 159-60)

This statement parallels one by Lang and Fitzgerald, (2006) which states that many businesses used methodologies in name only, and essentially leveraged techniques from the methodology. Whitten et al. (1994), through the statement above, indicate at the very least that they are aware that there is research which refutes the use of methodologies. Though Whitten et al. never dismisses the use of methodologies, they do agree with academics that the principle reasons for systems failure are a preoccupation with technology and a failure to recognize the importance of business issues and user needs. (Whitten et al., 1986, p. 104; Whitten et al., 1989, p.5).

\section{Summary of Changes with Respect of the IS Curriculum Guidelines, and Academic and Practitioner Views}

Though Whitten et al. (1986) is a strong representative of the 1982 ACM Curriculum Guidelines, the series improves with respect to these requirements in the subsequent two editions. Whitten et al. (1994) is an excellent representative of the 1995 ACM guidelines, even though the book precedes them by a year. This is not particularly surprising, however, as the ACM guidelines and Whitten et al. would be driven by similar issues in academia and practice. Whitten et al. very closely mirrors 
changes in practice, remaining consistently up-to-date with regard to tools, techniques, and technologies used in the industry. The authors do seem to follow the impressions of academics, particularly other SAD textbook authors, but they do not actively challenge the use of methodologies. Whitten et al. do seem to concede however, that a preoccupation with technology and tools often leads to systems failure, an issue raised by academics at that time.

\section{Question 3 - Justification and Presentation of Content Choices}

From Question 1 and 2, we see that the authors of the Whitten et al. series have demonstrated a great deal of alignment with the opinions of practitioners, academics, and with the IS Curriculum guidelines. It is also important to understand, if possible, the authors' justifications for this alignment, and how they present these justifications to the user. The authors' justifications provide evidence of the longterm consistency of their views, since their attitudes are likely to persist between editions.

The two most pervasive themes in the Whitten et al. series are that successful $S A D$ development hinges on serving the user, and that the path to success as an analyst lies in leveraging a large toolkit of concepts and techniques based on central principles and concepts. Though there are many views expressed by the authors over these three editions, these two particular views are the principle foundations which support their justifications for the content they have used in the book. Combined, these are the major themes of the series, and they provide the support the authors believe will promote their views of SAD.

\section{Justification One: The System is for the User}

Although the terms used by Whitten et al. to refer to the user change over editions, they consistently convey the message that the analyst's job is to design and build systems which solve user problems. Statements such as: "The system is for the user!" (1986, p. 673), "The analyst must recognize that the end-user is an integral part of the system" (1989, p. 62), and "Systems analysis is driven by system users' concerns" (1994, p. 253) are repeatedly made. Additionally, when the authors discuss their SDLC in detail, the first principle which supports it is that "The System is for the End-User" (Whitten et al., 1989, p. 81). 
The content of the book is often linked to the importance of user involvement. Users and communication activities are tied to most of the steps in the authors' SDLC methodology. The redesigned methodology of Whitten et al. (1994) uses people as one of its principal building blocks (p. 40) and many steps and diagrams use this building block as one of their key attributes. The authors also consider communication and interpersonal skills to be of key importance, and provide a module on these skills (Module $C$ in Whitten et al., 1986 and 1989, and Module D in Whitten et al., 1994). In the pre-chapter narratives (which the authors call minicases), system failure is often attributed to a failure to coordinate with users (for example, Whitten et al., 1994, p. 474 or Whitten et al., 1989, p. 397-8).

Other than direct statements by the authors, the two most common devices used to express the importance of user interaction are the pre-chapter mini-cases and the between chapter Analysts in Action narratives. Both devices can be found in all three editions, and they are fairly consistent in content and tone throughout all three editions.

The minicases and Analysts in Action episodes are used as contrasting forms of reinforcement. The minicase narratives appear at the beginning of nearly every chapter, while the Analyst in Action episodes occur every two or three chapters. The minicases are rarely more than a page to a page-and-a-half in length, while the Analyst in Action episodes are generally several pages long.

Particularly in Whitten et al. (1986) and Whitten et al. (1989), the minicases are overwhelmingly negative in tone, with the narrative usually ending as one of the actors admits to having made some error which led to problems or even project failure. The most common cause cited for failure is poor requirements definition due to communication issues with the user. The discussion questions which follow point out the error, and ask the reader to consider what lesson would need to be learned to improve future performance. In contrast, the Analysts in Action episodes have a positive tone, and represent a best practices version of the same material. Both the positive cases and the Analysts-in-Action cases reinforce the importance of user interaction, and often attribute the positive results of the narrative to proper consideration of user issues.

Sensing perhaps that starting the chapter with a negatively-toned narrative could dampen the students' enthusiasm for the content, the narratives are 
considerably less negative in Whitten et al. (1994). Seventy percent of the minicases in Whitten et al. (1986) and Whitten et al. (1989) are negative in tone. Only $50 \%$ of the minicases in Whitten et al. (1994) are negative in tone, and many more of the cases either have some positive elements in the case or the issues in the case cannot be directly attributed to fault by the analyst.

The importance of user interaction is echoed in the IS Curriculum guidelines, and demonstrates how aligned the Whitten et al. series is to these guidelines. One of the reasons Whitten et al. stress the need for user interaction in SAD is that information systems directly impact and can improve business productivity (Whitten et al., 1986, p. 41-2). This statement is echoed by the 1982 IS Curriculum Guidelines (Nunamaker et al., 1982, p. 783). People are a central element of effective information systems in Nunamaker et al. (1982, p. 785). Nunamaker et al. (1982) also states that the entry level system analyst works primarily with users to define information requirements (p. 784-5). Couger et al. (1995), the follow up IS'95 Curriculum guidelines, echoes a similar importance for user involvement ( $p$. 345) and considers communication and interpersonal skills to be representative characteristics of IS graduates (p. 346).

The authors do not link directly academic opinions to their justifications, but academics at that time stressed the importance of user interaction. Cheney (1988) and Cheney et al. (1990) list communication and interpersonal skills as essential for IS professionals. Whitten et al. also warn that analysts sometimes become too consumed with the pursuit of technology (Whitten et al. 1986, p. 7; 1989, p. 5), a criticism echoed by Ashenhurst (1972). In general however, Whitten et al. indicates that practitioners consider the user first. Nelson (1991) agrees with this sentiment, and thus provides both academic and practitioner justification links to Whitten et al.

\section{Justification Two: Successful SAD Involves Leveraging Tools and Techniques}

Although Whitten et al. consistently reinforce the message that the analyst serves the user, the actual foundation of the analyst's function lies in leveraging tools and techniques, based on a core set of principles and concepts.

"From this book, you have received a solid foundation in two skill sets that were introduced in Chapter 1 :

- Concepts and principles of systems analysis and design. 
- Tools and techniques of systems analysis and design." (Whitten et al., 1986, p. 692)

Essentially, the Whitten et al. series provides a set of concepts and principles for SAD in Part One of the book, and then follows with subsequent tool and technique parts for analysis (Part Two), design (Part Three), implementation (Part Four in Whitten et al., 1994), and cross-cycle activities (Modules). The series is very tool and technique heavy since only one part of the book is dedicated to the concepts and principles, but the authors do provide reinforcement of the concepts and principles guiding tool and technique use in later chapters. In the first section of each chapter in Parts Two, Three, and Four, the authors usually link the tool or technique to the governing principles and concepts.

Whitten et al. (1989) differs somewhat from the other two books in this regard. The authors state that Whitten et al. (1989) is meant to be used as a reference book in addition to a teaching book (Preface xxiv), and therefore, it would seem that tool and technique details fill a larger portion of each of the analysis, and design chapters. Particularly in the later chapters, the concepts and principles of Part One of the book are rarely mentioned, and the focus is on the details of executing the techniques themselves. Whitten et al. (1994) seems to bring the book back to its originally stated goals, and provides even stronger conceptual links to tools and techniques than its predecessors in the later chapters. Whitten et al. (1994) revises both the teaching methodology, and the SDLC methodology of the previous books, borrowing heavily from Zachman (1987)'s IS Framework (p. 79) and melding it with the previous pyramid model. They are very happy with the results, as can be demonstrated by how frequently it is referred to in the text. In Whitten et al. (1986) and Whitten et al. (1989) the pyramid model is referred to consistently in Part One of the book, occasionally in Part Two, and rarely in Part Three. Whitten et al. (1994) not only uses the IS pyramid as a central conceptual point in all three parts of the book, they pedagogically use colour to link the sides of their pyramid (each side of the pyramid is a different colour and a different aspect of systems development) to each of the techniques and tools appearing later in the text. For example, the DATA portion of the IS pyramid is yellow. All models that reference data elements of the system, such as ER Diagrams and data stores in data flow diagrams are coloured 
yellow. Similarly, the PEOPLE side of the pyramid is coloured purple. Any symbols representing people in any diagrams are similarly coloured purple.

The conceptual foundations for tools and techniques advocated by Whitten et al. are supported by academics. Boehm (1981) and DeMarco and Lister (1987) point out that methodologies are less important than the skills and ingenuity of developers. Stolterman (1992) and Fitzgerald (1996) both believe that a shared understanding of various tools and techniques forms a common 'language' for analysts.

Most practitioners at the time wanted their entry-level analysts to have a strong understanding of many tools and techniques (Sullivan-Trainor, 1988; Cheney, 1988). Though practitioners do not display the same emphasis for supporting concepts and principles that Whitten et al. and other academics demonstrate, the Whitten et al. series does provide this foundation in tools and techniques that supports the desires of practitioners. Trauth et al. (1993) indicate that practitioners and educators believe that a mix of human, technical, and business skills are necessary for an IS education. The Whitten et al. series does provide some business skill tools (primarily related to planning and project management), and places a strong emphasis on communication and technical skills. Misic and Graf (2004) later indicate that problem-solving and analytical skills are essential. Beginning with Whitten et al. (1994), the series takes a strong problem-solving focus. Whitten et al. are likely to be following trends that are emerging in business, which Misic and Graf (2004) will later document.

\section{Summary of Justification and Presentation of Content Choices}

Whitten et al. provide two primary justifications for their content choices. The first justification is that the system is for the user. They demonstrate this justification through consistent messages to the reader about user importance, through discussions about how system development concepts and tools impact the user, and through the use of mini-cases and narratives which often link system success or failure to user issues. The second justification that Whitten et al. provide for their content choices is that successful SAD involves leveraging tools and techniques. Tools and techniques form the bulk of the content in each book, and the authors often note that mastery of the basic tools and skills will promote system success. 
Academics and practitioners both support a strong knowledge of basic tools and techniques.

\section{Question 4 - Methodological Justifications}

The Whitten et al. series must be approached carefully when addressing the question about methodologies. We begin by considering the explicit statements the authors make about methodologies, but we must also consider two other subtle elements of the book to correctly understand the authors' position on methodological content. First, even if the authors present a particular opinion about methodologies, whether or not the authors actually use specific methodologies in their books must be considered. Second, we must also consider whether the techniques they use to educate the reader are methodological in nature. By considering these three opinions, we can determine whether the authors of Whitten et al. support methodologies and what justifications they present for this support.

\section{Direct Statements about Methodologies}

Whitten et al. makes an interesting transition between the books with respect to the authors' opinions on methodologies. Overall, they demonstrate a guarded support of methodologies, but we can see subtle changes in the statements they make as the books progress. In Whitten et al. (1986), the authors support methodologies in general but maintain that they are for experienced analysts only. Whitten et al. (1989) allows for the use of methodologies by less experienced analysts. Whitten et al. (1994) removes the question of experience entirely, and focuses on whether a methodology is used properly when it is employed.

There are numerous statements in Whitten et al. (1986) which provide a good impression of the authors' attitudes toward methodologies. The best summarizing statement of their attitudes is "Methodologies are specific strategies for applying specific tools and techniques in a disciplined manner to successfully develop systems." (p. 20). They promote methodological use for experienced analysts only, since they feel that it is important to learn and master the basic techniques and tools before embracing a particular strategy for their use (p. 20-21). They caution the reader that only by understanding how to leverage particular tools and techniques in specific situations can they avoid the "pitfall of blind devotion to any one 
methodology" (p. 21). At this point, the authors make a distinction between the SDLC and methodologies (p. 123). To them, the SDLC is a general pattern of design (p. 113-5), while a methodology is a specific set of steps that must be followed during one of more phases of the SDLC (p. 161). The authors favour adherence to the SDLC rather than to a particular methodology, though they note that there are many variants of the SDLC (p. 139) and they essentially group SDLCs and methodologies together.

Though present in Whitten et al. (1986), methodologies are certainly not the focus of the book. As the authors state, much more attention is paid to the tools and techniques that support these methodologies. Methodologies are mentioned in a section in Chapter 5 . In this section, the authors describe different types of methodologies, classifying them primarily by phase of the SDLC that each methodology focuses on (p. 161-3). They follow this with a cautionary passage about the problems with methodologies. In this passage they warn that methodologies are "the snake oil of the data processing business" (p. 163), and that methodologies are constantly being released, each claiming to be superior to its predecessors. The authors do not dismiss methodologies, but maintain that methodologies should only be considered after the analyst has a foundation in the tools and techniques that support these methodologies.

Two of the most important statements about methodologies made in Whitten et al. (1986) come at the end of this discussion about the problems with methodologies:

"We hope that you will then adapt these methodologies to the situations you encounter." (p. 165)

"Systems development is more satisfying and successful when you understand what you're doing and why." (p. 165)

The first statement strongly contrasts the rigidity that is assumed for methodological use, and echoes the complaint by Ahituv et al. (1984) that SDLCs and methodologies must be adapted to be used effectively. The statement is also somewhat inconsistent with other statements made by the authors that stipulate a need for discipline in the use of tools (for example, p. 20, 84, or 391). This inconsistency pervades the IS profession itself, however, as we hear calls for the 
both the rigidity of "software engineering" (as discussed by Fitzgerald, 1997) and the need to be flexible and to deal with systems on a case-by-case basis in many academic and practical articles. The second of the statements above is probably the best reflection of what the authors hope their readers gain: a fundamental understanding of the tools and techniques that Whitten et al. presents, such that they can make these choices when faced with them. This view is very consistent with the opinions of academics who do not support methodologies (such as Fitzgerald, 1997), though Whitten et al. present a much softer stance.

Whitten et al. (1989) is more inclusive of the structured methodology than its predecessor, and reflects the "methodology movement" that pervaded industry during the late 1980's and early 1990's (Avgerou and Conford, 1993). It would seem that although the authors maintain a balanced view of methodologies, the impact of the structured methodology on practice led the authors to be more inclusive of them. They state that structured methodologies are the most accepted and popular in industry (p. 110), and although the authors still focus on tools and techniques, and have an even stronger warning section on methodological use, the book actually contains even more content drawn from the structured methodologies than Whitten et al. (1986). The section in Whitten et al. (1986) about methodologies becomes an entire chapter (Chapter 5) in Whitten et al. (1989). The use of non-structured tools is minimized, and data-modeling methods based on Yourdon (1989)'s update to the structured methodology are integrated into the book. Although the actual methodological steps of the structured methodologies are not mentioned explicitly or followed in Whitten et al. (1989), the book is essentially a textbook in the tools and techniques of the structured methods.

The stated attitude of the authors towards methodologies remains the same in the Whitten et al. (1989), however, and the authors continue to present messages that warn of methodological devotion and the importance of balance. The chapter on methodologies begins with a parable that teaches the lesson that blind devotion to any path of action usually leads to failure (p. 108-110). Messages that shift the focus away from methodologies and towards tools and techniques are consistent in the second edition. One important distinction is made in Whitten et al. (1989), however, that must be explored, because it represents a divergence between the views of Whitten et al. and other academics. 
Although Whitten et al. warn about devotion to methodologies, they consistently drive readers toward following the SDLC. In a section entitled "Long Live the Life Cycle!" (Whitten et al., 1989, p. 111-2), the authors defend the use of the SDLC over methodologies. To them, the SDLC is a project management tool which organizes system development into general phases that, to their thinking, are universal in nature. Their SDLC is, however, essentially the waterfall method popularized by the structured methodology. Many of the critics of the structured methods, such as Bansler and Bødker (1993), McCracken and Jackson (1982), Alter (2002), and Ahituv et al. (1984) do not distinguish between the SDLC and the structured methodologies. Understanding this distinction made between the SDLC and the structured methodologies by Whitten et al. allows one to reconcile this very apparent incongruity in their beliefs.

In Whitten et al. (1989), methodologies are seen to be inferior to the SDLC for three reasons. The first reason is that no methodology covers every SDLC phase. The common phase that most methodologies are missing, however, is the systems support phase, which is not present in the SDLC of Whitten et al. (1986), but is a part of Whitten et al. (1989) SDLC. The second reason that methodologies are inferior is that most methodologies do not recognize the make-versus-buy decision, a criticism made by not only Whitten et al. (1989) but also by other academics (such as Fitzgerald, 1996). Finally, the last reason that the authors state that methodologies are inferior to the SDLC is that even if a methodology did address every phase of the SDLC, this would essentially be reinventing the wheel (p. 112), since the SDLC already addresses everything needed to develop a system.

Whitten et al. (1994) marks a new direction for the authors with respect to the methodology argument, largely by avoiding it. Sensing perhaps that lines were being drawn about whether or not methodologies are successful, the authors attempt to minimize the use of the term by redefining it. Whitten et al. (1994) states that, to be considered a methodology a design pattern must cover all phases of the SDLC (p. 143). To support the arguments the authors have made against methodological dominance, the authors now move to discredit the term methodology itself, since most methodologies at the time omitted system support and therefore cannot be truly considered methodologies in Whitten et al.'s opinion. They instead refer to incomplete methodologies, such as the structured methodology, as "techniques". To 
accomplish this transformation, the authors largely replace the term "methodology" with "technique" in Whitten et al. (1994), and also continue to reiterate the same arguments as Whitten et al. (1989) while using the new terminology. They now state that analysts should not blindly follow any one "technique" (p. 155). There are instances, however, where the authors continue to refer to the structured or other techniques as a methodology (such as p. 150-1). According to the authors, the terms "technique" and "methodology" are often used interchangeably in practice ( $p$. 143).

While moving away from using the term "methodology" to refer to the more general types of design patterns, the authors do introduce the term "commercial methodology" to refer to design patterns that are marketed by vendors. Of these, the authors only recognize a few (such as STRADIS) as completely adhering to their definition of a methodology. These new definitions give the authors leverage to make several important statements that they use to align themselves with critics of the methodological camp.

At the end of Chapter 4 of Whitten et al. (1994) (p. 160-1), the authors verbalize their position with regard to techniques, commercial methodologies, and the SDLC. They remain proponents of no single methodology, but advocate a blending of many "techniques" including the structured techniques, prototyping, and JAD. They admit that commercial methodologies have not found strong adoption in industry shops, but indicate that support is growing, largely due to the influence of CASE tools, which promote and assist in the use of these methodologies. They also note that although methodologies can quickly become "shelfware" (p. 160) if they are not properly managed, consultants and coordinators can provide the training required to properly execute a methodology. Ultimately, the authors feel that the SDLC can provide the guidance necessary for successful development.

\section{Methodologies Used in Whitten et al.}

The SDLC is the fundamental system development technique used in the Whitten et al. series. It is perceived by them to transcend methodologies though it is not until Whitten et al. (1994) that their SDLC begins to substantially deviate from the waterfall method that characterizes the structured methodology. The authors also often discuss and evaluate the SDLC and methodologies in a similar manner. For 
example, in Whitten et al. (1986) the authors provide a guide to evaluating either an SDLC or a methodology on the basis of seven systems development principles ( $p$. 165). Consistently throughout the series, methodologies are considered by the authors to generally be more detailed and more controlled versions of the SDLC, with more granular instructions for systems development.

The authors justify use of the SDLC because it presents a disciplined method for treating a system development process as a problem-solving process (Whitten et al., 1986, p. 142). The act of formulating a problem, researching the relevant issues, determining alternative solutions, and then implementing the chosen solution is mirrored in the SDLC process. Whitten et al. (1986) and Whitten et al. (1989) both state that most experts agree that there is a life cycle for systems, but that there is a great deal of argument about what it looks like (Whitten et al., 1986, p. 139; Whitten et al., 1989, p. 81). The books also suggest that most firms have an SDLC, but the minicase for the SDLC chapter (which is the same in both books) implies that the SDLC may not actually be implemented properly, or in a disciplined fashion.

Though Whitten et al. are consistent promoters of the concept of an SDLC, their SDLC is hardly static in nature. In Whitten et al. (1986), the SDLC is referred to as "an SDLC" (p. 113) and the authors are careful to say that many variations on the SDLC exist. Their original SDLC is an eight-phase waterfall-style SDLC that covers four development stages: planning, analysis, design, and implementation. In Whitten et al. (1989) an additional phase is added for the system support stage. Improvements to the waterfall-style nature of the model are also made by liberally using prototyping through development. Whitten et al. (1994) dispenses with the waterfall nature of the SDLC, and although it is still a five phase model (planning through support), many potential transition and return points between phases are introduced to the model (p. 100). These updates lead the authors to refer to the 1994 SDLC version as a "modern SDLC" (p. 98).

When considering the use of methodologies in the Whitten et al. series, Whitten et al. promote caution and experience when dealing with them (Whitten et al. 1986, p. 20-21). This opinion is essentially the same through all three books, though Whitten et al. (1986) and Whitten et al. (1989) actually use most of the tools of the Structured Methodologies, and use them in a manner consistent with the Structured Methodologies of the time. Whitten et al. (1986) and to a lesser extent 
Whitten et al. (1989) also use a number of "classical tools" that existed before the Structured Methodologies were developed. According to the authors however, Whitten et al. is not driven by methodological content, however, but rather by the tools themselves (Whitten et al., 1986, p. 20). Tools are chosen because they represent "best current practice" (Whitten et al., 1994, p. 283), because they are "popular" (Whitten et al., 1989, p. 225), "most common" (Whitten et al., 1986, p. 415), or "have been suggested by fellow experts in the systems analysis and design field" (Whitten et al., 1989, p. 627). None of the tools are chosen explicitly for their linkages to particular methodologies.

Use of the structured methodology tools in Whitten et al. (1986) and Whitten et al. (1989) are focused on the analysis part of the book (Part Two). The design part of the book (Part Three) includes a larger percentage of the classic tools, though fewer of these are found in Whitten et al. (1989) than in Whitten et al. (1986), demonstrating their decline. The classic tools are mostly removed from Whitten et al. (1994), though two classical tools, the printer layout chart and the screen layout chart, are used in all three books.

Though Whitten et al. (1986) and Whitten et al. (1989) are implicitly linked to the structured methodologies, the SDLC of Whitten et al. (1994) is explicitly linked to Zachman's Framework for Information Systems Architecture (Zachman, 1987), Information Engineering, and a commercial methodology called STRADIS. Information Engineering (IE) is essentially the second generation of the structured methodologies (Whitten et al., 1994, Preface viii), and it forms the basis for most of the tool and technique choices in Whitten et al. (1994). The analysis and design chapters are updated to reflect the IE updates to the structured tools and techniques. The Zachman framework is modified by the authors in order to revitalize the Information Pyramid that has been the conceptual base for all of the previous books (Whitten et al., 1994, Preface viii). STRADIS is a commercial methodology that was developed based on the structured methodology, and was marketed by McDonnell Douglas Professional Services (Whitten et al., 1994, p 572-3). Its implementation modeling process is employed in Chapter 14 of Whitten et al. (1994).

In addition to using some existing methodologies, Whitten et al. (1994) actually contains an invented methodology called FAST, which is described and employed by the actors in the Analysts in Action case episodes. The authors use it 
as a device to support methodologies when used in the correct manner. Whitten et al. stress in the Analyst in Action narratives that methodologies must be supported with dedicated staff that can answer questions and provide training (p. 34). The authors also reinforce the diligence and discipline messages they believe can allow methodologies to be used effectively. The use of the FAST methodology provides a strong indication that the authors believe that methodologies can succeed, if they are followed rigorously.

\section{Pedagogical Methodology}

Perhaps the greatest indication that Whitten et al. support methodologies is the methodological nature in which they teach the tools and techniques of their book. Particularly in the design chapters of each edition of the book, the process of using a particular technique is laid out in great detail, with specific sequences to follow. For example, in a section entitled "How to Design and Document Master and Transaction Files" (Whitten et al., 1986, p. 452-467) the authors give precise and detailed step-by-step instructions for performing this particular design task. In Whitten et al. (1989) and Whitten et al. (1994), this same section includes specific subheadings, such as "Step 1: Identify Files to Be Designed" (Whitten et al., 1989, p. 449) and "Step 2: Update the Record to Reflect Physical Requirements" (Whitten et al., 1994, p. 600). To reinforce the steps provided to use certain techniques in the series, Whitten et al. (1989) and Whitten et al. (1994) include CASE manuals which are directly linked to the content in the text. CASE tools strongly support the use of particular methodologies, and in this case, the CASE manuals facilitate Whitten et al.'s pedagogical methodology.

In fairness, it is likely that any text that demonstrates the usage of a technique or tool would require detailed instructions for how to perform the technique, or the reader would find it difficult to use or understand. The authors also attempt to provide a conceptual basis that grounds the technique, though this is principally done in the analysis chapters rather than the design chapters. Only Whitten et al. (1994) attempts to strongly link the model used to teach the conceptual elements of the text (their Information Pyramid) with the design elements of SAD. 


\section{Summary of Methodological Justifications}

We must consider three issues with regard to the justifications for methodological content in the Whitten et al. series. First, do the authors make explicit statements about methodologies? Second, what methodologies are included in the content of each book? Third, are the techniques the authors use to teach the reader methodological in nature?

In Whitten we see guarded support for methodologies, but only for experienced analysts. This restriction is lifted for Whitten et al. (1989), but methodologies are actively minimized in Whitten et al. (1994). Whitten et al. (1986) contains some information about methodologies, but focuses primarily on basic tools and techniques. Whitten et al. (1989) includes an entire chapter on the structured methodologies, while Whitten et al. (1994) is essentially the combination of the Zachman's (1987) IS Framework, Information Engineering, and a commercial methodology called STRADIS. Perhaps the two greatest signs of support for methodologies are the strong support demonstrated in all editions for the SDLC, and the distinctly methodological way in which content is taught in the series.

\section{Question 5 - Content Justifications and Misic and Russo (2000)}

Misic and Russo (2000) present several reasons they believe that the authors of systems analysis and design textbooks deviate from the opinions of academics, practitioners, and the IS curriculum guidelines. In fact, the Whitten et al. series is actually very well aligned with practitioner opinions and the IS curriculum guidelines, and is reasonably well aligned with academic view. It is still useful, however, to determine if these justifications presented by Misic and Russo (2000) are represented in the Whitten et al. series, or if the authors have other motivations for their content choices.

Misic and Russo present three justifications that they believe promote the content choices found in SAD textbooks. The first justification is that textbooks support the process of learning how to perform SAD activities rather than the realities of actually performing them. Often, the process of learning how to perform a technique requires practice and attention to detail that would not be necessary once the student has learned the content and can perform it naturally (Misic and Russo, 
2000, p. 71). Therefore, even though practicing analysts would not rate a particular activity as time-consuming or that it takes up a great deal of the SAD process, learning how to do the activity could be a lengthy process requiring a great deal of content coverage.

The second justification is related to the first. Even if a particular element of the SAD process may not be particularly time intensive, it may nevertheless be extremely important. For example, model building may not be a significant part of the development process with regard to time, but poor models may lead to a poor finished product (Misic and Russo, 2000, p. 71). Therefore, SAD textbook authors may concentrate on tasks that are critical to system development, even though they may not be a considerable part of the time required to complete systems.

Finally, the authors of SAD textbooks may perceive that some activities simply can be taught better by doing. Therefore, rather than expending considerable time exploring these subjects in their books, they promote the use of other teaching devices such as projects, or visits to development shops to learn these activities (Misic and Russo, 2000, p. 71). The authors of textbooks then choose to focus on topics which are better covered in the textbook format.

We will compare each of the justifications presented by Misic and Russo (2000) to the justifications for content inclusion that can be found in the Whitten et al. series. In addition, a section was added that addresses a serious issue that was uncovered while comparing the content percentages listed by Misic and Russo (2000) for Whitten et al. (1994) (the first Whitten et al. edition included in the series) to what we believe are the actual representative content percentages.

\section{Justification 1 - Learning versus Doing}

The Whitten et al. series supports the justification that learning a particular process may require more time and energy than performing it. As a textbook which focuses on practical, rather than theoretical elements, each edition includes extensive instructions on how to perform the techniques found in the text. This is particularly true of Whitten et al. (1989), which the authors also view as a reference book (Preface xxiv). Whitten et al. (1989) includes a fifteen-page section in Chapter 7 that only describes the conventions and guidelines for physical Data Flow Diagrams (p. 182-197). The actual process for using them is detailed step-by-step in 
an additional eleven page section (p. 197-208). Then an entirely different chapter (Chapter 9) describes how to develop logical data flow diagrams (p. 275-323).

In all of the textbook editions, Whitten et al.'s instructions for using tools or techniques tend to be very granular. If a tool is considered important, an entire chapter is usually dedicated to it. In Whitten et al. (1986) and Whitten et al. (1989) the chapter title usually included the name of the tool. Examples include "Defining Data and Information Requirements in a Data Dictionary" (Whitten et al., 1986, p. 284) and "Data Modeling with Logical Entity Relationship Diagrams" (Whitten et al., 1989 , p. 223). Whitten et al. (1994) abbreviates the generally long chapter title names of the previous editions, but includes the same detail when reviewing tools and techniques.

Statements by the authors also demonstrate the importance the authors place on learning the details of particular techniques. The authors feel that the only way for employees or students to learn something is if it has been adequately demonstrated (Whitten et al., 1986, Preface xxi). They praise their own book for how many topics it covers in detail (Whitten et al., 1989, Preface $x x v$ ) and complain that other books lack sufficient examples for students to be able to later apply the techniques that are demonstrated (Whitten et al., 1989, Preface xxiv). So much content and detail is woven into the text that the authors have to admit that the entire book cannot be covered in one course (Whitten et al., 1989, Preface xxviii).

\section{Justification 2 - Subject Importance and Textbook Coverage}

Misic and Russo (2000) propose that one of the reasons that some SAD content receives more coverage is because of its importance to the overall system development process. Whitten et al., however, go to great lengths, and use considerable numbers of pages to cover every step, stage, and task associated with system development. The authors pride themselves on the comprehensiveness of their series (Whitten et al., 1994, p. 23), and complain that other authors do not offer the same levels of topic coverage (Whitten et al., 1986, Preface xxi). Whitten et al, (1989) is considered by the authors to be more than just a teaching textbook, it is also a reference manual (Preface xxiv), that provides value to the reader after their course may be complete. 
The authors also make few statements which indicate that any of the steps that they outline are more significant that others. They occasionally make statements that may emphasize certain tasks during analysis or design (for example terminal dialogue design in Whitten et al., 1986, p. 380), or certain skills that must be developed (for example communication skills), but overall the content directed to each technique or tool seems to be governed more by its stage in the SDLC, than by its implied importance. Each task for each stage in the SDLC is generally given one chapter, unless there are multiple important tools and techniques used in the stage, in which case each technique may be given a chapter.

Perhaps the only tool or technique whose coverage can be explained by justification two is not considered a tool or technique by Whitten et al. The SDLC is the fundamental driving concept of their series, and receives extensive coverage, and strong praise from the authors. It features prominently in all editions of the text, and is linked to most chapters in each edition. The authors make numerous strong statements about the importance of the SDLC.

"The systems development life cycle is the basis for all of the tools and techniques you will learn about in the remainder of this book" (Whitten et al., 1986, p. 133)

"A systems development life cycle (hereafter called an SDLC) is a disciplined approach to developing information systems. Although such an approach will not guarantee success, it will improve the chances of success." (Whitten et al., 1989, p. 80)

"This chapter introduces a systems development life cycle (SDLC) as the framework for information systems development." (Whitten et al., 1994, p. 90)

"Has the life cycle become obsolete? NO! The life cycle is not dead!" (Whitten et al., 1994, p. 142)

Misic and Russo (2000), like many other academics, do classify the SDLC as a system development methodology, and therefore, Whitten et al. (1994) could be considered to agree with the justification that extensive topic coverage is due to the implied importance of the tool or technique to systems development. This is based on Whitten et al.'s consistent and strong dedication, both in message and in pages, to the SDLC. 


\section{Justification 3 - Appropriateness to the Textbook Medium}

Misic and Russo (2000) state that some topics are simply not appropriately demonstrated through a textbook medium, and require other activities, or experience to learn. To a certain degree, Whitten et al. agree with this sentiment. Although Whitten et al. go to considerable lengths to describe the topics they feel are important, Whitten et al. maintain throughout the series that true skill is developed through experience. The authors believe they provide a foundation for skill growth, but it is only through experience that an analyst's skills will develop (Whitten et al., 1986, p. 21). Only after an analyst has applied their skills to an actual project can they become a "good" analyst; textbook learning is simply not enough (Whitten et al., 1986, p. 21). Some important characteristics and traits of good analysts, such as patience, can only be gained through experience, and therefore some schools require students to do live projects in addition to textbook learning (Whitten et al., 1989, p. 17). The authors also specifically mention that some activities, such as systems planning, are only performed by experienced analysts (Whitten et al., 1994, p. 11).

The most consistent view with regard to experience and content coverage is the use of methodologies in Whitten et al. In the authors' opinion, methodologies are only meant to be tackled by analysts who have a strong foundation in the basic tools and techniques that support them (Whitten et al., 1986, p.20-21). Therefore the authors prefer to give the students an introduction to methodologies so that they understand their place, but they do not cover any methodology in detail.

Whitten et al. do not demonstrate, however, that there are specific general topics that cannot be covered in their series. Their books are very comprehensive, and although they stress the need for ongoing training for analysts, they support the use of their books as a solid beginning textbook for skills development, and as a good manual for extending that training (Whitten et al., 1994, p. 23). Whitten et al. do provide, however, a number of supplements that include case books that attempt to extend the learning experience, recognizing that active use of the tools and techniques taught in the book leads to better comprehension. 
Content Coverage Issues in Misic and Russo (2000) With Respect to Whitten et al. (1994)

Whitten et al. (1994) is the first edition of the Whitten et al. series to be examined in the Misic and Russo (2000) study. One of the content analysis categorizations made in Misic and Russo (2000) is with respect to particular tools, techniques, and methodologies used in the books they reviewed (Table 3, p. 70). There appear to be some rather glaring errors for the entries made for Whitten et al. (1994) that call into question the accuracy with which Misic and Russo (2000) conducted their study. Table 8 shows a list of the tools, techniques, and methodologies reviewed by Misic and Russo (2000) and the content percentages for Whitten et al. (1994).

\begin{tabular}{|l|l|}
\hline Tool, Technique, Methodology & $\%$ Rating for Whitten et al. (1994) \\
\hline Business System Planning & No Coverage \\
\hline CASE Tools & $1-5 \%$ \\
\hline Data Dictionary & No Coverage \\
\hline Data Flow Diagrams & $6-10 \%$ \\
\hline Decision Tree/Table & $<1 \%$ \\
\hline Entity Relationship-Diagram & $<1 \%$ \\
\hline Information Engineering & $<1 \%$ \\
\hline Joint Application Design (JAD) & $<1 \%$ \\
\hline Nassi Schneiderman Charts & No Coverage \\
\hline Object-Oriented Analysis and Design & $<1 \%$ \\
\hline Program Flowcharts & No Coverage \\
\hline Pseudocode & No Coverage \\
\hline Prototyping & $1-5 \%$ \\
\hline Rapid Application Design & No Coverage \\
\hline State Transition Diagram & $<1 \%$ \\
\hline Structured Analysis and Design & $<1 \%$ \\
\hline Structure Charts & $<1 \%$ \\
\hline Structured English & $<1 \%$ \\
\hline System Flowcharts & $<1 \%$ \\
\hline SDLC & $6-10 \%$ \\
\hline Warnier-Orr Diagrams & $<1 \%$ \\
\hline Table 9. Content Percentages for Tools, & \\
\hline
\end{tabular}

Table 9. Content Percentages for Tools, Techniques, and Methodologies for Whitten et al. (1994) in Misic and Russo (2000) (p. 70) 
If we add the coverage for all topics (using one-half a percentage point for the $<1 \%$ category, $3 \%$ for the $1-5 \%$ category, and $8 \%$ for the $6-10 \%$ category) we could roughly estimate that less than $25 \%$ of Whitten et al. (1994) discusses tools, techniques, or methodologies. Without even attempting to calculate the actual number of pages in the book that cover these topics, fourteen of the twenty chapters in Whitten et al. (1994) deal directly or indirectly with various tools, techniques, or methodologies. The content percentages that Misic and Russo present are simply too low to be realistic for this book, particularly considering Whitten et al.'s stated focus of the series as a "practical book about information systems development methods" (p. 2).

If we consider the relationships between the tools and techniques, and the methodologies they are associated with, the percentages make even less sense. Misic and Russo (2000) state that Information Engineering and Structured Analysis and Design each occupy less than $1 \%$ of the Whitten et al. (1994)'s content. Setting aside the fact that Information Engineering is a second generation version of Structured Analysis and Design, and that Whitten et al. is basically an entire textbook on both methodologies, Misic and Russo list Data Flow Diagrams at 6-10\% for Whitten et al. (1994), and the SDLC at 6-10\%. Since Information Engineering and Structured Analysis and Design use the DFD as its principle tool for SAD, and the SDLC is a core component of each, the math simply does not make sense. Just by adding the percentages for listed structured and/or IE tools together, at least $12 \%$ of the book would be dedicated to these methodologies.

Finally, some of the numbers listed for Whitten et al. (1994) simply do not seem possible. Entity-Relationship Diagrams are listed as less than $1 \%$ of the text content of Whitten et al. (1994). Chapter 8, Data Modeling, of Whitten et al. (1994) is focused on using the ERD to do data modeling. Chapter 13, Data Analysis focuses on data normalization, once again using the ERD. This puts the ERD in at least the $1-5 \%$ category, though the $6-10 \%$ category is much more likely. Business System Planning, which is Chapter 6 in Whitten et al. (1994), is listed as no coverage by Misic and Russo (1994). Pseudocode is listed as no coverage, but a quick glance at the index shows that it is listed in two locations (p. 446, 715) in Whitten et al. (1994). The Data Dictionary is listed as no coverage, even though 
Chapter 11 of Whitten et al. (1994) focuses on how to create a Project Repository, for which the term "data dictionary" is a common synonym (Whitten et al., 1994, p. 426).

\section{Summary of Content Justifications and Misic and Russo (2000)}

When comparing the content justifications by the authors of the Whitten et al. series to the determinations of Misic and Russo (2000), we see support for two of Misic's and Russo's (2000) determinations. Whitten et al.'s textbooks contain considerable detail about the tools and techniques required to perform SAD, which supports Misic's and Russo's (2000) contention that some topics require more time to learn than to perform. So much detail is included for each topic, however, that it is difficult to support Misic's and Russo's (2000) second contention, which is that some topics are more important than others, and therefore, receive more coverage. Whitten et al. include generous support for all SAD topics in their textbooks. Whitten et al. and Misic and Russo (2000) do seem to share a similar belief that some topics can only be mastered though practice. Therefore the justifications for content inclusion proposed by Misic and Russo (2000) are somewhat supported by the perceived intentions of the authors of the Whitten et al. textbook series. Unfortunately, questions about the execution of Misic's and Russo's methodology remain.

\section{Question 6-Importance of Textbooks to the Learning Process}

The question of how Whitten et al. perceive the value of their textbook in the learming process is interesting, particularly because there is a noticeable shift in their ideas between editions. The authors recognize the text as primarily an introductory text for developing systems analysis and design skills, but the intended audience for their book changes somewhat between the three editions. This shifts the importance of the textbook somewhat, since new students are more likely to have learned most of their introductory knowledge about SAD from their original course text (Ornstein, 1989). Whitten et al. (1989) also shifts the purpose of the text to a reference text, which would also shift the importance of the text in the learning process. This purpose is noticeably muted in Whitten et al. (1994), however. Finally, throughout 
the series, the authors recognize limitations in the textbook format, which they express to the reader.

\section{Audiences Changes between Editions}

Whitten et al. (1986) seems to be primarily directed towards student readers, but where these students were coming from is not necessarily simple to answer. Whitten et al. (1986) states that it "is intended to support a practical first course in computer information systems development" (Preface xix). The authors indicate that this course is generally taught in the second or third year of most IS programs. This statement remains largely unchanged in the later editions, though Whitten et al. (1989) mentions that the course may be taught in the final year (Preface xix), while Whitten et al. (1994) indicates that the course may be found at a graduate level in business programs (Preface vii). The audience of the books seems to change, however, despite the relative consistency of where they expect the course material to be learned.

In the early 1980's many of the students in SAD courses were actually professionals who were already in the working world. This is reflected in Whitten et al. (1986) by statements directed at the reader that use the terms such as "your company" (p. 783), "your boss" (p.94), or even "your secretary" (p. 95). The authors also generally make the assumption that the reader has previous work experience as a programmer ( $p .15)$. When discussing the analyst position, the authors state that analyst positions are generally filled from employees who have previously filled programmer roles (p. 656) and often refer to the reader audience as if they were programmers. Many of the questions posed at the end of each chapter assume that the reader has access to an IS development shops (for example, p. 22, 24, 95), where the reader might even be employed (Preface xxii, p. 58). Finally, there are also statements in Whitten et al. (1986) which lead one to believe that the age of the reader is perceived by the authors to be older than what would be expected for a sophomore student who had come to college directly from high school. In more than one instance they ask the reader to refer back to tax returns ( $p .323$ ) or home loan applications (p. 614-5), documents that younger students might be unfamiliar with.

Whitten et al. (1989) seems to adjust this perception somewhat although much of the text of Whitten et al. (1986) is carried over. There are fewer references 
to the reader in a professional capacity, and the emphasis seems to be on student readers. Chapter 1 "The Information Systems Analyst" begins with a discussion of who should read the book (p. 4). The authors note that even if the student is not planning to start their career as a systems analyst, that the book provides value. References are not made to people who would be continuing their careers, however. In the introductory episode of the Analysts in Action running case, we are introduced to a new hire named Bob. Although in all editions, Bob is a college graduate, but in Whitten et al. (1986), Bob mentions that he interned as a computer programmer for two summers at a computer company (p. 25). In Whitten et al. (1989) and Whitten et al. (1994), the internship reference is removed, and more emphasis is made in the text of getting Bob started with system development.

Whitten et al. (1994) even more strongly identifies with a student audience which has not had previous employment. Expanding on the "Who Should Read This Book?" section in Chapter 1, Whitten et al. (1994) describes what the reader should expect when "preparing for a career as a computer professional" (p. 7), and lists what activities would be performed by a "Future Computer or Information Systems Specialist" (p. 7). The section found in Whitten et al. (1986) and Whitten et al. (1989) that compared programmers to systems analysts was removed in Whitten et al. (1994), since there is no expectation that the student can draw parallels to the computer position, and thus learn the changes that come from moving to an analyst position. Instead, the computer professionals (analysts or programmers alike) who produce systems are now compared to end-users who consume systems, a parallel that is more likely for an introductory reader.

\section{Whitten et al. as a Reference Text}

Though all three editions of Whitten et al. can be considered comprehensive due to their overall size and the attention that is paid to detail in each volume, the authors state that Whitten et al. (1989) has a secondary purpose as a reference text, in addition to its use as an introductory text book (Preface xxiv). The authors even include a section in Whitten et al. (1989) that addresses the considerable length of the book, and admit that even the authors cannot squeeze all the material in the book into one course (Preface xxviii). It is possible, therefore, that the positioning of 
the book as a reference text is done to mitigate the size of the book, rather than consciously repositioning the purpose of the text.

Whitten et al. (1994) however, does not maintain this goal and the passage regarding the use of the text as a post-course reference and the passage about the size of the text are both removed from the 1994 edition. Whitten et al. (1994) also streamlines many of the chapters, integrating many of the topics and focusing on the SDLC, rather than the techniques. Ironically, Whitten et al. (1994) is actually 70 pages longer than Whitten et al. (1989).

\section{Limitations of the Textbook Format}

Although the authors place considerable stock in the value of their textbook series, they do admit to limitations in the textbook format. These limitations are linked to three main themes; the ability to provide proper coverage for topics, the necessity for active practice of topics, and the need for experience and development of skills.

The topic coverage theme is directly tied to two main topics, which the authors feel are only lightly covered in the Whitten et al. series: databases and methodologies. Databases receive increasing coverage over the three editions as the authors attempt to expand the scope of the book in this regard. Methodologies, however, are given the biggest focus in Whitten et al. (1989). As discussed before, the authors seem to draw back from promoting methodological content in Whitten et al. (1994), sensing that methodologies are increasingly being criticized by academics and practitioners.

The topic of databases is introduced in Whitten et al. (1986) as a module. In the authors' own words: "Database is often considered too advanced a subject to include in an introductory systems analysis and design course" (p. 1294). Ironically, Whitten et al. (1989) moves the database content to the main body of the book, though it still notes that the reader could not possibly master database design in one chapter, and that additional education beyond the scope of the book is necessary ( $p$. 471). Whitten et al. (1994) does not reinforce the notion of the book being solely an introduction to databases, and removes many of the statements made in previous editions that drive the reader to other sources. It does note, however, that the 
"technical idiosyncrasies of specific database management systems" are left to other courses and textbooks (p. 605).

In Whitten et al. (1986), methodologies are considered an advanced subject that only students who have mastered the basic tools and techniques should consider (p. 21). Methodologies are described in the book; the focus is solely on the SDLC and the tools and techniques that form the basis of the structured methodologies. Whitten et al (1989) expands the coverage on the structured methodologies, including an entire chapter on the topic. Much of this chapter, however, talks about prototyping and CASE; two other tools that are introduced in the book. The authors are much more open about the links between the tools and the structured methodology, although they still maintain that focus should be on the basics, rather than the methodology. Whitten et al. (1994) takes a step back from a pro-methodology position, by masking the term "methodology" as "technique" and creating arguments that most methodologies are not complete enough to be truly considered a methodology (p. 143). There is a chapter which discusses system development methods and techniques, but this is essentially an overview of the structured methodologies, prototyping, and commercial methodologies (p. 140-163). In all three editions the Suggested Readings and Reference section at the end of the chapter discussing methodologies directs the reader to better sources for detailed methodological knowledge.

The admission that the textbook medium is limited is closely linked by the authors to the need to practice what you learn. This is addressed by Whitten et al. by providing a number of supplements to the text in each edition. All the editions have a matching Instructors Guide which provides activities and lesson plans to enhance student learning. All the editions also include a Project and Case book which provide concrete activities where students can practice the skills they have learned in the book. Whitten et al. (1989) and Whitten et al. (1994) also include CASE tool books which demonstrate how to use the Excelerator CASE tool to practice using the tools shown in the book.

Despite the skill development practice that Whitten et al. believe comes from the use of their supplements, they maintain that only through experience can the concepts, tools, and techniques of systems development be mastered: 
"Plainly stated, there is no substitute for good old-fashioned experience in systems analysis and design." (Whitten et al., 1986, p. 21)

"No textbook can provide that experience!" (Whitten et al., 1989, p. 17)

Interestingly, the two above statements, which appear in both Whitten et al. (1986) and Whitten et al. (1989) are removed from Whitten et al. (1994). There are, however, statements which still stress the need for continued training and skill development (p. 23). It is not clear, however, if the previous statements were removed because the authors actually believe that experience is not required for proper use of tools and techniques. It is more likely that the statements were removed because they might be perceived by the reader to show a limitation in the textbook series, and therefore prompt the reader to consider a different text.

\section{Summary of the Importance of Textbooks to the Learning Process}

The Whitten et al. textbook series is primarily directed at undergraduate students as an introductory SAD textbook. The authors demonstrate that their text is an important first step on the path to SAD mastery, though they admit that experience is the best teacher. They also promote the use of other pedagogical tools, including case books and projects, which they supply additional source texts for. Whitten et al. (1989) is also touted as a reference book, though that purpose is muted in Whitten et al. (1994). Overall, the authors views seemed aligned with those of Ornstein (1989) who suggests that textbooks are the central teaching tool for course content.

\section{Question 7 - Alignment with Practitioners, Academics, and the IS Curriculum Guidelines}

The previous six questions have demonstrated that the Whitten et al. series has attempted to align itself with the opinions of practitioners, academics, and the IS curriculum guidelines. They have also demonstrated that a blanket statement that textbook authors are misaligned from these opinions is not appropriate. To summarize the state of the Whitten et al. series, we will review the alignment with each important stakeholder position, and the reiterate the justifications that Whitten et al. provide for their content choices. 


\section{Alignment to Practitioner Opinions}

The Whitten et al. textbook series is strongly aligned with the opinions of practitioners. Whitten et al. closely follow changes in practice (Question 2), providing an industry-guided perspective. They consistently modify their books, following changes in technologies, tools, and techniques (Question 1). These changes can be dramatic or subtle, based on the extent of change in the industry. Matching the "best practice" opinions of both practitioners and academics, Whitten et al. justify the content in their books based on a need to provide students with a foundation of tools and techniques (Question 3). These tools and techniques are leveraged to provide user-focused systems development, an opinion echoed by practitioners (Question 3). Though it is difficult to discern whether or not practitioners strongly support methodological content, it is certainly clear that both practitioners and Whitten et al. share a common belief that proper system development involves disciplined use of tools and techniques (Question 4). Whitten et al. admit however, that methodological use in practice is inconsistent, due to a lack of training in methodological use. Whitten et al. believe that their book will allow students to develop the core skills and techniques necessary to begin a career in systems development, but that experience is necessary to master the techniques that are introduced in the book (Question 6), a statement echoed by practitioners.

\section{Alignment to the IS Curriculum Guidelines}

Although the only IS curriculum guidelines released during the period covered from Whitten et al. (1986) to Whitten et al. (1994) are the 1982 ACM Guidelines (Nunamaker et al., 1982), Whitten et al. demonstrates alignment with both this IS curriculum guideline, and the 1995 ACM Guidelines (Couger et al., 1995) that would follow (Question 2). Since the Whitten et al. editions are covered solely by one guideline, change would not be necessary between editions since Whitten et al. (1986) is considered to be aligned with the 1982 ACM Guidelines. That said, subsequent editions of Whitten et al. draw the book even closer to the ACM 1982 Guidelines, and Whitten et al. (1994) is actually very representative of the $1995 \mathrm{ACM}$ Guidelines (Question 2). In fact, Whitten et al. (1994) seems to better represent the state of practice and academia than Couger et al. (1995). Whitten et al. only rarely mention the ACM guidelines directly, but justify their content choices for reasons that 
mirror statements in the ACM guidelines (Question 3). The 1982 ACM Guidelines discuss the teaching of methodologies, but the 1995 ACM Guidelines are strongly supportive of methodological content. Sensing the potential for backlash from practice and the academic community, Whitten et al. do not endorse methodologies quite so strongly as Couger et al. (1995). That said, the book leverages several methodologies in its content and selection of tools and techniques, and has a distinctly methodological flavour to its teaching format, which is very much in line with the 1995 ACM Guidelines (Question 5). The 1982 and 1995 ACM Curriculum guidelines list textbooks as a primary teaching tool, but also briefly mention that some computer resources should be used to aid teaching. Whitten et al. provide supplements to enhance learning that include CASE tools, as well as teaching tools not mentioned in the ACM guidelines (Question 6).

\section{Alignment to Academic Views}

There are few statements in the Whitten et al. series which speak directly to academic opinions. That said, the authors are actually academics, and to a certain extent, the IS Curriculum guidelines act as a proxy for academic opinions at that time. Overall, the Whitten et al. series seems to be reasonably in line with academic opinions at the time, although they certainly do not adopt the stronger messages against methodological adoption voiced by some academics (Question 2). They do present a number of warning messages about methodological adoption, and certainly do not favour devotion to any one methodology. Whitten et al. updates their editions consistently to match developments in systems development theories, discussing prototyping, CASE tools, Expert Systems, Object-Oriented design and many other topics as they become available (Question 2). The authors also use numerous academic references in their book, indicating they are very aware of academic opinions at the time, particularly those authors who write about system development. The dissenting academic voice about methodologies is missing from the references, however, and Whitten et al. do not actively condemn methodologies, though they do promote tools and techniques over methodologies (Question 4). Whitten et al. are also devoted to the SDLC, which many academics consider to be a methodology itself. Whitten et al. do not share this view, stressing that it transcends methodologies or techniques. 
The beliefs that systems development should be user-focused and that tools and techniques are of greater importance than methodological content are shared by Whitten et al. and other academics, demonstrating that the justifications provided by Whitten et al. for their content align with academic opinions (Question 3). Whitten et al. aligns somewhat with the content justifications found in Misic and Russo (2000) (Question 5), focusing on content that teaches the core elements of SAD that cannot be learned through experience. Unfortunately, what seem to be errors in the execution of Misic and Russo (2000)'s methodology cast a shadow over that study's determinations.

\section{Summary}

The initial hypotheses that were formulated to prevent bias in the analysis (Hirsch, 1967) proved largely incorrect, based on the evidence provided by the analysis. Although Whitten et al. initially promote a number of techniques that they are familiar with, these techniques are largely phased out in favour of newer techniques. It is correct to state that Whitten et al do indeed focus on teaching base skills to students, but they cannot at all be said to be out of touch with SAD thought at the time. In fact, they have demonstrated quite the opposite; Whitten et al. consistently modified their content to remain current with the prevailing thoughts of the time.

Again, when examining the change of content between editions, we see little evidence to support the initial hypotheses. Whitten et al. changes considerably through three editions. The books are consistent with regard to their largest organizational structure, the "Parts", and are somewhat consistent at the paragraph level. Extensive changes can be found, however, at the organization levels in between. Additionally, considerable content is added and removed between editions, and the books undergo such drastic visual changes that Whitten et al. (1986) and Whitten et al. (1994) would be difficult to visually distinguish as being the same series. Whitten et al. (1989) also demonstrates a change in the purpose of the book, and the series narrows its audience from a wide audience including experienced practitioners to a narrower student-focused audience. It is difficult to judge if the change in publishers between Whitten et al. (1986) and Whitten et al. 
(1989) gave the authors more freedom to change content, but the hypothesis would be difficult to support given the extensive changes between Whitten et al. (1989) and Whitten et al. (1994), both of which were published by the same publisher.

I believe that the strongly differing nature between my initial hypotheses and the results of the analysis provide a strong indication that the opinions of the authors have not been masked by my own prejudices or through distanciation. In fact, due to the considerable detail in which Whitten et al. describe the techniques, technologies, and prevailing ideas of the time, combined with the considerable amount of literature that I studied in preparation for the analysis, I believe that I have a strong understanding of the context in which the books were created. This has allowed me to avoid the loss in fidelity with regard to authorial intent that is assumed to occur due to the differing nature of the contexts in which the series was written, and the context of today.

It must also be stated that the process of reviewing several editions of the same text drastically improves the ability for the reader to immerse himself or herself in the context of the authors and their books. The repetition of the reading experience improves the understanding of the authors' intentions, while the ability to note changes between editions helps to accentuate the transitions that have occurred in the context over time and thus understand the motivations for the authors to modify their content. A side-by-side comparison of editions also improves the chances that important elements of the text will catch the reader's attention. For example, I often found that important elements of a previous edition did not become clear until I compared the text to the following edition and noticed a change in the content, or simply viewed the content differently after having progressed further in the analysis. Overall, I believe that the hermeneutic process that was used to analyze Whitten et al. proved not only effective in answering the research questions of the study, but it strongly emphasized the hermeneutic tradition as a means to understand the authorial intent. 


\section{Part 5: Conclusions}

Education is central to the growth and development of any discipline. Therefore, proper adherence to the guidelines developed by practitioners and academics for educational materials is essential. If the authors of textbooks, the central pedagogical tool in IS education, are not following the guidelines set out by their peers in the IS community and the IS curriculum guidelines, this must be addressed and corrected.

The purpose of this study was to determine why authors of textbooks appear to be in conflict with the opinions of academics and practitioners, and with the IS curriculum guidelines, and to begin a dialogue to correct this apparent contradiction within IS education. Misic and Russo (2000) discovered a significant discrepancy in the content of systems analysis and design (SAD) textbooks. This study has attempted to refine some of the points made by Misic and Russo (2000), by exploring the specific reasons that authors present for this discrepancy, and by extending Misic's and Russo's (2000) study by directly addressing the opinions of these textbook authors.

Using a hermeneutical methodology based on the comparison of multiple editions of the same textbook over time, this study has presented strong but preliminary evidence that the conclusions of Misic and Russo (2000) do not properly consider the historical context within which textbook series was written. Ignoring a historical context can lead to mistaken determinations about results, since opinions of academics and practitioners at the time each textbook was released are not necessarily the same as the time when the study was completed. The results of this study must, however, be considered preliminary for two reasons.

First, only one textbook series, Whitten et al., was considered. The results of the analysis of the Whitten et al. series strongly indicate that great efforts were made on the part of the authors to align with the opinions of practitioners, academics, and the IS Curriculum guidelines. Through three editions, from 1986 to 1994, the authors have consistently updated their textbooks to present the prevailing and dominant views on systems development. Each Whitten et al. edition has been considerably and deliberately modified to reflect the most current ideas of the time, 
and the authors have also gone to great lengths to foreshadow the future of system analysis and design. The determinations of Misic and Russo simply are not reflective of the content and content justifications found in the Whitten et al. series from 1986 to 1994 . There may also be evidence that Misic and Russo did not properly categorize the content in Whitten et al. (1994).

Nevertheless, it must be said that the other two series that were originally considered for this study, Wixom and Denis, and Satzinger et al. may not have followed trends in systems development with the same diligence that Whitten et al. did. Whitten et al. is considered to be the most popular system analysis and design textbook, and one of the reasons this may be so is because the authors better followed changes in systems development. This seems unlikely, and I am guessing that the other series would have presented similar results.

The second limitation of this study is that only three of the seven editions of Whitten et al. were reviewed. It is certainly possible that later editions of the Whitten et al. series began to diverge in content from what practitioners, academics, and the IS Curriculum guidelines believed to be optimal. Whitten et al. (1994), however, indicate that future editions of the text would contain content about object-oriented design, the next systems development paradigm to emerge. This, combined with the diligence that Whitten et al. have shown in the previous three editions with respect to maintaining current with the most accepted design paradigms, makes me doubt that this would be the case. Still, I must again concede that this forces the results of this study to be considered preliminary.

Regardless of the preliminary nature of this study, a number of strong contributions have still been made. To begin, this study contributes to the argument that quantitative research is often supported, extended, or corrected by qualitative techniques. In this case, a quantitative study, the results Misic and Russo (2000) were called into question due to the preliminary results of a qualitative study. The methodology of this qualitative study demonstrated flaws in Misic's and Russo's (2000) determinations, due to a lack of proper contextual consideration.

A second contribution from this study is that it demonstrates that a historical perspective provides the essential contextual considerations that many other studies lack. The review of repeated editions of the same text provided a means to overcome distanciation and to better reflect the true views of the authors. Then, by 
demonstrating that a group of textbook authors did attempt to consistently update the content in their textbooks to match the prevailing views of practitioners, academics, and the IS Curriculum guidelines, we open the floor to reconsidering many of the determinations of other studies. A simple example of this can be made by extending the context of this study.

Many of the academic references in this study have strong negative opinions of methodological content (for example, Fitzgerald, 1996). Care has been taken in this study, however, to compare the content found in Whitten et al. to the opinions of academics that are as temporally proximate as possible to the release dates of the textbooks. In many studies, such as Misic and Russo (2000), the references that are used to support assertions by the study's author may not actually represent the prevailing views of this time. Misic and Russo (2000) support their study with textbooks taken from 1989 to 1999 . This period included numerous important changes in systems development including the rise and wane of the structured methodologies, and the development and dominance of competing paradigms such as prototyping, Rapid Application Design, and Object-Oriented Design. Had Misic and Russo (2000) considered the views of academics at each point in time that corresponded to the release date of each textbook in their study, they might have come to very different conclusions.

A final contribution of this study is that it provides a concrete and detailed research methodology that leverages hermeneutics. Most studies in the IS discipline use hermeneutics simply as a justification for an interpretive study, or they only use particular principles from the hermeneutic tradition, such as the hermeneutic circle. Few studies attempt to implement the full range of hermeneutic principles and even fewer sufficiently document their research methodology in order to allow peers to evaluate or imitate their methodology. It is hoped that the methodology of this study proves robust enough that future researchers will consider it for their studies. It is my belief that this methodology can be used for research subjects that extend beyond books or reports that are printed in editions.

A general application for this methodology would be to use it to consider the progression in views of a particular author, or the progression of views for a particular topic. For example, in this study we have looked at the progression of views for the textbook series Whitten et al. A branching study from this study could 
consider how the opinions of academics have progressed over this same period. By selecting prominent authors on the subject of methodologies, such as Fitzgerald or Ciborra, we could map their research papers over time. It is likely that the views of these authors have changed over time, influenced by other researchers, their own experiences, and the prevailing views during this period. Exploratory studies of this nature might not only support the findings of studies such as this one, but might provide surprising results about how academics came to their conclusions. 


\section{References}

AAAS (American Association for the Advancement of Science) (2007). Project 2061 Textbook Evaluations. Retrieved June 14, 2007 from http://www.project2061.org/. publications/textbook/default.htm?txtRef=http\%3A\%2F\%2Flibraries\%2Eluc\%2Eedu $\% 2$ Fresearch $\% 2$ Fhandouts $\% 2 F$ TextEval\%2Eshtml\&txtURIOld=\%2Fnewsinfo\%2Fre search $\% 2$ Ftextbook\%2Fdefault\%2Ehtm

Ahituv, N., Hadass, M., and Neumann, S. (1984). A Flexible Approach to Information System Development. MIS Quarterly, 8(2), 69-78.

Alavi, M. (1993). Making CASE an Organizational Reality: Strategies and New Capabilities Needed. Information Systems Management, 10(2), 15-20.

Alter, S. (2002). The Work System Method for Understanding Information Systems and Information System Research. Proceedings of the Eighth Americas Conference on Information Systems, 2372-2380.

Archer, C.B. (1983). What Does Business and Industry Expect from Computer Science Graduates Today? ACM SIGCSE Bulletin 15(1), 82-84.

Ashenhurst, R.L. (Ed.) (1972). Curriculum Recommendations for Graduate Professional Programs in Information Systems. Communications of the $A C M, 15(5)$, May, 365-398.

Avgerou, C. and Cornford, T. (1993). A Review of the Methodologies Movement. Journal of Information Technology, 8(4), 277-287.

Avison, D.E. and Fitzgerald, G. (1988). Information Systems Development: Current Themes and Future Directions. Information and Software Technology, 30(8), 458-66.

Avison, D.E. and Fitzgerald, G. (1991). Information Systems Practice, Education, and Research. Information Systems Journal, 1(1), 3-22.

Avison, D.E. and Fitzgerald, G. (2003). Where Now for Development Methodologies? Communications of the ACM, 46(1), 78-82.

Avison, D.E. and Fitzgerald, G. (2006). Information systems development: Methodologies, techniques and tools: $4^{\text {th }}$ Edition. London: McGraw-Hill.

Avison, D.E., Fitzgerald, G., and Powell, P. (2001). Reflections on Information Systems Practice, Education and Research: 10 Years of the Information Systems Journal. Information Systems Journal, 11(1), 3-22.

Bailey, G.D. (1988). Guidelines for Improving the Textbook/Material Selection Process, NASSP Bulletin, 72(506), 87-92. 
Bansler, J.P. and Bødker, K. (1993). A Reappraisal of Structured Analysis: Design in an Organizational Context. ACM Transactions on Information Systems, 11(2), 165193.

Barnett, T.O. and Constantine L.L. (Eds.) (1968). Modular Programming: Proceedings of a National Symposium. Cambridge, MA: Information \& Systems Press.

Bartlett, T. (2003, June 27). Selling Out: A Textbook Example. The Chronicle of Higher Education, 49(42), A8. Retrieved June 13, 2007 from http://chronicle.com /free/v49/142/42a00801.htm

Baskerville, R., Travis, J. and Truex, D. (1992). Systems Without Method: The Impact of New Technologies on Information Systems Development Projects. In K.E., Kendall, K. Lyytinen, J.I. DeGross (Eds.) The Impact of Computer Supported Technologies in Information Systems Development, Proceedings of the IFIP WG8.2 Working Conference on The Impact of Computer Supported Technologies in Information Systems Development. Minneapolis, Minnesota, USA, 14-17 June, 1992.

Benbasat, I. and Weber, R. (1996). Rethinking Diversity in Information Systems Research. Information Systems Research, 7(4), 389-399.

Benbasat, I. and Zmud, R.W. (1999). Empirical Research in Information Systems: The Practice of Relevance. MIS Quarterly, 23(1), 3-16.

Betti, E. (1980). Hermeneutics as the General Methodology of Geisteswissenshaften. In J. Bleicher Contemporary Hermeneutics: Hermeneutics as Method, Philosophy, and Critique (pp. 51-94). London and New York: Routledge \& Kegan Paul. Originally published in Die Hermeneutik als allgemeine Method der Geisteswissenschaften (Tübingen: J.C.B. Mohr, 1962).

Bierman, P. (2006, May 24-26). Reconsidering the Textbook. Presentation at The National Academy of Sciences, Washington. Retrieved on June 1, 2007, from http://serc. carleton.edu/textbook/.

Blanchard, K. and Johnson, S. (1982). The One Minute Manager. New York: Berkley Publishing Group.

Bleicher, J. (1980). Contemporary Hermeneutics: Hermeneutics as Method, Philosophy and Critique. London and Boston: Routledge \& Kegan Paul.

Boehm, B.W. (1979). Software Engineering. IEEE Transactions on Computers, 1226 $-1241$.

Boehm, B.W. (1981). Software Engineering Economics. Englewood Cliffs, New Jersey: Prentice-Hall. 
Boland, R.J. Jr. (1985). Phenomenology: A Preferred Approach to Research in Information Systems. In E. Mumford, R.A. Hirschheim, G. Fitzgerald, and T. WoodHarper (Eds.), Research Methods in Information Systems (pp. 193-201). Amsterdam: North Holland.

Boland, R.J. Jr. (1991). Information System Use as a Hermeneutic Process. In H.-E. Nissen, H.K. Klein, R.A. Hirschheim (Eds.) Information Systems Research: Contemporary Approaches and Emergent Traditions (pp. 439-464). Amsterdam: North Holland.

Burrell, G., and Morgan, G. (1979). Sociological Paradigms and Organizational Analysis, London: Heinemann.

Butler, T. and Fitzgerald, B. (1997). A Case Study of User Participation in the Information Systems Development Process. Proceedings of the Eighteenth International Conference on Information Systems, Atlanta, Georgia, United States, $411-426$.

Byme, J.A. (1990, October 29). IS Research In The Ivory Tower 'Fuzzy, Irrelevant, Pretentious'?, Business Week, 62.

Callahan, D. and Pedigo, B. (2002). Educating Experienced IT Professionals by Addressing Industry's Needs. IEEE Software, 19(5), 57-62.

Caputo, D.J., Kovacs, P. and Turchek J.C. (2006). Defining the Essential Skill and Functional Areas of Study in Information Technology as Measured by a Survey of Field Professionals. Information Systems Education Journal, 4(6). Retrieved on May 24, 2007, from http://isedj.org/4/6/ISEDJ.4(6).Caputo.pdf

Cavaye, A.L.M. (1995). User Participation in System Development Revisited. Information and Management, 28, 311-323.

Cerveny, R. P. and D. A. Joseph, (1988). Effects of Software Engineering on Productivity. Information \& Management, 14, 243-251.

Cheney, P.H. (1988). Information Systems Skills Requirements: 1980 \& 1988. Proceedings of the ACM SIGCPR Conference on Management of Information Systems - Special Interest Group on Computer Personnel Research, College Park, Maryland, United States, 1-7.

Cheney, P.H., Hale, D.P., and Kaspar, G.M. (1990). Knowledge, Skills, and Abilities of Information Systems Professionals: Past, Present and Future. Information \& Management, 19(4), 237-247.

Chikofsky, E. (1989). How to Lose Productivity with Productivity Tools. Proceedings of 3rd IFAC/IFIP Workshop, Indiana, US, 120-124. 
Chu, B.T., Dasigi, V., Gorgone, J., and Spooner, D. (2001). Information Technology Curriculum Development. ACM SIGCSE Bulletin, Proceedings of the Thirty-Second SIGCSE Technical Symposium on Computer Science Education SIGCSE '01, 33(1).

Ciborra, C.U. (1999). A Theory of Information Systems Based on Improvisation. In W. L. Currie and B. Galliers (Eds.), Rethinking Management Information Systems (pp. 136-155). Oxford, UK: Oxford University Press.

Ciborra, C., Brachhi, G., Maggiolini, P. (1980). A Multiple-Contingency Review of Systems Analysis Methods and Models. In H.C. Lucas Jr., F.F. Land, T.J. Lincoln, and K. Supper (Eds.) The Information Systems Environment, Proceedings of the IFIP TC8.2 Working Conference on The Information Systems Environment, Amsterdam: North-Holland Publishing Company.

Ciborra, C.U. and Lanzara, G.F. (1994). Formative Contexts and Information Technology: Understanding the Dynamics of Innovation in Organizations. Accounting, Management, \& Information Technology, 4(2), 61-86.

Clegg, C., Axtell, C., Damodaran, L., Farbey, B., Hull, R., Lloyd-Jones, R., Nicholls, J., Sell, R., and Tomlinson, C. (1997). Information Technology: A Study of Performance and the Role of Human and Organizational Factors. Ergonomics, 40, $851-871$.

Colter, M.A. (1984). A Comparative Examination of Systems Analysis Techniques. MIS Quarterly, 8(1), 51-66.

Couger, J.D. (Ed.) (1973). Curriculum Recommendations for Undergraduate Programs in Information Systems. Communications of the ACM 16(12), 727-749.

Couger, J.D., Davis, G.B., Dologite, D.G., Feinstein, D.L., Gorgone, J.T., Jenkins, A.M., Kasper, G.M., Little, J.C., Longenecker Jr., H.E., and Valacich, J.S. (1995). IS'95: Guideline for Undergraduate IS Curriculum, MIS Quarterly, 19(3), 341-359.

Crane, K. (1990, November 26). Retraining for Changing Times. Computerworld, 13(12), 96.

Crawford, K. (2003). Editorial - The Role and Purpose of Textbooks. International Journal of Historical Learning, Teaching, and Research. 3(2).

Cronbach, L.J. (1963). Course Improvement through Evaluation. Teachers' College Record, 64, 672-683. Reprinted in D.L. Stufflebaum, G.F. Madaus, and T.Kellaghan (Eds.) Evaluation in Education and Human Services, Volume 49 (pp. 236-247). Netherlands: Springer.

Cross, N. (2001). Designerly Ways of Knowing: Design Discipline versus Design Science. Design Issues, 17(3), 49-55. 
Davis, G.B., Gorgone, J.T., Couger, J.D., Feinstein, D.L., and Longenecker, H.E. Jr. (1997). IS '97: Model Curriculum and Guidelines for Undergraduate Degree Programs in Information Systems. ACM SIGMIS Database, 28(1).

Davis, G.B., Lee, A.S., Nickles, K.R., Chatterjee, S., Hartung, R., and Wu, Y. (1992). Diagnosis of an Information System Failure: A Framework and Interpretive Process. Information \& Management, 23(5), 293-318.

DeGrace, P. and Stahl, L. (1990). Wicked Problems, Righteous Solutions: A Catalogue of Modern Software Engineering Paradigms. Englewood Cliffs, New Jersey: Yourdon Press, Prentice Hall.

DeMarco, T. (1978). Structured Analysis and System Specification. New York: Yourdon Inc.

DeMarco, T. and Lister, T. (1987). Peopleware: Productivity Projects and Teams. New York: Dorset House.

DeMarco, T. and Plauger, P.J. (1978). Structured Analysis and System Specification. New York: Yourdon, Inc.

Dennis, A. and Wixom, B.H. (2000). Systems Analysis and Design: An Applied Approach. New York: John Wiley \& Sons, Inc.

Dilthey, W. (1900). Die Entstehung der Hermeneutik [The Origin of Hermeneutics]. Gesammelte Schriften, Vol. V.

Doherty, N. F. and King, M. (1998). The Consideration of Organizational Issues During The Systems Development Process: An Empirical Analysis. Behaviour \& Information Technology, 17(1), 41-51.

Eason, K. (1988). Information Technology and Organisational Change. London: Taylor \& Francis.

Eisenhardt, K. (1989). Building Theory from Case Study Research. Academy of Management Review, 14(4), 532-550.

Elliott, R.W. (1968). Master's Level Computer Science Curricula. Communications of the $A C M, 11(7), 507-508$.

Eriksen, L. (2000). Limitations and Opportunities of Systems Development Methods in Web Information System Design. In R. Baskerville, J. Stage, and J. DeGross (Eds.) Organizational and Social Perspectives on Information Technology (pp. 473486). Boston: Kluwer.

Ewusi-Mensah, K. (1997). Critical Issues in Abandoned Information Systems Projects. Communications of the ACM, 40, 74-80. 
Fitzgerald, B. (1996). Formalized Systems Development Methodologies: A Critical Perspective. Information Systems Journal, 6(1), 3-23.

Fitzgerald, B. (1997). The Use of Systems Development Methodologies in Practice: A Field Study. Information Systems Journal, 7(3), 201-212.

Fitzgerald, B. (1998). An Empirical Investigation into the Adoption of Systems Development Methodologies. Information \& Management, 34(6), 317-328.

Fitzgerald, B. (2000). System Development Methodologies: The Problem of Tenses. Information Technology and People, 13(3), 174-185.

Fitzgerald, G., Philippides, A., and Probert, S. (1999). Information Systems Development, Maintenance, and Enhancement: Findings from a UK Study. International Journal of Information Management, 19(4), 319-328.

Floyd, C. (1987), Outline of a paradigm change in software engineering, In G. Bjerknes, P. Ehn, M. King (Eds.), Computers and Democracy: A Scandinavian Challenge, Brookfield, VT: Avebury Gower.

Fowler, G.C. and Discenza, R. (1986). Model Curricula and Industry's Perceptions. Proceedings of the Twenty-Second Annual Computer Personnel Research Conference on Computer Personnel Research Conference CPR '86.

Frampton, K., Thom, J.A., Carroll, J., and Crossman, B. (2006). Information technology architects: approaching the longer view. Special Interest Group on Computer Personnel Research Annual Conference. Proceedings of the 2006 ACM SIGMIS CPR Conference on Computer Personnel Research: Forty Four Years of Computer Personnel Research: Achievements, Challenges \& The Future, 221-229.

Gadamer, H.-G. (1976). Philosophical Hermeneutics. Berkeley: University of California Press.

Galin, D., and Avrahami, M. (2006). Are CMM Program Investments Beneficial? Analyzing Past Studies. IEEE Software, 23(6), 81-87.

Gane, C. and Sarson, T. (1977). Structured Systems Analysis: Tools and Techniques. Englewood Cliffs: Prentice Hall.

Gibbs, W.W. (1994, September). Software's Chronic Crisis. Scientific American, 8695.

Glaser, B. and Strauss, A. (1967). The Discovery of Grounded Theory: Strategies of Qualitative Research. London: Wiedenfeld and Nicholson.

Gorgone, J.T. (2001). IS education: The IS2001 Curriculum in CC2001 Computing Compendium. ACM SIGCSE Bulletin, 33(4). 
Gorgone, J.T., Davis, G.B., Valacich, J.S., Topi, H., Feinstein, D.L., and Longenecker Jr., H.E. (2003). IS 2002: Model Curriculum Guidelines for Undergraduate Degree Programs in Information Systems. ACM SIGMIS Database, $34(1)$.

Grindley, C.B.B. (Ed.) (1987). Information Technology Review 1987/88, London, UK: Price Waterhouse.

Hackathorn, R. and Karimi, J. (1988). A Framework for Comparing Information Engineering Methods. MIS Quarterly, 12(2), 202-220.

Hammer, M. (1990). Reengineering Work: Don't Automate, Obliterate. Harvard Business Review, July-August, 104-11

Hedberg, B. \& Jönsson, S. (1978). Designing Semi-Confusing Information Systems for Organizations in Changing Environments. Accounting, Organizations and Society, 3(1), 47-64.

Heidegger, M. (1962). Being and Time, translated by J. Macquarrie and E. Roinson, New York: Harper \& Row, Publishers, Inc.

Henry, N.B. (1922). Review: A Method of Evaluating Textbooks. The School Review, 30(1), 71-72.

Hevner, M. and Park, R. (2004). Design Science in Information Systems Research. MIS Quarterly, 28(1), 75-105.

Hidding, G.J. (1997). Reinventing Methodology: Who Reads It And Why? Communications of the ACM, 40(11), $102-109$.

Hirsch Jr., E.D. (1967). Validity in Interpretation. New Haven: Yale University Press.

Hirschheim, R. and Klein, H. (1989). Four Paradigms of Information Systems Development. Communications of the ACM, 32(10), 1199-1216.

Hornby, C., Clegg, C., Robson, J., Mcclaren, C., Richardson, S. and O' Brien, P. (1992). Human and Organisational Issues in Information Systems Development, Behaviour \& Information Technology, 11(3), 160-174.

Huisman, M. and livari, J. (2006). Deployment of Systems Development Methodologies: Perceptual Congruence between IS Managers and Systems Developers. Information \& Management, 43(1), 29-49.

Humphrey, W.S., Snyder, T.R., and Willis, R.R. (1991). Software process improvement at Hughes Aircraft. IEEE Software, 8(4), 11-23.

Hunter, G.T. (1969, September 8-9). Manpower Resources for Management Information Systems. Proc. Founder's Conference, SMIS. 
Hunter, M.G. (1998). Managing Information Systems Professionals: Implementing a Skill Assessment Process. Special Interest Group on Computer Personnel Research Annual Conference, Proceedings of the 1998 ACM SIGCPR conference on Computer Personnel Research, Boston, Massachusetts, United States, 19-27.

IBM (2009). Mainframe Family Tree and Chronology. Retrieved Mar. 1, 2009 from http://www-03.ibm.com/ibm/history/exhibits/mainframe/mainframe_FT2.html

livari, J., Hirschheim, R., and Klein, H.K.A. (1998). Paradigmatic Analysis Contrasting Information Systems Development Approaches and Methodologies. Information Systems Research, 9(2), 164-193.

livari, J. and Huisman, M. (2007). The Relationship between Organizational Culture and the Deployment of Systems Development Methodologies. MIS Quarterly, 31(1), 35-58.

livari, J. and Maansaari, J. (1998). The Usage of Systems Development Methods: Are We Stuck to Old Practices? Information and Software Technology, 40, 501-510.

Introna, L.D. and Whitley, E.A. (1997). Against Methodism, Exploring the Limits of Methods. Information Technology \& People, 10(1), 31-45.

Isaac, G., Rajendran, C., and Anantharaman, R.N. (2003). Do Quality Certifications Improve Software Industry's Operational Performance?-Supplemental Material, Software Quality Professional, 6(1). Retrieved Mar 31, 2007, from http://www.asq.org/pub/sqp/past/vol6_issue1/sqpv6i1issac.pdf

Irwin McGraw-Hill (2008). About the Authors: Jeffrey L. Whitten. Retrieved June 15, 2008 from http://www.mhhe.com/business/mis/whitten/information/olc/whitten.mhtml

Jackson, R.B. and Satzinger, J.W. (2003). Teaching the Complete Object-oriented Development Cycle, Including OOA and OOD, with UML and the UP. Information Systems Education Journal, 1(28). Retrieved on June 1, 2007, from http://isedj.org/1/28/.

Jiang, J.J., Klein, G., and Means, T. (1999). The Missing Link between Systems Analysts' Actions and Skills. Information Systems Journal, 9(1), 21-33.

Jenkins, A., Naumann, J., and Wetherbe, J. (1984). Empirical Investigation of Systems Development Practices and Results, Information \& Management, 7(2), 7382.

Joint ACMIAIS Undergraduate Curriculum Revision Task Force (2009). IS Curriculum Wiki. Retrieved May 14, 2009 from http://blogsandwikis.bentley.edu/iscurriculum/index.php/Main_Page.

Kautz, K. and Pries-Heje, J. (1999). Systems Development Education and Methodology Adoption, ACM SIGCPR Computer Personnel, 20(3), 6-26. 
Kearsey, J. and Turner, S. (1999). Evaluating Textbooks: the Role of Genre Analysis. Research in Science \& Technological Education, 17(1), 35-43.

Keitel, E. (1997). Reader-Response Criticism. In M. Payne (Ed.) A Dictionary of Cultural and Critical Theory (pp. 455-457). Oxford: Blackwell.

Keen, P.W. (1980). MIS Research: Reference Disciplines and a Cumulative Tradition. In E. McLean (Ed.) Proceedings of the First International Conference on Information Systems, Philadelphia, PA, 9-18.

Kendall, K. and Kendall, J. (1988). Systems Analysis and Design. Englewood Cliffs, $\mathrm{NJ}$ : Prentice-Hall.

Keyes, J. (1992). How Software is Developed Undergoing Basic Changes. Software Magazine, 12(1), 38-40, 43-7, 55-6.

Klecun-Dabrowska, E. and Cornford, T. (2000). Telehealth Acquires Meanings: Information and Communication Technologies within Health Policy. Information Systems Journal, 10(1), 41-63.

Klein, H.K. and Myers, M.D. (1999). A Set of Principles for Conducting and Evaluating Interpretive Field Studies in Information Systems. MIS Quarterly, 23(1), 67-93.

Kohli, R. and Gupta, J.N.D. (2003). Effectiveness of Systems Analysis and Design Education: an Exploratory Study, Advanced Topics in End-User Computing, 191211.

Lacity, M., and Janson, M.A. (1994). Understanding Qualitative Data: A Framework of Text Analysis Methods. Journal of Management Information Systems, 11(2), 137156.

Landry, J.P., Pardue, J.H., and Longenecker, H.E. Jr. (2001). Adoption and Usage of the IS'97 Model Curriculum: Results of a Faculty Survey. Americas Conference on Information Systems (AMCIS 2001), Boston, MA.

Landry, J.P., Pardue, J.H., Longenecker, H.E. Jr., and Feinstein, D.F. (2003). A Common Theme for IT Degree Programs. Communications of the ACM, 46(11).

Lang, M. and Fitzgerald, B. (2006). New Branches, Old Roots: A Study of Methods and Techniques in Web/Hypermedia Systems Design. Information Systems Management, 23(3), 62-74.

Lawlis, P.K., Flowe, R.M., and Thordahl, J.B. (1995). A Correlational Study of the CMM and Software Development Performance. Crosstalk, Retrieved Mar 31, 2007, from http://www.stsc.hill.af.mil/crosstalk/frames.asp?uri=1995/09/Correlat.asp 
Lawson, E., Reichgelt, H., Lunt, B., Ekstrom, J.J., Kamali, R., Miller, J., and Gorka, S. (2006). The Information Technology Model Curriculum. Information Systems Education Journal, 4(79). Retrieved June 1, 2007, from http://isedj. org/4/79/.

Lee, A.S. (1991). Integrating Positivist and Interpretive Approaches to Organizational Research. Organization Science, 2(4), 342-65.

Lee, A.S. (1994). Electronic Mail as a Medium for Rich Communication: An Empirical Investigation Using Hermeneutic Interpretation. MIS Quarterly, 18(2), 143-157.

Lee, D.M.S, Trauth, E.M., and Farwell, D. (1995) Critical Skills and Knowledge Requirements of IS Professionals: A Joint Academic/Industry Investigation. MIS Quarterly, 19(3), 313-340.

Lidtke, D.K. and Stokes, G.E. (1999). An Information Systems-Centric Curriculum ISCC 99. Frontiers in Education Conference, FIE '99, 29th Annual 2(10-13), 12B5/15-12B5/20.

Lincoln, Y.S. and Guba, E.G. (1985). Naturalistic Inquiry. Beverly Hills, CA: Sage Publications.

Lindquist, C. (2005, November 15). Fixing the Requirements Mess. ClO Magazine, Retrieved November 13, 2006, from http://www.cio.com/article/print/14295.

Lyytinen, K. (1987). Different Perspectives on Information Systems: Problems and Solutions, ACM Computing Surveys (CSUR), 19(1), 5-46.

Lyytinen, K. (1989). New Challenges of Systems Development: A Vision of the 90's. Data Base, 20(1), 1-12.

Lyytinen, K., Grover, V., Linder, J., Mendelson, H., Senn, J., and Sviokla, J. (1999). Making Information Systems Research More Relevant (Panel Session): Academic and Industry Perspectives, Proceedings of the 20th International Conference on Information Systems, International Conference on Information Systems, United States: Charlotte, North Carolina, 574-577.

Lyytinen, K. and Hirschheim, R. (1987). Information System Failures: A Survey and Classification of the Empirical Literature. In: Zorkoczy, P. (Ed.) Oxford Surveys in Information Technology, Volume 4 (pp. 257-309). Oxford: Oxford University Press.

Lyytinen, K. and Robey, D. (1999). Learning Failure in Information Systems Development. Information Systems Journal, 9(2), 85-101.

MacDonald, I.G. (1988). Automating Information Engineering. Information and Software Technology, 30(6), 393-400. 
Maddison, R., Baker, G., Bhabuta, L., Fitzgerald, G., Hindle, K., Song, J., Stokes, N., and Wood, J. (1984). Feature Analysis of Five Information Systems Methodologies, In T. Bemelmans (Ed.), Beyond Productivity: Information Systems Development for Organizational Effectiveness (pp. 277-306). Amsterdam: North-Holland Press, Elsevier Science Publishers B.V.

Malhotra, A., Thomas, J.C., Carroll, J.M., and Miller, L.A. (1980). Cognitive Processes in Design. International Journal of Man-Machine Studies, 12(2), 119-140.

Mandt, J. (1982). The Failure of Business Education and What to Do About It. Management Review, 71(8), 47-55.

Markus, M.L. (1994). Electronic Mail as the Medium of Managerial Choice. Organization Science, 5(4), 502-527.

Mason, R. (1991). Commentary on Survey Research on Information Systems. In K. Kraemer (Ed.), The Information Systems Research Challenge: Survey Research Methods (pp. 59-65). Boston: Harvard Business School, Publishing Division.

Mawhinney, C.H., Morrell, J.S., Morris, G.J., and Monroe, S.R. (1999). Updating the IS curriculum: Faculty Perceptions of Industry Needs. Proceedings of the 1999 ACM SIGCPR Conference on Computer Personnel Research SIGCPR '99.

McCarthy, R.V., White, B., and Grossman, M. (2005). Object Oriented Analysis and Design: Do We Need More UML in the Classroom? Information Systems Education Journal, 3(46). Retrieved June 1, 2007, from http://isedj.org/3/46/.

McCracken, D.D. and Jackson, M.A. (1982). Life Cycle Concept Considered Harmful. ACM SIGSOFT Software Engineering Notes, 7(2), 29-32.

McCubbrey, D.J. and Scudder, R.A. (1988). The Systems Analyst of the 1990's. Special Interest Group on Computer Personnel Research: Proceedings of the ACM SIGCPR Conference on Management of Information System Personnel, 8-16

McKenney, J.L., and Tonge, F.M. (1971). The State of Computer Oriented Curricula in Business Schools 1970. Communications of the ACM, 14(7), 443-448.

McKenzie, W.B. (2006). Information Systems Curriculum Revision in a Hostile Environment: Declining Interest, Threats from Offshore, and Proprietary Certification. Information Systems Education Journal, 4(105). Retrieved on June 1, 2007, from http://isedj.org/4/105/

Middleton, P. (1994). Euromethod: the Lessons from SSADM. In W. Baets (Ed.) Proceedings of the Second European Conference on Information Systems, Brekelen: Nijenrode University Press.

Misic, M.M. and Graf, D.K. (2004). Systems Analyst Activities and Skills in the New Millennium. Journal of Systems and Software, 71(1-2), 31-36. 
Misic, M.M. and Russo, N.L. (2000). Reading between the Lines: An Examination of Systems Analysis and Design Texts. Journal of Systems and Software, 50(1), 65-73.

Misic, M.M. and Russo, N.L. (1999). An Assessment of Systems Analysis and Design Courses. Journal of Systems and Software, 45(3), 197-202.

Mueller-Vollmer, K. (Ed.) (1988). The Hermeneutic Reader. New York, NY: Continuum.

Mumford, E. (1986). Using Computers for Business Success: The ETHICS Method, Manchester: Manchester Business School.

Mumford, E., Hirschheim, R., Fitzgerald, G. and Wood-Harper, A.T. (Eds.) (1985). Research Methods in Information Systems. Amsterdam: North Holland.

Myers, M.D. (2004). Hermeneutics in Information Systems Research. In J. Mingers and L.P. Willcocks (Eds.), Social Theory and Philosophy for Information Systems (pp. 103-128). Chichester: John Wiley \& Sons.

Myers, M.D. (2007). Qualitative Research in Information Systems. Retrieved May 2, 2007, from http://www.qual.auckland.ac.nz/

Nandhakumar, J. and Avison, D.E. (1999). The Fiction of Methodological Development: A Field Study of Information Systems Development, Information Technology \& People, 12(2), 176-191.

Naur, P., Randell, B., and Buxton, J. (1976). Software Engineering: Concepts and Techniques, New York: Charter Publishers.

Nelson, R. (1991). Educational Needs as Perceived by IS and End-User Personnel: A Survey of Knowledge and Skill Requirements. MIS Quarterly, 15(4), 503-521.

Newton, K.M. (1989). Hermeneutics and Modern Literary Criticism. British Journal of Aesthetics, 29, 116-127.

Nord, G.D., Hilton, T., Wood, W.A., and Nord, J.H. (1998). Information Systems Curriculum Development (Panel): Skills and Knowledge for Today and the Future.

Proceedings of the 1998 ACM SIGCPR Conference on Computer Personnel Research SIGCPR' 98.

Nunamaker, J.F. (1981). Educational Programs in Information Systems. Communications of the ACM, 24(3), 124-133.

Nunamaker, J.F., Couger, J.D., and Davis, G.B. (1982). Information Systems Curriculum Recommendations for the 80's: Undergraduate and Graduate Programs. Communications of the ACM, 25(11), 781-805. 
O'Toole, J. and Mitroff, I. (1989). Curricular Reform: An Impertinent Proposal. New Management, 49-53.

Ornstein, A.C. (1989). Textbook Instruction: Processes and Strategies for Selection, Use. NASSP Bulletin, 73(521), 105-111.

Palmer, R.E. (1969). Hermeneutics. Evanston: Northwestern University Press.

Radding A. and Magitta, J. (1993, April 26). Techno Renaissance: After a Decade of Business Focus, The Pendulum is Swinging Back to Technology. IS Execs, Get Ready for the Techno Renaissance. Computerworld, 67.

Raywid, M.A. (1980). The Toppling Textbook? Journal of Teacher Education, 31(4), 63.

Reynolds, J.H., Longenecker Jr., H.E., Landry, J.P., Pardue, J.H., and Applegate, B. (2004). Information Systems National Assessment Update: The Results of a Beta Test of a New Information Systems Exit Exam Based on the IS 2002 Model Curriculum. Information Systems Education Journal, 2(24). Retrieved June 1, 2007, from http://isedj.org/2/24/.

Ricoeur, P. (1981). Hermeneutics and the Human Sciences, Edited By J.B. Thompson. New York, NY: Cambridge University Press.

Ricouer, P. (1991). From Text to Action. London: The Athlone Press.

Ross, D.T. (1961). A Generalized Technique for Symbol Manipulation and Numerical Calculation. Communications of the ACM, 4(03), 147-150.

Ross, D. T. and Brackett, J. W. (1976). An Approach to Structured Analysis. Computer Decisions, 8(9), 40-44.

Russo, N.L. and Klomparens, R. (1993). Formal Applications Development Methodologies in the '90's. (Working Paper). DeKalb, IL: Northern Illinois University.

Sachs, P. (1995). Transforming Work: Collaboration, Learning, and Design. Communications of the ACM, 38(9), 36-44.

Saroyan, A. and Geis, G.L. (1988). An Analysis of Guidelines for Expert Reviewers. Instructional Science, 17, 101-128.

Satzinger, J.W., Jackson, R.B., and Burd, S.D. (2002). Systems Analysis and Design in a Changing World, $2^{\text {nd }}$ Edition. Boston, MA: Course Technology.

Satzinger, J.W., Jackson, R.B., and Burd, S.D. (2004). Systems Analysis and Design in a Changing World, $3^{\text {rd }}$ Edition. Boston, MA: Course Technology. 
Saulnier, B.M. (2003). Creating Significant Learning Experiences in Systems Analysis and Design: Towards a Service Learning Paradigm. Information Systems Education Journal, 1(4). Retrieved June 1, 2007, from http://isedj.org/1/4/.

Schaumbach, T., and Blanton, J.E. (2002). The Professional Development Challenge for IT Professionals. Communications of the ACM, 45(4), 83-87.

Schön, D. (1983). The Reflective Practitioner. London: Temple-Smith.

Scriven, M. (1967). The Methodology of Evaluation. In R. Tyler (Ed.) Perspectives of Curriculum Evaluation (pp. 39-83) Chicago, IL: Rand McNally.

Seymour, L., Scott, E., Malamoglou, S., Meyerowitz, J., and Morar, A. (2006). Skills Learnt During a Systems Development Course: Graduate Perceptions of Skills Transfer and Industry Alignment. Information Systems Education Journal, 4(85). Retrieved June 1, 2007, from http://isedj.org/4/85/.

Shriver, K.A. (1989). Evaluating Text Quality: The Continuum from Text-Focused to Reader-Focused Methods. IEEE Transactions on Professional Communication, 32(4), 238-255.

Smith, D.W. (2007). Phenomenology. Stanford Encyclopedia of Philosophy. First published on Nov 16, 2003. Retrieved May 7, 2007 from http://plato.stanford.edu /entries/phenomenology/

SEI (Software Engineering Institute) (2006a). CMMI for Development, Version 1.2. Pittsburgh, PA: Carnegie Mellon Software Engineering Institute. Retrieved Mar 30, 2007, from http://www.sei.cmu.edu/cmmi/models/.

SEI (Software Engineering Institute) (2006b). Process Maturity Profile - 2005 Update. Pittsburgh, PA: Carnegie Mellon Software Engineering Institute. Retrieved Mar 30, 2007, from http://sas.sei.cmu.edu/pars/.

SEI (Software Engineering Institute) (2007). Published Appraisal Results, Pittsburgh, PA: Carnegie Mellon Software Engineering Institute. Retrieved Mar 30, 2007, from http://sas.sei.cmu.edu/pars/pars.aspx

Standish Group (2001). Extreme Chaos. Retrieved November 12, 2006 from http://www.standishgroup.com/sample_research/chaos_1994_1.php

Stevens, W.P., Myers, G.J., and Constantine, L.L. (1974). Structured Design. IBM Systems Journal, 13(2). Reprinted in P. Freeman and A. I. Wasserman (Eds.) Software Design Techniques. Long Beach: IEEE, 1977; and E. N. Yourdon (Ed.) Classics in Software Engineering. New York: Yourdon Press, 1979.

Stolterman, E. (1992). How System Designers Think About Design and Methods: Some Reflections Based On an Interview Study. Scandinavian Journal of Information Systems, 4, 137-150. 
Suchman, L.A. (1983). Office Procedure as Practical Action: Models of Work and System Design, ACM Transactions on Information Systems (TO/S), 1(4), 320-328.

Sullivan-Trainor, M. (1988, March 7). MIS Stares at Skills Crunch. Computerworld. $22,10$.

Sweeney, R.B. (2003). An Examination of Creativity in the Information Systems Curriculum Model and a Proposal for Revision. Information Systems Education Journal, 1(13). Retrieved June 1, 2007, from http://isedj.org/1/13/.

Taylor, C. (1976). Hermeneutics and Politics. In P. Connerton (Ed.), Critical Sociology, Selected Readings. Harmondsworth: Penguin Books Ltd.

Taylor, M.J., Moynihan, E.P., and Wood-Harper, A.T. (1998). End-User Computing and Information System Methodologies. Information Systems Journal, 8(1), 85-96.

Teichroew, D. (Ed.) (1971). Education Related to the Use of Computers in Organizations (Position Paper-ACM Curriculum Committee on Computer Education for Management). Communications of the ACM, 14(9), 573-588.

Tesch, D.B., Klein, G., and Sobol, M.G. (1995). Information System Professionals' Attitudes: Development Tools and Concepts. Journal of Systems and Software, 28(1), 39-47.

Thompson, J.B. (1981). Critical Hermeneutics: A Study in the Thought of Paul Ricoeur and Jürgen Habermas, Cambridge: Cambridge University Press.

Thompson ,G. and Hunston, S. (2000). Evaluation: An Introduction. In S. Hunston and G. Thompson (Eds.) Evaluation in Text: Authorial Stance and the Construction of Discourse (pp. 1-27). Oxford: Oxford University Press.

Trauth, E.M., Farwell, D.W., and Lee, D. (1993). The IS Expectation Gap: Industry Expectations versus Academic Preparation. MIS Quarterly, 17(3), 293-307.

Unger, E.A., Hasset, C.M., and Castro, C. (1987). IS and MIS: A Compromise? Technical Symposium on Computer Science Education, Proceedings of the Eighteenth SIGCSE Technical Symposium on Computer Science Education, St. Louis, Missouri, United States, 483-489.

Vessey, I. and Conger, S.A. (1994). Requirements Specification: Learning Object, Process, and Data Methodologies. Communications of the ACM, 37(5), 102-113.

Vitalari, N. (1985). Knowledge as a Basis for Expertise in Systems Analysis: An Empirical Study. MIS Quarterly, 9(3), 221-241.

Vitalari, N.P. and Dickson, G.W. (1983). Problem Solving for Effective Systems Analysis: An Experimental Exploration. Communications of the ACM, 26(11), 948956. 
Wachterhauser, B.R. (1986). Hermeneutics and Modern Philosophy. Albany, NY: State University of New York Press.

Walz, D.B. and Wynekoop, J. (1994). Creativity and Software Design: Is Formal Training Helping or Hurting? Proceedings of the IEEE International Conference on Systems, Man and Cybernetics, 1, 842-846.

Wand, Y. and Weber, R. (2002). Research Commentary: Information Systems and Conceptual Modeling - A Research Agenda. Information Systems Research, 13(4), 363-376.

Wang, S. and Wang, H. (2005). Shift the Subject of Systems Analysis and Design from Construction to Acquisition. Information Systems Education Journal, 3(11). Retrieved June 1, 2007, from http://isedj.org/3/11/.

Ward, P. (1991). The Evolution of Structured Analysis: Part 1 - The Early Years. American Programmer, 4(11), 4-16.

Wastell, D.G. (1996). The Fetish of Technique: Methodology as a Social Defence. Information Systems Journal, 6(1), 25-40.

Wastell, D. and Newman, M. (1993). The Behavioral Dynamics of Information System Development: A Stress Perspective. Accounting, Management \& Information Technology, 3(2), 121-148.

Weinburg, V. (1978). Structured Analysis. New York: Yourdon Press.

Welke, R.I (1994). The Shifting Software Development Paradigm. Data Base, 25(4), 9-16.

Whitten, J.L., Bentley, L.D., and Ho, T.I.M. (1986). Systems Analysis \& Design Methods. St. Louis: Times Mirror / Mosby College Publishing.

Whitten, J.L., Bentley, L.D., and Barlow, V.M. (1989). Systems Analysis \& Design Methods, $2^{\text {nd }}$ Edition. Homewood, IL: Irwin.

Whitten, J.L., Bentley, L.D., and Barlow, V.M. (1994). Systems Analysis \& Design Methods, $3^{\text {rd }}$ Edition. Burr Ridge, IL: Irwin.

Wikipedia, (2009). Microsoft Windows. Retrieved January 17, 2009 from http://en.wikipedia.org/wiki/Microsoft_Windows.

Williams, C.L. and Pomykalski, J.J. (2006). Comparing Current IS Curricula to the IS 2002 Model Curriculum. Information Systems Education Journal, 4(76). Retrieved June 1, 2007, from http://isedj.org/4/76/. 
Wimsatt, W.K. and Beardsley, M.C. (1954a). The Intentional Fallacy. Sewanee Review, 54 (1946), 468-488. Revised and republished in W.K. Wimsatt, The Verbal Icon: Studies in the Meaning of Poetry (pp. 3-18), Lexington: University of Kentucky Press.

Wimsatt, W.K. and Beardsley, M.C. (1954b). The Affective Fallacy. In W.K. Wimsatt, The Verbal Icon: Studies in the Meaning of Poetry. Lexington: University of Kentucky Press.

Winograd, T. and Flores, $F(1986)$. Understanding Computers and Cognition. A New Foundation for Design. Norwood, NJ: Ablex.

Wynekoop, J.L. and Russo, N.L. (1995). Systems development methodologies: Unanswered Questions. Journal of Information Technology, 10(2), 65-73.

Wynekoop, J.L. and Russo, N.L. (1997). Studying System Development Methodologies: An Examination of Research Methods. Information Systems Journal, $7(1), 47-65$.

Yourdon, E. (1967). Real-Time Systems Design, Cambridge, Mass.: Information \& Systems Press.

Yourdon, E. (1979). Classics in Software Engineering. New York: Yourdon Press.

Yourdon, E. (1982). Managing the Systems Life Cycle. New York: Yourdon Press.

Yourdon, E. (1989). Modern Structured Analysis. Englewood Cliffs, NJ: Prentice Hall.

Zachman, J. (1987). A Framework for Information Systems Architecture. IBM Systems Journal, 26(3), 276-292.

Zahedi, F., Van Pelt, W.V., and Srite, M. (2006, Summer). Web Documents' Cultural Masculinity and Femininity. Journal of Management Information Systems, 23(1), 87128.

Zmud, R (1996). Editor's Comments. MIS Quarterly, 20(3), xxxvii-xxxviii. 


\section{Appendices}

\section{Appendix 1 - Hermeneutics Literature Review}

Section 1 begins with a general description of hermeneutics. This is followed by a section which addresses the particular hermeneutic principles to be employed in the study. Then, we look at the contributions of the two hermeneutics scholars, Emilio Betti and E.D. Hirsch Jr., who drive the central concept of authorial intent researched in this study. Finally we examine the use of hermeneutics in IS studies, to get a perspective of how it has been used in the past.

\section{Section 1: Hermeneutics as a Research Approach}

From Ricouer (1991), hermeneutics is "the theory of the operations of understanding in their relation to the interpretation of texts" (p. 53). This definition reflects a more contemporary view of hermeneutics, which differs slightly from its original purpose of interpreting the Bible and other religious texts. Eventually, hermeneutics was employed for the interpretation of non-religious texts, and the definition of "text" was amended to include most forms of human communication, including painting, movies, conversation, and other communicative arts. Boland (1991) rephrases Ricouer's definition slightly: "Hermeneutics is the study of interpretation, especially the process of coming to understand a text" (Boland, 1991, p. 439). This presents hermeneutics as a general process of interpretation, though not all hermeneutic scholars have felt that hermeneutics should be expanded beyond the written form and some, such as Ricoeur (1991), feel the written word holds more value for interpretation than other forms. This opinion is not formed from an incompatibility of hermeneutic techniques to non-written communication, but rather a preference for the elegance of the written word.

Over time, the purpose of hermeneutics has expanded greatly. No longer simply a method of translating texts, through Heidegger and Gadamer it has become an ontological position for understanding existence itself. Palmer (1969) lists six definitions of hermeneutics, including a theory of biblical exegesis, a philological methodology, a science of linguistic understanding, a core discipline for the 
understanding of all other human disciplines, a phenomenology of being and of existential understanding, and a system of interpretation. Myers (2007) categorizes hermeneutics as one of the two philosophical bases (the other being phenomenology) for all interpretive research. A history of hermeneutics including the various perceptions of hermeneutics as a technique and as an approach can be found in Appendix 2.

Hermeneutics is therefore the obvious choice for the interpretation of texts (Lee, 1994). Though the term "text" has been expanded considerably to cover a host of communicative forums including conversation and most other expressive acts (Ricoeur, 1991; Myers, 2004), the original purpose of hermeneutics was the study of written texts, particularly the Bible (Boland, 1991).

There are, however, a number of different forms of hermeneutic study. They extend from the classical hermeneutic studies of Schleiermacher and Droysen, to the philosophical and existential studies of Heidegger and Gadamer, to the more critical hermeneutic methods of Ricoeur and Habermas.

For IS studies, Gadamer's work is often referenced as a theoretical justification for a hermeneutical approach (Boland, 1991; Zahedi et al., 2006). This is based on Gadamer's "philosophical hermeneutics" (1976), which leverages hermeneutics as a general ontological position, and follows the tradition of Heidegger's Being and Time (1962), where hermeneutics is viewed as a means to understand all social phenomena. Gadamerian studies are often based on transcribed conversations, rather than the traditional written texts that would seem to follow the methods of older hermeneutic scholars.

The ontological position of hermeneutics through Heidegger and Gadamer is leveraged in many IS studies based simply on the interpretive nature of the study, and follows Myers (2007) claim of two research approaches to interpretive research; hermeneutics and phenomenology. The distinction between these two perspectives can be very difficult to make however, as Boland (1985) essentially treats hermeneutics as technique of interpretation within a phenomenological approach, while Heidegger treated hermeneutics as a base ontological position that incorporated elements of phenomenology as a method.

Phenomenology focuses on our experiences within the world (Smith, 2007) and attempts to strip away preconceptions with the purpose of understanding the 
'essence' of phenomena that we experience (Boland, 1985). Based on our own interpretation, as phenomenologists, we would observe a phenomenon, and then attempt to understand our own prejudices and the inherent prejudices of the technique we are using to examine the phenomenon in order to identify the true essence of the phenomenon. Hermeneutics, by contrast, focuses on understanding the historical development of the phenomenon and ourselves. Though they are similar in purpose, they each have a different emphasis. Phenomenology accepts bias as a necessary element of understanding the true nature of things. Phenomenology extends our understanding by creating a dialectic about the true nature of the thing. Hermeneutics treats bias itself as the true nature of things, since each of us possesses a unique interpretation of any thing. Hermeneutics then extends our understanding by creating a dialectic about our interpretations.

The numerous and open definitions of hermeneutics result in a great deal of confusion with regard to what actually constitutes a hermeneutic study. In particular, many studies seem to ignore the actual constructs, such as distanciation or the hermeneutic circle, that define the hermeneutical tradition. For example, Zahedi et al. (2006) claims to be a hermeneutic study and mentions the hermeneutic circle as a central part of its analysis process. Confusingly, the principle technique of data analysis of the study is actually semiotics, which involves the recognition and categorization of signs and symbols in texts, rather than their interpretation of the text within a particular context. Hermeneutics is a term that in many studies seems to be used synonymously with interpretive research, rather than being distinctly defined based on the use of hermeneutic techniques and traditions.

\section{Section 2: Principles of Interpretation}

Hermeneutics is in many ways, an art of interpretation. The term "art" is used in this context to imply the personal, fluid, and often imprecise nature of interpretation rather than the clear, concise, global, and static nature of a science. Interpretation can be shared, and can form a dialogue, however it is ultimately something that we each possess, and which we are intrinsically bound to. Our interpretations reflect not only our understanding of the phenomenon in question, but 
also ourselves. Our interpretations are subject to change, based on our increased exposure to the phenomenon at hand, and to others' interpretations of the same phenomenon. This implies that the interpretations of two individuals can be compared, or that we can evaluate a single individual's interpretations at multiple points in time (Ricoeur, 1991).

\section{The Dilemma of Multiple Interpretations}

The possibility of multiple interpretations can make the hermeneutic process both exhilarating and frustrating. An example based on my own literature review will illustrate the dilemma. During my initial research on hermeneutics, I hoped to isolate a definition of hermeneutics such that I could use it to categorize the studies I would review to determine whether or not they fit within the hermeneutic tradition. Myers (2007) seemed to provide a satisfactory definition, and provided a seemingly clear categorization of interpretive studies based on a philosophical base grounded in either hermeneutics or phenomenology. My earlier readings on phenomenology had not provided me with enough information to build a valid interpretation of the term, so I began to explore the articles that Myers (2007) suggested to form an understanding of phenomenology within the IS discipline. Before doing so, I looked at a couple of quick definitions (Wikipedia, 2009 and Smith, 2007) just to get a flavour of the idea. The definitions left me somewhat puzzled, as they seemed to share little in common with each other, and were couched in philosophical rhetoric beyond my current breadth of comprehension. I proceeded to then read Boland (1985), considered by Myers (2007) to be the exemplar for an IS phenomenological study.

Boland (1985) confounded me due to his extensive use of the term "hermeneutics" as a twin aspect to phenomenology. By the end of the article, I understood phenomenology better, but understood less where the line between hermeneutics and phenomenology could be drawn. Myers (2007) interpretation of Boland's work seemed to defy Myers (2007) own definition of the terms in question, which prodded me to continue exploring the literature Myers suggested. My next reading, Boland (1991), further confused me, as he seemed to use the terms "phenomenology" and "hermeneutics" as synonyms, buffering his hermeneutical argument using his 1985 phenomenological paper. 
In Boland (1991), Boland leverages several other works to describe hermeneutics, including the works of Ricoeur, who introduced a phenomenological hermeneutics. Seeing the terms together, in that order, indicated to me a potential evolution in Boland's interpretation of the terms. In Boland (1985) he referred to hermeneutics as a technique within the phenomenological approach. In Boland (1991), he claims Ricoeur's phenomenological hermeneutics as a voice within the hermeneutic tradition. The status of 'phenomenology' as an adjective modifying the noun 'hermeneutics' in this case demonstrates that phenomenology is in fact, a subordinate element to hermeneutics.

At this point, my own interpretation of the two terms has been altered several times, and my interpretation is very likely not to be what Boland had intended through the usage of his terms. Additionally, I was also faced with attempting to understand Ricoeur's interpretation of the terms, in order to better understanding Boland's interpretation of Ricoeur's work, and therefore, to better understand Boland's work. Since Ricoeur's work was based on his interpretations of Hegel and Husserl, it can be quickly deduced that what I faced was the daunting prospect of understanding the fluid interpretations of numerous authors, and the consumption of a mountain of literature.

\section{The Fluidity of Interpretive Research}

Interpretive research can be both celebrated and criticized for this fluid nature. Interpretive research is forgiving by nature. Since our interpretations are molded constantly by what we encounter, it is generally felt that there is no "perfect interpretation". That said, there are guidelines which can be set to determine how valid a particular interpretation is, based on a greater understanding of the subject matter and the intent of the author (Hirsch, 1967). This does not, however, invalidate one's view if they lack a complete understanding, since interpretation is largely a personal exercise.

This belief, however, can be abused. Statements like "I understand the author better than themselves" or "the author's intent can never be understood and is therefore irrelevant" betray the spirit of hermeneutics as a tool for understanding. It may certainly be possible to understand the subject matter of an author's text better than they, or to realize meaning that the author may have unconsciously 
inserted into the text, but the wholesale dismissal of the author and their intended message is not generally valid (Hirsch, 1967).

In many ways, hermeneutics is a victim of its own intent. By justifying the existence of multiple differing but potentially valuable interpretations, the actual nature of hermeneutics itself can become subject to interpretation. Hermeneutics can be many things to many researchers, and seemingly can be instantiated in many forms based on the needs of the researcher. This lack of consensus is compounded by the existence of a host of terms (many of which are not even directly translatable into English) that "define" the precepts of hermeneutics, and have many proximate interpretations.

Hermeneutics therefore lacks a definitive methodological process which can guide interpretation. Though there are certainly guides for determining validity of interpretation, such as Lincoln and Guba (1985) and Hirsch (1967), many flavors of hermeneutics discount these on philosophical grounds. Unfortunately, without rules to govern interpretation, and a united belief in the validity of individual interpretation, less circumspect researchers can essentially justify predetermined and highly personally biased interpretations (Hirsch, 1967).

\section{Stages of Interpretation}

Interpretation is a three-part process (Hirsch, 1967). First, before we can make a valid interpretation of a particular text, we must first understand it. If we do not speak Greek, we cannot make a valid interpretation of a text written Greek, despite how familiar we may be with the text's subject matter. Understanding can be difficult to evaluate, but exists at numerous levels, including:

- An understanding of the physical symbols and signs used in the language in which the text is written

- An understanding of the use of these symbols in linguistic and grammatical structures

- An understanding of the contextual factors which give to these linguistic structures one of a number of potential meanings

- Knowledge of the author's intent which formulates a particular meaning for the contents of the text and a perspective for why it was written and what the author meant to convey. 
Once we have an understanding of the text, we move to the second interpretive stage, where we can then make an interpretation of the text that includes our perception of the nature of the way in which the text was written, its stylistic elements, and how well the author managed to make their point. Our interpretation precedes the formulation of our response, since it occurs during and in tandem with the understanding process. Our interpretation is also subject to change, as our understanding of the text and its contents grows.

When we have completed our interpretation we then write our own text, so that we may convey that interpretation to others. This forms the final part of an interpretation, the "commentary" on the text (Hirsch, 1967, p. 143) which may be critical or praiseworthy in nature, but relies on the reasonableness of our interpretation, and our skill in communicating that interpretation to others.

\section{The Concept of Foreknowledge}

Gadamer used the term "foreknowledge" to describe our ideas, preconceptions, biases, and knowledge of a particular subject (Klecun-Dabrowska and Conford, 2000). Though viewed as a negative influence to be carefully controlled for in positivistic research, hermeneutic researchers believe that foreknowledge helps build the mutual world that is shared by us and the text (Ricoeur, 1991, pp.148-9). It is important to acknowledge and note this foreknowledge however, because to be unaware of it may lead us to make premature determinations that we cannot justify based on the contents of the text. This form of self-determinate interpretation invalidates the hermeneutic process (Hirsch, 1967, pp.164-8).

Foreknowledge allows us to bridge the contextual differences between our world and the author's world (Ricoeur, 1991). We learn more about the author through the text, through other literature written by the author, and through other literature created at the same point in history as the original text (Betti, 1980; KlecunDabrowska and Cornford, 2000). This helps us interpret the original text, and facilitates a common understanding with the author. 


\section{The Hermeneutic Circle}

Perhaps the most enduring concept within hermeneutics is the hermeneutic circle. It is the perception of the interpretive process as a continual shifting between looking at the text as a whole, and looking at it based on its component parts. As we read each part of the text, a picture of the entire text as a whole forms. This understanding of the whole text, however, influences how we continue to evaluate the other parts of the text. We therefore alternate back and forth from whole to parts until we come to an overall understanding of the text and its contents.

We can also extend the analogy of the hermeneutical circle beyond the actual text itself. If we consider the author's life, other writings produced at the same time, and other contextual factors as additional "parts" of the interpretation, we see that they also contribute to the "whole" (Hirsch, 1967; Klecun-Dabrowska and Conford, 2000). Therefore, our hermeneutical circle extends to become a much larger cyclic journey as we increase our knowledge of the subject matter of the text and the context surrounding the text (Betti, 1980).

The cyclic nature of the hermeneutic circle also includes repeated readings of the text (Lacity and Johnson, 1994). Our understanding of the text improves not just with the better development of background knowledge of the subject matter of the text, but as we re-read the text we uncover nuances of the meaning of the text we may have missed before, and which build from what we have previously learned.

\section{Ending the Hermeneutic Cycle}

Since, in principal, the hermeneutic circle could follow infinite cycles, there must be some reasonable determination of when to halt the interpretation. There are, however, many alternatives for determining the completion of an interpretation, but they are not necessarily incompatible.

According to Hirsch (1967), when developing an interpretation the interpreter will develop many alternative hypotheses for the author's intended message. When the number of plausible alternative hypotheses has been reduced to one, and the evidence supporting the chosen alternative outweighs all alternative hypotheses, the interpreter can consider the interpretation to be complete. When using this method of ending the circle, the researcher follows a pattern of gestating new hypotheses, 
and then either building support for them, or dismissing them based on the evidence that can be procured from the interpretive process.

Myers (2004) presents an alternative method of determining when to complete a hermeneutic cycle. If the text contains apparent absurdities or internal conflicts then the goal of each successive pass with the hermeneutic circle will be to resolve these conflicts by understanding the true meaning of the actors' motivations in the text. When we have reached the point where all internal conflicts and absurdities have been explained using rational theories of action, we can consider our hermeneutic process to be complete. When following this process, any irreconcilable facts in the case or actions on the part of the actors of the text (including the author) that seem nonsensical are set aside at the end of an interpretive cycle. During the next hermeneutic cycle, we attempt to resolve these conflicts by applying theories that seem appropriate and can be supported by evidence within the text. When all of these conflicts have been resolved, the overall process is complete.

Care must be exercised when using this method of evaluating an interpretation, however. If the goal of finding a plausible theory to explain the conflicts found within the text becomes more important than the interpretation itself, the researcher can lose the intent of the hermeneutic process and stretch the bounds of plausibility. This may be the case with Davis et al. (1992), an excellently developed quasi-hermeneutical study which, in a possibly desperate search for a theory to explain the conflicts leading to information system failure, finally settles with Theory $X$. Therefore we are faced with the questionable determination that information system failure is essentially due to lazy employees.

\section{The Importance of Narrative}

A hermeneutic study is a chronicle. It explains a series of events that are tied together and bring us from an initial realization of an underlying conflict in the text through the factors which unearth the nature of the conflict to a final understanding of the true nature of the elements of the text (Ricouer, 1991, pp.1-7). The task of hermeneutics according to Ricouer (1991) therefore is to find the: 
"internal dynamic that governs the structuring of the work and, on the other hand, the power that the work possesses to project itself outside itself and give birth to a world that would truly be the 'thing' referred to by the text" (p. 17).

In any text, be it novel or conversation, fictional or historical recount, we attempt to decipher the plot of the text. The plot is important, not only as an account of the message of the text, but because it aids us in coalescing our interpretation. We conceive of stories as a journey from a beginning to an end, and therefore the use of this device enables us to build our interpretations as a journey from idea to realization.

\section{Distanciation and Autonomization}

Hermeneutics is often employed when historical chronicles are created. Since we cannot be present at events of the past, we must attempt to decipher the meaning of the historical artifacts we uncover. As we move farther from the initial event, our interpretations become prejudiced by the events of our own time, and our interpretations begin to reflect not only the events of the past, but the events of the present (Wachterhauser, 1986).

This occurs due to two hermeneutic concepts called distanciation and autonomization. Once a text is created, it acquires a life of its own. The text contains a static message, while the ideas of the author and the context around which the original message was created continue to change. The author and the text become less and less connected, particularly because others reading the text may not know the author or understand the context in which the text was formed. This is distanciation.

Distanciation occurs because the text itself cannot completely re-immerse the reader in the original context of the writing, nor completely express the author's intended message. Even if the author exhaustively described the contextual factors that impacted their work, the author cannot prevent the person reading the text from bringing their own preconceptions to the reading, and therefore interpreting the text differently from what the author might expect. The ability for there to be contextual 
compatibility between the author's world and the reader's world is highly dependent on the similarity of the worlds, and the amount of time that separates them.

Our understanding of the text then becomes separated from the original intent of the author. The text acquires a life of its own, and becomes a separate entity from the author. This is autonomization. Due to the autonomization of the text, many generations of readers may form their own interpretations of a particular text, each one a unique blend of what the text can recreate of the original context and intent of the author, and the context brought by the reader.

Distanciation was originally defined by Ricoeur (1981), but like many things in philosophy, is not an uncontested idea. Conflict with regards to distanciation falls on two main points: the existence of a single or infinite number of valid interpretations, and the ability to immerse ourselves within the original context of the text.

\section{Section 3: Hirsch and the Dialectic of Single or Infinite Interpretations}

The dialectic with regard to the existence of a single or infinite number of valid interpretations divides the world of classical hermeneutics and the world of metaphysical hermeneutics. Classical hermeneutics tasks itself with finding the true message within a text, and attempts to unearth it with a detailed study of the text that is being studied, the author who wrote it, the subject matter of the text, other texts written at the same time, and the general history of that time period (Bleicher, 1980).

This form of hermeneutics fell out of favour with the works of Dilthey, Heidegger, and Gadamer, who saw hermeneutics as an ontological means of understanding existence itself through the messages that evolve not just from the language of the text, but from our own existence. Since we are all individuals, this foretells an infinite number of potential valid interpretations, based on our own experiences, and our preconceptions of the meaning of the text. By communicating our unique interpretations to others, we share meaning with them and build a collective understanding.

E.D. Hirsch Jr., in his seminal literary criticism work - Validity in Interpretation (Hirsch, 1967), counters this idea of infinite interpretations based on practical, rather than philosophical, grounds. Although each of our interpretations of a text may be unique, that does not necessarily imply that our interpretations are sound, or follow 
the intent of the author when the author created the text. There are interpretations which are obviously superior to others, and which capture more of the original intent of the author.

Authorial intent is very important to Hirsch, since the creation of a work of literature, art, or even conversation has a purpose, and that purpose is meant to be communicated through the work. As readers, we attempt to learn that purpose in our reading of the text and therefore attempt to capture that author's intent. If distanciation creates a gulf between our world and the author's world, then our task is to recreate that world by immersing ourselves in the author's world, as they describe it in the text. Unlike classical hermeneutic scholars, however, Hirsch maintains that the text itself can contain enough of the context to properly convey the message. If it cannot, then we can then say that the author is not effective in communicating their message. We cannot say however that this is due to an impassable gulf caused by a separation of our relative contexts.

Hirsch (1967) defends his ideas by noting the difference in interpretation between meaning and significance. Meaning is the linguistic determination of the words that the author organized, and how they interact to present a cohesive message. Meaning is therefore limited with respect to interpretation, since the lexical symbols employed by the author can only be deciphered in specific patterns and with particular results. Significance, however, is the importance of the author's work to the interpreter and to the larger literary and historical world. Significance indicates how effective the author's message is, and is highly dependent on the contextual factors of both the author's and the interpreter's world. Hirsch (1967) holds that debates about the significance of a work are important, and may resurface in many ages with different determinations, but that debates about meaning can lead to only to the singular determination of the author's intent. Debates about authorial intent can only focus on the usage of the language within the author's original context, and are inflexible with regard to distanciation.

\section{Appropriation and the Immersion within the Context of the Original Text}

Ricoeur termed the unique perception of a text's message based on distanciation as "appropriation" (Ricoeur, 1981). When we interpret a text we "appropriate" its meaning, a process whereby we make the message that is within 
the text our own. Whatever the original text meant to convey is modified by our own prejudices and our own context, distancing us from the historical moment of the text's creation. In Ricoeur (1991)'s words:

"For what must be interpreted in a text is a proposed world that I could inhabit and wherein I could project one of my own most possibilities. That is what I call the world of the text, the world proper to this unique text" (p. 86, emphasis in original text).

Therefore, according to Ricoeur, we cannot bridge the gulf between the author's world and our own, because what we create when we read a text is, in fact, a new world that is different from its originator's.

Lee (1994) extends Ricoeur's definition of appropriation to make it mutual between the reader and the text. As we immerse ourselves in this proposed world through the text, we become an agent of that world, and it appropriates us as we appropriate it. Mutual appropriation is important because once we are agents of a particular world we may be directed to perform some function of behalf of that world. Additionally, in order to communicate with others with regard to the contents of the text, they must also be appropriated by it. This appropriation could occur directly, through their reading of the same text as we, or through us on the text's behalf, if we teach them what we have learned.

Hirsch (1967) deflates Ricoeur's notion of appropriation based once again on practical rather than philosophical terms. Hirsch's claim is that as we become familiar with the text and with the subject matter of the text, we can recreate the context of the text. This is not to say that our own prejudices and perceptions do not impact our imaging of the context of the text, but the belief that we cannot somehow reach out and know the world of the author is extreme. Were we experts with regards to a particular author, their writings, their culture and history, the works of other authors at the time, and the language in which the author wrote, it seems unreasonable that we could not proximate an understanding of the world in which the author wrote a particular text. If this were not the case, all writing would seem alien to us. 


\section{Section 4: Betti and the Concept of Objective Interpretation}

Though he was also a hermeneutics scholar, Hirsch is viewed primarily as a literary critic. Emilio Betti, however, is known as a hermeneutic scholar and theologian, contributing significantly to theories of the interpretation of laws. Betti believed in an 'objective form of interpretation', a concept at odds with the scholars of the Germanic tradition, such as Heidegger and Gadamer, who believed that all interpretation was by nature individual and highly subjective due to the impact of distanciation. Though Betti supported the idea of the impact of context on interpretation, he held that the objects of interpretation were autonomous with respect to their self-meaning. These "meaning-full forms" as he called the objects are artifacts created by authors with the purpose of carrying the author's message (Betti, 1980, p. 58). Therefore, the purpose of interpretation is not to "create" meaning in the Germanic tradition, but rather to expose the meaning within the meaning-full form. In this way, interpretation can be objective, since what is uncovered during an interpretation can be measured against the author's intention. Skill in interpretation is based on the interpreter's inner affinity for the object's purpose, and the interpreter's ability to accept the author's impregnated meaning.

Betti recognizes the possibility of misinterpretation due to the time and space between author and reader, but in his mind, the interpretive purpose is to bridge that gulf. Distanciation is therefore not an insurmountable impediment to recapturing the author's meaning. The author and reader are part of a triadic relationship where the object to be interpreted is the bridge between author and reader. It is the reader's duty to prepare themselves for a faithful interpretation by recognizing and setting aside bias, in particular (Bleicher, 1980, p. 34):

- The conscious or unconscious resentment of positions that differ from the generally accepted ones, or the reader's

- Self-righteousness or close-mindedness which sees issues only in black or white

- Conformist views which tend towards dominant positions

- Intellectual or moral laziness

Though the text of the object is subject to semantic intersubjectivity, this does not impinge on the autonomy of the text as embedded authorial meaning (Bleicher, 
1980, p. 38). This creates the possibility for an objective, albeit possibly imperfect, interpretation.

The argument may be presented that objective interpretation is not possible because the author may be unaware of the meanings embedded in the text does not hold water. Hirsch (1967) explains that although the author may not be consciously aware of the meanings they have embedded in their texts, this does not imply unawareness (p. 22). Even if the author has unconsciously embedded meaning into a text, that meaning is still the author's. It is simply impossible to create meaning without intent.

Betti formulated a number of canons which are used to guide interpretation. These canons aid the interpreter in recognizing and addressing bias during the interpretation, and attempt to instill objectivity in the interpreter's actions.

The first canon is the hermeneutical autonomy of the object (Betti, 1980, p. 58). This implies that an object carries within it the meaning of the author who created the object. Once it is created, however, the meaning within the object is static and autonomous from the author. Though it can be interpreted, this interpretation should be for the purpose of recapturing the meaning within the object and not for any other purpose relevant to the interpreter.

Betti's second canon mirrors the hermeneutical circle, and is called the canon of the coherence of meaning (Betti, 1980, pp. 59-61). Each meaning-full form is a work in totality and it must be understood as a whole. When interpreting a meaningfull form, the parts of the whole build toward a unified meaning, while the meaning of each part is flavored by the overall meaning of the whole. Interpretation is therefore the cyclic journey described by the hermeneutic circle, a shifting of perspective from part to whole. The canon of the coherence of meaning extends beyond a single work, and can be used to understand the complete works of an author as parts which build an understanding of that author, or as parts which build an understanding of a community, or even a culture. In this way hermeneutics can be used to understand how a culture expresses meaning through its works.

Betti's third canon moves away from the object of interpretation and looks toward the subject. Called the canon of actuality of understanding (Betti, 1980, p. 62), this canon states that the interpreter is tasked with retracing the steps of the author of the interpreted object. The interpreter must integrate the thoughts of the 
author within their own intellectual frameworks, and synthesize them. In this way, interpretation is subject to the reader's context, which the German tradition holds with. Betti differs from this tradition in the belief that the author's message can be recaptured in its original form, however, and melded with the interpreter's own beliefs.

A key to this ability lies within Betti's final canon of interpretation, the canon of the hermeneutical correspondence of meaning (Betti, 1980, pp. 84-86). An objective interpretation is based on the interpreter's personal intuition and their understanding of the subject matter, guided by a willingness to accept another's thoughts. The interpreter's understanding of the context of the meaning-full form acts as a bridge towards gaining a true understanding of the other's thoughts, embedded within the meaning-full form. The interpreter cannot be close-minded, and they must possess a strong interest in the material. Betti's canon, however, reaches beyond this and requires a humbling and self-effacement in the presence of the meaning-full form. It is only by an honest recognition and a concerted effort to minimize the impact of prejudice that an interpretation can approach objectivity. The interpreter must also understand the issues that surrounded the creation of the object, and be motivated by a desire to address those issues and determine how the object represented a response by the author.

Betti, like Hirsch (1967), recognizes the difference between meaning and significance. He attributes the confusion between significance and meaning as a major stumbling block in objective interpretation. Though each age that encounters a historical artifact may interpret the importance of that artifact differently, the author's intended meaning for that artifact does not change. Therefore, the significance of a meaning-full form is dependent on the interpreter and the context of the interpretation, however, the actual meaning of the object should not be infringed by this context.

\section{Section 5: Validating an Interpretation}

With respect to the criticism and interpretation of literature, an important gauge of the validity of a critical interpretation is the fidelity of that interpreter's determinations with respect to the subject manner (Hirsch, 1967, p. 8-10). We must 
question whether or not our critical interpretation reasonably considers both the verbal meaning of the text (what the author says by virtue of the use of language and linguistic symbols) and the intentions and aims of the author (what the author meant to convey as a message through their use of language). If we manage to convey to others that our understanding of a text follows the intentions of the author and we are able to speak meaningfully with respect to those intentions, then our critical interpretation may be valid (Hirsch, 1967, p. 161).

Since the evaluation of a critical interpretation of a text is based on the ability to understand the aims of author with respect to the text, this is a focal element of the interpretation. Without a proper understanding of what message the author intended to convey with their text, it is impossible to later develop a meaningful and useful interpretation of the text, and finally to create a useful criticism of that text. It must be realized, however, that any divinations are in fact guesses. One cannot read the author's mind directly. Even if we could confront the author, it is unlikely they could reproduce their exact state of mind at the time the original text was written. Therefore, an interpretation is an approximation of the author's intention, though it is obviously our hope that the interpretation is a good approximation.

All interpretations must be guesses since they rely on the intrinsic characteristics of the interpreter (Hirsch, 1967, p. 166). Since there is no conclusive methodology that can promote the accuracy of guessing, there is no a priori method to ensure a correct interpretation. We can take several steps, however, to promote the likelihood of making good guesses however.

First, a sound understanding of the subject matter improves the likelihood that the linguistic elements of the text are interpreted correctly. That is to say, before attempting to understand the motivations or the intended message of the author, we must first understand what the author is talking about. This follows both Hirsch (1967)'s and Betti (1980)'s requirements for proper preparation for interpretation.

Next, we can formulate a number of potential hypotheses for what the author's aim and message are (Hirsch, 1967, p. 171-2). During the interpretation, we divine and build evidence for each hypothesis, until it is clear which hypothesis is most likely. It is very possible that multiple hypotheses may have validity, which makes our task one of weighing the relative value of each hypothesis, or combining them to provide a single reasonable response. 
Since it is likely that the interpreter has preconceived hypotheses even before the interpretation has begun, it is important that they divulge these hypotheses so that the interpreter is aware of the preconceptions, and the audience is not made to believe that the hypotheses evolved from the text. A preconceived hypothesis is not necessarily invalid, and may be a very accurate assessment of the author's intent. It may be based on previous knowledge of the author and their work, or through reference to the text from other sources. It is important to note, however, that a predetermined hypothesis is contextually different from an emergent hypothesis. A predetermined hypothesis is more likely to be shaped by the interpreter's contextual background, and their intended purpose for the interpretation (Hirsch, 1967, p. 166). The interpreter is likely to be hunting for proof within the text for a predetermined hypothesis, rather than allowing the hypothesis to evolve through an accumulation of evidence that becomes apparent from the contents of the text. By stating the nature of the origin of the hypothesis the audience can then judge if author has been circumspect or self-serving in their evidence gathering.

Evidence used to support a hypothesis can come from within or without the text (Hirsch, 1967, p. 185-8,197). Each hypothesis is defined by a set of traits that make it unique within the hypothesis set. The presence of these traits can be supported or refuted by the evidence we discover, and therefore we can dismiss disparate hypotheses.

Ultimately, the purpose of any critical review of a text is to convince the reader that the interpreter has made a convincing interpretation of the text. Therefore, the validity of an interpretation can be measured, in one sense, by the ability of the interpreter to convince the community of scholars knowledgeable in the subject matter of the text. 


\section{Appendix 2 - History of Hermeneutics}

This section was developed from Mueller-Vollmer (1988), Introduction and from Myers (2004).

\section{Renaissance Period (14 ${ }^{\text {th }}$ and $15^{\text {th }}$ century)}

Interest in classical Greek and Roman texts prompts the development of systematic methods of interpretation. During the early Renaissance, hermeneutics as an epistemology is subsumed by interpretation.

1463 - Constantius Rogerius writes Treatise Concerning the Interpretation of Laws, a culmination of the legal hermeneutics employed to interpret the Roman Code of Justinian (A.D. 533)

1567 - Matthias Flacius Illyricus writes the Clavis Scripturae Sacrae, a manual which refutes the Catholic Church's sovereign right to translate the Bible. The manual promotes the idea of the self-sufficiency of the Bible. A key element to this argument is the idea that the Bible must be interpreted in light of the entire Scriptures, and that poor translations of the Bible were due to poorly trained interpreters.

\section{Enlightenment Period (18 ${ }^{\text {th }}$ century)}

Numerous hermeneutical texts are written. It is at this time, however, that hermeneutics is claimed by the domain of logic and philosophy. General hermeneutics which apply not to a specific literary domain but rather to all knowledge is developed. This will be an important influence for philosophers such as Heidegger and Gadamer. Authors such as Christian Wolff forward the idea that works must be examined critically and that the strength of their arguments are based on the proper usage of words and structural formats.

1742 - Chladenius publishes his Introduction to the Correct Interpretation of Reasonable Discourses and Books. The book contains a collection of practical rules for interpretation. Chladenius develops the idea that any utterance, whether written 
or spoken, must be interpreted. He also develops the concept of "point of view", which dictates that the interpretation of a particular utterance cannot be identical for two individuals unless they are able to view the event from identical physical vantage points, and with identical backgrounds. Since this is not possible, he contends that no two interpretations can be the same.

Though Chladenius is often considered the founder of modern day hermeneutics, his work is still largely normative, and he contends that a "perfect interpretation" is possible; a statement that counters current hermeneutic thought.

\section{Romantic Period (late $18^{\text {th }}$ through early $19^{\text {th }}$ century)}

Developments from many authors in the Romantic period lead to the concept of the author as a creator and their works as extensions of their creative self. German philosophers produce the foundations of modern hermeneutic thought.

Early 1800's - The greatest contributor and the arguable father of modern hermeneutics is Freidrich Schleiermacher, who teaches hermeneutics to students at the University of Berlin. Unfortunately, most of his work is contained in his study notes and in the notes of his students. A coherent collection of his work is not made until long after his death. Much of his work is absorbed by others, and Dilthey, who produces "The Origin of Hermeneutics" (1900) which brings together the ideas that have been developed during the Romantic period, mentions him as simply an advocate of some hermeneutical ideas.

Schleiermacher perceives works of writing as an organic whole, subject to infinite interpretations. Under Schleiermacher's tutelage, hermeneutics begins a transcendental turn and is grounded in the concept of understanding. No longer a method of deciphering ancient texts, hermeneutics becomes a journey of selfrealization, as the act of understanding becomes intrinsically linked with the ability to understand. Any speaker's utterances, for Schleiermacher, involved two planes of understanding. On one plane the reader must interpret the utterance based on its use of language and grammar. On another plane, the reader must understand the utterance as a point in the development of the speaker's life. 
Mid 1800's - Wilhelm von Humboldt expands the concept of understanding to the study of history. In his "On the Task of the Historian", Humboldt rejects the notion that history can be interpreted clinically. Since the historian is not actually present at the time of the historical occurrence, they piece together historical occurrences by providing an internal coherence. This coherence is based on their own understanding of the events and their own background, implying that the interpretation is unique to the individual, and that an interpretation serves a purpose within the particular era that the interpreter makes their interpretation. Additionally, since the interpreter provides a cohesive whole to individual events, this means that the hermeneutical process is based on a repetitive transition from looking at the whole to the parts and then back to the whole. This is the foundation of the hermeneutic circle.

1883 - Johann Gustav Droysen produces the Historik, which follows Humboldt's belief that historians cannot, and should he not, he added, produce objective historical reports. Droysen explained that historical understanding is based on one's self understanding, and that each of one's expressions carry more than simply the language and message, but also carry psychological, emotional, and spiritual content. Historical understanding is grounded in the common ability for people to express their inner nature, and our understanding of the acts of those before us comes from this common ability. Droysen also felt that explicitness was essential to correct interpretation, and produced rules of presentation for historical interpretations.

1886 - August Boeckh, a student of Schleiemacher, produces the Encyclopedia and Methodology of the Philological Sciences. Boeckh defined philology as the task of understanding that which is known and has been produced by humankind in written or spoken form. But philology was more than simply categorization or explanation of these texts. Boeckh believed that, in many cases, the true nature of these textual artifacts was not apparent even to the creators themselves, since the internal and external influences on the creator may not have been apparent to them at the time of creation. This implies that a philologist must employ hermeneutics as a mode of thinking, and had to understand these cultural artifacts better than their creators. 
Late 1800's - Wilhelm Dilthey produces the Critique of Historical Reason. Echoing the thoughts of many of the German philosophers of the time, Dilthey argues for the establishment of the human sciences as distinct from the natural sciences, and therefore the establishment of research methods not based on positivist techniques, but on hermeneutical understanding. In his work he also conceives of the hermeneutical concept of distanciation, which holds that a text gains a life of its own after its creation, independent of its author. Therefore interpretation is not of the author's intended expression of the work (termed Ausdruck) but of the work itself and the life it has gained since its production (termed Äusserung). Dilthey's work represents the transition from $19^{\text {th }}$ to $20^{\text {th }}$ century hermeneutical thought, and was the impetus for Heidegger to write Being and Time.

\section{Contemporary Hermeneutics (20 ${ }^{\text {th }}$ Century)}

Though existential hermeneutics is credited to Heidegger and Gadamer, a number of authors in the first part of the $20^{\text {th }}$ century had a direct impact on their work. In particular, Edmund Husserl developed a series of methodological elements for contemporary hermeneutics that Heidegger's work lacked. In his Logical Investigations, Husserl studies the nature of conscious acts and presented a theory of meaning and understanding. Husserl separated the intended meaning of an expressive act (noemata), and the act itself and its content (noesis). If we correctly apprehend an expressive act then we may automatically equate the two linked elements, but a student of understanding must be able to separate the parts. Particularly, it must be recognized that a particular meaning may be expressed in many different acts, which may carry the meaning identically. Again the audience plays a crucial role in the delivery of a message through an expressive act, based on their own interpretations of the content of the expressive act and their ability to decipher the message contained in the content.

At this time many of the critics of the Germanic tradition begin to disassemble the philosophical positioning of hermeneutics. In particular, some authors refute the idea of infinite interpretation and the Intentionalist school rises to challenge Heidegger's and Gadamer's ideas. 
1927 - Martin Heidegger's Being and Time is released. The book revolutionizes philosophy by attacking the problem of explaining existence based not from philosophical or theological vantage points, but from a hermeneutical vantage point. $\mathrm{He}$ presents the case that the understanding of human existence requires a preunderstanding of ontological concepts. Essentially, in order to explore the nature of being, we must acknowledge that there are elements of being which allow us to make that exploration. The purpose of Being and Time was to expose the hidden constructs of human existence, so that the interpretation of this existence could be made.

This position seems distant from the more practical elements of hermeneutics, but is actually quite relevant for all interpretation. When we make an interpretation, our interpretation is simply the realization of what we already understand. When we make statements based on an understanding, we are simply expressing our interpretation. We are limited in our understanding by the underlying structures that are required for preunderstanding and the interpretative process which builds understanding.

Heidegger also linked language and speech to understanding, promoting Humboldt's ideas that language itself impacts understanding and that understanding is of a linguistic nature. Gadamer would build from these ideas in his work.

1950 - Rudolf Bultmann produces the "The Problem of Hermeneutics" and develops the school of the "New Hermeneutics". He is a student of Heidegger, though his work is theological rather than philosophical in nature. Bultmann believed that interpretation was based on a central existential relationship between the author and the interpreter based on the subject matter of the text. The interpreter's position with respect to the subject matter, and their preunderstanding of the subject matter determined the nature and direction of the interpretation.

1954 - Wimsatt and Beardsley produce twin articles, "The Intentional Fallacy" and "The Affective Fallacy" which challenge the idea of authorial intent. Based on these articles a new school of literary criticism is formed called the New Critics, which 
abandons most of the traditions of hermeneutical interpretation in favour of the emerging ideas of Heidegger and the other German philosophers.

1960 - Hans-Georg Gadamer produces Truth and Method - Outline for a Philosophical Hermeneutics. Gadamer's thoughts are not dissimilar from Heidegger, but push philosophical hermeneutics in a more traditional and methodological direction. Most contemporary definitions for hermeneutical concepts are drawn from Gadamer's work.

Gadamer maintains that interpretation is intrinsically linked to the period of history in which interpreter has been raised, and that an interpreter brings prejudices to the interpretation based on this raising. Rather than viewing these prejudices as detrimental to the interpretation, Gadamer believes that these prejudices are necessary in order to overcome the strangeness of the subject matter being studied, and to transform the subject matter into something that is familiar to the interpreter. A necessary part of historical understanding therefore includes reflection on the relationship between the historical matter and the interpreter, and the interpreters developed cultural and traditional prejudices. Gadamer calls this "effective history".

1967 - Jürgen Habermas produces On the Logic of the Social Sciences. He is critical of Gadamer's position; feeling that, like Heidegger, Gadamer is simply presenting a theoretical position for the understanding of existence, rather than providing methodological guidance for solving problems in the human and social sciences. Habermas searches for the development of specific hermeneutic categories. His thoughts are echoed by Karl-Otto Apel who finds the need for both a general hermeneutics for the understanding of existence and understanding itself, and for specific hermeneutics that can be applied to problems in the human and social sciences.

1967 - E.D. Hirsch Jr., a prominent literary critic and hermeneutic scholar, attacks the ideas of Heidegger, Gadamer, and in particular Wimsatt and Beardsley in his book Validity in Interpretation. The book presents a number of arguments in favour of a belief in authorial intent, and reestablishes the idea of a single correct interpretation, based on its proximity to the author's intentions. Hirsch separates the 
ideas of meaning and significance, allowing traditional hermeneutics (based on meaning taken from authorial intent) and philosophical hermeneutics (based on the significance of the work to the individual reader) to coexist. From this book, and similar articles from other authors, the Intentionalist school emerges to counter the beliefs of the New Critics.

Late $20^{\text {th }}$ Century (Myers 2004) - Hermeneutics as a technique for understanding expands among many disciplines in the human and social sciences. Hermeneutical categories are defined. General or classical hermeneutics treats texts as objects that can be investigated, though this must be done through empathic understanding. Existential hermeneutics, based on Heidegger's and Gadamer's work, represents an ontological position to facilitate the understanding of existence. Postmodern hermeneutics challenges the belief that a "true" understanding of a text can be made, and argues that every interpretation is unique and contingent on the community which determines the validity of the interpretation. Critical hermeneutics takes a stance between general and postmodern hermeneutics, recognizing that interpretation is highly dependent on the interpreter and the context of the interpretation, but conceding that some interpretations may be better than others. Intentionalists refute the idea of multiple valid interpretations and hold to the belief that the only valid interpretation is that which distills the original message of the author. 


\section{Appendix 3- Hermeneutical IS Studies}

\section{Boland (1991)}

Boland (1991) is considered one of three exemplar studies by Myers (2007). Boland, however, possesses a different interpretation of the nature of hermeneutics than many other IS researchers. Boland considers hermeneutics to be a technique of interpretation, but that technique is situated within the phenomenological approach. He seems to use the terms "hermeneutics" and "phenomenology" as synonyms and justifies "the hermeneutic approach" (1991, p. 439) using a phenomenology approach paper as justification (Boland, 1985).

Boland (1991) takes a fresh look at research in information systems, treating the output of these systems as a text which can be interpreted hermeneutically. In this article, Boland unites the ideas of three other authors, Stephen C. Pepper, Richard Rorty, and Paul Ricoeur, and weaves them together to make his point regarding the interpretation of information systems.

Pepper believed that the pursuit of a single encompassing theory of everything was not possible because there were several plausible competing theories, each based on a different organizing theme. Pepper created a two-by-two grid with each of four theories in a quadrant. The horizontal axis is based of whether the theory was analytical (examining ideas by breaking them into components), or synthetic (examining ideas by understanding their place within larger wholes). The vertical axis determines whether the theory is dispersive (looks at ideas as separate elements which have no fixed relation to each other) or integrative (looks as ideas as fixed elements which combine in law-like systems).

Though Boland does not deal extensively with Pepper's categorizations, he indicates that the importance of the different perspectives is that no idea can wholly explain reality without refuting the ideas of the other perspectives. Therefore, either the ideas must co-exist naturally, implying multiple valid positions to any problem, or one position must dogmatically deny the other positions. Though Pepper favoured a view where all perspectives were considered equally valid, his critics found his ideas too open to relativism. Boland segues to the work of the second author, Rorty, as a means to counter Pepper's critics. 
Rorty lends supports to Pepper's flexibility of categorizations based on a belief that the world is subject to infinite interpretation and it is only through that interpretation that we understand the world. In other words, Rorty argues for a hermeneutic perspective, rather than an absolute view, which Rorty feels is characteristic of the philosophical tradition of the social sciences. He sees the vocabularies we build not as approximations of the essence of things, but rather as a device for the creation of our own understanding of the world. This view, somewhat ironically, is in stark contrast with the phenomenological view that Boland seems to espouse in his previous literature. This view of the world as created by our own vocabularies and the understanding that our interpretation provides us is distinctly hermeneutic in my interpretation, and provides a sharp contrast to Boland's (1985) phenomenological account. It would seem that Boland's interpretation of phenomenology is essentially a description of hermeneutics, or that Boland is undergoing a profound change in attitude during the creation of this article. Since Boland does not seem to draw attention to this transition, it is likely that he sees phenomenology and hermeneutics as the same. If this is the case, then Myers (2007) categorization of Boland (1995) may be flawed. The similarity of phenomenology and hermeneutics is justified based on Boland's involvement of Ricoeur (1991) in the dialogue. Ricoeur (1991) perceives a very close relationship between phenomenology and hermeneutics, eventually describing his own "phenomenological hermeneutics".

\section{Butler and Fitzgerald (1997)}

Butler and Fitzgerald performed a case-based study of an organization in order to determine the nature of user participation in system development. The study follows the recommendations of an extensive review of user participation in SAD by Cavaye (1995), calling for a qualitative case-based empirical study that treats user participation as a complex phenomenon. Butler and Fitzgerald (1997) attempted to expand Cavaye (1995)'s work, to provide a meta-analytic framework to explain the previous work, and guide new research.

Butler and Fitzgerald (1997)'s study is an exploratory case-study of one organization studied during two particular development projects. It is not specifically stated in the case why the organization that was studied was chosen, though it can 
be inferred due to the fact that one of the authors was a member of the organization and therefore had intimate knowledge and access to the organization.

Though the authors state that their research included twenty-one interviews of members associated with the development of the two projects, they also refer to "documentary sources" as a potential text for their interpretation. It is not clear if the interviews were done separately for each project, though the projects had very different total lengths and the interviewing period lasted one month. It might be reasonable to assume that the interviews were conducted after the completion of both projects, since the authors give details about the entire development process for both projects. It is not stated whether or not the interviews were conducted directly after the completion of either of the projects. This is important, because the attitudes and views of the participants can change over time, as the event in question recedes from the present, and new experiences temper older views (Ricoeur, 1991, p. 5).

It is also not made clear if any or all of the interview participants were involved with both projects, though the nature of the two systems (one a serviceman appointment system and the other a geographical information system) make it likely that the at least some of the interviews involved discussions about a single project. It may be the case, however, that some of the development staff was involved with both projects, though this is not stated. This is also important, as the experiences of persons involved with both projects may be difficult for them to isolate, and they may be speaking in general about development at the firm.

The role of the author who was a member of the firm in the projects is unspecified, though the description of his general involvement makes it likely he was not a direct member of either project, but was knowledgeable about development in general at the firm, and the climate of the organization during the periods when the projects occurred. Overall, therefore, it is likely that the observations, interpretations, and opinions of the author, the texts of the interviews themselves, and a number of other sources have been woven into the study, making it very difficult to specify exactly what the "text" that was interpreted is. This is not necessarily problematic with respect to the conclusions that the authors make, but it does call into question their specification of the scope of the research, as it is likely that their interpretation reflects elements outside of the two projects in question. 
The hermeneutical elements of the study are never specified, such as historicity, the hermeneutic circle, and distanciation. The analysis seems to follow a qualitative checklist, based on an amended form of Cavaye (1995)'s study which simply indicates the elements of user participation that were detected during the study. It is also not specified what the underlying conflict is which is resolved through the interpretation, a central element to the use of hermeneutics as a method of analysis (Taylor, 1976). Though there is conflict with regards to the perception of user participation as a means to improve systems, this conflict is within the academic discipline, not within the text itself, and is therefore not hermeneutically linked to the study. It is difficult, therefore, to actually call this an actual hermeneutic study. It is perhaps better to say that this is an interpretive or qualitative study that may have been guided by the interpretive elements of the hermeneutic tradition.

This is an important observation, since it would seem that in many cases, hermeneutics is employed more in name than in substance in many studies. Hermeneutics seems to a certain extent to defy a tight definition, being a method of analysis (Myers 2007), a philosophical vantage point from when interpretation is guided (Heidegger, 1962, p. 31), a research approach (Lee, 1994), and a technique for the interpretation of texts (Ricouer, 1991, p. 16).

\section{Davis et al. (1992)}

Davis et al. (1992) is a novel study for many reasons. The study builds a framework for diagnosing system failure, using a four-by-four grid based on a social system dimension and a technical system dimension. The placement of data within each location in the grid is informed by an interpretive process, and then the overall interpretation of the resulting completed grid is subjected to a second interpretive process in order to build a narrative of the system failure. We therefore have a positivistic classification system for diagnosing system failure which is informed by two successive interpretive processes.

Unlike many hermeneutic studies which liberally sprinkle their study with references to the hermeneutic principles or to the prominent hermeneutic researchers, Davis et al. (1992) focuses on a two principal hermeneutic ideas. The 
first is the concept of underlying conflicts which become reasonable through subsequent interpretation of the text. The second is the hermeneutic circle.

The layout and construction of the paper is also novel because it is probably the only paper I encountered which contains a complete account of the methodological process used to interpret the data. Each step of the interpretation process is fully chronicled, from the initial building of the categories of the framework, through the initial interpretation and categorization of the data, to the challenges to the initial interpretations, the development of alternate theories which explained the apparent conflicts in the data, and the eventual resolution of anomalies in the data.

As the authors move from step to step, they describe the nature of the conflicts they face and how they employed theories-in-use to resolve the conflicts. Ultimately, they resolve the conflicts in the text by employing Douglas McGregor's Theory $\mathrm{X}$, a motivational theory that presumes that employees are lazy and must be motivated and controlled. Therefore, the somewhat amusing determination of this study is that systems fail primarily because employees are lazy.

\section{Klecun-Dabrowska and Conford (2000)}

This study is a hermeneutical analysis of four UK health policy papers published between 1989 and 1998. Since the principle texts of the study are actually written documents, as opposed to transcriptions of interviews, I felt that this would be an excellent study to gain a methodological understanding of a hermeneutic process.

The stated purpose of the study is to gain an understanding of the emerging concept of telehealth, which encompasses the use of information and communication technologies (ICTs) for the purpose of promoting health among a wide range of people of differing age and health backgrounds. Since the concept was considered to be very new at the time of the study, the authors attempt to build an understanding of the concept based on a selection of white and green papers that discuss it in a larger health context.

The hermeneutical stance of the paper is interesting, since it reveals the conflicts in Gadamer's work that led to Hirsch's criticisms. This is not intentional on Klecun-Dabrowska's and Conford's part, but rather it evolves from their use of two Gadamerian principles that seem to conflict, or at least in my interpretation do so. In 
the first passage, we are introduced to Gadamer's belief in the lack of authorial intention.

"The notion of validity of interpretation was linked in particular to uncovering the author's intentions. However, this view came to be disputed later, notably by Gadamer (1976). He emphasizes the historical perspective of meaning and the role of an interpreter (reader of the text) in the process of understanding. Thus, the text can have many meanings rather than one meaning. Gadamer considers meaning as dependent on the context, and he see understanding as situated, e.g. historically and culturally. Yet this approach does not imply total relativity and that any interpretation is acceptable. Gadamer suggests that understanding must be critical and reflexive, involving a dialogue with the text and awareness of our own (the reader's) prejudices." (Klecun-Dabrowska and Conford, 2000, p. 44)

Already, there are questions that rise to my mind with the statements above. If the understanding of the text is based solely on our preconceptions and the content of the text, then any interpretation that comes to our mind during the reading would, in theory, be valid. Regardless of metaphysical considerations, unless the text can actually respond to the act of reading it, its position within the dialogue is static. The actual words do not change each time the text read the text, only the perceptions of the reader change. Therefore, only the reader's considerations of the text are valid, as per Gadamer's argument.

If we conceive of the text as an actual member of a dialogue, as Gadamer seems to describe, then it must have a message of its own embedded within. But where does this message come from? Again, setting metaphysical considerations aside, since the text is static in its nature then the most likely source for the message is the text's author. But that would conflict with Gadamer's earlier statements.

The position becomes further muddled when Klecun-Dabrowska and Conford (2000) discuss the concept of foreknowledge, which they credit as central to hermeneutics (pp. 4-5). Foreknowledge, which is our prejudices or preconceptions of a text, form part of the interpretation process, and it is essential that they be 
questioned and made specific. Klecun-Dabrowska's and Conford's examples of foreknowledge make specific reference to background information that would be external to the text. Once again, this is in contrast to Gadamer's position of the text as an isolated and complete whole. Additionally, if we are made aware of the author's intentions for the message of the text through this background information, how could we possibly discount this in our interpretation?

The strength of Klecun-Dabrowska and Conford (2000) as a hermeneutic study comes from their explicit adherence to the hermeneutic circle. The explicitly note that a first interpretation was made of the papers studied, and they indicate their transitory findings at the completion of that cycle of the hermeneutic circle. They develop a number of hypotheses to explain these initial interpretations, which they first subject to alternative interpretations, and then, through a second reading, bind to existing IS theories. Regrettably, they neglect to explain the process by which these hypotheses are extracted from the text.

\section{Klein and Myers (1999)}

Klein and Myers (1999) responds to a growing interest in determining how interpretive research should be conducted, and how to validate it. Since interpretive research has now established itself as a legitimate means to study phenomenon related to information systems interests, researchers must now learn how to actually conduct interpretive research, and editors and other researchers must learn how to evaluate that research. This study focuses on the conduct of interpretive field research studies but does not explore other possible uses of hermeneutic techniques. Therefore, I have focused primarily on the elements of the study that are relevant to general hermeneutical research in IS.

The most useful general principles come from the introduction Klein and Myers (1999) make with regard to differentiating the terms "qualitative" and "interpretive" in research. This is important as the terms tend to be treated as synonyms, though, as shown in Myers (2007), qualitative research can also be positivist or critical, depending on the underlying research philosophy. Positivist research assumes a priori hypothesis, quantifiable measures of variables, and the ability to infer determinations about the general population based on a sample. This is similar to most quantitative research, but employs techniques based on case study 
reports and other qualitative data sources. Critical research investigates the nature of social phenomena for the purpose of social critique. Interpretive research assumes that our knowledge of reality is constructed through language, shared meaning, texts, and other artifacts. The authors provide examples of positivist, critical, and interpretivist qualitative research to demonstrate their descriptions.

\section{Lee (1994)}

Lee (1994) is the second exemplar hermeneutic study as judged by Myers (2007). In some ways, Lee (1994) may be one of the most important interpretive studies within the IS discipline. Allen Lee has held various editor positions with the information systems journal Management of Information Systems (MIS) Quarterly from 1990 until 2004. While he was a senior editor at MIS Quarterly, Allen Lee made an important contribution to the perception of interpretive research. In 1994, a hermeneutic-based interpretive article he authored was published in an issue of MIS Quarterly. Previous to this inclusion, MIS Quarterly had been perceived as solely a quantitative-based journal. Lee effectively opened the doors for further interpretive and qualitative research to be included in the magazine, and through its placement in the premiere journal in the IS discipline, opened the doors for the inclusion of qualitative research studies in other top-level IS journals. Without Lee's contribution, it may have taken many more years for qualitative research to be legitimized within the IS research community.

In the article "Electronic Mail as a Medium for Rich Communication", Lee (1994) performs a hermeneutical study of a series of electronic mail conversations ${ }^{2}$ between members of an organization. The electronic mails were drawn from another study by Lynn Markus (Markus, 1994), and revolve around a member's request for further training. The email is sent to a number of members in the organization, including members that the sender should not normally have contacted directly. This causes a cascade of reply emails from different parts in the company, including involvement by an Executive Vice President.

\footnotetext{
${ }^{2}$ The term "electronic mail" is used instead of e-mail since the system was a proprietary communication system and not actual e-mail.
} 
The stated purpose of Lee's (1994) paper was to demonstrate, through a hermeneutic interpretation of the text consisting of the electronic messages, that the characteristics of a rich communication can be found in this medium. Additionally, the paper provides evidence for employing interpretive techniques to study phenomenon that have traditionally been studied using positivist techniques, and have been evaluated using positivist theories. Lee (1994) is developed with a strong adherence to the principles of hermeneutics, such as distanciation, autonomization, appropriation, and enactment, and he describes these in the paper.

Lee's study is largely a description of the interpretation of the emails performed by Markus (1994), which he highlights elements of to demonstrate the hermeneutic techniques. This causes a "double hermeneutic" situation, since Lee is interpreting Markus's interpretation of the original emails in the text. "Double hermeneutics" are often problematic as they represent multiple layers of distanciation from the original source material. Lee does include excerpts from the original conversations found in Markus's study, which allows the reader of Lee's study to form their own opinions with regard to the validity of his conclusions.

As a hermeneutic study, Lee's paper is a very brief interpretation of a small section of the overall text. He does not expose the methodology he used in his study, nor does he provide a great deal of background information for the electronic messages that form the text he used for the interpretation. He highlights specific messages that illustrate his points, and though he makes a good case for his argument, there is a certain sense that his article was meant to be illustrative of how a hermeneutic study would be completed, rather than being a complete hermeneutic study in itself. He explains the concepts that underlie hermeneutic interpretations, and includes samples from the text that demonstrate these concepts. Overall, his paper can be considered a good introduction to Hermeneutics, though it is lacking somewhat as a complete hermeneutic study.

\section{Lacity and Janson (1994)}

Lacity and Janson present a framework for the organization of text-analysis methods. They categorize the methods as positivist, linguistic, or interpretivist. Positivist approaches search for regular patterns within text, and assume an objective outsider's role for the researcher. Linguistic text-analysis methods also 
assume an outsider's role for the researcher but search for an emergent meaning in the text, based on the relationship between language and the reality it creates. Interpretive text-analysis methods are subjective, where the researcher is an intimate part of the meaning development process itself and forms a unique opinion that may differ from the author and audience of the text.

The paper balances discussions of the three types of text-analysis and presents both methods and examples of each type within the IS literature domain. The paper also contains a section for each type discussing how the method is generally validated.

Though it was interesting and enlightening to examine the other types of textanalysis methods and philosophies that existed, my primary purpose in reading the paper was to learn about specific methods related to interpretive research. The study describes hermeneutics based primarily on the older tradition of biblical exegesis, rather than the more contemporary ontological or metaphysical hermeneutics. Traditional hermeneutics focuses on determining the author's message within the text, while considering of course the contexts of the author's and the reader's world. Interestingly, the authors state that hermeneutics may not have a place in contemporary research, since the texts that are interpreted are generated in the present, rather than the past. This view would seem to indicate that the authors are not well versed in the more contemporary forms of hermeneutics, which have largely dispensed with the interpretation of classical passages in favour of interpretations of conversations, actions, and even the principles of knowledge itself. This interpretation, however, is not supported by their choice of references which include Gadamer, Husserl, and Winograd and Flores (1986). In particular, the reference to Winograd and Flores (1986) would seem to imply an understanding that hermeneutics can be applied to modern concepts in IS, as Winograd and Flores leverage hermeneutics to interpret contemporary information systems.

Moving past this contradiction in the text, I will say that this classical view follows nicely with Hirsch's criticisms of modern hermeneutics, which he feels have obliterated the importance of the author in the search for existential principles (Hirsch, 1967). It also aligns better with the purpose of my study. Though I recognize the importance and usefulness of Heideggerian and Gadamerian hermeneutics, for my purposes the more classical hermeneutics, or its resurgence in 
Ricoeur's or Hirsch's work are more pertinent. I do not concur with Lacity and Janson (1994)'s belief that classical hermeneutics techniques may be inappropriate to the interpretation of current texts. The temporal proximity of the author's and the reader's worlds would seem to boost the probability of an accurate interpretation, though even temporal proximity may not alleviate other contextual differences such as culture. The author's later statement that hermeneutics "typically deals with ancient manuscripts" may be best explained by their interest in what they consider to be the alternative interpretive technique, intentional analysis. Since the study used as an example for this technique is authored by Lacity, the authors may simply have a preference for intentional analysis and are biased against hermeneutics.

Whether biased or not, Lacity and Janson (1994) do present a number of useful techniques to be employed in a hermeneutical study. They state that a critical element of making an interpretation is an understanding of the other work of the author, as well as other texts of the same time period. Though this principle seems to be lacking in much of the current hermeneutic thought (as criticized by Hirsch, 1967), I feel it essential for understanding the author's message. Perhaps the most compelling element of hermeneutics for me is the link between the author and the author's world and the bridge that must be built to meet the reader and the reader's world. Lacity and Janson (1994) provide an example of this immersion by Newton (1989). Newman hoped to understand the intent of a project manager he interviewed. To supplement this understanding, he interviewed a number of other members of the organization, to build a picture of the world in which they worked.

Lacity and Janson (1994) state that hermeneutic interpretation is a process of immersion, which they support using reference to Gadamer's hermeneutic circle. This interpretation often requires additional readings of the text, so that the author can "live with a text to understand it" (Lacity and Janson, 1994, p. 150, emphasis in original text). I must consider this and incorporate it into my study. Overall, Lacity and Janson (1994) provides an interesting view of classical hermeneutics (whether intentionally or not) and provides a number of methodological ideas that I can incorporate into my study. 


\section{Zahedi et al. (2006)}

Zahedi et al. (2006) represents an analytical form of hermeneutical study. The authors of the study evaluated ninety web pages, with the purpose of determining how the text on these pages could be classified as masculine or feminine, and what particular traits corresponded to each gender of page. The choice of pages seems to have been guided by a desire to capture exemplars of each gender, as masculine pages included the U.S. Army, Field and Stream, Men's Health, Popular Mechanics, and Soldier of Fortune. Feminine pages included Family Circle, Voices of Women, Country Living, and Woman's Day. The study develops four signifiers of masculinity and femininity in the messages of these pages:

- Belief Signifiers - Show the underlying assumptions for what is acceptable for masculinity and femininity for the message

- Attitude Signifiers - Show the message's feeling and emotional state

- Rhetoric Signifiers - How language is used stylistically and for persuasion purposes in the message

- Syntactic Signifiers - The actual method of organizing and displaying words for the purposes of conveying the message, such as the use of highlighting, emphasis, and sentence structure.

The authors of the study present a very clear picture of the structural divisions of their methodology. In their words:

"Our approach could be viewed as a hierarchy, starting with the interpretive perspective on the top, next moving to a specific methodology (grounded theory), and, finally, using techniques (hermeneutics and semiology) for data collection and analysis." (p. 90)

The study claims to employ Gadamer's philosophical hermeneutics for the analysis of their data, essentially categorizing this as a "universal mode of philosophy" (p. 90, quoting Burrell and Morgan, 1979). They claim to use Habermas's "critical hermeneutics" approach for the discussion of their results. It is interesting to note in this study the employment of multiple hermeneutical perspectives at differing levels of the methodology. It must be said, however, that the data is analyzed principally using semiotics (the study of symbols and signs in language) which focuses on the 
nature of the message for the purpose of classification rather than focusing on the deeper meaning it represents with the purpose of understanding the goals and context of the webpage. Therefore, the link to Gadamer's hermeneutics is somewhat weak. Myers (2007) classifies semiotics and hermeneutics as separate techniques for the study of textual material, rather than classifying semiotics as a method of hermeneutical study, supporting this conclusion. The authors do, however, employ Gadamer's hermeneutical circle, which focuses on a broad understanding of the text before focusing on parts of the text, as a guiding method for their analysis.

Though the study claims to the use of grounded theory as a methodology, the stark contrast between the likely messages expected from masculine and feminine classified web sites, and the wealth of previous literature on the difference between male and female means of communication make it likely that the study was heavily influenced by the preconceptions of the authors. The authors, in the proper hermeneutical tradition, do expose this possibility of influence from their previous understandings of the topic, but the determinations of their study seem to fall into patterns that confound the nature of a grounded theory study. Perhaps the most interesting element of their study was their admittedly small selection of sites that displaying gender traits opposite to that which was to be expected. 


\section{Appendix 4 - Citations for Sample Textbooks}

Dennis, A. and Wixom, B.H. (2000). Systems Analysis and Design: An Applied Approach. New York: John Wiley \& Sons, Inc.

Dennis, A. and Wixom, B.H. (2003). Systems Analysis and Design: An Applied Approach, $2^{\text {nd }}$ Edition. New York: John Wiley \& Sons, Inc.

Dennis, A., Wixom, B.H., and Roth, R.M. (2000). Systems Analysis and Design: An Applied Approach, $3^{\text {rd }}$ Edition. New York: John Wiley \& Sons, Inc.

Satzinger, J.W., Jackson, R.B., and Burd, S.D. (2002). Systems Analysis and Design in a Changing World, $2^{\text {nd }}$ Edition. Boston, MA: Course Technology.

Satzinger, J.W., Jackson, R.B., and Burd, S.D. (2004). Systems Analysis and Design in a Changing World, $3^{\text {rd }}$ Edition. Boston, MA: Course Technology.

Whitten, J.L., Bentley, L.D., and Ho, T.I.M. (1986). Systems Analysis \& Design Methods. St. Louis: Times Mirror / Mosby College Publishing.

Whitten, J.L., Bentley, L.D., and Barlow, V.M. (1989). Systems Analysis \& Design Methods, $2^{\text {nd }}$ Edition. Homewood, IL: Irwin.

Whitten, J.L., Bentley, L.D., and Barlow, V.M. (1994). Systems Analysis \& Design Methods, $3^{\text {rd }}$ Edition. Burr Ridge, IL: Irwin.

Whitten, J.L., Bentley, L.D., and Dittman, K.C. (2004). Systems Analysis \& Design Methods, $6^{\text {th }}$ Edition. Boston, MA: McGraw-Hill / Irwin.

Whitten, J.L. and Bentley, L.D. (2007). Systems Analysis \& Design Methods, $7^{\text {th }}$ Edition. Boston, MA: McGraw-Hill / Irwin. 


\section{Appendix 5 - Contextual Timeline for Subject Texts}

\begin{tabular}{|c|c|c|c|c|c|c|}
\hline $\begin{array}{c}\text { Text } \\
\text { Name }\end{array}$ & Edition & $\begin{array}{c}\text { Release } \\
\text { Date }\end{array}$ & Context & $\begin{array}{c}\text { Practitioner Views at } \\
\text { the Time }\end{array}$ & $\begin{array}{c}\text { Academic Views at } \\
\text { the Time }\end{array}$ & $\begin{array}{l}\text { Curriculum } \\
\text { Guidelines }\end{array}$ \\
\hline $\begin{array}{l}\text { Whitten et } \\
\text { al. }\end{array}$ & $1^{\text {st }}$ & 1986 & $\begin{array}{l}\text { Many marketed } \\
\text { methodologies } \\
\text { (Avison and } \\
\text { Fitzgerald, } \\
\text { 1988) } \\
\text { - CASE tools } \\
\text { emerging } \\
\text { Frequent IS } \\
\text { project failure } \\
\text { - User } \\
\text { involvement } \\
\text { becoming } \\
\text { critical }\end{array}$ & $\begin{array}{l}\text { - } \quad \text { Strong engineering focus } \\
\text { - Management pressure for } \\
\text { methodological adoption } \\
\text { - Some practitioners still } \\
\text { show faith in } \\
\text { methodologies despite } \\
\text { issues (Jenkins et al } \\
\text { 1984) } \\
\text { - Practitioners looking for } \\
\text { organizational skills and } \\
\text { business analysis skills in } \\
\text { employees } \\
\text { - Specific technical skills very } \\
\text { important }\end{array}$ & $\begin{array}{l}\text { Increased rigour, but } \\
\text { links to practice (Keen, } \\
1980 \text { ) } \\
\text { Early questions of the } \\
\text { validity of structured } \\
\text { approach } \\
\text { Believe that focus of } \\
\text { education should be } \\
\text { career development not } \\
\text { job training }\end{array}$ & $\begin{array}{ll}\text { - } & \text { ACM } 1982 \\
\text { - } & \text { Direct } \\
\text { undergraduate } \\
\text { path to IS analyst } \\
\text { positions } \\
\text { - } \quad \text { Methodological } \\
\text { focus begins } \\
\text { - Early tools still in } \\
\text { place }\end{array}$ \\
\hline $\begin{array}{l}\text { Whitten et } \\
\text { al. }\end{array}$ & $2^{\text {nd }}$ & 1989 & $\begin{array}{l}\text { Mini and } \\
\text { microcomputers } \\
\text { emerge } \\
\text { CASE tools } \\
\text { established } \\
\text { - End-user } \\
\text { computing } \\
\text { developed } \\
\text { IS graduates still } \\
\text { a minority }\end{array}$ & $\begin{array}{l}\text { - Methodologies common but } \\
\text { not disciplined in use } \\
\text { - Many emerging } \\
\text { technologies prompt review } \\
\text { of development paradigms } \\
\text { - Prototyping emerges as a } \\
\text { new development } \\
\text { paradigm }\end{array}$ & $\begin{array}{l}\text { Methodology movement } \\
\text { (Avgerou and Cornford, } \\
\text { 1993) } \\
2^{\text {nd }} \text { generation of early } \\
\text { methodologies. } \\
\text { Information engineering } \\
\text { and Yourdon's } \\
\text { structured analysis } \\
\text { update (Yourdon, 1989) }\end{array}$ & - $\quad$ ACM 1982 \\
\hline $\begin{array}{l}\text { Whitten et } \\
\text { al. }\end{array}$ & $3^{\text {rd }}$ & 1994 & $\begin{array}{l}\text { - PC are now } \\
\text { common in } \\
\text { business } \\
\text { Business } \\
\text { process } \\
\text { redesign } \\
\text { concepts } \\
\text { emerge } \\
\text { Many } \\
\text { established } \\
\text { systems } \\
\end{array}$ & $\begin{array}{l}\text { Desire to integrate IT and } \\
\text { business } \\
\text { - IT viewed as an enabler of } \\
\text { business } \\
\text { - Prototyping now an } \\
\text { established design } \\
\text { paradigm } \\
\text { - Methodology use is very } \\
\text { fragmented. }\end{array}$ & $\begin{array}{l}\text { - JAD, RAD, and Object- } \\
\text { Oriented system } \\
\text { development paradigms } \\
\text { emerge } \\
\text { - Strong condemnation } \\
\text { for structured } \\
\text { methodologies and } \\
\text { SDLC emerging. } \\
\text { (Fitzgerald, } 1996 \text { and } \\
\text { others) }\end{array}$ & $\begin{array}{l}\text { - ACM } 1995 \text { would } \\
\text { follow soon } \\
\text { however. } \\
\text { Strong } \\
\text { methodological } \\
\text { focus }\end{array}$ \\
\hline
\end{tabular}




\section{Appendix 6 - Additional Bibliography}

Additional sources used in the study, but not referenced by name.

Alter, S. (1999). A General, Yet Useful Theory of Information Systems. Communications of AIS, 1(13), 1-70. Retrieved October 16, 2006, from http://cais.isworld org/articles/1-13/.

Alter, S. (2004). Desperately Seeking Systems Thinking In the Information Systems Discipline. Proceedings of the Twenty-Fifth International Conference on Information Systems, 757-770.

Alter, S. and Browne, G.J. (2005). A Broad View of Systems Analysis and Design: Implications for Research. Communications of the Association for Information Systems, 15, 981-999.

Angell, I.O. and Straub, B.H. (1993). Though This Be Madness, Yet There is Method In 't. Journal of Strategic Information Systems, 2(1), 5-14.

Atwater, J.B. and Pittman, P.H. (2006). Facilitating Systemic Thinking in Business Classes, Decision Sciences Journal of Innovative Education 4(2), 273-292.

Avgerou, C. (2000). Information Systems: What Sort of Science is it? Omega, 28(5), 567580.

Avgerou, C. (2005). Doing Critical Research in Information Systems: Some Further Thoughts. Information Systems Journal, 15(2), 103-109.

Avgerou, C. and Siemer, J. (1999). The Academic Field of Information Systems in Europe. European Journal of Information Systems, 8(2), 136-150.

Avison, D.E. and Fitzgerald, G. (1991). The Nature of Information Systems and the Role of Practice. Systems Thinking in Europe, Proceedings of the United Kingdom Systems Society Conference, 459-64.

Avison, D.E. and Wood-Harper, A.T. (1986). Multiview - An Exploration in Information Systems Development. Australian Computer Journal, 18(4), 174-179.

Baskerville, R. and Myers, M.D. (2004). Special Issue on Action Research in Information Systems: Making IS Research Relevant to Practice--Foreword. MIS Quarterly, 28(3), 329335.

Benbasat, I., Goldstein, D.K. and Mead, M. (1987). The Case Research Strategy in Studies of Information Systems. MIS Quarterly, 11(3), 369-386.

Berelson, B. (1952). Content Analysis in Communications Research. Glencoe, IL: Free Press. 
Bjerknes, G. (1992). Dialectical Reflection in Information Systems Development. Scandinavian Journal of Information Systems, 4, 55-77.

Boynton, A.C. and Zmud, R.W. (1987). Information Technology Planning in the 1990's: Directions for Practice and Research. MIS Quarterly, 11(1), 58-71.

Braa, K. and Ogrim, L. (1994). Quality Assurance - An Assurance of Quality? Application of the ISO standard in System Development, Proceedings of the Twenty-Seventh Hawaii International Conference on System Sciences. Vol.IV: Information Systems: Collaboration Technology Organizational Systems and Technology, 842-51.

Braa, K. and Ogrim, L. (1995). Critical View of the Application of the ISO Standard for Quality Assurance, Information Systems Journal, 5(4), 253-270.

Brewer, J.L., Dittman, K., and Ghatge, G. (2006). A Study of Software Methodology Analysis:"Great Taste or Less Filling". Information Systems Education Journal, 4(71). Retrieved June 1, 2007, from http://isedj.org/4/71/.

Brown, J. and Cooke, S. (2006). A Business School Information Systems Development Process Review. Information Systems Education Journal, 4(51). Retrieved June 1, 2007, from http://isedj.org/4/51/.

Bryant, K.C. (2003). A Methodology for the Design of Courses in Information Systems. Proceedings of the Fifth Australasian Conference on Computing Education, 20.

Burnett, G., Dickey, M.H., Kazmer, M.M., and Chudoba, K.M. (2003). Understanding Virtual Community through Language: A Cultural Hermeneutic Examination. Academy of Management Proceedings, A1-A6.

Butler, T. (1998). Towards a Hermeneutic Method for Interpretive Research in Information Systems. Journal of Information Technology, 13(4), p285-300.

Butler, T. (2000). Transforming Information Systems Development through Computer-Aided Systems Engineering (CASE): Lessons from Practice. Information Systems Journal, 10(3), 167-193.

Butler, T. and Murphy, C. (2007). Understanding the Design of Information Technologies for Knowledge Management in Organizations: A Pragmatic Perspective. Information Systems Journal, 17(2), 143-163.

Cardinali, R. (1988). Business School Graduates - Do They Meet the Needs of MIS Professionals? Words, 16(5), 33-35.

Cassel, L., McGettrick, A., and Sloan, R.H. (2006). A Comprehensive Representation of the Computing and Information Disciplines. ACM SIGCSE Bulletin, Proceedings of the 37th SIGCSE Technical Symposium on Computer Science Education SIGCSE '06, 38(1).

Chalmers, M. (2004). Hermeneutics, Information and Representation. European Journal of Information Systems, 13(3), 210-220. 
Chapman, A. (1980). The Textbook as a Primary Source: How to Wring Benefits from Conventional Textbooks. Social Education, 44, 87-91.

Chatzoglou, P.D. and Macaulay, L.A. (1996). Requirements Capture and IS Methodologies. Information Systems Journal, 6(3), 209-225.

Chatzoglou, P.D. and Macaulay, L.A. (1997). Importance of Human Factors in Planning the Requirements Capture Stage of a Project. International Journal of Project Management, 15(1), 39-53.

Chen, B. (2006). Teaching Systems Analysis and Design: Bringing the Real World into the Classroom. Information Systems Education Journal, 4(84). Retrieved June 1, 2007, from http://isedj.org/4/84/.

Clausen, H. (1994). Designing Computer Systems from a Human Perspective: The Use of Narratives. Scandinavian Journal of Information Systems, 6(2), 43-58.

Constantine, L. and Yourdon, E. (1979). Structured Design. Englewood Cliffs, N.J.: Prentice Hall, 1979.

Cox, J.F. and Snyder, C.A. (1985). Systems Analysis in a Complex Environment: An Interactive Educational Approach. Information and Management, 8(5), 247-252.

Crispin, L. (2006). Driving Software Quality: How Test-Driven Development Impacts Software Quality. IEEE Software, 23(6), 70-71.

Cronholm, S. (2006). Nine Principles for Designing a Study Program. Information Systems Education Journal, 4(31). Retrieved June 1, 2007, from http://isedj.org/4/31/

Daigle,R., Longenecker Jr., H.E., Landry, J.P., and Pardue, J.H. (2004). Using the IS 2002 Model Curriculum for Mapping an IS Curriculum. Information Systems Education Journal, 2(1). Retrieved June 1, 2007, from http://isedj.org/2/1/.

Davidson, E,J. (2002). Technology Frames and Framing: A Socio-Cognitive Investigation of Requirements Determination. MIS Quarterly, 26(4), 329-359.

Davis, G.B., Feinstein, D., Stohr, T., Valacich, J., and Wigand, R. (1998). The Master's Degree Program in Information Systems (Invited Session). Proceedings of the International Conference on Information Systems ICIS '98.

Desouza, K.C., El Sawy, O.A., Galliers, R.D., Loebbecke, C., and Watson, R.T. (2006). Beyond Rigor and Relevance Towards Responsibility and Reverberation: Information Systems Research That Really Matters. Communications of AIS, 17, 2-26.

Downey, J. (2005). A Framework to Elicit the Skills Needed for Software Development. Special Interest Group on Computer Personnel Research Annual Conference, Proceedings of the 2005 ACM SIGMIS CPR Conference on Computer Personnel Research, Atlanta, Georgia, USA, 122-127. 
Feik, R.W. (1938). The Policy of Prolonging the Life of Textbooks. The Elementary School Journal, 38(6), 429-435.

Fitzgerald, B. and Howcroft, D. (1998). Towards Dissolution of the IS Research Debate: From Polarization to Polarity. Journal of Information Technology, 13(4), 313-327.

Fleming V., Gaidys U., And Robb Y. (2003). Hermeneutic Research in Nursing: Developing a Gadamerian-Based Research Method. Nursing Inquiry, 10, 113-120.

Floyd, R.C. (2004). Curriculum Design I: A Model for Information Technology Curriculum. Proceedings of the 5th Conference on Information Technology Education CITC5 '04.

Frezza, S., Tang, M.-H., and Brinkman, B.J. (2006). Creating an Accreditable Software Engineering Bachelor's Program. IEEE Software, 23(6), 27-35.

Gadamer, H.G. (1959). "On the Circle of Understanding", in J.M. Connolly and T. Keutner (Eds.), Hermeneutics versus Science? (pp.68-78), Indiana: University of Notre Dame Press.

Galbraith, J.R. (1977). Designing Organizations. Reading, MA: Addison-Wesley.

Galliers, R.D. (1994). Relevance and Rigour in Information Systems Research: Some Personal Reflections on Issues Facing the Information Systems Research Community. IFIP Transactions A (Computer Science and Technology), A-54, 93-101.

Geanellos R. (2000). Exploring Ricoeur's Hermeneutic Theory of Interpretation as a Method of Analysing Research Texts. Nursing Inquiry, 7, 112-119.

Ginzberg, M.J. and Baroudi, J.J. (1988). MIS Careers - A Theoretical Perspective. Communications of the ACM, 31(5), 586-594.

Gorgone, J.T. (1998). Information Systems Curricula and Accreditation. ACM SIGCSE Bulletin, 30(4).

Gorgone, J.T. (1999). Graduate Information Systems Curriculum for the 21st Century. ACM SIGCSE Bulletin. The Proceedings of the Thirtieth SIGCSE Technical Symposium on Computer Science Education SIGCSE '99, 31(1).

Gorgone, J.T. (2005). IS Education: Information Systems: Program Location, Business Component, and Accreditation. ACM SIGCSE Bulletin, 37(4).

Gorgone, J.T., Gray, P., Stohr, E.A., Valacich, J.S., Wigand, R.T. (2006). MSIS 2006: Model Curriculum and Guidelines for Graduate Degree Programs in Information Systems. ACM SIGCSE Bulletin, 38(2).

Gorgone, J.T., Lidtke, D.K., and Feinstein, D. (2001). Status of Information Systems Accreditation. ACM SIGCSE Bulletin, Proceedings of the Thirty-Second SIGCSE Technical Symposium on Computer Science Education SIGCSE '01, 33(1). 
Grinter, R.E. (1997). From Workplace to Development: What Have We Learned So Far and Where Do We Go? Proceedings of the international ACM SIGGROUP Conference on Supporting Group Work: The Integration Challenge GROUP '97, ACM Press.

Hansson, C., Dittrich, Y., Gustafsson, B., and Zarnak, S. (2006). How Agile are Industrial Software Development Practices? Journal of Systems \& Software, 79(9), 1295-1311.

Harkins, R.J. (2006). Using the Software Development Life Cycle as a Curriculum Design Tool in the Development of a "Companion Course" for Beginning Programmers. Information Systems Education Journal, 4(96). Retrieved on June 1, 2007, from http://isedj.org/4/96/.

Harris, W.V. (1996). Literary Meaning. New York: New York University Press.

Havelka, D. (2003). Students Beliefs and Attitudes toward Information Technology. Information Systems Education Journal, 1(40). Retrieved on June 1, 2007, from http://isedj.org/1/40/.

Hirsch Jr., E.D. (1972). Three Dimensions of Hermeneutics. New Literary History, 3(2), 245261.

Hirschheim, R. and Newman, M. (1991). Symbolism and Information Systems Development: Myth, Metaphor and Magic. Information Systems Research, 2(1), $29-62$.

Holland, C.P. (2003). Information Systems Research and Practice: IT Artifact or a Multidisciplinary Subject? Communications of AIS, 12, 599-606.

Holmström, H., Fitzgerald, B., Ågerfalk, P.J., and Conchúir, E.ó. (2006). Agile Practices Reduce Distance In Global Software Development. Information Systems Management, 23(3), 7-18.

Howatt, J. and Jensen, J. (2006). Designing an MIS Major for a Liberal Arts College. Information Systems Education Journal, 4(93). Retrieved June 1, 2007, from http://isedj.org/4/93/.

Huang, W. and Watson, R.T. (1998). Can A Lean E-Mail Medium Be Used For Rich Communication? A Psychological Perspective. European Journal of Information Systems, $7(4), 269-274$

Humphrey, W.S. (1989). Managing the Software Process. Boston: Addison-Wesley Professional.

Hunter, M.G. (1993). A Strategy for Identifying 'Excellent' Systems Analysts, Journal of Strategic Information Systems, 2(1), 15-26.

Japanese Ministry of Foreign Affairs (2007). Textbook Examination Procedure. Retrieved June 13, 2007, from http://www.mofa.go.jp/policy/education/textbooks/overview-3.html.

Jacquet-Lagreze, E., and Shakun, M.F. (1982). Decision Support Systems for SemiStructured Buying Decisions, European Journal of Operational Research, 16, pp. 48-58. 
Jayaratna, N. (1994). Understanding and Evaluating Methodologies. London: McGraw-Hill.

Jayartna, N. and Fitzgerald, B. (Eds.) (1996). Lessons Learned from the Use of Methodologies: Fourth Conference on Information Systems Methodologies, University College Cork, Cork, Ireland, 97-106.

Kaplan, B. and Duchon, D. (1988). Combining Qualitative and Quantitative Methods in Information Systems Research: A Case Study. MIS Quarterly, 12(4), p570-586.

Keen, C. (1996). Treatment of Metaphors in Software Engineering Education.

Proceedings, Software Engineering: Education and Practice, Jan 24-27, 329-335.

Keen, P.G.W. (1987). Decision Support Systems: The Next Decade, Decision Support Systems, 3, pp. 253-65.

Kelleher, D. (1995). Business Programme and Information System Methodologies. Information Systems Journal, 5, 2.

King, J.L. and Applegate, L.M. (1997). Crisis in the Case Study Crisis: Marginal Diminishing Returns to Scale in the Quantitative-Qualitative Research Debate. In A.S. Lee, J. Liebenau, and J.I. DeGross (Eds.), Information Systems and Qualitative Research (pp. 28-30). London: Chapman \& Hall.

Krippendorff, K. (1980). Content Analysis: An Introduction to its Methodology. Beverly Hills: Sage Publications.

Lethbridge, T.C., LeBlanc, R.J., Kelley Sobel, A.E., Hilburn, T.B., and Diaz-Herrera, J.L. (2006). SE2004: Recommendations for Undergraduate Software Engineering Curricula. IEEE Software, 23(6), 19-25.

Liegle, J.O. and Johnson, R.D. (2003). A Review of Premier Information Systems Journals for Pedagogical Orientation. Information Systems Education Journal, 1(8). Retrieved June 1,2007 , from http://isedj.org/1/8/.

Livingston, J.S. (1971). Myth of the Well-Educated Manager. Harvard Business Review, 7989.

Longenecker, H.E. and Feinstein, D.L. (2005). Assessment of IT competencies: Development of assessment for undergraduate programs of information technology, and certification for program graduates. Proceedings of the 6th conference on Information technology education SIGITE '05.

Lutz, M.J. and Bagert, D. (2006). Guest Editors' Introduction: Software Engineering Curriculum Development, IEEE Software, 23(6), 16-18.

Lyytinen, K. (1987). A Taxonomic Perspective on Information Systems Development. In R. Boland, and R. Hirscheim (Eds.), Critical Issues in Information Systems Research (pp. 341). Chichester: John Wiley and Sons. 
Lyytinen, K. (1999). Empirical Research in Information Systems: On the Relevance of Practice in Thinking of MIS Research. MIS Quarterly, 23(1), 25-27.

Lyytinen, and J.I. DeGross (Eds.) (1992). The Impact of Computer Supported Technologies on Information Systems Development. Amsterdam: North-Holland.

Lyytinen, K., Rose, G., and Welke, R. (1998). The Brave New World of Development in the Internetwork Computing Architecture (InterNCA): Or How Distributed Computing Platforms Will Change Systems Development. Information Systems Journal, 8(3), 241-253.

Maiden, N. (2006). Improve Your Requirements: Quantify Them. IEEE Software, 23(6), 6869.

Markus, L., Marjchrzak, A., and Gasser, L. (2002). A Design Theory for Systems That Support Emergent Knowledge Processes. MIS Quarterly, 26(3), 179-212.

Markus, M.L. and Robey, D. (1983). The Organisational Validity of Management Information Systems, Human Relations, 36(3), 203-226.

Mawhinney, C.H. and Morrell, J.S. (1998). The IS Undergraduate Curriculum: Predicting Student Outcomes in the IS'97.5 Course (Programming, Data, File, and Object Structures). Proceedings of the 1998 ACM SIGCPR Conference on Computer Personnel Research SIGCPR' 98 .

McCarthy, R.V., Claffey, G., and White, B. (2004). The Balance between Teaching and Research: The Development of a Survey Instrument to Assess Factors that Affect MIS Research. Information Systems Education Journal, 2(4). Retrieved June 1, 2007, from http://isedj.org/2/4/.

McGrath, K. (2005). Doing Critical Research in Information Systems: a Case of Theory and Practice Not Informing Each Other. Information Systems Journal, 15(2), 85-101.

McMenamin, S. and Palmer, J. (1984). Essential Systems Analysis. New York: Yourdon Press.

Microsoft, (2009). Windows History - Windows Desktop Products History. Retrieved January 17, 2009 from http://www.microsoft.com/windows/WinHistoryDesktop.mspx.

Mingers, J. (2001). Combining IS Research Methods: Towards a Pluralist Methodology. Information Systems Research, 12(3), 240-259.

Mintzberg, H. (1987). Crafting strategy. Harvard Business Review, 65(4), 66-75.

Mishra, A. and Mishra, D. (2006). Software Quality Assurance Models In Small and Medium Organisations: A Comparison. International Journal of Information Technology \& Management, 5(1), 1. 
Moody, D.L. (2000). Building Links between IS Research and Professional Practice: Improving the Relevance and Impact of IS Research, Proceedings of the Twenty First International Conference on Information Systems ICIS 2000, Association for Information Systems, 351-360.

Moody, D.L., and Sindre, G. (2003). Incorporating Quality Assurance Processes into Requirements Analysis Education. ACM SIGCSE Bulletin, Proceedings of the 8th Annual Conference on Innovation and Technology in Computer Science Education ITICSE '03, 35(3), 74-78.

Morien, R. (2006). A Critical Evaluation Database Textbooks, Curriculum and Educational Outcomes. Information Systems Education Journal, 4(44). Retrieved June 1, 2007 from http://isedj.org/4/44l.

Mumford, E (1985). Designing System Requirements to Meet Business Needs: A Case Study Example, Computer Journal, 28(2), 97-104.

Mumford, E. (1997). The Reality of Participative Systems Design: Contributing to Stability in a Rocking Boat. Information Systems Journal, 7(4), 309-322.

Myers, M.D. (1995). Dialectical Hermeneutics: A Theoretical Framework for the Implementation of Information Systems. Information Systems Journal, 5(1), 51-70.

Naugler, D. and Surendran, K. (2004). Simplicity First: Use of Tools in Undergraduate Computer Science and Information Systems Teaching. Information Systems Education Journal, 2(5). Retrieved June 1, 2007, from http://isedj.org/2/5/.

Naur, P. (1985). Programming as Theory Building. Microprocessing and Microprogramming. $15,253-261$.

Necco, C.R., Gordon, C.L., and Tsai, N.W. (1987). Systems Analysis and Design: Current Practices, MIS Quarterly, 11(4), 461-476.

Nerur, S. and Balijepally, V. (2007). Theoretical Reflections on Agile Development Methodologies. Communications of the ACM, 50(3), 79-83.

Newman, M. (1989). Designing a Centralized Admissions System in a Loosely-Coupled Organization: An Episode in Screen Design. Office: Technology \& People, 4, 53-73.

Papp, R., Benbasat, I., Galliers, B., Oppelland, H., and Williams J. (1999). The Efficacy of Information Systems Journals (Panel Session). Proceeding of the 20th International Conference on Information Systems ICIS 1999, Charlotte, North Carolina, United States, 586-588.

Parnas, D.L. (1997). Software engineering: an unconsummated marriage.

Communications of the ACM, 40(9), 128. 
Pearson, J.M., Pearson, A., and Shim, J.P. (2005). The Relevancy of Information Systems Research: The Practitioner's View. Information Resources Management Journal, 18(3), 5067.

Phillips, N., Brown, J.L. (1993). Analyzing Communication In and Around Organizations: A Critical Hermeneutic Approach. Academy of Management Journal, 36(6), 1547-1576.

Pliskin, N., Romm, T., Lee, A., and Weber, Y. (1993). Presumed Versus Actual Organisational Culture: Managerial Implications for Implementation of Information Systems. The Computer Journal, 36(2), 143-152.

Pomykalski, J.J. (2006). Teaching Systems Analysis and Design as a Writing-Intensive Course. Information Systems Education Journal, 4(70). Retrieved June 1, 2007, fromo http://isedj.org/4/70/.

Pomykalski, J.J. (2003). Critical Thinking through Writing in Information Systems Courses. Information Systems Education Journal, 1(38). Retrieved June 1, 2007, from http://isedj.org/1/38/.

Quinn, B., Barroca, L., Nuseibeh, B., Fernandez-Ramil, J., Rapanotti, L., Thomas, P., and Wermelinger, M. (2006). Learning Software Engineering at a Distance. IEEE Software, 23(6), 36-43.

Reynolds, C.W. (2006). IT Education - Curriculum Development: Engineering the Information Technology Curriculum with Pervasive Themes. Proceedings of the 7th Conference on Information Technology Education SIGITE '06.

Robey, D. and Markus, M.L. (1984). Rituals in Information System Design. MIS Quarterly, $8(1), 5-15$.

Romm, C.T., Pliskin, N., and Weber, Y. (1995). The Relevance of Organizational Culture to the Implementation of Human Resources Information Systems. Asia Pacific Journal of Human Resources, 33(2), 63-80.

Roussev, B. and Rousseva, Y. (2004). Active Learning through Modeling: Introduction to Software Development in the Business Curriculum. Decision Sciences Journal of Innovative Education, 2(2), 121-152.

Russo, N.L., Hightower,_R., and Pearson, J.M. (1996). The Failure of Methodologies to Meet the Needs of Current Development Environments. In N. Jayaratna, and B. Fitzgerald (Eds.), Lessons Learned from the Use of Methodologies: Fourth Conference on Information Systems Methodologies (pp. 387-394).

Sarker, S. and Lee, A.S. (2006). Does the Use of Computer-Based BPC Tools Contribute to Redesign Effectiveness? Insights from a Hermeneutic Study. IEEE Transactions on Engineering Management, 53(1), 130-145. 
Sauer, C. and Lau, C. (1997). Trying to Adopt Systems Development Methodologies - A Case-Based Exploration of Business Users' Interests. Information Systems Journal, 7(4), 255-75.

Senn, J. (1998). The Challenge of Relating IS Research to Practice. Information Resources Management Journal, 11(1), 23-28.

Seshagiri, G., Agerfalk, P., Fitzgerald, B., Clarke, T.R.H., Bjerstrom, N.J., Vasiljevic, N., Simonelis, A., McDowell, C., Werner, L., Bullock, H.E., Fernald, J., Fitting, M., Anand, B.S., and Naur, T. (2006). Forum. Communications of the ACM, 49(12), 11-13.

Shah, S.K. and Corley, K.G. (2006). "Building Better Theory by Bridging the QuantitativeQualitative Divide", Journal of Management Studies, 43 (8), 1821-1835.

Silva, D. and McFadden, K.L. (2005). Combining Operations Management and Information Systems Curricula: Assessing Alumni Preparations for the Workforce, Decision Sciences Journal of Innovative Education, 3(2), 307-321.

Smith, M.L. (2006). Overcoming Theory-Practice Inconsistencies: Critical Realism and Information Systems Research. Information \& Organization, 16(3), 191-211.

Srivastava, S.C. and Teo, T.S.H. (2006). Understanding, Assessing, and Conducting Interpretive Management Research. IIMB Management Review, 18(2), 195-208.

Standing, C. and Standing, S. (1999). The Role of Politics in IS Career Progression. Systems Research \& Behavioral Science, 16(6), 519-531.

Stapleton, J. (1997). Dynamic Systems Development Method: The Method in Practice.

Harlow, U.K: Addison-Wesley.

Stodolsky, S.A. (1989). Is Teaching Really By The Book? In P.W. Jackson and S. Haroutian-Gordon (eds.) Eighty-Ninth Yearbook of the National Society for the Study of Education (pp. 159-184), Bloomington, IL: Public School Co.

Stolterman, E. (1999). The Design of Information Systems: Parti, Formats and Sketching. Information Systems Journal, 9(1), 3-20.

Synnott, W.R. (1987). The Information Weapon: Winning Customers and Markets With Technology. New York, NY: John Wiley \& Sons.

Thomson, C.K. and Otsuji, E. (2003). Evaluation of Business Japanese Textbooks: Issues of Gender. Japanese Studies, 23(2), 185-203.

Tranfield, D., Denyer, D., and Smart, P. (2003). Towards a Methodology for Developing Evidence-Informed Management Knowledge by Means of Systematic Review. British Journal of Management, 14(3), 207-222. 
Tsang, S. (2005, May 1). What ClOs Need from IT Schools. Managing Information Strategies (www.misweb.com), Retrieved May 24, 2007, from http.//www.misweb.com/magarticle.asp?doc_id=24566\&rgid=5\&listed_months=0

Ulema, M. (2005). A Comparative Analysis of Undergraduate Information Systems Curricula in Selected Business Schools. Information Systems Education Journal, 3(17). Retrieved June 1, 2007, from http://isedj.org/3/17/.

van Veen, M., Mulder, F., and Lemmen, K. (2004). What is Lacking in Curriculum Schemes for Computing/Informatics? ACM SIGCSE Bulletin, Proceedings of the 9th Annual SIGCSE Conference on Innovation and Technology in Computer Science Education ITICSE '04, 36(3).

Vessey, I. and Conger, S. (1993). Learning To Specify Information Requirements: The Relationship between Application and Methodology. Journal of Management Information Systems, 10(2) 177-201.

von Post, I. and Eriksson K. (1999). A Hermeneutic Textual Analysis of Suffering and Caring In the Peri-Operative Context. Journal of Advanced Nursing, 30(4), 983-989.

Walls, J.G., Widmeyer, G.R., and El Sawy, O.A. (1992). Building an Information System Design Theory for Vigilant EIS. Information Systems Research, 3(1), 36-59.

Walsham, G. (1995). The Emergence of Interpretivism in IS Research. Information Systems Research, 4, 376-394.

Walz, D.R. and Wynekoop, J.L. (1997). Identifying and Cultivating Exceptional Software Developers. Journal of Computer Information Systems, 37(4), 82-8.

Ward, P. (1992). The Evolution of Structured Analysis: Part 2 - Maturity and Its Problems. American Programmer, 5(4), 18-29.

Watson, H.J., Sousa, R.D., and Junglas, I. (2000). Business School Deans Assess the Current State of the IS Academic Field - Group Of 3. Communications of the Association for Information Systems, 4(4), 1-31.

Watson, H.J., Taylor, K.P., Higgins, G., Kadlec, C., and Meeks, M. (1999). Leaders Assess the Current State of the Academic IS Discipline, Communications of the AIS, 2(2), 1-28.

Westrup, C. (1999). Knowledge, Legitimacy, and Progress? Requirements as Inscriptions in Information Systems. Information Systems Journal, 9(1), 35-54.

Whitehead L. (2004). Enhancing the Quality of Hermeneutic Research: Decision Trail. Journal of Advanced Nursing, 45(5), 512-518.

Wiklund, L., Lindholm, L. and Lindström, U.A. (2002). Hermeneutics and Narration: A Way to Deal with Qualitative Data, Nursing Inquiry, 9, 114-125.

Wirfs-Brock, R.J. (2006). Explaining Your Design. IEEE Software, 23(6), 96-98. 
Wood-Harper, A.T., Antill, L., and Avison, D.E. (1985). Information Systems Definition: The Multiview Approach, Oxford: Blackwell Scientific.

Wynekoop, J.L. and Walz, D.B. (1994). Software development--is creativity suppressed? 1994 Proceedings Decision Sciences Institute, 1994 Annual Meeting, Part 2, 1131-1133.

Wynekoop, J.L. and Walz, D.B. (2000). Investigating traits of top performing software developers. Information Technology and People, 13(3), 186-195.

Yin, R.K. (2003). Case Study Research: Design and Methods, Third Edition, Thousand Oaks, CA: Sage Publications, Inc.

Zahorik, J.A. (1991). Teaching Style and Textbooks. Teaching and Teacher Education, 7(2), 185-196. 